[Aus dem hygienischen Institut der k. k. Universität Wien.]

\title{
Die Donau vom Leopoldsberge bis Preßburg, die Abwässer der Stadt Wien und deren Schicksal nach ihrer Einmündung in den Strom.
}

Von

Dr. Ernst Brezina.

(IIIerzu Tar. Y.)

In den letzten Jahrzehnten hat bekanntlich in Mittel- und Westeuropa ein ungemein rasches Wachstum der Städte und der Industrie stattgefunden. Dadurch kam es zur Ansammlung großer Mengen ron Abfallstoffen verschiedenster Art auf verhältnismäßig kleinen Gebieten. Eine sofortige Verwertung dieser Stoffe zu landwirtschaftlichen Zwecken, wie dies bei ländlicher Bevölkerung die Regel bildet, war in den groBen Städten und Industriezentren ausgeschlossen; man mußte daher früher oder später zum Bau von Kanälen schreiten. Man entledigte sich der so gesammelten Abwässer - in vielen Fällen waren diese durch Niederschlagswässer verdünnt, aber auch vermehrt - am einfachsten durch Einleiten in den nächsten Wasserlauf. Die Folge davon war die zunehmende Verunreinigung der Flüsse. Es verlauteten daher zahlreiche Klagen der Uferbewohner und insbesondere von seiten der an dem Zustande des Wassers interessierten Industriellen und Landwirte über die durch die Einleitung der Kanalabwässer hervorgerufenen Mißstände. Diesen Vorgang suchte man zu rechtfertigen, und zwar unter Hinweis auf die sogenannte Selbstreinigung der Flüsse, die seit jenen Zeiten Gegenstand mannigfacher Untersuchungen wurde. 
Vorliegende Arbeit, die auf Anregung des Hrn. Prof. Dr. A. Schattenfroh entstand, wurde ermöglicht durch das weitgehende Entgegenkommen des Hrn. Baurates Josef $\mathrm{K}_{0 \mathrm{hl}}$ rom Wiener Stadtbauamte, der die Messung der in den beiden Hauptsammelkanälen Wiens abfließenden Wassermengen ausfähren lie $B$ und mir so die quantitative Bestimmung der Abfallstoffe möglich machte. Dadurch wurde für die übrigen Untersuchungen eine sichere Basis geschaffen. Baurat Kohl übernahm auch die Durchsicht und. Ergänzung des die Wiener Kanalisation betreffenden Abschnittes dieser Arbeit. Die Erlaubnis zur jedesmaligen Benützung einer der $\mathbf{k}$. k. Donau-Regulierungskommission gehörigen Weidzille verdanke ich Hrn. Ingenieur Brandl. Dieser hat auch die weiter unten folgenden hydrologischen Daten überprüft und ergänzt. Ich erlaube mir diesen beiden Herren meinen herzlichen Dank auszusprechen.

Ferner verdanke ich auch den Herren Professoren Hofrat Dr. Penk, Wiesner und . Wettstein, sowie Hrn. k. k. Baurat Bauer einzelne wertvolle Winke und mündliche Mitteilungen.

Im folgenden sollen zunächst die wichtigeren der mir zugänglichen Arbeiten über Verunreinigung und Selbstreinigung der Flüsse auszugsweise wiedergegeben werden. Im Anschlusse daran folgt die Besprechung einiger Publikationen, welche zwar andere Themen behandeln, doch für. die vorliegende Frage vọn Wichtigkeit sind.

Eine der ersten wissenschaftlichen Untersuchungen über Verunreinigung und Selbstreinigung der Flüsse wurde an der Seine bei Paris durchgeführt (1).

Dieser Fluß führt bei Niederwasser nur 45 Sek.-cbm, wurde damals in Paris durch zahlreiche kleine Kanäle verschmutzt und nahm unterhalb der Stadt die beiden Hauptsammler auf, welche ibren Inhalt der Seine zumischten.

Hierdurch wurde die Seine zu einem schwarzen; stinkenden Gewāsser, welchem Gasblasen bis zu $1.5 \mathrm{~m}$ Durchmesser entstiegen. Infolge der Langsamkeit der Strömung (oft nur 0.13 m) fand ausgiebiges Sedimentieren und Bildung gewaltiger Schlammbänke von anfangs 2 bis $3^{\mathrm{m}}$ Höhe statt, das Wasser selbst aber reinigte sich schnell und hatte nach einem Isaufe von $160^{\mathrm{km}}$ chemisch wieder die gleiche Beschaffenheit wie oberhalb Paris, nachdem es schon früher geruchlos und klar geworden war. Bei Hochwasser wanderten die Sedimente stromabwärts. Die chemischen Untersuchungen, auf Tabellen zusammengestellt, ergaben bedeutende $\mathrm{Zu}$ nahme des Stickstoffgehaltes im Wasser (ca. auf das 4 fache), die Menge des gelösten Sauerstoffes nahm stark ab, ihr Minimum (etwa $1 / 6$ der Menge oberhalb Paris) trat weit unterhalb der gröBten Verschmutzung auf, an einer 
Stelle, wo der Fluß für das Auge nicht mehr verunreinigt war. Die Pariser Kanäle führten dem Wasser pro Sekunde $3^{\mathrm{cbm}}$ mit fast $4^{\mathrm{kg}}$ festen Stoffen und $0.18 \mathrm{~kg}$ Stickstoff $\mathrm{zu}$.

Als einziges Mittel, diesen Zuständen zu steuern, wurde, da Baggerung voraussichtlich nicht geholfen hätte, die Anlage von Rieselfeldern empfohlen, so dah die Einleitung der Abfallstoffe in die Seine ganz entfiele.

Frank (3) untersuchte die Veränderungen des Spreewassers in Berlin. Die Untersuchungen fanden in den Jahren 1886 und 1887 statt, erstreckten sich auf die Spree in und unterhalb Berlins und den Landwehrkanal. $\mathrm{Zu}$ jener Zeit gelangten noch die Abgänge des fünften Teiles der Berliner Bevölkerung durch Kanäle in die Spree. Die Wasserentnahmen fanden in der FluBmitte statt. Die Sekunden-Wassermengen des Flusses wurden ermittelt. Die Keimzahlen, oberhalb der Stadt durchschnittlich 4000 bis 5000 im Kubikzentimeter (Proskauer), nabmen in Berlin sukzessive sehr stark zu, ganz besonders im Landwehrkanale, hingegen eine Strecke unterhalb der Stadt stark ab (Zunahme der Wassermenge, seeartige Erweiterungen). Die Keimzahlen an ein und derselben Entnahmestelle waren an den einzelnen Untersuchungstagen ungemein verschieden. Die chemische Beschaffenheit der Spree oberhalb Berlins war nach Proskauer folgende: Rückstand 137.5 bis $202 \cdot 0$, Ammoniak Spuren bis 0.8 , Kalk 39.6 bis $\mathbf{7 2 . 2}$, Oxydierbarkeit 13.7 bis $34 \cdot 1$, Chlor 14.5 bis $28.4 \mathrm{mg}$ im Liter. Während des Laufes durch Berlin nahm die chemische Verunreinigung meist etwas, doch nicht stark und nicht konstant zu.

Ursache der Spreeverschmutzung in Berlin sind nach Frank die derzeit noch einmündenden Abwässerkanäle, der Schiffsverkehr (Vorwärtsstoßen der Schiffe mit Stangen) und die zeitweilige Tätigkeit der Notauslässe. Alle diese Momente machen sich im Landwehrkanal am meisten geltend, auch führt dieser die geringste Wassermenge. Daher ist er am meisten verunreinigt und wirkt auch noch ungünstig auf die Beschaffenheit der Spree nach seiner Vereinigung mit ihr. Die verschieden starke Abnahme der Keimzahlen in den Seen rührt daher, daB die Keime bald an größeren, bald an kleineren suspendierten Körpern haften und so rerschieden rasch sedimentieren. Wegen der ungemein starken Schwanliungen der Befunde, insbesondere der Keimzahlen, unterließ es der Verfasser, Durchschnittszahlen zu berechnen. Hierzu wäre eine viel größere Zahl von Untersuchungen nötig gewesen.

Prausnitz (4) hat eingehende Untersuchungen der Isar angestellt.

Die Isar ist ein reiBender FluB (Geschwindigkeit bis über $2^{\mathrm{m}}$ ). Das tief in den Boden eingegrabene Bett ist auf die Breite von $22^{m}$ bei Nieder- und von $43^{\mathrm{m}}$ bei Mittelwasser reguliert. 
Hohe Wasserstände herrschen von April bis Oltober.

$\left.\begin{array}{cr}\text { Pegelstand } & \text { Sek.cbm } \\ -2.5 & 29.5 \\ -1.8 & 81.0 \\ -1.7 & 91.0 \\ 0.0 & 288.0 \\ +0.1 & 302.0 \\ +0.8 & 417.0\end{array}\right\}$ Hitederwasser

Farbe des Wassers bei Schneeschmelze grau, sonst grün. Das Wasser hat oberhalb Münchens einen Trockenrückstand von stets mehr als $200 \mathrm{mg}$ im Liter, 3 bis $4.5 \mathrm{mg}$ Chlor, 3 bis $8 \mathrm{mg}$ Kaliumpermanganatverbrauch, einige Hundert Keime im Kubikzentimeter, in München oberhalb des Hauptsiels 1000 bis 2000 Keime im Kubikzentimeter.

Die Münchener Kanäle, zur Zeit der Untersuchungen noch frei von Harn und Fäkalien, münden an verschiedenen Stellen in die Isar und die von ihr in München abgegebenen Seitenarme. Das Hauptsiel, die Abgänge von ca. $1 / 4$ der Münchener Grundstücke aufnehmend, mündet bei der Bogenhauser Brücke links und wurde öfters morgens, einmal stündlich durch 24 Stunden, untersucht. Das Abwasser ist dort, im Gegensatz zu einigen kleineren, gleichfalls untersuchten Sielen, ziemlich verdünnt, enthält nicht sehr viel Chlor und Ammoniak und nur einige Hunderttausend Keime im Kubikzentimeter. Die gröBte absolute Unratmenge wurde 8 bis $10 \mathrm{Uhr}$ früh und 5 bis $9 \mathrm{Uhr}$ abends beobachtet, die geringste 1 bis $3 \mathrm{Uhr}$ früh. Der Wasserstand war nach jener Tabelle die ganzen 24 Stunden über gleich. Aus den Tabellen des Verfassers, welche die Resultate seiner Untersuchungen darstellen, ergibt sich folgendes:

Im Flusse sinkt am linken Ufer die Keimzahl von der Sielmündung an, wo bis über 200000 Bakterien im Kubikzentimeter gefunden wurden, rasch bis auf einige Tausende. Rechts erfolgt nur vorübergehend schwache Zunahme der Bakterienmenge. Einige Untersuchungsreihen (offenbar in der FluBmitte), bis zum 10., 13. und $33 . \mathrm{km}$ stromabwärts von der Sielmündung geführt, ergaben, daB die Stelle der stärksten Verschmutzung wenige Kilometer unterhalb der Sielmündung liegt, und zwar unterhalb der Einmündung des Eisbachs. Dieser nämlich bringt selbst Schmutzwasser und führt durch die Gewalt seiner Strömung eine gründliche Durchmischung des Isarwassers herbei. Bei Niederwasser hohe Keimzahlen (bis 80000 ), bei Hochwasser nur einige Tausende im Kubikzentimeter. Der Kaliumpermanganatverbrauch steigt mäBig, andere Verunreinigungen sind kaum merklich. Nur die Keimzahlen sind eine längere Strecke wesentlich höher als oberhalb Münchens. Untersuchungen des 
Isarwassers bei Freising ergaben, daß sich dieses in seiner chemischen Zusammensetzung tagsüber nicht ändert. Verfasser schlieBt daraus, daß das Wasser dort von den Abwässern Münchens nicht mehr beeinfluBt wird. Gleichzeitige Keimzählungen wurden dort nicht ausgeführt. Die Untersuchungen zeigen, wie Verfasser meint, daß der FluB sich seiner Verunreinigung ziemlich rasch entledigt.

Verfasser ist für Einführung der Schwemmkanalisation in Nünchen. Infehtionen sind hierbei nicht zu fürchten, da die Isarufer unbewohnt sind, Schiffahrt fehlt, und das Wasser zum Baden zu kalt ist. Auch findet wegen des reißenden Laufes keine Schlammbankbildung statt:

Den Bakterien weist Verfasser keine Rolle bei der Selbstreinigung 'zu, da sie sich sonst im Flusse vermehren und nicht abnehmen würden (s. Classen, zitiert bei Kruse [34]). Sedimentierung von Bakterien in dem reißenden Flusse hält Prausnitz für unwesentlich. Auch seine Versuche im Reagensglase ergaben keine wesentliche Sedimentierung von Bakterien im Wasser. Die Frage, wodurch die Selbstreinigung der Flüsse zustande kommt, glaubt Prausnitz nicht gelöst zu haben, indem zum Studium dieser Frage die Isar mit ihrer relativ geringen Verunreinigung ungeeignet sei.

Schlatter (5) untersuchte die Limmat bei Zürich.

Diese entströmt sehr keimarm mit 17 bis 92 Sek.-cbm dem Züricher See. Unterhalb Zürichs nimmt sie die Abwässer dieser Stadt (200 bis 250 Sek.Liter von 67000 Einwohnern) auf. Die Einmündung findet an drei Stellen, und zwar am rechten und linken Ufer und in der Mitte statt. So entstehen drei Schmutzwasserstreifen, welche sich jedoch bald verwischen. Verfasser untersuchte zunächst oberhalb den Keimgehalt der noch sichtbaren Schmutzwasserstreifen, eine Strecke weiter stromabwärts den des Mischwassers. Die Keimzahlen des letzteren sind viel kleiner als die der Schmutzwasserstreifen. Noch eine Strecke fluBabwärts findet weitere Abnahme der Keimzahlen statt. Das Verhältnis der Abwässer zur Limmatwassermenge beträgt in extremen Fällen $1: 85$ beziehungsweise $1: 368$. Die Wasserentnahme erfolgte in der Flußmitte.

Löw (6) zeigt, daß grüne Algen bei Lichtabschluß in Faulwasser leben und sich vermehren können, also organische Substanz assimilieren. Damit sei ihre Rolle bei der Selbstreinigung der Flüsse bewiesen.

Pettenkofer (7) hält das Isarwasser für mehr als ausreichend zur Verdünnung der Münchner Abwässer. Die Selbstreinigung kommt durch Algen zustande und wird durch den raschen Flußlauf unterstützt, der die Sedimentierung und ihre Folgen, lokale Unratansammlungen, verhindert; solche könnten die Algen nicht bewältigen. 
Nach Schmidts (8) Beobachtungen ist Bewegung für den Selbstreinigungsvorgang bedeutungslos, da nur derartig heftige Bewegungen (Erschütterungen) die Bakterien schädigen, wie sie in Flüssen nie vorkommen.

Nach Baumeister (9) sind nicht die Abwassermengen, sondern die Unratmengen maßgebend für die FluBverunreinigung. Die Unratmenge (trocken), die ron dem Kanalisationssystem abhängt, beträgt durchschnittlich $190^{\mathrm{g}}$ pro Kopf und Tag. Dabei sind alle gelösten, von den suspendierten nur die organischen Stoffe als Unrat betrachtet. Verfasser stellt weiterhin eine mathematische Formel (Verunreinigungskoeffizient) auf.

Nach Buchner $(10,15)$ wirkt Sonnenlicht und auch diffuses Tageslicht schädigend auf Keime verschiedener Art, selbst durch eine $2^{\mathrm{m}}$ dicke Wasserschicht. Die Isar oberhalb Münchens ist am Morgen keimärmer als abends, was auf Wirkung des Tageslichtes zurückzuführen sei.

Pfeiffer und Eisenlohr (12) beobachten die Kryptogamenvegetation an den Isarufern.

Beggiatoa alba tritt nur bei und unterhalb Münchens und nur an denjenigen Stellen auf, an welchen das Wasser der Isar unter dem Einflusse des Sielwassers steht; das Wachstum des Pilzes war um so reichlicher, je näher einem Siel die untersuchte Stelle lag. Sobald die Durchmischung vollständig ist, hört das Wachstum der Beggiatoa auf, es treten grüne Algen an ihre Stelle. Da $14^{\mathrm{km}}$ unterhalb Münchens (Ismaning) Beggiatoa nicht mehr vorkommt, halten Verfasser die Selbstreinigung hier für vollendet. Eine ziemlich weit unterhalb dieser Stelle geschöpfte Wasserprobe zeigte beim Stehen Fäulniserscheinungen, obwohl an der Schöpfstelle keine Zeichen von Verunreinigung bemerkbar waren, hingegen grüne Algen reichlich vorkamèn.

Uffelmann (13) zāhlt folgende Faktoren auf, welche für die Selbstreinigung der Flüsse in Betracht kommen, und beleuchtet ihre Bedeutung für diesen Vorgang: 1. Sedimentierung - unzurerlässig wegen der Möglichkeit der Schlammaufwirbelung, 2. Verdünnung - oft sehr gering, 3. Organische Stoffe verzehrende Wasserpflanzen und Tiere - nach Verfassers Versuchen quantitativ bedeutungslos, 4. Mikroorganismen - ihre Rolle ist noch wenig gekannt, 5. Lüftung = Sauerstoffabsorption - nach Wolffhügel nur bei sehr heftiger Bewegung von Wert, 6. Sonnenlicht seine Bedeutung noch unerforscht, 7. Ausfällung unorganischer Verbindungen - kommt nicht immer zur Geltung.

15 bis 20 fache Verdünnung des Abwassers genügt nicht, um dieses unschädlich zu machen. Wenn die pathogenen Mikroorganismen im Flusse absterben, so ist die Ursache dafür noch unbekannt, doch ist Verbreitung ron Epidemien bis $17^{\mathrm{km}}$ stromabwärts konstatiert. Sedimentierte 
Schmutzstoffe sind nicht definitiv unschädlich. Abwässer sollten nur gereinigt in Flüsse geleitet werden dürfen.

Axfield (14) mischte keimreiches Brunnenwasser a) mit oberhalb Münchens entnommenem, von Protozoen freiem, b) mit unterhalb Münchens entnommenem, an Protozoen reichem Isarwasser. Nur in letzteren Fällen erfolgte in vitro Keimabnahme.

Girard und Bordas (16) machten eine gröBere Reihe von Untersuchungen an der Seine.

Corbeil liegt am Beginne der untersuchten Strecke, Paris bei $\mathrm{km} 20$ bis 35, unterhalb dieser Stadt St. Denis, wo ein großer Pariser Sammler mündete, viel weiter unten Nantes, bei $\mathrm{km} 200$ Rouen. Untersucht wurde 1. Kaliumpermanganatverbrauch, 2. absorbierte Sauerstoffmenge, $\dot{3}$. Keimzahl. 1 und 3 zeigten analoge, letztere jedoch viel größere Schwankungen, 2 solche in entgegengesetzter Richtung. Zahl der Entnahmestellen zehn. Das Maximum der Verunreinigung war bei Niederwasser in St. Denis, bei mittlerem Wasserstande etwas weiter unten, bei Hochwasser und eine Zeitlang nach dem Ablaufen desselben sogar erst bei Nantes. In Rouen ist der Zustand des Wassers der gleiche wie oberhalb Paris. Die Zahl der aëroben Keime ist am kleinsten bei Niederwasser im Sommer.

Von Heider (17) wurden die Donau und der Donaukanal in einer großen Reihe von Fahrten untersucht, und zwar noch vor dem Bau der Wiener Sammelkanäle und vor der Durchführung der Wienflußregulierung. Die Wien war damals ziemlich stark verschmutzt, die Größe der Verunreinigung schwankend.

Heider gibt eine Reihe von Tabellen verschiedener Autoren über die Zusammensetzung des Donauwassers. Der Donaukanal wurde durch Tabelle I.

Chemische Beschaffenheit des Inhaltes der wichtigsten Wiener Sammelkanäle nach Heider. Milligramme pro Liter.

\begin{tabular}{|c|c|c|c|c|c|c|c|c|c|c|c|}
\hline \multirow[b]{2}{*}{$\mathrm{K}$ a d a 1} & \multirow[b]{2}{*}{$\begin{array}{c}\text { Datum } \\
1891\end{array}$} & & \multicolumn{3}{|c|}{ Suspendierte Stoffe } & \multicolumn{6}{|c|}{ Gelöste Stoffe } \\
\hline & & & 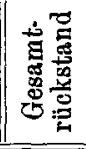 & 总总 & 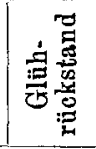 & 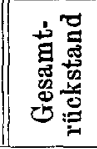 & 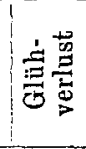 & 音总 & $\frac{\overrightarrow{0}}{0}$ & 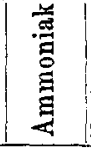 & 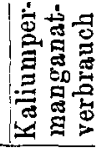 \\
\hline Ringstr.-K. & 1. VI. & Regen & 484 & $321 \cdot 2$ & $162 \cdot 8$ & 690 & 162 & 528 & $136 \cdot$ & $112 \cdot 5$ & $\overline{219 \cdot 4}$ \\
\hline Alsbach-K. & 8. VI. & 8 & 2302 & 1455 & 847 & 1837 & 559 & 1278 & $349 \cdot$ & $153 \cdot 6$ & b 874 \\
\hline R. Cholera-K. & 18. XII & 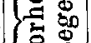 & 1738 & 1347 & 391 & $2379 \cdot 6$ & 884 & $1495 \cdot 6$ & $365 \cdot$ & $209 \cdot 5$ & 1388 \\
\hline L. Cholera.K. & 18. & $1>0$ & 2060.8 & 1378 & $682 \cdot 8$ & $2196 \cdot 4$ & $+931 \cdot 6$ & $1264 \cdot 8$ & 317.7 & $192 \cdot 1$ & 1434 \\
\hline Alsbach-K. & 22. ", & & 2476 & 1474 & 1002 & 2382 & $910 \cdot 8$ & $1471 \cdot 2$ & $472 \cdot 1$ & $385 \cdot 9$ & $941 \cdot 5$ \\
\hline $\begin{array}{r}\text { Brigittenauer } \\
\mathrm{K} .\end{array}$ & 22. , & - & $1599 \cdot 6$ & $1332 \cdot 4$ & $267 \cdot 2$ & $2059 \cdot 6$ & $605 \cdot 6$ & 1454 & $337 \cdot 3$ & $215 \cdot 7$ & 723 \\
\hline Mittel: & & & 1776.7 & 1217 & $558 \cdot 8$ & $1924 \cdot 1$ & $675 \cdot 5$ & 1248 & 329 & $211 \cdot 6$ & 930 \\
\hline
\end{tabular}


die sukzessive in ihn einmündenden Wiener Kanäle (vorwiegend am rechten Ufer) schon innerhalb der Stadt verschmutzt. Die Selrundenabwassermenge gibt Berger für die rechtsufrigen Sammler mit $1.257 \mathrm{cbm}$, Wilhelm für sämtliche Kanäle mit $1.4^{\mathrm{cbm}}$ an. (Diese Angaben dürften wohl ebenso wie die von Heider selbst gewonnenen Daten über die Zusammensetzung des Kanalwassers [Tab. I] annähernd dem Tagesmaximum entsprechen.)

\section{Tabelle II.}

Beschaffenheit des Donauwassers bei Nußdorf (Reinwasser) nach Heider. Milligramme pro Liter.

\begin{tabular}{|c|c|c|c|c|c|c|c|}
\hline Datum & 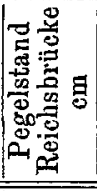 & 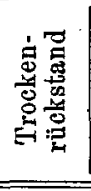 & 总 & Chlor & 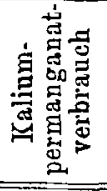 & $\begin{array}{c}\text { Zahl der } \\
\text { Keime im } \\
\text { Kubik- } \\
\text { zentimeter } \\
\text { nach 48 Std. } \\
\text { gezählt }\end{array}$ & $\begin{array}{c}\text { Zahl der } \\
\text { Keime im } \\
\text { Kubik- } \\
\text { zentimeter } \\
\text { nach } 72 \text { Std. } \\
\text { gezählt } \\
\end{array}$ \\
\hline 1591 & & & & & & & \\
\hline 25. IV. & -76 & $214 \cdot 2$ & 0.15 & $3 \cdot 55$ & $10 \cdot 36$ & & . \\
\hline 1. V. & -18 & & & & & & 1640 \\
\hline 16. V. & +62 & $162 \cdot 6$ & 0.125 & $3 \cdot 37$ & $5 \cdot 83$ & & \\
\hline 30. V. & -8 & & & & & 1260 & \\
\hline 17. VII. & +42 & $177 \cdot 5$ & & $2 \cdot 49$ & $11 \cdot 13$ & & \\
\hline 25. VII. & +33 & & & & & 2942 & \\
\hline 2. VIII. & +196 & $155 \cdot 9$ & 0 & $2 \cdot 31$ & $8 \cdot 68$ & & \\
\hline 6. VIII. & +110 & & & & & 2305 & 3375 \\
\hline 26. IX. & -82 & $190 \cdot 1$ & 0 & 2.84 & 8.06 & & \\
\hline 29. IX. & -105 & & & & & 221 & 391 \\
\hline 8.X. & -114 & $206 \cdot 1$ & 0 & $2 \cdot 84$ & $5 \cdot 65$ & & \\
\hline $\begin{array}{l}\text { 22. X. } \\
1892\end{array}$ & -134 & & 0 & $3 \cdot 64$ & $5 \cdot 05$ & & \\
\hline 2. III. & +20 & & 0 & $3 \cdot 66$ & $7 \cdot 55$ & 2060 & 3615 \\
\hline 25. III. & -56 & & 0 & $4 \cdot 97$ & $9 \cdot 39$ & & \\
\hline 10. IV. & +62 & & 0 & $3 \cdot 2$ & $9 \cdot 97$ & 896 & 1865 \\
\hline 23. IX. & -14 & & 0 & $3 \cdot 91$ & $5 \cdot 93$ & 1382 (nach & h 36 Stunden) \\
\hline 28. IX. & -24 & $178 \cdot 0$ & 0 & $3 \cdot 2$ & $5 \cdot 58$ & & \\
\hline $\begin{array}{c}\text { 22. XII. } \\
1893\end{array}$ & -88 & $202 \cdot 0$ & Spur? & $3 \cdot 02$ & $9 \cdot 96$ & & \\
\hline 5. IV. & -4 & $178 \cdot 8$ & 0 & $4 \cdot 08$ & $7 \cdot 27$ & 1477 & \\
\hline $20 . \mathrm{V}$. & $+\tilde{5} 0$ & $146 \cdot 4$ & 0 & $\begin{array}{c}3 \cdot 84 \\
\text { (früh) }\end{array}$ & $5 \cdot 68$ & 2396 & \\
\hline $20 . \mathrm{V}$. & $+\tilde{5} 0$ & & & $\begin{array}{c}2 \cdot 84 \\
\text { (nachm.) }\end{array}$ & $4 \cdot 79$ & 2580 & \\
\hline
\end{tabular}


Die Selbstreinigung der Donat.

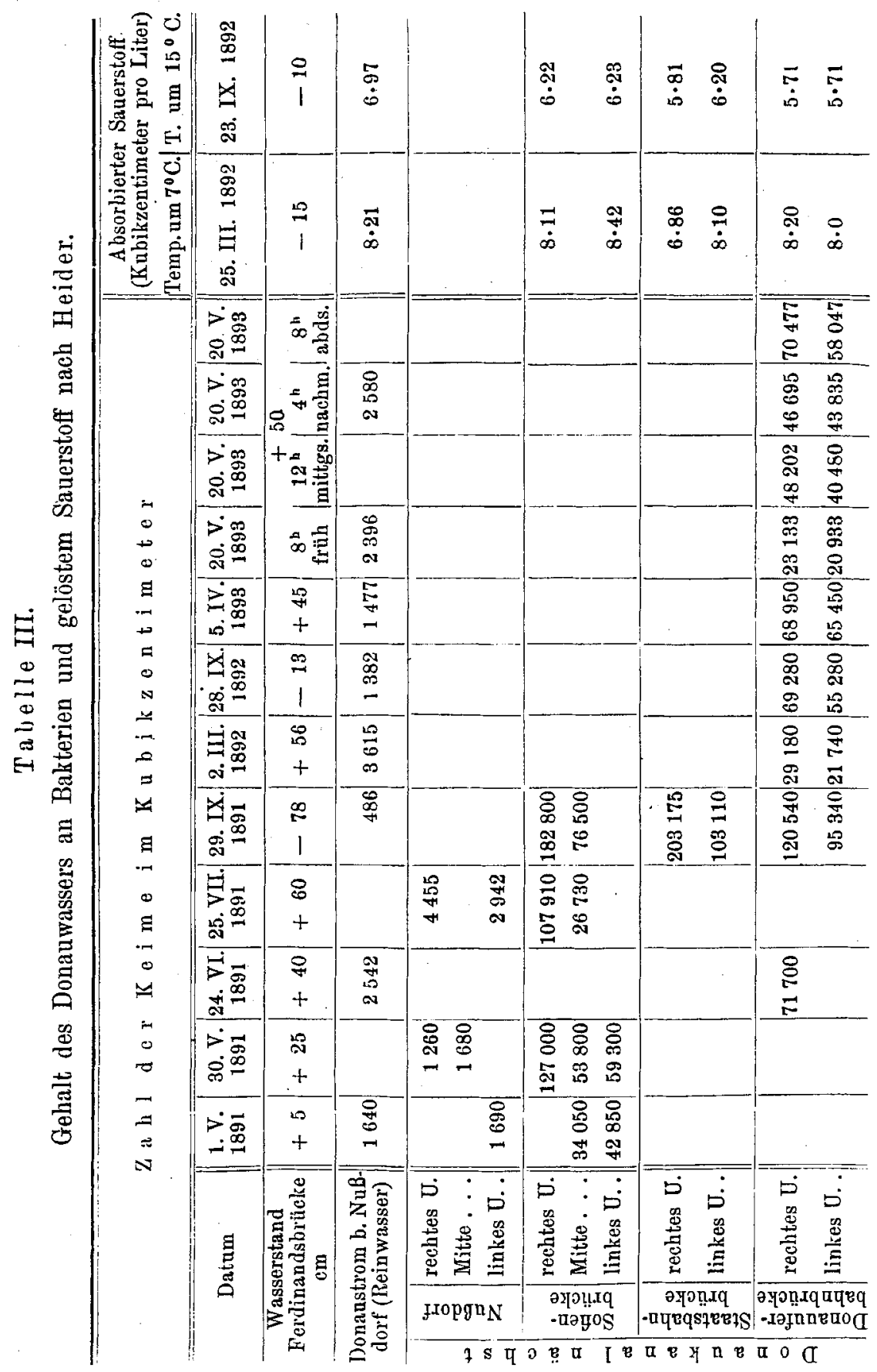


Der größere Teil von Heiders chemischen und bakteriologischen Untersuchungen bezog sich auf den Donaukanal.

Tabelle IV.

Beobachtete Differenzen in der chemischen Beschaffenheit des Wassers an der Donaukanalmündung und im Reinwasser (NuBdorf) nach Heider. Es enthielt das Wasser an der Donaukanalmündung an folgenden Substanzen mehr als das Reinwasser in Milligrammen pro Liter.

\begin{tabular}{|c|c|c|c|c|c|c|}
\hline $\mathrm{T}$ a $\mathrm{g}$ & $\begin{array}{l}\text { Pegelstand } \\
\text { Ferdinands- } \\
\text { brücke }\end{array}$ & Zeit & $\begin{array}{l}\text { Trocken- } \\
\text { rückstand } \\
\text { im nicht } \\
\text { filtrierten } \\
\text { Wasser }\end{array}$ & Ammoniak & Chlor & $\begin{array}{l}\text { Kalinm- } \\
\text { permanganat- } \\
\text { verbrauch }\end{array}$ \\
\hline 24. VI. 1891 & +40 & - & $3 \cdot 8$ & $1 \cdot 3$ & $1 \cdot 03$ & 0.82 \\
\hline 8.X. , , & -93 & - & $14 \cdot 8$ & $1 \cdot 4$ & $2 \cdot 49$ & $5 \cdot 8$ \\
\hline 22. X. & -105 & - & - & $4 \cdot 13$ & $7 \cdot 19$ & $10 \cdot 92$ \\
\hline 2. III. 1892 & +56 & - & - & $0 \cdot 235$ & 0.61 & $2 \cdot 05$ \\
\hline 25. III. , & -15 & - & - & $1 \cdot 5$ & $2 \cdot 14$ & $5 \cdot 49$ \\
\hline 23. IX. & -10 & - & 一 & $2 \cdot 5$ & $1 \cdot 77$ & $6 \cdot 78$ \\
\hline 28. IX. & -13 & - & $33 \cdot 6$ & $1 \cdot 1$ & $1 \cdot 65$ & $4 \cdot 22$ \\
\hline 22. XII. s" & -48 & - & $5 \cdot 0$ & $2 \cdot 39$ & $3 \cdot 8$ & $12 \cdot 99$ \\
\hline 5. IV. 1893 & +45 & - & $5 \cdot 2$ & $0 \cdot 75$ & 0.22 & $4 \cdot 91$ \\
\hline $20 . \mathrm{V}$. & +85 & $8^{\text {h }}$ früh & - & 0.35 & 0.56 & $0 \cdot 395$ \\
\hline ” & +85 & $12^{\mathrm{h}}$ mittgs. & - & 0.8 & $1 \cdot 63$ & $1 \cdot 895$ \\
\hline , & +85 & $4^{\text {b }}$ nachm. & - & 0.58 & $1 \cdot 56$ & $1 \cdot 78$ \\
\hline$"$ & $+8 \mathbf{5}$ & $7^{\text {h }}$ abds. & - & 0.58 & $\because 1 \cdot 38$ & $2 \cdot 93$ \\
\hline
\end{tabular}

Tabelle V.

Berechnete Differenzen in der chemischen Beschaffenheit des Wassers des Donaukanales vor und nach Aufnahme der Wiener Abwässer (nach Heider). Nach Heiders Schätzungen und Untersuchungen der Menge und Beschaffenheit der Wiener Abwässer betrug der Zuwachs einzelner Substanzen bei verschiedenen Pegelständen in Milligrammen pro Liter.

\begin{tabular}{c|c|c|c|c|c}
\hline $\begin{array}{c}\text { Pegelstand } \\
\text { Ferdinands- } \\
\text { brücke } \\
\text { em }\end{array}$ & $\begin{array}{c}\text { Suspendierte } \\
\text { Stoffe }\end{array}$ & $\begin{array}{c}\text { Trocken- } \\
\text { rü̈kstand } \\
\text { im unfiltriert. } \\
\text { Wasser }\end{array}$ & Ammoniak & Chlor & $\begin{array}{c}\text { Kalium- } \\
\text { permanganat- } \\
\text { verbrauch }\end{array}$ \\
\hline 0 & $14 \cdot 1$ & 15.27 & 1.68 & 2.61 & 7.38 \\
-100 & 29.6 & 32.07 & 3.53 & 5.49 & 15.5 \\
-200 & 55.5 & 60.13 & 6.61 & 10.3 & 29.06
\end{tabular}

Heider war der erste Autor, der die Verschiedenheit der Zusammensetzung des Wassers innerhalb eines Profiles gebührend gewürdigt und so gefunden hat, daB der an seinem rechten Ufer mehr Abwässer auf- 
nehmende Donaukanal auch rechts durchweg weit stärkcr verunreinigt ist, und daß der Unterschied sich nur allmählich stromabwärts zu ausgleicht.

Heider hat auch die Schwankung der innerhalb 24 Stunden dem Donaukanale zugeführten Unratmenge erkannt. Leider unternahm er seine Fahrten auf dem Strome nach Hainburg zu früh am Morgen und erhielt so meist Minima der Verschmutzung, insbesondere an den unteren Schöpfstellen, da sein Boot, wie er selbst sagt, der Strömung voraneilte und so auf Wasserschichten stieB, die zu einer früheren Stunde Wien passiert hatten. Die wichtigsten Daten Heiders bezüglich des Donaustromes siehe Tabellen VII und VIII.

\section{Tabelle VI.}

Zunahme einzelner Fremdstoffe im Donaustrome durch die Einmündung des Donaukanales verursacht, mit Rücksicht auf die stattfindende Verdünnung berechnet von Heider. Milligramme pro Liter.

\begin{tabular}{|c|c|c|c|c|c|c|c|}
\hline Datum & \begin{tabular}{|c|} 
P eg el \\
$\mathrm{cm}$ \\
$\begin{array}{c}\text { Ferdinand- } \\
\text { brücke }\end{array}$ \\
\end{tabular} & $\begin{array}{l}\text { tand } \\
\text { Reichs- } \\
\text { brücke }\end{array}$ & Tageszeit & 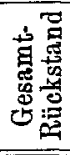 & 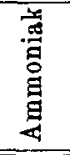 & 宫 & $\begin{array}{l}\text { Kalium- } \\
\text { permanganat- } \\
\text { verbrauch }\end{array}$ \\
\hline 24. VI. 1891 & +40 & +50 & - & $0 \cdot 48$ & $0 \cdot 16$ & $0 \cdot 13$ & 0.1 \\
\hline 3. X. & -93 & -114 & - & $1 \cdot 85$ & 0.17 & $0 \cdot 31$ & 0.73 \\
\hline 22. X. & -105 & -134 & - & - & 0.52 & $0 \cdot 9$ & $1 \cdot 37$ \\
\hline 2. III. 1892 & +56 & +20 & - & - & 0.03 & 0.08 & 0.26 \\
\hline 25. III. & -15 & -56 & - & - & $0 \cdot 19$ & 0.27 & 0.69 \\
\hline 23. IX. & -10 & -14 & - & - & $0 \cdot 31$ & 0.22 & 0.85 \\
\hline 28. IX. & -13 & -24 & 一 & $4 \cdot 2$ & $0 \cdot 14$ & $0 \cdot 21$ & 0.53 \\
\hline 22. XII. & -48 & -88 & 一 & 0.63 & 0.3 & 0.48 & $1 \cdot 62$ \\
\hline 5. IV. 1893 & +40 & -4 & 一 & 0.65 & 0.09 & 0.03 & 0.61 \\
\hline 20. V. & +85 & +50 & $8^{h}$ früh & - & 0.04 & 0.07 & 0.05 \\
\hline , & +85 & +50 & $12^{\text {h }}$ mittgs. & 一 & $0 \cdot 10$ & $0 \cdot 20$ & 0.24 \\
\hline, & +85 & +50 & $4^{\text {h }}$ nachm. & - & 0.07 & $0 \cdot 20$ & 0.22 \\
\hline$"$ & +85 & +50 & $8^{\text {b }}$ abds. & - & 0.07 & $0 \cdot 17$ & $0 \cdot 37$ \\
\hline
\end{tabular}

Wie aus den Tabellen hervorgeht, fand Heider in chemischer Beziehung nur geringe Unterschiede zwischen Schmutz- und Reinwasser, desto gröBere aber hinsichtlich der Keimzahlen.

Das verunreinigte Donaukanalwasser mischt sich mit dem reinen Wasser des Stromes so langsam, daB die Mischung in Hainburg noch nicht vollständig ist. Die Bestimmung des gelōsten Sauerstoffes leistete Heider keine guten Dienste. 
ERnst Brezina:

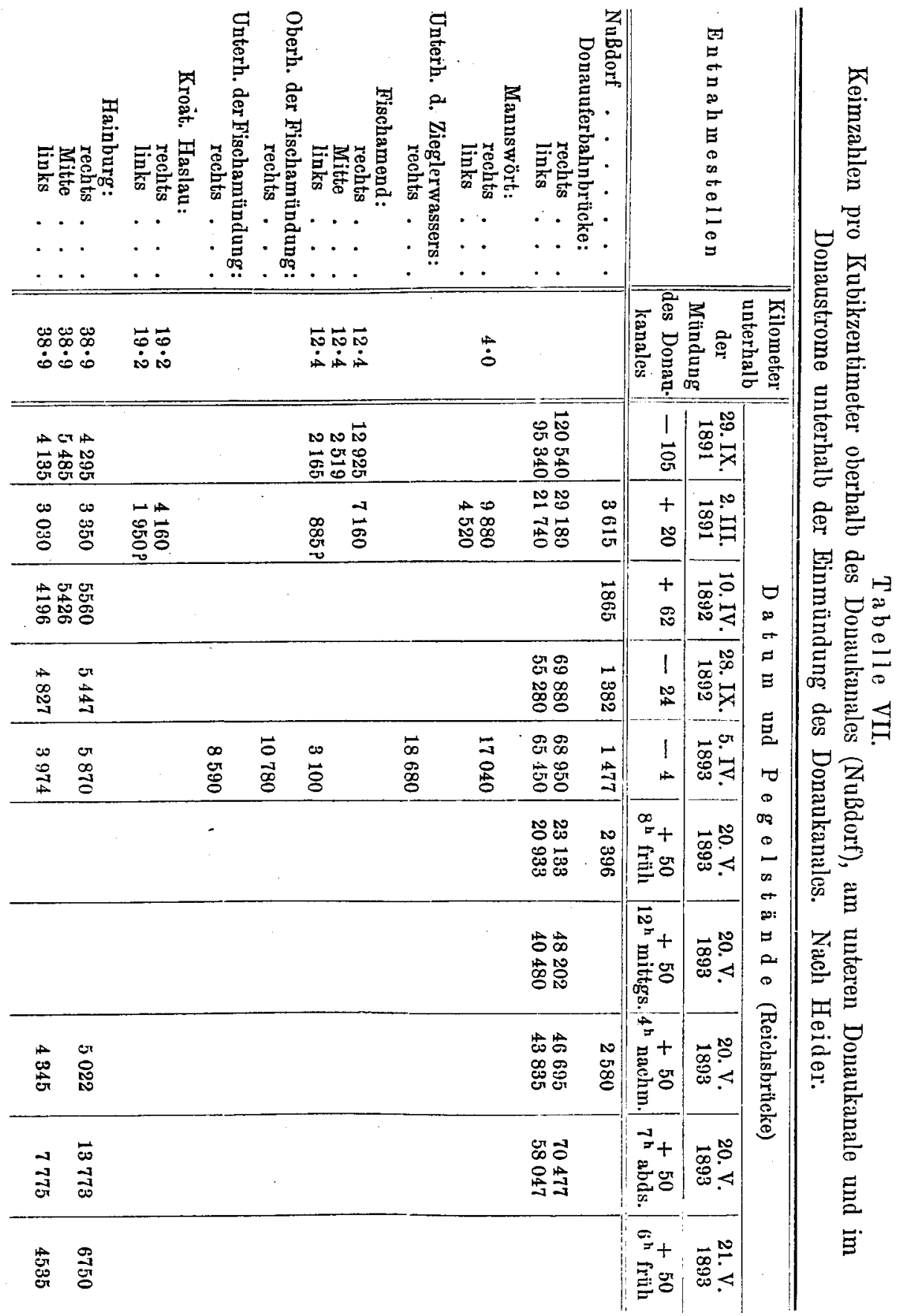


Heider findet in Hainburg meist (Tabelle VIII) weniger Keime im Kubikzentimeter, als er mit Rücksicht auf die im Strome statthindende Verdünnung des Donaukanalwassers dort erwartete, nur einmal, am 20. Mai 1893, findet er mehr Keime als die berechnete Zahl. (Die Befunde sind nicht auffallend, denn Heider eilte, wie oben gesagt, mit seinem Boote der Strömung voraus und untersuchte daher in Hainburg wenig verschmutztes Wasser, nur am 20. Mai 1893 gelangten die gleichen Wasserschichten an der Donankanalmündung und bei Hainburg zur Untersuchung. Das Resultat war auch dementsprechend anders.

\section{Tabelle VIII.}

Berechnete und beobachtete Zunahme der Keimzahlen im Donaustrome zwischen NuBdorf und Hainburg nach Heider. Zahl der Keime pro Kubikzentimeter.

\begin{tabular}{|c|c|c|c|c|c|c|c|c|}
\hline Datum & $\begin{array}{l}\vec{\sigma} \\
\dot{x} \\
\dot{\alpha}\end{array}$ & $\begin{array}{l}\text { o } \\
\text { 㟔 } \\
\text { a }\end{array}$ & $\begin{array}{l}\text { gi } \\
\vdots \\
\dot{0}\end{array}$ & 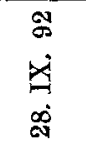 & : & \multicolumn{3}{|c|}{$\begin{array}{c}\text { 20. V. } 93 \\
\text { zu verschiedenen } \\
\text { Tagesstanden }\end{array}$} \\
\hline Pegelstand Reichsbrücke cm & -105 & +20 & +62 & -24 & -4 & +50 & +50 & +50 \\
\hline Nußdorf (Reinwasser) . & 486 & 3615 & 1865 & 1382 & 1477 & 2395 & 2395 & 2580 \\
\hline $\begin{array}{l}\text { Hainburg (aus den Beob- } \\
\text { achtungen gerechnete } \\
\text { Mittelzahl) }\end{array}$ & 4638 & 3190 & 5061 & 5137 & 4922 & 4684 & 10765 & 5643 \\
\hline $\begin{array}{l}\text { Der beobachtete Zuwachs } \\
\text { in Hainburg gegenüber } \\
\text { NuBdorf betrug demnach }\end{array}$ & $\stackrel{+}{4152}$ & -425 & $\stackrel{+}{3196}$ & $\stackrel{+}{3755}$ & $\stackrel{+}{3445}$ & $\stackrel{+}{2889}$ & $\stackrel{+}{8370}$ & $\stackrel{+}{3063}$ \\
\hline $\begin{array}{l}\text { Nach den Keimzahlen an der } \\
\text { Donaukanalmündung and } \\
\text { der Verdünnung berech. } \\
\text { neter Zuwachs. . . . }\end{array}$ & 13432 & $\stackrel{+}{2731}$ & & $\stackrel{+}{7612}$ & $\stackrel{+}{8251}$ & $\stackrel{+}{2455}$ & $\stackrel{+}{5243}$ & $\stackrel{t}{7710}$ \\
\hline
\end{tabular}

Ungemein gründlich sind Heiders mikroskopische Untersuchungen des Wassersedimentes. Wenige der zahlreichen Autoren, welche über Selbstreinigung der Flüsse arbeiteten, haben sich die Mühe genommen, die Sedimente genau zu untersuchen. Heider hat die Charakteristika der Kanalverunreinigungen: Papierreste, gallig gefärbte Objekte, besonders quergestreifte Muskulatur, Stärkekörner, Reste von pflanzlichen Geweben alle beobachtet. Er fand diese Körper mitunter noch bei Hainburg. Auch Kotballen bonnte er dort zuweilen noch sehen.

Außerdem ist die Zahl der Keime in Hainburg wesentlich höher als in NuBdorf. Demnach hat das Donauwasser in Hainburg den Reinheitszustand noch nicht wieder erlangt, den es ror der Einmündung der Abwässer Wiens besaß. 
Heider sagt ferner mit Recht, daß die große Verdünnung der Abwässer durch den Strom die Hauptursache ihres scheinbaren Versçhwindens in der Donau sei. Ob eine absolute Abnahme der Schmutzstoffe auf der untersuchten Strecke stattfindet, konnte nicht eruiert werden, hierzu ist eben die im Strome stattfindende Verdünnung $z u$ weitgehend.

Köhn (16) stellt allgemeine Normen zur Feststellung der Selbstreinigung der Flüsse auf. Er hält Bestimmung des Trockenrückstandes, der organischen Substanz, des Chlors, der salpetrigen, der Salpetersäure und der Keimzahlen für wichtig. Witterungsverhältnisse und Wasserstand sind zu beobachten, an mehreren Stellen eines jeden Profils im Flusse ist Wasser zu schöpfen.

Schenk (19) beobachtet die Algenflora des Rheins. Der Rhein ist arm an Algen. Sie sind daher für die Selbstreinigung des Stromes schon wegen ihrer geringen Menge bedeutungslos, selbst wenn sie die Fähigkeit haben sollten, organische Stoffe zu assimilieren. Dagegen kommt Beggiatoa alba massenhaft, besonders an unreinen Stellen ror und hat wohl Bedeutung für die Selbstreinigung. Sie kann aber selbst faulen und dann verunreinigend wirken, doch kann die Ablagerung durch Steilmachen der Ufer vermieden werden.

Bokorny (20) bezweifelt die Behauptung Schenks, daß die Algenvegetation im Rhein spärlich, auf die Ufer beschränkt und für die Selbstreinigung wertlos sei. Er weist den Algen bei der Selbstreinigung der Flüsse die Hauptrolle zu, indem er durch Züchten derselben in organischer Nährlösung ihre Fähigkeit zur Assimilation organischer Stoffe wie Glyzerin und Methylenblau in bestimmter Konzentration nachweist.

Klett (22) macht Beobachtungen über das Verhalten von Keimen im Schmutzwasser.

In konzentrierter Jauche findet reichliche Keimvermehrung statt, in der durch Flußwasser verdünnten dagegen Keimabnahme, manche Arten verschwinden ganz, doch mūssen die pathogenen nicht notwendig unter diesen sein, da z. B. Typhus- und Cholerakeime noch am zweiten Tage in sehr stark verdünnter Jauche nachweisbar sind. Neben Sedimentierung sei daher Verdünnung Hauptursache bei der Selbstreinigung.

Stutzer und Knublauch (23) schöpften 600 Proben aus dem Rhein bei Köln und berechneten für jede Entnahmestelle eine Durchschnittszahl.

Die Entnahmezeiten wurden mit Rücksicht auf die Geschwindigkeiten der Strömung gewählt, so daB bei jeder Untersuchungsreihe ein und dieselbe Wasserschicht untersucht wurde. In der folgenden Tabelle IX ist die Keimzahl bei Schöpfprofil 1 mit 100 angesetzt, die übrigen Zahlen sind entsprechend reduziert. 
Tabelle IX.

Keimzahlen im Rhein unterhalb Köln pro Kubikzentimeter nach Stutzer und Knublauch, reduziert auf 100 für Entnahmestelle Nr. 1.

\begin{tabular}{|c|c|c|c|c|}
\hline $\begin{array}{c}\text { Entnahmestelle- } \\
\text { Nr. }\end{array}$ & Kilometer & Links & Mitte & Rechts \\
\hline 1 & 0 & 100 & 100 & 100 \\
\hline 2 & 8.0 & 1295 & 197 & 175 \\
\hline 3 & $11 \cdot 0$ & 615 & 162 & 136 \\
\hline 4 & $17 \cdot 0$ & 418 & 215 & 182 \\
\hline 5 & $19 \cdot 5$ & 315 & 198 & 1265 \\
\hline 6 & $22 \cdot 0$ & 354 & 214 & 283 \\
\hline 7 & $34 \cdot 0$ & 186 & 174 & 251 \\
\hline 8 & $47 \cdot 5$ & 122 & $\cdot 198$ & 143 \\
\hline
\end{tabular}

Zwischen Entnahmestelle 1 and 2 am linken Ufer Einmündang der Ảbwässer der Stadt Köln, zwischen Entnahmestelle 4 und 5 am rechten Ufer Mündung der stark verunreinigten Wupper.

Die absoluten Zahlen an der Entnahmestelle Nr. 1 (Reinwasser) schwanken zwischen wenigen Hunderten und 14000 im Kubikzentimeter, Durchschnittszahl über 4000. Verfasser glauben, daB die Keime des Abwassers und der Wupper gleich nach Einmündung in den Strom abnehmen. Leider ist der Arbeit keine Angabe über Menge und Beschaffenheit der Kölner Abwässer, ebensowenig über die Beschaffenheit des Wupperwassers beigegeben, auch fehlen Daten über die Sekundenwassermenge beider Flüsse.

Blasius und Beckurts (25) untersuchten die Oker bei Braunschweig, die hauptsächlich durch die Abwässer von Zuckerfabriken verunreinigt wird. Starke Verschmutzung findet also nur durch einige Monate des Jahres statt. Die Aatoren ermittelten die Menge der verarbeiteten Rüben, Menge und Beschaffenheit der Fabriksabwässer sowie die Sekundenwassermenge der Oker. Diese schwankt stark (beobachtete Extreme 0.86 und 32.985 Sek.-cbm). Der Lauf der Oker ist stark geschlängelt. Untersucht wurde unterhalb Braunschweigs eine über $50 \mathrm{~km}$ lange Strecke. Die Wasserentnahme erfolgte in der FluBmitte. Nach Einmündung der Abwässer traten Ammoniak, salpetrige Säure und Salpetersăure im Flusse auf, waren aber am Ende jener Strecke wieder verschwunden. Die Keimzahlen nahmen in dem untersuchten Abschnitte des Flusses einmal von 9560 auf 180 , ein andermal von 1.3 Millionen auf $660 \mathrm{ab}$. Auch die Menge der organischen Substanzen nahm stark ab (auch das Chlor). Bei kaltem Wetter und besonders unter einer Eisdecke, also bei Licht- und Luftmangel, unterblieb die Selbstreinigung. In letzterem 
Falle waren die Keimzahlen am Ende der untersuchten Strecke offers sehr hoch. Bei höherem Wasserstand war die Selbstreinigung viel ausgiebiger als bei Niederwasser. Nach Einführung der Rieselfeldwirtschaft für die Fabriksabwässer besserte sich der Zustand der Oker wesentlich. Verfasser schließen, daß Verdünnung der Abwässer im Flusse, Licht und Luftzutritt, hohe Temperatur Hauptfaktoren der Selbstreinigung sind.

Mutschler (26) stellt seine Beobachtungen an der Aare an. Dieser FluB, im Thuner See geklärt, nimmt bei Bern die Abwãsser von 40000 Menschen auf kurzer Strecke auf. Verfasser gibt Daten über die Aarewassermenge, sowie über die Menge der Berner Abwässer und ihrer Bestandteile, letztere jedoch nur auf Grund von Schätzungen und Rechnungen, nicht ron Beobachtung. Demnach ist die Verdünnung der Abwässer bei extremem Niederwasser 1:125, meist 1:500. Es tritt baldigst vollständige Wassermischung ein. Die Zunahme der chemischen Verunreinigung ist gering (Oxydierbarkeit, Chloride nehmen nicht, Glühverlust auf das Doppelte zu). Die Keimzahl, oberhalb Berns einige 100, unterhalb einige 1000 im Kubikzentimeter, bleibt hinter der auf Grund der Verdünnung des Abwassers berechneten zurück. Bacterium Coli, auch oberhalb Berns stets zu finden, nimmt stark zu. Die Keimzahlen nehmen bald wieder ab, bleiben aber auBer an sebr sonnigen Tagen höher als sie oberhalb Berns waren, Algen finden sich im Flusse und an den Ufersteinen oberhalb Berns fast gar nicht, unterhalb sehr reichlich, sind daher als Hauptursache der Reinigung aufzufassen, dieselbe ist $50 \mathrm{~km}$ unterhalb Bern noch nicht vollendet, da dort die Algen immer noch reichlich vorkommen. Bakterien sind an der Selbstreinigung unbeteiligt, gehen durch Belichtung allmählich zugrunde. Endlich soll nach Verfassers Beobachtungen an Wehren starke Durchlüftung des Wassers durch Sauerstoffaufnahme im Sinne der Selbstreinigung günstig wirken.

Kabrhel (27) machte durch viele Monate fast täglich zwischen 2 und $3 \mathrm{Ohr}$ nachmittags Bestimmungen des Keimgehaltes der Moldau an drei Entnahmestellen: 1. oberhalb Prags, 2. bald nach ihrem Eintritt in die Stadt, 3. nach Aufnahme des gröBten Teiles der Verunreinigungen. Stets wurden Temperatur und Wasserstand gemessen. Die Zählung der auf den Gelatineplatten aufgegangenen Kolonien wurde nach 5 bis 6 Tagen mit der Lupe vorgenommen. Keimzahlen im Kubikzentimeter bei Entnahmestelle 1: 1000 bis $\mathbf{3 2} 000$ (kleine Zahlen bei Niederwasser, rasche Zunahme bei stärker steigendem Wasser, Abnahme der Keimzahlen bei länger dauerndem hohem Wasserstande). Bei Entnahmestelle 2 ähnliche Zahlen wie bei 1 . Bei 3 höhere Keimzahlen, doch in ähnlicher Weise schwankend wie an den beiden anderen Stellen. GroBe plötzliche Änderungen der Keimzahl pflegen nicht vorzukommen. Die industriellen An- 
lagen oberhalb Prags bewirken mitunter Zunahme der Keime bei Entnahmestelle 1 und 2. Der Parallelismus zwischen Pegelstand und Keimzahl ist durch Zunahme der Stromgeschwindigkeit und Hinzutreten neuer, unreiner Zufiüsse bei steigendem Wasser zu erklären. Eirsteres Moment wirkt der Sedimentierung und der bakteriziden Wirkung des Lichtes entgegen, letzteres kommt nur bei lokalen Regengüssen in Betracht und entfällt bei länger dauerndem Hochwasser, wo dann durch vermehrten Zutritt keimarmen Grundwassers wieder Abnahme der Keimzahl eintritt. In zeitweisen Hochwässern sieht Verfasser ein Hauptmoment der Selbstreinigung. Diese schwemmen die an seichten Stellen aufgehäuften Sedimente $\mathrm{ab}$.

Verfasser unterscheidet: 1. normale Verunreinigung (Industrie, Kanäle) von wenig schwankender GröBe; 2. abnorme, das ist temporäre Verunreinigung, durch zeitweise Niederschläge bedingt, welche den Schmutz der Strassen, der Höfe von Bauerngütern etc. abspülen.

Vor dieser kann man die Flüsse nicht schützen. Bei beginnendem Hochwasser tritt die normale gegen die temporäre Verunreinigung in den Hintergrund. Jene ist eruierbar nach langer, Trockenheit. Temperatur ist bei Niederwasser ohne Bedeutung, bei steigendem Wasser ist die Bakterienzunahme durch Anreicherung größer, wenn zugleich hohe Temperatur herrscht. Nach Verfasser kann eine Beobachtung der Keimzahl bei steigendem Wasser zu Fehlschlüssen verleiten, wenn man daraus auf die normale Verunreinigung schließen will, falls der Fluß durch stark bevölkerte Gegenden zieht. Wegen der niedrigen Keimzahl (1000) bei Niederwasser oberhalb Prags nimmt Kabrhel eine bedeutende Selbstreinigung von den Verschmutzungen im Oberlaufe an.

Verfasser glaubt, daß bei starker organischer Wasserverunreinigung auch nachträglich Keimvermehrung im Wasser stattfinden kann. Er stellt einen

Verunreinigungsquotienten $=\frac{\text { Bakterienzahl der stärkst verunreinigten Stelle }}{\text { Baliterienzahl der reinsten Stelle }}$ auf. Dieser ist ein unechter Bruch, nähert sich bei Hochwasser der Zahl 1, kann sogar zu einem echten Bruch werden.

Die Arbeit von Goldschmidt, Luxenburger, F., H. und L. Neumayer, Prausnitz (28) bildet eine Ergänzung der früher von Prausnitz allein ausgeführten Untersuchungen der Isar. Seit jener Zeit ist in Uünchen die Schwemmkanalisation eingeführt worden. Vorliegende Untersuchungen des Flusses sind teils vorher, teils nachher gemacht. Untersuchungen der Kanalabwässer jedoch fehlen in der Arbeit. Verfasser glauben, daß bald nach der Sieleinmündung durch den in die Isar stürzenden Eisbach eine vollständige Wassermischung stattfinde. HierZeitschr. f. Hygiene. IIII. 
durch wird die Selbstreinigung gefördert. Die Entnahmen erfolgten bald vom Ufer, bald von der Mitte des Flusses aus. (Im Einzelfalle ist dies nicht angegeben.)

Die Wasserentnahmen fanden statt: 1. oberhalb Münchens, die folgenden unterhalb der Sielmündung und zwar $2.3 \mathrm{bis} 5^{\mathrm{km}}, 3.13^{\mathrm{km}}$, 4. $33^{\mathrm{km}}, 5.72^{\mathrm{km}}$ stromabwärts von dieser. Mitunter wurde alle 2 Stunden an mehreren Stellen zugleich Wasser geschöpft und der Durchschnitt berechnet. Die Resultate letzterer Versuche ergaben: an Schöpfstelle 1: 640, 2: $13530,3: 15070,4: 6370$, 5: 3190 Keime im Kubikzentimeter. Es erfolgte also wohl Keimabnahme, doch auch $72 \mathrm{~km}$ unterhalb des Siels war die Keimzahl noch 5 mal so groß wie oberhalb Münchens.

Die Keimzahl ist bei Schöpfstelle 3 wenig, bei 4 auf die Hälfte, bei 5 auf 13 bis 20 Prozent der Keimzahl nach Einmündung der Abwässer gesunken.

Ein großer Teil der Keime geht also in der Isar zugrunde. Da pathogene Keime im Wasser meist vor den Saprophyten eingehen, ist anzunehmen, daB jene bei Freising nicht mehr im Wasser vorkommen.

Schlüsse der Verfasser: 1. Bakterien sind an der Selbstreinigung der Flüsse unbeteiligt, 2. Licht fördert ihr Absterben wohl, doch findet dieses auch nachts statt, 3. das Absterben erfolgt sehr rasch (50 Prozent in 8 Stunden), 4. die Erfahrungstatsache, daB Epidemien nicht fluBabwärts ziehen, wird durch die Befunde erklärt (siehe die gegenteilige Behauptung Uffelmanns [13] und Kruses [34]).

Nach Ansicht des Ingenieurs Classen (zitiert bei Kruse), erfolgt unterhalb Münchens Versitzen eines großen Teiles des Isarwassers in einem ron diesem Flusse selbst gebildeten Geschiebekegel. Das Wasser tritt in Gestalt von Quellen wieder zu Tage und wird im Isarbett durch Grundwasser, also vermutlich keimfreies Wasser, ersetzt. Falls diese Behauptung richtig ist, erklärt sich die von den Verfassern sowie früher von Prausnitz allein beobachtete Tatsache der raschen Keimabnahme in einfachster Weise. Die mit den meisten Untersuchungen anderer Autoren im Widerspruch stehende Erklärnng dieses Befundes durch die Annahme, daß ein rasches Absterben der in die Isar gelangten Keime des Münchner Abwassers erfolge, ist dann nicht stichhaltig.

$\mathrm{Mez}$ (29) sagt in seinem umfangreichen Werke „Mikroskopische Wasseranalyse" unter anderem: Pilze, Algen sind nicht Zeichen der Verschmutzung, sondern Reiniger von organischer Substanz und daher ibre Anwesenheit im verschmutzten Wasser wünschenswert; ein gleiches gilt ron den Bakterien. Da letztere im Moment der beendeten Selbstreinigung natürlich nicht gleich verschwinden, ist eine hohe Bakterienzahl kein Index der Verschmutzung eines Flusses. Ein bereits gereinigtes Wasser 
kann mehr Keime enthalten als manches Schmutzwasser, in dem sie sich aus irgend einem Grunde nicht entwickeln können, und in welchem dann auch die Reinigung ausbleibt. Die festsitzende Ufervegetation eines verunreinigten Flusses nimmt dagegen nach beendigter Selbstreinigung sofort wieder ihren ursprünglichen Charakter an. Sie gibt daher den besten Indikator dafür $\mathrm{ab}$, wo die Selbstreinigung als vollendet anzusehen ist. Die chemischen Methoden eignen sich hierfür nicht, da sie zu wenig empfindlich sind. Der Kaliumpermanganatverbrauch zeigt nicht allein verunreinigende, sondern auch harmlose Stoffe an.

v. Rigler (30). Die chemischen und bakteriologischen Eigenschaften des Donauwassers. Mathematisch-naturwissenschaftliche Berichte aus Ungarn. Bd. XIV, S. 22.

Verfasser hat an 6 Profilen eine $40 \mathrm{~km}$ lange Strecke der Donau bei Budapest, rechts, in der Mitte und links entnehmend, untersucht. Kurz unterhalb der ersten Entnahmestelle münden links die Abwässer Budapests mit Maschinenkraft eingepumpt in den Strom. Die Mischung ist daher gut, und es wurden nirgends sehr hohe Keimzahlen (nicht über 25000 Keime) gefunden. (Oberhalb Pest enthält die Donau nach Verfassers Tabellen mehr Chlor, dagegen etwas weniger Keime als oberhalb Wiens.) Die angewendeten Methoden waren ähnlich denen Heiders. v. Rigler sagt, die Donau habe bei Pest die 10 fache - statt, wie tatsächlich, die $11 / 2$ fache - Wassermenge gegenüber Wien. . Das Donauwasser soll oberhalb Pest viel reiner sein als oberhalb Wien. Doch zeigt der Vergleich der Tabellen v. Riglers und Heiders keinen nennenswerten Unterschied. Die von Heider untersuchte $35 \mathrm{~km}$ lange Strecke von der Donau-Kanalmündung bis Hainburg beträgt nach $v$. Rigler nur $23 \mathrm{~km}$. Verfasser findet oberhalb Pest am Abend kleinere Keimzahlen im Strome als morgens; er bezieht das auf Schädigung der Bakterien durch das Tageslicht.

Schorler (31) macht Untersuchungen über die Algen- und Pilzflori der Elbe:

Höhere Pflanzen kommen in der Elbe kaum vor, dagegen reichlich Wasserfadenpilze (Cladothrix, Beggiatoa) und viele Individuen und Arten von Algen. Hauptsitz letzterer ist der ,untergetauchte Hang" mit seinen festsitzenden, dabei porösen Steinen. Dagegen meiden sie Sand, Geschiebe und tiefes, rasch flieBendes Wasser. Auf Steinen bilden sie grüne, nach der Jahreszeit wechselnde Überzüge. Die Zusammensetzung des Wassers kümmert sie wenig. Pilze lieben dagegen Schmutzwasser. Beggiatoa alba wirkt reinigend durch Oxydation von Schwefelwasserstoff zu Schwefel und dann zu Schwefelsäure, kann daher nur gedeihen, wo anBer Schwefel auch Sauerstoff rorkommt. Wo dieser mangelt, fault Beggiatoa, und es bildet sich dann Schwefelwasserstoff zurück. Da sie keine Kohlensäure ver- 
atmet, wirkt sie nur dort reinigend, wo sie massenhaft vorkommt. Infusorien unterstützen ihre Wirkung. Die Assimilation organischer Substanz durch Algen ist wahrscheinlich unwesentlich. Der absorbierte Sauerstoff dient nur indirekt, indem er das bakterielle Leben fördert, zur Oxydation.

Dirksen und Spitta (32) machen in ähnlicher Weise wie Frank Untersuchungen über die Veränderungen des Wassers der Spree in ihrem Laufe durch Berlin. (Tabelle $\mathbf{X}$.)

Seit Franks Untersuchungen ist die Kanalisation (Rieselfelder) vollständig geworden, so daß nur mehr unbedeutende Kanäle in die Spree münden, dafür hat aber der Schiffsverkehr zugenommen.

Die Keimzahlen in der Spree an der ersten Entnahmestelle in Berlin haben seit Franks Untersuchungen zugenommen, an den übrigen Stellen im Flusse ist kein wesentlicher Unterschied konstatierbar, im Landwehrkanale fanden Verfasser im ganzen kleinere Keimzahlen als Frank. Besonders hoch sind dieselben an Stellen mit lebhaftem Lösch- und Ladeverkehr. Die aus den chemischen Befunden gewonnenen Durchschnittswerte ergaben in der Spree nach ihrem Eintritt in die Stadt Neuauftreten ron Ammoniak, salpetriger und Salpetersäure, Zunahme des Trockenrückstandes, der Suspensa und der organischen Substanzen, dagegen Gleichbleiben des Gehaltes an Chloriden (=Indikator der Verunreinigung durch Harn und Kot bzw. durch Rieselfeldabwässer). Verfasser berechneten aus ibren eigenen und auch aus Franks Befunden Durchschnittszahlen. Die Resultate sind ähnlich, doch haben die Mengen der organischen Substanzen, des Rückstandes, der Chloride und des Kalks (Maxima und Minima) von 1886 auf $1896 \mathrm{zu}$ genommen. Die Verunreinigung der Spree ist also in diesem Zeitraume größer geworden. Verfasser konnten keinen Einfluß der Notauslässe auf die Beschaffenheit des Wassers konstatieren. Bei Niederwasser ist die Verunreinigung der Spree gröBer als bei hohem Pegelstande. Verfasser meinen, daß Frank einen Fehler beging, keine Durchschnittswerte zu berechnen. Dirksen and Spitta schlieBen aus ihren Befunden sowie aus denen Franks, daß nicht die in die Spree mündenden Kanäle, auch nicht die Rieselfeldabwässer und Notauslässe, sondern einzig und allein der Lösch- und Ladeverkehr Ursache der Spreeverunreinigung in Berlin ist und war. (Auf Tabelle $\mathrm{X}$ sind die von Frank und die von Dirksen und Spitta gefundenen Keimzahlen zusammengestellt. Aus der Tabelle ergibt sich, daB im Jahre 1896 die Keimzahlen im ganzen wesentlich kleiner waren als 1886.)

Frank (33) wendet. sich in einer späteren Arbeit gegen die Kritik seiner Untersuchungen durch Dirksen und Spitta. Er hält daran fest, daB die Berechnung ron Durchschnittswerten für die Keimzahlen in der 


\begin{tabular}{|c|c|c|}
\hline-7 & $\stackrel{\unrhd}{ت}$ & $=0$ o \\
\hline 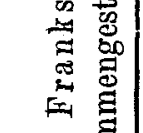 & 言 & 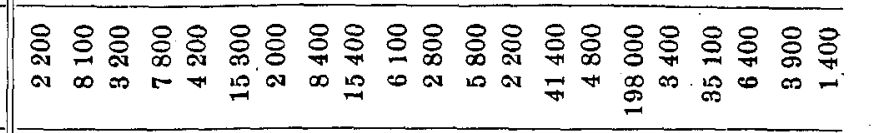 \\
\hline & $\infty^{\circ}$ & 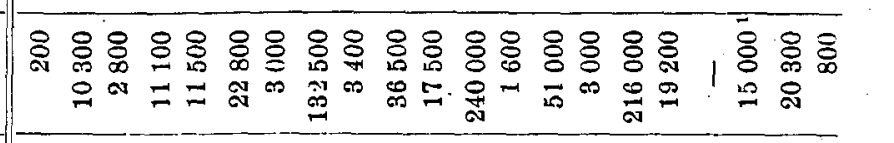 \\
\hline & 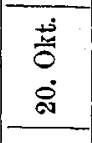 & 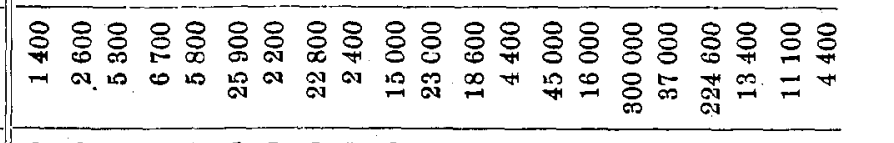 \\
\hline & $\dot{ \pm}$ & 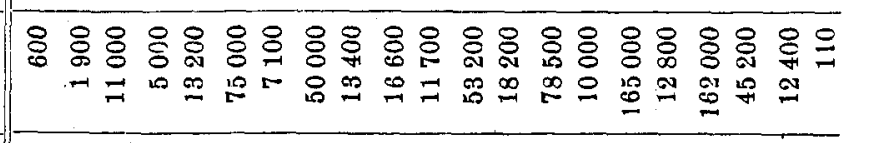 \\
\hline & 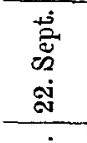 & 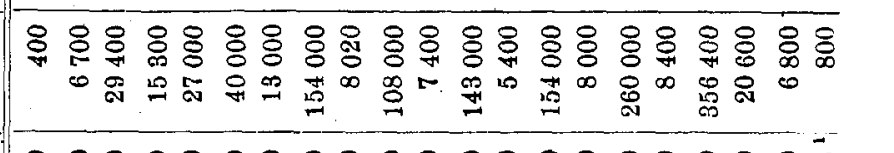 \\
\hline & 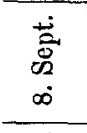 & 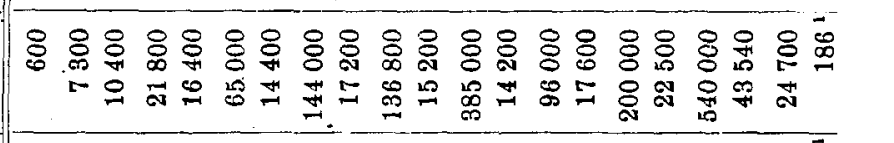 \\
\hline & 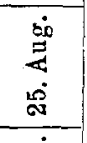 & 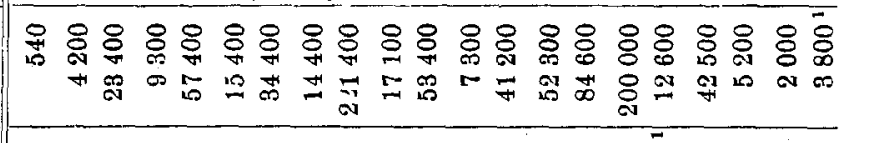 \\
\hline & 苞 & 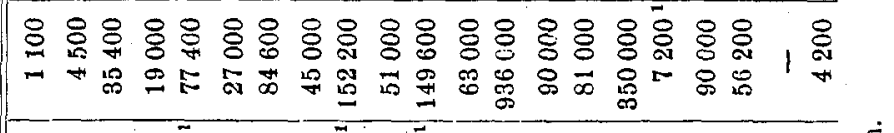 \\
\hline & & 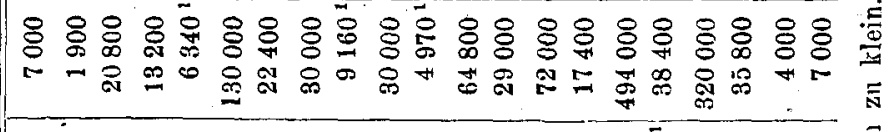 \\
\hline & -7 & 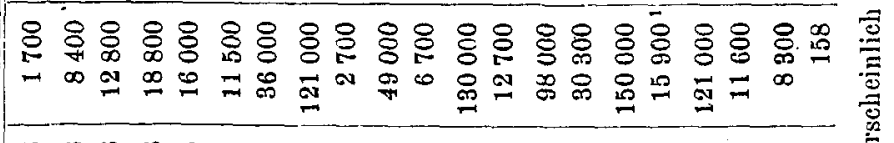 \\
\hline & & 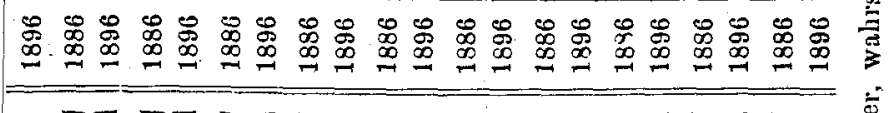 \\
\hline & & 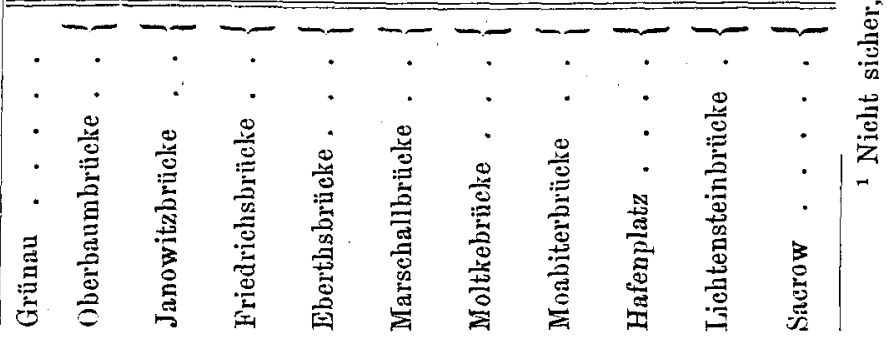 \\
\hline
\end{tabular}


Spree bei Berlin nicht angebracht sei, wenn nicht eine sehr große Zahl von Befunden für jede Entnahmestelle vorliegt. Die Schwankungen der Bakterienmengen an jeder einzelnen Schöpfstelle sind zu groB. Frank vergleicht seine Tabellen mit denen der Autoren und weist nach, daB die Zunahme der Keimzahlen (s. Tabelle $\mathrm{X}$ ) in der Spree während ihres Laufes durch Berlin in dem Zeitraume von 1886 auf 1896 geringer geworden ist. Verminderung der Chlorzunahme auf der gleichen Strecke hat innerhalb jener Zeit nicht stattgefunden, obwohl die Zahl der in den FluB mündenden Abwässerkanäle abgenommen hat. Da nun der vermehrte Chlorgehalt der Spree auf menschliche Abgänge zurückgeführt werden $m u B$, so kann er nur von den Notauslässen herrühren. Das zweite Moment der Verschmutzung der Spree in jenem Zeitraume ist der Schiffsverkehr. Dieser hat in jenem Zeitraume zugenommen.

Kruse (34) unterwirft die bisher geübte Methode bei der Bestimmung der Verunreinigung und Selbstreinigung der Flüsse einer Kritik und stellt gewisse Normen auf.

Nach vielfacher Erfahrung wirken die Einmündungsstellen großer Kanäle in Ströme oft sehr störend auf die Sinne und sollten daher an wenig frequentierte Punkte verlegt werden, da weiter stromabwärts durch eintretende Mischung jedes ästhetische und sonstige Bedenken gegen die Einleitung des betreffenden $\Delta$ bwassers schwindet. Von den einzelnen Faktoren der Flußverunreinigung gilt folgendes:

1. Die Suspensa sind am meisten in die Augen fallend und unangenehm. Sie nehmen je nach der Geschwindigkeit des Flusses verschieden rasch durch die Sedimentation ab. Die Folge ist bei langsamer Strömung Reinigung des Flusswassers, dagegen, wenn die Menge der Suspensa gro $B$ ist, Bildung von Schlammbänken mit allen ihren bekannten Mibständen.

2. Stinkende Gase. Diese werden relativ bald durch Verdünnung und Verdunstung unschädlich. Speziell Ammoniak nimmt mehr ab als der Verdünnung entspricht, eine Erklärung hierfür fehlt, da Verdunstung und Nitrifizierung - diese wenigstens in den bei FluBverunreinigung in Betracht kommenden Zeiträumen - nicht zustande kommt.

3. Die $\mathrm{Zu}$ - und dann auch die Abnahme der gelösten organischen Substanz ist meist zu gering, als $d a B$ aus den Zahlen etwas Sicheres bezüglich der Selbstreinigung zu schließen wäre.

4. Gelöste organische Stoffe können der Fällung unterliegen, doch tritt dies nur selten ein.

5. Bakterien. Die bisher bekannten Resultate der Keimzählungen an verschiedenen Flüssen sind zum Teil wegen der angewandten Methode nicht einwandfrei und schwer miteinander vergleichbar. 
Dif Selbstreinigung Der Donad.

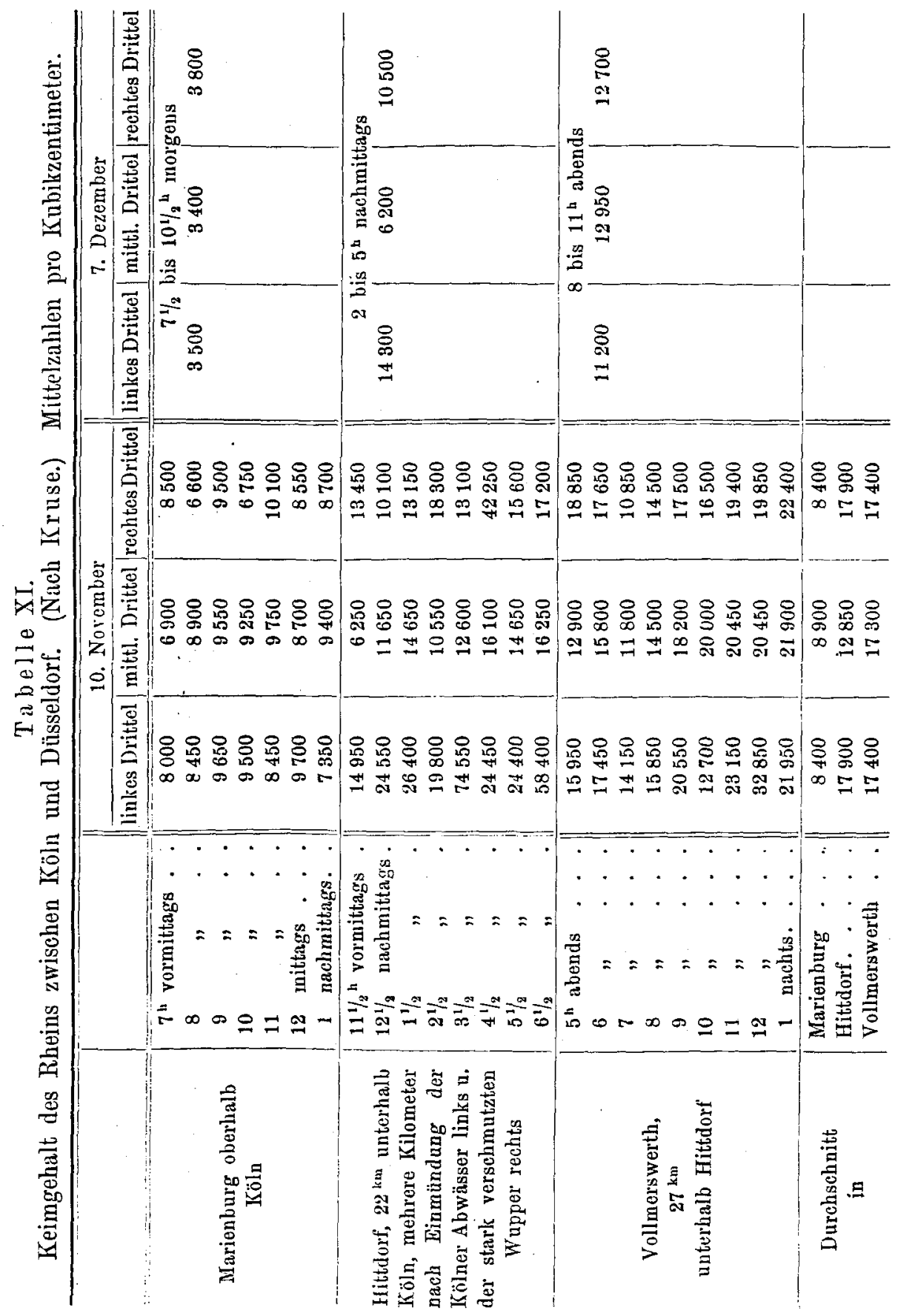


Verfasser und sein Schüler Lossen haben den Rhein auf verschiedenen Strecken untersucht und dabci jedes Profil in 3 Teile geteilt, aus jedem zahlreiche Proben oberfăchlich geschöpft und eine Mischung derselben zur Aussaat verwendet; ferner wurde auf die Geschwindigkeit des Wassers Rücksicht genommen. (Tabellen XI u. XII.)

Tabelle XII.

Bakteriengehalt des Rheins bei und unterhalb Mainz. Nach Kruse. (Mittelzahlen pro Kubikzentimeter.)

$80^{\mathrm{km}}$ lange Strecke. Stärkere Verunreinigung nur oberhalb dieser Strecke. Sämtliche Untersuchungen an sehr sonnigen Tagen ausgeführt.

\begin{tabular}{|c|c|c|c|c|}
\hline \multirow{2}{*}{ Ort der Entnahme } & \multirow{2}{*}{ Zeit der Entnabme } & \multicolumn{3}{|c|}{ Mittelzahlen } \\
\hline & & links & Mitte & rechts \\
\hline $\begin{array}{c}\text { Rhein oberhalb der Main- } \\
\text { mündung }\end{array}$ & $\begin{array}{l}\text { 15. IX. } 6^{b} \text { abends } \\
\text { 16. LX. } 9^{b} \text { morgens }\end{array}$ & $\begin{array}{r}13675 \\
7115\end{array}$ & $\begin{array}{r}15250 \\
9275\end{array}$ & $\begin{array}{r}13575 \\
7875\end{array}$ \\
\hline Rhein bei Niederwald & $\begin{array}{l}\text { 15. IX. } 9^{\text {h }} \text { abends } \\
\text { 16. IX. } 11^{\text {b }} \text { vormittgs. }\end{array}$ & $\begin{array}{r}12150 \\
6975\end{array}$ & $\begin{array}{r}11400 \\
6550\end{array}$ & $\begin{array}{r}11550 \\
8025\end{array}$ \\
\hline Rhein bei Rüdesheim. & $\begin{array}{l}\text { 16. IX. } 6^{\text {h }} \text { morgens } \\
\text { 16. IX. } 6^{\text {h }} \text { abends }\end{array}$ & $\begin{array}{l}9175 \\
5575\end{array}$ & $\begin{array}{l}9625 \\
5425\end{array}$ & $\begin{array}{l}9350 \\
5925\end{array}$ \\
\hline Rhein b. ABmannshansen & $\begin{array}{l}\text { 16. IX. } 7^{\mathrm{b}} \text { abends } \\
\text { 16. IX. } 10^{\mathrm{b}} \text { vormittgs. }\end{array}$ & $\begin{array}{l}5275 \\
7700\end{array}$ & $\begin{array}{l}4550 \\
5625\end{array}$ & $\begin{array}{l}7200 \\
6300\end{array}$ \\
\hline Rhein bei St. Goar & $\begin{array}{l}\text { 16. IX. } 9^{\mathrm{h}} \text { abends } \\
\text { 17. IX. } 1^{\mathrm{h}} \text { nachmitt. }\end{array}$ & $\begin{array}{l}5100 \\
5450\end{array}$ & $\begin{array}{l}5050 \\
5600\end{array}$ & $\begin{array}{l}5925 \\
5450\end{array}$ \\
\hline Rhein bei Oberlahnstein & $\begin{array}{l}\text { 17. IX. } 8^{\mathrm{h}} \text { morgens } \\
\text { 17. IX. } 6^{\mathrm{h}} \text { abends }\end{array}$ & $\begin{array}{l}5125 \\
6150\end{array}$ & $\begin{array}{l}4825 \\
5275\end{array}$ & $\begin{array}{l}5100 \\
4950\end{array}$ \\
\hline
\end{tabular}

Eine wirkliche (nicht auf Wassermischung beruhende) Abnahme der Keimzahlen beobachtete Kruse nur bei einer Untersuchungsreihe; es herrschte damals sehr klares, sonniges Wetter. Der Autor führt daher die Keimabnahme auf den bakterienschädigenden EinfluB des Lichtes zurück. Die Keimabnahme war nur mäBig und zeigte sich hauptsächlich dadurch, daß die knapp unterhalb der Verunreinigung je nach der Tageszeit verschieden hohen Keimzahlen (verschieden groBe Abwassermengen) eine längere Strecke stromabwärts keine Unterschiede zwischen den einzelnen Tagesstunden aufwiesen. Wesentliche Keimabnahme durch Sedimentierung fand Frank (Tabelle $X$ ) in der Spree erst dort, wo ihr Lauf durch seeartige Erweiterungen ungemein langsam wird. Die von Prausnitz und von Goldschmidt, Luxenburger usw. gefundene Keimabnahme in der rasch flieBenden Isar scheint nach Classen darauf zu beruhen, da $B$ ihr Wasser zum Teil in einem von dem Flusse gebildeten 
Geschiebekegel versitzt und durch Grundwasser - also keimfreies Wasser ersetzt wird. Die Erfahrung, daß Epidemien nicht flußabwärts ziehen, ist, wie Kruse meint, nicht sichergestellt.

Verfasser berechnet auf Grund der Baumeister'schen Annahme über Abwasserzusammensetzung die Größe der Verunreinigung, die ein Fluß erleiden wird, wenn seine Wassermenge die der eingeleiteten $A b$ wässer um das 15., 100. und 1000 fache übertrifft. Im ersten Falle ist die Zunahme der gelösten organischen Stoffe nicht, wohl aber die der Suspensa - daher bei langsamen Strömen die Schlammbildung - bedenklich (Seine unterhalb Paris). Die Schlammbildung kann bei sehr langsamen Flüssen auch noch bei 100 facher Verdünnung erheblich sein (Spree bei Berlin), die Schmutzwassereinleitung ist daher in diesem Falle zu verbieten. Bei 1000 facher Verdünnung ist höchstens noch die Zunahme der Bakterien um einige 1000 bemerkbar (Rhein) und wenn 'sich darunter auch einige Infektionserreger befinden, so ist die hierdurch bewirkte Infektionsgefahr verschwindend gering.

Stets sollten Abwässer vor ihrer Einleitung in einen FluB durch Rechen von ihren groben Schwimm- und Schwebestoffen befreit werden, auch sollte man für rasche Mischung derselben mit dem Flußwasser Sorge tragen.

Königs (35) Untersuchungen beziehen sich auf das Schicksal verschiedener, das Wasser verunreinigender Stoffe.

Nur Eisenverbindungen und Schwefelwasserstoff werden direkt oxydiert, Ammoniak nur durch Mikroorganismen. Dieses rerschwindet aber beim langen Rinnen in dünner Schicht vorwiegend durch Verdunstung.

Verfasser meint, daß folgender Kreislauf bei der Selbstreinigung der Flüsse gilt: Schmutzstoffe, Algen, kleine Tiere, große Tiere. Den Algen wird von König ein Anteil an der Selbstreinigung vindiziert.

Spitta (36) setzte die von ihm mit Dirksen gemachten Untersuchungen des Spreewassers fort. Die.Entnahmen erfolgten aus der Flußmitte. Spitta untersuchte das Plankton des Spree-Havelgebietes, fand in den reinen Seen ein reichliches, grünes Plankton, nur aus Algen bestehend, in der Spree ein Gemisch von Algen und Detritus, im Landwehrkanal ein schwärzliches, hauptsächlich aus Schmutzstoffen bestehendes Plankton, darin reichlich Protozoen. Die Planktonmenge an einer und derselben Untersuchungsstelle schwankt ungemein ron Tag zu Tag. Der Trockenrückstand ist an den rerschmutzten Stellen relativ größer. An stark bewohnten Stellen war die Algenmenge geringer, die gesamte Planktonmenge größer. Bedeutung der Algen für die Selbstreinigung war nach diesen Befunden auszuschlieBen. Eine Strecke unterhalb Berlins ist das Plankton wieder spärlicher und algenreich. Spitta machte auch 
Untersuchungen im Rhein. Dieser Strom führt viel feinen Sand suspendiert mit fort, sein Plankton ist sehr arm an Algen.

Aus Experimenten des Verfassers über die Geschwindigkeit der Sedimentierung feiner Materialien im Wasser geht hervor, daB die am langsamsten zu Boden sinkenden Stoffe in der Spree $250 \mathrm{~m}$, im Rhein $5000^{\mathrm{m}}$, in der Elbe $3000^{\mathrm{m}}$ nach dem Hineingelangen in den FluB sedimentieren müssen.

(Die Versuchsanordnung ahmt zwar mit viel Scharfsinn die natürlichen Verhältnisse so gut wie möglich nach, doch immer noch nicht so getreu, da.B man ihre Resultate ohne weiteres auf die natürlichen Verhältnisse übertragen könnte.) Die Bakterien sedimentieren hauptsächlich, indem sie mit totem organischem Materiale zu Boden sinken, an diesem bilden sie groBe Nester. Algen sind meist bakterienfrei. Ihre Bedeutungslosigkeit für die Selbstreinigung des Wassers erwies Verfasser auch durch Versuche: Zylinder mit verdünntem Abwasser gefüllt zeigten bei Luftzutritt rasche Reinigung, keine Algenregetation, bei LuftabschluB viel Algen, keine Reinigung. Die gleichzeitige Abnahme des Ammoniaks ohne Auftreten seiner Oxydationsprodukte spricht wohl dafür, daB dieses zum Aufbau der Bakterienleiber verwendet wird.

Zur Untersuchung der im Wasser sich abspielenden Oxydationstorgänge bestimmte Verfasser nicht nur den Sauerstoffgehalt zahlreicher Wasserproben im Augenblicke der Entnahme aus dem Flusse, sondern auch dessen Abnahme bei mehrtägigem Stehen im Laboratorium. Es zeigte sich, daB auch in Wasserproben mit ursprünglich gleichem Sauerstoffgehalt mit der Zeit Unterschiede nachweisbar wurden, indem verschieden energischer Sauerstoffverbrauch auftrat.

Tabelle XIII gibt die am Rhein gewonnenen Daten Spittas wieder. Das Wasser des Rheins war im ganzen reicher an Sauerstoff als das der Spree, doch war solcher auch in diesem Flusse stets nachweisbar.

In sterilisiertem Wasser tritt Sauerstoffzehrung nicht auf, sie kommt daher durch Bakterientätigkeit zustande. Sie ist um so ausgiebiger, je reicher das Wasser an organischen Substanzen ist und hört nur nach Zerstörung der organischen Substanz oder infolge Bakterienmangels auf. Dieser kommt in Flüssen wohl nie vor. Verfasser machte Versuche über die in verschiedenen stark verschmutzten Wässern eintretende Sauerstoffzehrung. Aus diesen ergab sich, daß die Intensität dieses Vorganges ein Reagens auf den Gehalt eines Wassers an organischen, durch Bakterien zerstörbaren Substanzen ist. Parallelismus zwischen Sauerstoffzehrung und Kaliumpermanganatverbrauch besteht nicht, da dieser auch die Anwesenheit von Substanzen anzeigt, welche durch Bakterien nicht angegriffen werden. Bacterium coli und Bacterium fluorescens liquefaciens sind nach 
Die Selbstretnigung DeR Donad.

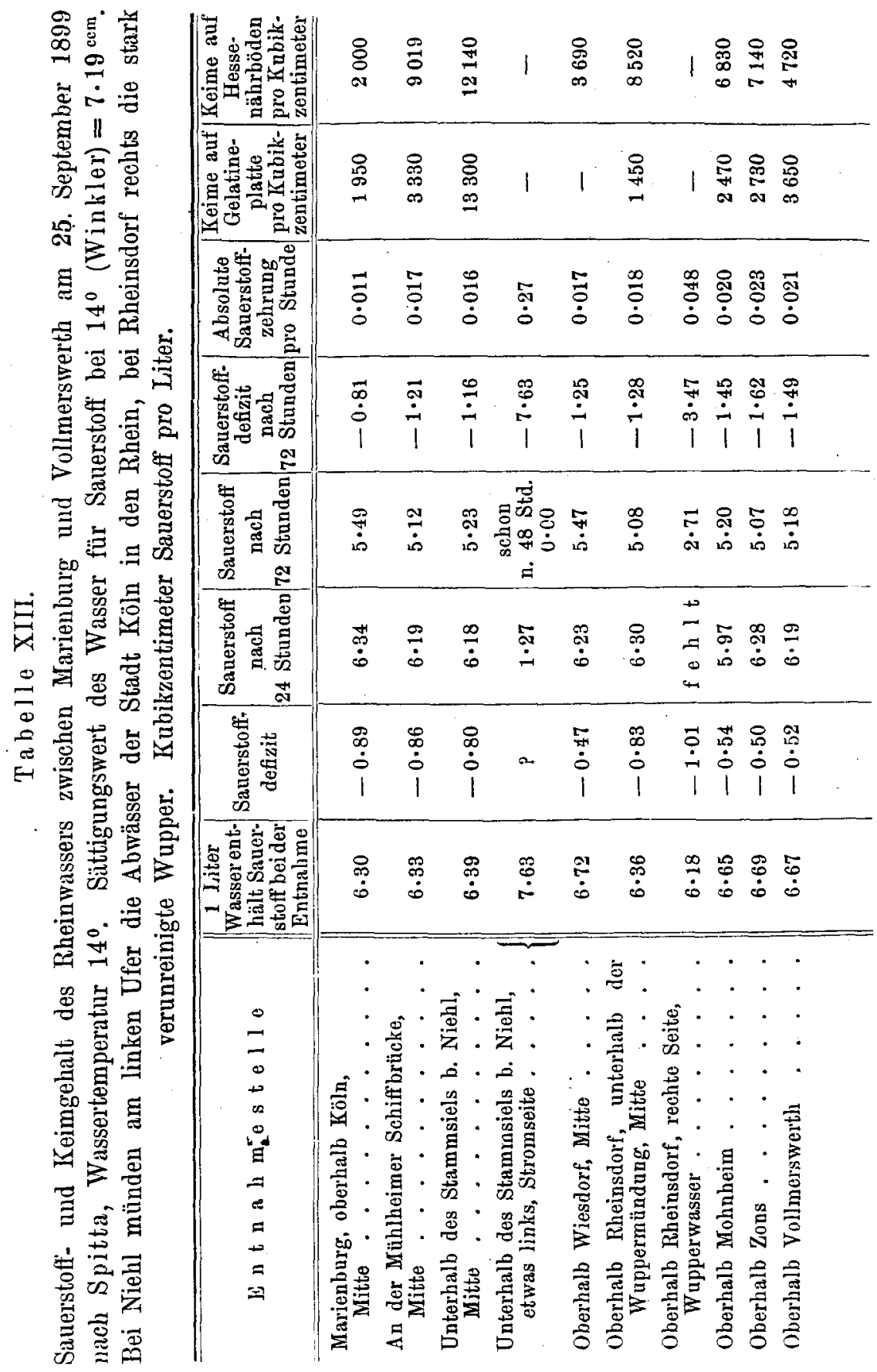


vergleichenden Versuchen des Verfassers die besten Sauerstoffzehrer. Jedenfalls müssen die Keime in den Flüssen im Interesse der Selbstreinigung erhalten und nicht ferngehalten werden, da möglichstes Verschwinden der organischen Substanz das erstrebenswerte Ziel ist. Die Selbstreinigung erinnert an das biologische Verfahren der Abwässerreinigung. Durchlüftung zum Zwecke reichlichen Sauerstoffzutritts ist wünschenswert.

Der Boden des Spreebettes zeigt an den der Verschmutzung ausgesetzten Stellen eine mit Sand gemischte, durch Eisenverbindungen schwarz gefärbte Schicht, in der Eisen- und Stickstoff eben quantitativ bestimmbar sind. Mikroskopisch Algen und Phanerogamenreste, etwas Kohle. 10 bis 15 Prozent Trockenrückstand. Den Boden der Seen bildet reiner Sand. An den verschmutzten Stellen des Spreebettes kommt es durch Sauerstoffmangel zu stinkender anaërober Zersetzung und Gasbildung. Die Schlammbildung stammt in der Spree aus der Zeit ror der Anlage der Rieselfelder. Wegen der langsamen Strömung werden die Sedimente nicht weggeschwemmt, daher würde nur Baggerung helfen.

Eine weitere Arbeit Spittas ergab folgende Resultate: Die suspendierten Stoffe der Abwässer sind Bakterienreservoire und beherbergen oft den dritten Teil der in der gesamten Abwassermenge enthaltenen Keime. (Nachweis durch möglichstes Zerkleinern und Ausschütteln dieser Stoffe.) Mit den Suspensis sinkt eine groBe Menge Keime zu Boden.

Die Aufzehrung der organischen Substanzen der suspendierten Stoffe erfolgt, nach der Sauerstoffzehrung beurteilt, langsamer als die der gelösten. In einem tiefen Fluß kann durch vollständige Sauerstoffzehrung anaërobe Zersetzung eintreten. Tătigkeit der Notauslässe erhöht stets die Verunreinigung der Spree auf kurze Zeit, und zwar steigen zunächst Sauerstoffzehrung und Keimzahl an, der Sauerstoffverbrauch sinkt bald wieder ab, später erst die Bakterienmenge. Vermutlich findet also allmählich Schwächung der Keime statt, ihre oxydative Tätigkeit geht herab.

Verfasser untersuchte die Sauerstoffzehrung von Wasser: 1. Der Berliner Wasserleitung, 2. der Spree, 3. des Landwehrkanals, 4. verschiedener Sielwasserverdünnungen, in offenen Gefäben. Stets erfolgte anfangs Sinken des Sauerstoffgehaltes, dann Wiederansteigen durch Überwiegen der Sauerstoffaufnahme aus der Luft gegenüber dem Verbrauche des Gases. Das Sauerstoffminimum (Beginn des Wiederansteigens der Sauerstoffmenge) konnte um so früher nachgewiesen werden, je schmutziger das Wasser war. Das Spreewasser war reiner als die Sielwasserverdünnung 1:100, bei tätigen Notauslässen gleich der Verdünnung 1:50. Die Notauslässe sind also keine Kalamität, nur wäre Abfangen der groben Schwimmstoffe aus āsthetischen Gründen zu wünschen. Anaërobe Zersetzung, welche vermieden werden muB, tritt in der Spree nie auf. Die Fische drängen 
sich sogar an die tätigen Notauslässe. Verfasser zieht folgende Schlüsse aus seinen Untersuchungen:

1. Die gelösten Stoffe sind die intensivere Verschmutzungsquelle in einem Flusse, die ungelösten die länger dauernde (Verschiedenheit der Sauerstoffzehrung), 2. die Hauptzersetzung ist in 24 bis 48 Stunden vollendet. Der beste Indikator ist die Sauerstoffzehrung, 3. die Grenze der zulässigen Verunreinigung wird überschritten, wenn das Wasser, in hoher Schicht bei erhöhter Temperatur stehend, seinen Sauerstoffgehalt aus der Luft nicht mehr decken kann, 4. die Verunreinigung der Spree in Berlin durch die Tätigkeit der Notauslässe ist in ästhetischer Hinsicht beklagenswert, hingegen 5. sanitär unbedenklich, 6. Badeanstalten in der Spree sind nicht einwandfrei, 7. der Landwehrkanal ist mit Notauslässen überlastet.

Haubenschmidt (37) findet den Zustand der Isar seit Einführung der Schwemmkanalisation in München unterhalb dieser Stadt bei Landshut aus ästhetischen Gründen bedenklich. Alle Schwimmkörper erhalten einen schleimigen Überzug, bis unter Freising schwimmt eine Fettschicht auf dem Wasser. Nur zeitweisen Hochwässern ist es $\mathrm{zu}$ danken, daß die Fische nicht absterben. Als Nutzwasser ist die Isar unbrauchbar, jedenfalls sollte mechanische Klärung stattfinden. (Verfasser schildert das Aussehen der Isar anders als Prausnitz [42].)

Büsing (40) referiert über die Untersuchungen der Elbe und ihres Bettes bei Hamburg. Diese haben ergeben, dab trotz der für die Sedimentierung günstigen Verhältnisse (Gezeiten) keine Schlammablagerungen daselbst vorkommen (außer in der Umgebung der Sielmündungen). Die Selbstreinigung leistet also mehr als man glaubt und geglaubt hatte, und zwar nicht nur durch direkte Oxydation, sondern auch durch biologische Vorgänge. Die Schmutzstoffe dienen Möven, Fischen, Bakterien, Algen, Protozoen, K Krustazeen, Würmern, Schnecken, Muscheln zur Nahrung. Der Schmutz wird dadurch zerstört und in neue Formen umgewandelt. Das Tierleben im Strom ist am intensivsten in der Nähe der Siele. Der Fischbestand ist günstig. Klärung der Abwässer Hamburgs ist heute nicht nötig. Dagegen wăre das Anbringen von Sandfängen und Rechen, bessere Verteilung der Abwässer im Strome durch entsprechende Verlegung der Sielmündungen, Ausschluss der Krankenhausabwässer von der Elbe zu empfehlen.

Gärtner und Rubner (41) geben ein Gutachten über die Zulässigkeit der Einleitung der Abwässer Dresdens in die Elbe. Verfasser veschreiben die Herkunft der gegenwärtigen Dresdner Abwässer und berechnen, wie ihre Menge und Beschaffenheit nach Fertigstellung der neuen Kanalisationsanlagen sein wird, und zwar ist der Berechnung einerseits 
die gegenwärtige Einwohnerzahl $(430000)$ und andererseits eine höhere, zukünftige (720000) zugrunde gelegt. Die Tagesmenge der Abwässer wird demnach 73613 bezw. 123293 cbm betragen, deren Trockensubstanz 81700 bezw. $136000 \mathrm{~kg}$. Letzteren Zahlen ist Baumeisters Schätzung: 190 grm Trockensubstanz pro Kopf und Tag, zugrunde gelegt. Die SeliundenAbwassermenge beträgt 0.852 bezw. $1.427 \mathrm{cbm}$.

Bei der Elbe wurden folgende Daten neben anderen erhoben. Der Flußboden oberhalb Dresdens besteht aus reinem Kies und Sand, unterhalb der Stadt ist er schmutziger. Ufer daselbst flach, zu Ablagerungen geeignet, gegen Hochwasser durch Deiche geschützt, schwach bewohnt, Stromberölkerung ca. 5000 Personen. Wassermenge bei Magdeburg etwa $2 \mathrm{mal}$, bei Hamburg $3 \mathrm{mal}$ so groß als bei Dresden. Häufigste Pegelstände zwischen -150 und -20 .

Tabelle XIV.

Beziehungen zwischen der Elbwassermenge und der Einwohnerzahl Dresdens, sowie den Abwässern der Stadt nach Einführung der Schwemmkanalisation.

\begin{tabular}{|c|c|c|c|c|c|c|c|c|c|c|}
\hline & Pegel & 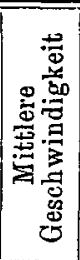 & 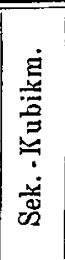 & 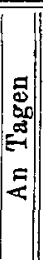 & $\begin{array}{r}\text { Verhä } \\
\text { von Ab } \\
\text { zu Elb } \\
\text { be } \\
\text { e i } \\
430000\end{array}$ & $\begin{array}{l}\text { altnis } \\
\text { wasser } \\
\text { wasser } \\
\text { ei } \\
\text { ner E E } \\
720000\end{array}$ & $\begin{array}{l}\text { Auf } 1 \\
\text { komme } \\
\text { lich K } \\
\text { Elbwas } \\
\text { in w o }\end{array}$ & $\begin{array}{l}\text { Einw. } \\
\text { en täg. } \\
\text { nbikm. } \\
\text { sser bei } \\
\text { h n erz } \\
720000 \mid\end{array}$ & $\begin{array}{l}\text { Auf 1 } \\
\text { Elbw } \\
\text { kom } \\
\text { Milligy } \\
\text { Unra } \\
\text { a h l v } \\
430000\end{array}$ & $\begin{array}{l}\text { Liter } \\
\text { asser } \\
\text { men } \\
\text { ramme } \\
t \text { bei } \\
\text { on } \\
720000\end{array}$ \\
\hline tasser, . & -175 & 4 & 63 & 1 & $1: 74$ & $1: 44$ & $12 \cdot 66$ & $7 \cdot 56$ & 15 & $25 \cdot 13$ \\
\hline Mittelwasser . . & -163 & - & - & -1 & - & - & $16 \cdot 1$ & $9 \cdot 6$ & $11 \cdot 8$ & $19 \cdot 79$ \\
\hline archschnitt & $\mid \begin{array}{l}-78 \\
+200\end{array}$ & $\begin{array}{l}0 \cdot 61 \\
1 \cdot 375\end{array}$ & $\begin{array}{r}230 \\
1230\end{array}$ & $\begin{array}{l}50 \\
15\end{array}$ & $\begin{array}{c}1: 270 \\
-\end{array}$ & $\begin{array}{c}1: 161 \\
-\end{array}$ & $\begin{array}{c}46 \cdot 21 \\
-\end{array}$ & $\begin{array}{c}27 \cdot 6 \\
-\end{array}$ & $\begin{array}{c}4 \cdot 112 \\
-\end{array}$ & $\begin{array}{c}6 \cdot 884 \\
-\end{array}$ \\
\hline asser & $\begin{array}{l}+250 \\
+550\end{array}$ & $3 \cdot 4$ & $\frac{-}{5000}$ & - & $\begin{array}{c}1: 1772 \\
-\end{array}$ & $\begin{array}{c}1: 1058 \\
-\end{array}$ & $\begin{array}{c}303 \cdot 4 \\
-\end{array}$ & $\begin{array}{c}182 \cdot 2 \\
-\end{array}$ & $\begin{array}{c}0.626 \\
-\end{array}$ & $\begin{array}{c}1 \cdot 043 \\
-\end{array}$ \\
\hline
\end{tabular}

Der Zuwachs an festen Stoffen im Elbwasser wird bei Niederwasser 12 mgrm pro Liter betragen.

Gegenwärtig nimmt in der Elbe unterhalb der Einmündung der $A b$ wässer der Trockenrückstand nicht, die sonstige chemische Verunreinigung und das Sauerstoffdefizit eben noch merkbar zu.

Utber das Elbwasser liegen zahlreiche Untersuchungen verschiedener Beobachter vor, auch zahlreiche bakteriologische nach verschiedenen Methoden. Eine 24 stündige Untersuchungsreihe gab folgende Durchschnittswerte bei - 156 Pegelstand. Gelatineplattenmethode. (Tabelle XV.) 
Tabelle XV.

Keimgehalt der Elbe bei Dresden.

\begin{tabular}{|c|c|c|c|c|c|}
\hline & & $\begin{array}{l}\text { Oberhalb } \\
\text { Dresden }\end{array}$ & $\begin{array}{l}0 \cdot 75 \mathrm{~km} \text { unterhalb } \\
\text { der Sielmündung }\end{array}$ & $7^{\mathrm{km}}$ weiter & $\frac{\text { Nach }}{\text { weiteren } 14^{\mathrm{km}}}$ \\
\hline Links & . . . & 5558 & 37000 & 13550 & 7954 \\
\hline Mitte & . . . & 3858 & 7900 & 7183 & 7050 \\
\hline Rechts & $\cdot \cdot \cdot$ & 2808 & 6900 & 5362 & 5795 \\
\hline
\end{tabular}

Die maxima waren 5 bis $10^{\mathrm{h}}$ abends, die minima morgens beobachtet.

Die Suspensa fallen, soweit sie nicht sehr fein sind, aus. Schwimmkörper werden an den Ufern abgelagert.

Niedner hat auf Agar Aussaaten gemacht und die Keime bei $37^{\circ}$ wachsen lassen. Er fand durchweg viel höhere Keimzahlen als andere Untersucher, dieselben nahmen weiter unten nur wenig ab.

Prausnitz (42) gibt $z \mathfrak{u}$, daß die mit seiner Billigung erfolgte Einleitung der Münchener Abwässer in die Isar nicht entsprechend ist. Das Abwasser wird aber nicht, wie er vorgeschlagen hat, von den groben Schwimm- und Schwebestoffen befreit. Verfasser weist auf die Geringfügigkeit der bei Landshut noch nachweisbaren chemischen Verunreinigung der Isar hin. Die ästhetisch störenden Algenfetzen sieht man nach Prausnitz nur im Herbst und Winter. Die Keimzahl nimmt stark $a b$, ist bei Hochwasser auch oberhalb Münchens hoch.

Rubner (44) unterzieht die bisherige Methodik und die landläufigen Ansichten über FluBverunreinigung einer Kritik und trachtet für künftige Arbeiten auf diesem Gebiete Winke zu geben und eine Grundlage zu schaffen. Hervorgehoben wird unter anderem besonders folgendes:

Das Flußwasser ist nicht immer rein, wo der Flußboden rein, nicht immer schmutzig, wo dieser schmutzig ist.

Neben den gewöhnlichen aëroben kommen auch anaërobe Zersetzungsvorgänge in den Flüssen vor und sind wichtig.

Verunreinigungen sind temporär oder permanent, die Größe beider sehr schwankend.

Bei den bisherigen Untersuchungen wurde auf die gelösten Stoffe zu viel, auf die suspendierten zu wenig Rücksicht genommen, da erstere teils an sich unschädlich sind, teils durch Verdünnung unschädlich werden. Letzteres ist bei den Suspensis nicht der Fall, so z. B. bei den gröBtenteils unlöslichen Fäkalien. Es ist unrichtig, vom Sinken der Keimzahl auf vollzogene Selbstreinigung zu schlieBen, da sich die Arten der Bakterien geändert haben können. 
Ungelöste Stoffe geben Infektionserregern Schutz, die im Wasser frei schwimmend bald zugrunde gehen würden. Aus dem Kot ausgelaugte Substanz dient Bakterien zur Nahrung. Bestimmung von Fett, Seifen, Kohlenstoff, Größe des mit Eisenacetat erhaltenen Niederschlags, des Stickstoff- und Verbrennungswertes in diesem Niederschlage und im Trockenrückstande des Wassers (bei Abwasser und Flußwasser) werden empfohlen.

Der gröBere Teil der im Eisenniederschlage enthaltenen Stoffe (Fett, Cellulose) ist für aërobe Bakterien unangreifbar, die Selbstreinigung bezieht sich also nur auf den kleineren Teil der Schmutzstoffe.

Verfasser meint, daB 100 fache Verdünnung des Sielwassers, wenn für gute Mischung gessorgt ist, vom sanitären und ästhetischen Standpunkte genügt.

Im - verunreinigten Flusse nimmt die Keimzahl stärker $a b$ als in den im Laboratorium stehenden Wasserproben, Sedimentierung dürfte bei der Keimabnahme viel ausmachen, Keimzunahme kommt nicht vor. Die Verunreinigung eines Flusses überschreitet die zulässige Grenze nicht, solange kein Sauerstoffmangel zu befürchten ist.

Ohlmüllers (45) Gutachten bezieht sich anf die Einleitung der Mainzer Kanalwässer einschließlich der Fäkalien in den Rhein.

Zwischen Bodensee und Mainz gelangen die von mehr als 1 Million Menschen produzierten Abfallstoffe in den Rhein. Die Fäkalien des größeren Teiles dieser Bevölkerung sind zwar davon ausgeschlossen, dafür aber ist das Gebiet sehr reich an Industrie. Die gröBte Wassermenge führt der Rhein als alpiner Fluß im Juni, die kleinste im Winter. Main und Neckar haben umgekehrt im Winter höhere Wasserstände, im Sommer kleinere. Die Geschwindigkeit des Rheins bei Nittelwasser beträgt ca: $0.9 \mathrm{~m}$, die kleinste vom Verfasser beobachtete Wassermenge betrug 440 Sek.-cbm, gewöhnlich ist sie über 2000 Sek.-cbm gelegen. Der Main führt meist von suspendierten Mineralstoffen trübes Wasser. Dieses mischt sich lange nicht mit dem des Rheins. Der hohe Chlorgehalt des Mains bewirkt nur am rechten Rheinufer ein starkes Ansteigen der Chlormenge, in der Strommitte nur geringe Zunahme der Chloride, ein gleiches gilt von den hohen Keimzahlen des Mains. (Aus den der Arbeit beigeschlossenen graphischen Darstellungen ergibt sich, daß nach Einmündung des Mains die Zahlen für Chlor am rechten Rheinufer auf das doppelte, die Keimzahlen auf das mehrfache steigen. Trotzdem macht sich in der Strommitte die Chlorzunahme stärker fühlbar als die der Keime. Die Chloride scheinen sich daher rascher gleichmäBig über das ganze Rheinprofil auszubreiten als die Bakterien.) Verfasser schätzen den Trockenrückstand der Unratmenge nach vollendeter Kanalisation der Stadt Mainz (inklusive Fäkalien) bei 
87581 Einwohnern auf 583.929 Sekundengramm, wobei sie annehmen, daß die Hauptmenge in 12 Stunden abläuft. Die dem Rhein gegenwärtig zugeführte Unratmenge verursacht keine chemisch nachweisbare Verunreinigung, jedoch beträchtliche Keimvermehrung. Mitunter kommen jedoch auch oberhalb Mainz Keimzahlen (Hunderttausende von Bakterien im Kubikzentimeter) vor, welche höher sind, als zu anderen Zeiten die Bakterienzahlen unterhalb dieser Stadt. Verfasser glaubt nicht oft genug untersucht zu haben, um ein klares Bild dieser Verhältnisse geben zu können. Der Chlorgehalt des Rheins unterhalb der gegenwärtigen Sielmündung sinkt bald auf sein normales Niveau.

Eine nennenswerte Zunahme der Verschmutzung des Rheins ist somit durch die Kanalbauten nicht zu befürchten, doch bält $0 \mathrm{hlmüller}$ folgende Maßnahmen für erforderlich:

1. Mechanisches Zurüekhalten grober Schwimmkörper von den Sielmündungen, 2. Sorge für rasche Mischung des Abwassers mit dem Stromwasser, 3. Zurückhalten der Schwimmkörper an den Notauslässen, 4. Verlegen der Badeanstalten und Schifflandungsplätze aus der Nähe der Kanäle, 5. Desinfektionspflicht bei Typhus, 6. Allgemeine Abwasserdesinfektion bei Epidemien, 7. Trinkgelegenheiten für Schiffer.

Aus der Arbeit von Holst, Geirsvold, Schmidt-Nielsen (38) über Verunreinigung des Hafens und des Flusses Ackerselven durch die Abwässer von Christiania sei nur hervorgehoben, daB im Unterlaufe des Flusses und in den anschlieBenden Gebieten des Hafens Schlanmbildung mit Fäulnis und Aufsteigen von Gasblasen stattfindet. Der Chlor- und Keimgehalt des Wassers im Hafen ist unter anderem ron der Windrichtung abhängig.

Marsson, Spitta und Thum, Gutachten über die Zulässigkeit der Fäkalienabschwemmung der Stadt Hanau in den Main (70).

Die Grundlage für die Untersuchungen gibt eine wiederholte chemische Analyse der Abwässer der Stadt (gegenwärtig ohne Fäkalien) sowie des Mainwassers oberhalb der Kanalmündung nebst Bestimmung der Keimzahlen. Auch die Menge der Abwässer und die Sekundenwassermenge des Mains wurde bestimmt. Die Abwässer sind von geringer Konzentration, das Mainwasser ziemlich rein (Keimzahlen meist unter 2000 im Kubikzentimeter) nur der Kaliumpermanganatverbrauch ist relativ hoch (ca. 38 mgrm pro Liter). Die Einleitung der gegenwärtigen Abwässer der Stadt hat nur eine Zunahme der Keimzahlen um einige Tausend, chemisch keine erkennbare Änderung der Wasserbeschaffenheit zur Folge. Bei Einleitung der Fäkalien in den FluB wird der Zuwachs an gelösten Stoffen unwesentlich, jedoch die Zunahme der ungelösten Stoffe eine nennenswertc sein, deswegen muß eine entsprechende Vorbehandlung der Abwässer ein- 
treten, zur Vermeidung der Infektionsgefahr muß eine Reihe weiterer sanitärer Maßregeln durchgeführt werden, wenn die Einleitung der Fäkalien in den FluB gestattet werden soll.

Die biologische Untersuchung des Mainwassers ergab schon oberhalb Hanau eine grobe Menge Pilze (daneben auch Algen) verschiedener Art, teilweise gingen diese in Fäulnis über, zeitweise schädigten sie den Fischbestand. Ursache dieser Erscheinung waren die Abwässer einer eine größere Strecke oberhalb Hanau gelegenen Cellulosefabrik, durch welche dem Wasser viel organische Substanz zugeführt wird. Zu größeren Kalamitäten kommt es nicht, dank der raschen Strömung. Die Abwässer der am Main liegenden Ortsehaften beeinflussen die biologische Beschaffenheit des Wassers nicht. (Im vorliegenden Falle zeigt die Zunahme der Pilzflord eine Verunreinigung des Wassers mit organischer Substanz an, welche sich durch höhere Keimzahien nicht kund gibt.)

\section{Anderweitige einschlägige Arbeiten.}

Der Bericht über die vom k. k. Ackerbau-Ministerium einberufene Expertise, betreffend die landwirtschaftliche Verwertung der Wiener $A b$ wãsser (47) datiert aus der Zeit, wo der Bau der beiden Hauptsammler noch nicht ausgeführt, doch schon projektiert war. Für die nachfolgende Arbeit sind die Messungen der Wassermenge, an den damaligen gröBten Sammelkanälen der Stadt vorgenommen, von Wichtigkeit.

Die Resultate sind auf Tabelle XVI zusammengestellt.

Tabelle XVI.

Die Wiener Sammler führen folgende Wassermengen:

\begin{tabular}{|c|c|c|c|c|c|c|}
\hline \multirow{2}{*}{$0 \mathrm{rt}$} & \multicolumn{4}{|c|}{$S \circ f \circ r t$} & \multicolumn{2}{|c|}{$\begin{array}{c}\text { Nach Erweiterung } \\
\text { des Kanalnetzes }\end{array}$} \\
\hline & Einwohner & Sek.-Lit. & $\begin{array}{l}\text { Kabikm. } \\
\text { pro Tag }\end{array}$ & \begin{tabular}{|} 
Liter pro \\
Einwohner
\end{tabular} & $\begin{array}{l}\text { Sekunden- } \\
\text { Liter }\end{array}$ & $\begin{array}{l}\text { Kubikm. } \\
\text { pro Tag }\end{array}$ \\
\hline Rechter Sammler & 1160100 & 913 & 78883 & 68 & 938 & 81043 \\
\hline Linker Sammler & 154900 & 174 & 15034 & 97 & 174 & 15034 \\
\hline Summe & 1375000 & 1087 & 93917 & 71 & 1112 & 96077 \\
\hline
\end{tabular}

Auch chemische Analysen und Berechnungen des Wertes der Abwässer wurden ausgefübrt, und zwar beides im Hinblicke auf die Land. wirtschaft.

Monti (48) untersuchte die Abwässer zweier Radialsysteme Berlins nach Passieren der Sandfãnge und Rechen. Der Kanalinhalt wurde auf 
ein Sieb von $7 \mathrm{~mm}$ Maschendurchmesser aufgegossen, das abfließende Wasser passierte dann noch weitere 4 immer feinere Siebe und endlich ein Papierfilter. So erhielt Monti 6 Portionen suspendierter Stoffe. Auch das Filtrat (7. Portion) erhielt noch feinste Suspensa. Den Rückstand der gröberen Siebe bildeten distinkte Körper, auf den feineren lagerte sich eine' aus feinen, miteinander verfilzten Fasern bestehende Schicht ab. Mikroskopisch wurden Papier, Gewebsfasern, Getreidereste, gallig gefärbte Partikel (auch quergestreifte Muskulatur) gefunden. Das spezifische Gewicht der Trockensubstanz war bei den Rückständen der feineren Siebe größer, diese Rückstände hatten auch einen größeren Wassergehalt.

In den Kanälen findet demnach ein fortschreitender Zerfall der Suspensi statt, es bildet sich die genannte Fasersubstanz, daher geht auch ein großer Teil der suspendierten Stoffe durch die Siebe durch. Der Stickstoffgehalt ist geringer in dem auf den feinen Sieben bleibenden Rückstande, im Filtrat wieder gröBer. Nur 3 bis 11 Prozent des Unrates bleibt auf den Sieben. (besonders auf den feinen), viel mehr auf dem Filter. Die größte Unratmenge führten die Kanäle mittags, die geringste morgens.

Blachstein ( 50 ) untersucht das Wasser aus der Leitung des Institut Pasteur und das Seinewasser, das rerschiedene Strecken unterhalb der Mündung der Pariser Sammelkanäle geschöpft wurde. Methode: Zusatz des Wassers zur 10 fachen Menge Bouillon, dann 2 bis mehrtïgiger Aufenthalt im Brutschrank. In den Leitungswasserröhrchen gingen koliartige Bakterien neben anderen auf. Mit diesen Kulturen wurden Kaninchen, Mäuse und Meerschweinchen intraperitoneal behandelt. Nur letztere Versuchstiere erkrankten an den Folgen der Injektion, wenn sie Dosen von minclestens $1^{\mathrm{ccm}}$ erhalten hatten. In den mit Seinewasser beschickten Röhrchen kam vorwiegend Bacterium coli zur Entwicklung, wenn jenes knapp unterhalb der Sammlermündung geschöpft war. Auch Kaninchen gingen auf intraperitoneale Injektionen von $1^{\mathrm{ccm}}$ zugrunde. Je weiter unterhalb der Verunreinigung das Wasser entnommen wurde, desto ähnlicher war es in seinem bakteriologischen Verhalten dem Leitungswasser.

Hammerl (53) untersucht das Wasser der Mur in versehiedenen Distanzen von den Kanalmündungen auf Vorkommen von Bacterium coli (Kultur auf Gelatineplatten). Er findet im Bereiche einiger Kilometer unterhalb des Kanales jeder Ortschaft unter anderen Kolonien solche von Bacterium coli, in größeren Distanzen von den Mündungen dieser Gerinne jedoch niemals. Verfasser hat kein Anreicherungsverfahren verwendet.

Levy und Bruns (54) finden im Wasser regelmäBig koliartige Bakterien, doch nur in verunreinigtem Wasser sind sie pathogen. Verfasser setzen dem Wasser Pepton und Kochsalz zu je 1 Prozent zu und züchten durch 48 Stunden im Brutschrank. Intraperitoneale Injektionen solcher 
Kulturen sind harmlos, wenn sie von hygienisch einwandfreiem Wasser stammen, bei verunreinigtem Wasser werden Mäuse $(0.2$ bis $0.5 \mathrm{~cm})$, Meerschweinchen ( 1 bis $2 \mathrm{~cm}$ ) und Kaninchen $(2$ bis 3 com $)$ getötet. Die Obduktion ergibt das. Vorhandensein von Bacterium coli, daneben oft andere Bakterien (Proteus).

Petruschky und Pusch (56) bestimmten bei einer Reihe ron Wässern die kleinsten Mengen, aus denen beim Züchten im Brutschrank noch Bakterien zur Entwicklung kamen. Zur Anreicherung wurde den Wässern Bouillon zugesetzt. Die gefundene kleinste Menge nannten Verfasser den "Thermophilentiter" des betreffenden Wassers. Die kleinsten Mengen Wassers, aus der sich noch Bacterium coli auf diesem Wege züchten ließ, wurde „Colititer" genannt. Meist waren Thermophilen- und Colititer einander gleich. Der Titer schwankt bei den von Verfassern untersuchten Wässern zwischen 100 und $0.1 \mathrm{~cm}$. Stets handelt es sich um Brunnenwasser.

Wolf (57) macht folgende Beobachtungen: Elbwasser ist weich und enthält stets Bacterium coli und Bacterium vulgare. Die Brunnen im Gebiete des die Elbe begleitenden Grundwasserstromes enthalten gewöhnlich hartes, keimarmes Wassers, dem obige Bakterienspezies fehlen. Beim Steigen der Elbe nimmt die Härte der Brunnenwässer langsam ab, beim Fallen des Stromes langsam wieder zu. Die Keimzahlen steigen rasch, um auch ziemlich schnell wieder zu fallen. In dem keimreichen Wasser kommen die genannten Bakterienarten beide vor, selten Bacterium coli allein. Dieses wurde durch Zusatz von 1 Prozent Pepton und Kochsalz zum Wasser nach 48 stündigem Züchten im Brütschrank nachgewiesen. Meerschweinchen, welchen $2^{\mathrm{ccm}}$ dieser Flüssigkeit intraperitoneal injiziert wurden, starben nach 20 Stunden biș 4 Tagen.

Bolton (59) läßt Wasser verschiedener Herkunft (Brunnen-, Quell-, Teichwasser, destilliertes Wasser mit eingesäten Bakterien) in hohen Zylindern stehen. Durch 36 Stunden erfolgt Keimvermehrung, und zwar nicht durch Auflōsung von Verbänden in einzelne Individuen, sondern wirkliche Vermehrung. Dann findet Abnahme der Keime statt, und zwar nicht allein durch Sedimentieren. Die anfängliche Vermehrung geht parallel dem Nährstoffgehalt, fehlt aber in destilliertem Wasser auch nicht ganz. Dem . Wasser zugefügte pathogene Bakterien nehmen zwar rascher an Zahl $a b$ als andere, halten sich aber doch durch längere Zeit (Wochen) infektionstüchtig.

Wolffhügel und Riedel (61). Wasserbakterien vermindern sich im Eisschrank, vermehren sich aber bei Zimmertemperatur; bei dieser rermehren sich auch pathogene Keime, besonders Milzbrand, weniger stark Typhus, Choleraspirillen nehmen anfangs an Zahl ab, dann oft wieder zu. 
Rubner (63) untersuchte einen unbenützten Brunnen.' Daselbst gingen in der Regel Neubildung und Sedimentierung von Keimen gleichzeitig nebeneinander vor sich, so daß die Keimzahl stets gleich blieb. Bei höherer Temperatur gingen beide Vorgänge im verstärkten Maße vor sich. Beim Steigen des Wasserspiegels durch Regen erfolgte Keimvermehrung. Im Zimmer aufgestellte Gefäße mit Proben des gleichen Wassers zeigten Vermehrung der Keime bis zum 6. Tag, dann Abnahme durch Sedimentierung und durch Absterben. Die einzelnen Arten verhielten sich bezüglich Vermehrung, Sedimentieruug und Absterben nicht gleich, Zusatz von Fleischextrakt bewirkte langsame, doch starke Zunahme der Keimzahl, Auftreten von Ammoniak und Salpetersäure, später Sinken der Keimzahl unter Zunahme der organischen Substanz. Schon kleine Verunreinigungen machten starke Vermehrung der Bakterien.

Kraus (60) zeigt, daß Typhuskeime, in gutes oder schlechtes Brunnenwasser eingesät, nach 7, Milzbrandbazillen nach 4, Choleravibrionen nach 2 Tagen verschwinden. Auf Grund dieser seiner Versuche spricht er dem Wasser jede Bedeutung als Epidemieverbreiter ab.

Krüger (62) untersucht den Sedimentierungsvorgang bei Bakterien. Pulverförmige unlösliche Sinkstoffe reißen die Keime mit zu Boden und zwar um so mehr, je kleiner das spezifische Gewicht des Pulvers, je langsamer daher das Sinken erfolgt. Am Boden findet dann wieder Vermehrung der Keime statt, stärker als in den Kontrollproben ohne künstliche Fällungsmittel.

Emich (64) macht Versuche über das Verhalten von Jauche beim Stehen im Laboratorium.

In sterilisiertem Schmutzwasser findet keine 0xydation statt, diese ist daher ein vitaler ProzeB. In Schmutzwasserproben nahm bei Versuchen des Verfassers der Kaliumpermanganatverbrauch pro Liter beim Stehen an der Luft in mehreren Monaten von 12 auf 2 bis $3^{\mathrm{mg}}$ ab. Ammoniak wird zu salpetriger, dann zu Salpetersāure oxydiert; in Flüssen findet letzterer Vorgang nicht statt. Auch Ozon- und Wasserstoffsuperoxydzusatz ändert in sterilisirtem Schmutzwasser dic Oxydierbarkeit nicht. Demnach sind Bakterien die Ursache der Reinigung.

Auch nach Uffelmanns (65) Versuchen geht die Oxydation des Ammoniaks im Wasser und im Boden auf biologischem Wege vor sich.

H. Chicks (68) Studien betreffen die einzellige Alge Chlorella pyrenoidosa. Diese kommt sehr gut im Sielwasser fort, läBt sich daraus rein züchten und wächst gut in einer Glukose und. Harnstoff enthaltenden Lösung. Enthält der Nährboden freies Ammoniak, so verschwindet es unter dem Einflusse ibres Wachstums, dagegen nimmt Albuminoid-Ammoniak 
zu, nicht aber salpetrige und Salpetersäure. Das Ammoniak wird daher zum Aufbau der Leibessubstanzen der Alge verwendet.

Kolkwitz und Marsson, Grundsätze für die biologische Beurteilung des Wassers nach seiner Flora und Fauna (69).

Verschmutzung des Wassers mit organischen Stoffen hat reichliche Entwicklung tierischer und pflanzlicher Organismen zur Folge. Durch genaues Studium derselben wird es möglich sein auf Art und Größe der Verunreinigung des Wassers zu schließen, auch dort wo die chemische Analyse des Wassers im Stiche läBt. Es wird gelingen für bestimmte Verschmutzungsarten und -grade charakteristische Leitorganismen zu finden, wo sich aus dem Auftreten einzelner Arten kein Urteil bilden lïBt, kann die Bestimmung des gemeinsamen Vorkommens bestimmter Organismen „Leit-Biocönosen" zum Ziele führen.

Die vorliegenden Arbeiten umfassen einen längeren Zeitraum. Während desselben haben sich die Anschauungen über chemische und biologische Vorgänge in mancher Hinsicht geändert. Die Untersuchungen betreffen Wasserläufe mit durchaus verschiedenen hydrologischen Verhältnissen und verschieden starken Verunreinigungen. Die Autoren wendeten nicht immer gleiche Untersuchungsmethoden an, legten bei der Beobachtung bald auf den, bald auf jenen Vorgang mehr Wert und arbeiteten überhaupt öfters ohne die bereits erschienenen Publikationen über das gleiche Thema entsprechend $\mathrm{zu}$ berücksichtigen.

Als Flußverunreinigungen werden angesehen:

a) Ungelöste Stoffe, und zwar das von einem. Flusse mitgeführite leblose Material (whwimm- und Schwebestoffe), hauptsächlich das organische, während die unorganischen Körper wie Sand und Ton keine derartige Bedeutung haben (Baumeister [9]). Die organischen Schwimmund Schwebestoffe sind verläBliche Indikatoren stattgehabter Verunreinigung, namentlich die menschlichen Exkrete. Diese wurden am gründlichsten von Heider (17) studiert. Sie können als Träger von Infektionsstoffen gefährlich werden. Organische Schwimm- und Schwebestoffe sind zum Teil leicht zersetzlich und können dann in Fäulnis geraten.

b) Gelöste Stoffe. Von diesen waren im Flußwasser in der Regel Trockenrückstand, organische Substanz, Ammoniak, salpetrige und Salpetersäure, Chlor, öfters Glühverlust und Schwefelwasserstof Gegenstand der Untersuchung. Die genannten anorganischen Verbindungen, an sich völlig harmlos, kommen nur in Betracht, weil sie Verunreinigung mit organischen Stoffen anzeigen, aus denen sie durch Zusetzhng hervor- 
gegangen sind, insbesondere Ammoniak und Chloride sind Indikatoren einer Verunreinigung des Wassers mit Harn und Kot. Die bisherigen Untersuchungen lehren jedoch, daß diese Stoffe nur bei sehr ausgiebiger Flußverunreinigung in vermehrter stets quantitativ bestimmbarer Menge auftreten, bei den großen Strömen Mitteleuropas, wie Elbe, Rhein und Donau, ist dies meist nicht der Fall. Chloride können übrigens auch dem Gesteine entstammen und zeigen dann eine FluBverunreinigung in unserem Sinne nicht an. Vermehrung der organischen Substanz dagegen ist selbst als Verunreinigung eines Wasserlaufes anzusehen, da diese Substanz wenigstens zum Teil fäulnisfähig ist. Bisher ist freilich keine Methode bekannt, mittelst welcher die fäulnisfähigen organischen Stoffe von den übrigen unterschieden werden könnten. Der Kaliumpermanganatverbrauch zeigt jene Substanzen, harmlose Huminstoffe und andere an. Eine konstante Vermehrung des Kaliumpermanganatverbrauches in Wasserläufen nach stattgehabter Verunreinigung findet höchstens statt, wenn diese sehr ausgiebig ist.

Eine Bereicherung hat in neuester Zeit die chemische Wasseranalyse durch Bestimmung des Sauerstoffgehaltes des Wassers und der Sauerstoffzehrung beim stehen lassen im Laboratorium erfahren.

Die Veränderungen der biologischen Verhältnisse, welche die Wasserläufe durch Verunreinigungen erfahren, stehen derzeit wohl im Vordergrunde des Interesses. Die Keimzahlen steigen auch bei mäßigen Flußverunreinigungen stark an, und aus den Tabellen der Autoren, welche chemische und bakteriologische Untersuchungen nebeneinander anwendeten, ergibt sich ausnahmslos die Überlegenheit der letzteren. Sie zeigen Wasserverunreinigungen noch ganz deutlich an, die auf anderem Wege längst nicht mehr erkennbar sind. Im Beginne der bakteriologischen Ära war es kein Wunder, wenn man keimreiches FluBwasser als gleichbedeutend mit unreinem Flußwasser setzte, und doch sind die meisten im FluBwasser rorkommenden Bakterien recht harmlos.

Die Keimzahlen sind daher, und auf diesem Standpunkte stehen alle neueren Autoren, lediglich vorzügliche Indikatoren einer stattgehabten Verunreinigung. Die Frage, ob und wie lange sich pathogene Bakterien in einem Flusse in infektionstüchtigem Zustande halten können, ist ganz unentschieden. Prausnitz (4, 28) meint, daß Epidemien nicht flußabwärts ziehen, Uffelmann (13) hält das Gegenteil für erwiesen. Die Entscheidung der Frage im Wege der experimentellen Forschung ist nicht möglich, da eine Nachahmung der natürlichen Verhältnisse bei Versuchen nicht durchzuführen ist.

Jedenfalls konnte es kein Autor glaubhaft machen, daß Infektionserreger nach dem Hineingelangen in einen Fluß sofort zugrunde geben. 
Den richtigsten Standpunkt nimmt wohl Kruse (34) ein, welcher sagt, $\mathrm{da} B$ die Infektionsgefahr durch Fluß wasser verschwindend gering ist, wenn die hineingelangenden Unratstoffe so weit verdünnt werden, daB anderweitige Schäden vermieden bleiben.

Hin und wieder wurde der Versuch gemacht, die Bakterien eines FluBwassers nach dem Vorhandensein oder Fehlen der Gelatineverflüssigung zu unterscheiden (v. Rigler [30]). Die Resultate solcher Untersuchungen waren ohne Belang.

Von anderen Lebewesen aus der Klasse der Pilze kommen im Flusse die Wasserfadenpilze, namentlich Beggiatoa alba, in Betracht. Nur einzelne Autoren haben ihr Vorkommen beachtet. Sie geben übereinstimmend an, daß diese Pilze das Schmutzwasser vorziehen, (Pfeiffer und Eisenlohr [12], Schenk [19], Schorler [31]). Diese Pilze sind somit, wenigstens bei reichlicherem Vorkommen, als Zeichen einer Wasserverunreinigung anzusehen. Äholiches kann man wohl von Protozoen und andern niederen Tieren sagen. Sie sind von Spitta (36) in der Spree, nach Büsing (40) in der Elbe vorwiegend im verschmutzten Wasser beobachtet worden.

Minder eindeutig ist die Frage nach der Bedeutung der grünen Algen beantwortet worden. Nach Mutschler (26) ziehen sie unreines, nach Spitta (36) und nach Pfeiffer und Eisenlohr (12) reines Wasser vor.

Die Verhältnisse scheinen daher in verschiedenen Flüssen nicht gleich zu sein, und Schorler (31) kommt wohl der Wahrheit am nächsten. Wie er meint, können die Algen im Wasser von verschiedenster Zusammensetzung gut gedeihen, ihr Vorkommen in einem Flusse ist mehr von der Tiefe des Wassers, von der Raschheit der Strömung, besonders aber von der Oberflächenbeschaffenheit der Ufersteine abhängig. Die Algen zeigen daher weder das Bestehen noch das Fehlen einer Fluß. verunreinigung an.

Pfeiffer und Eisenlohr sowie Schorler haben auch gezeigt, daß Wasserfadenpilze und grüne Algen in Fäulnis geraten, also selbst eine rerunreinigende Wirkung haben können,

Das Bestehen einer Selbstreinigung verschmutzter Wasserläufe ist allgemein anerkannt, wesentlich verschiedene Ansichten bestehen aber hinsichtlich ihrer Größe, Raschheit und praktischen Bedeutung und noch mehr hinsichtlich ihrer Ursachen. Die Hauptpunkte dieser Fragen sind schon von Uffelmann (13) im Jahre 1892 zusammengefaßt worden. Zweifellos geht aus den bisherigen Arbeiten hervor, daß die hydrologischen Verhältnisse eines Flusses von maßgebendem Einflusse auf den Verlauf der Selbstreinigung sind. Es geht daher nicht an, die an verschiedenen Wasserläufen erhobenen Befunde einfach miteinander zu vergleichen.

Sedimentierung suspendierter Körper ist ron Bedeutung bei sehr 
langsam fließenden Gewässern wie Seine und Spree. Dieser Vorgang führt ziemlich rasch zur Selbstreinigung des Wassers. Ein Nachteil ist aber bei stark verschmutzten Flüssen die Bildung. von Schlammbänken mit einer Reihe allgemein bekannter Mißstände, die besonders Frank (3) und Kruse (34) hervorhheben. Tritt dann Hochwasser ein, so werden die Sedimente stromabwärts geführt, und die Verschmutzung des Wassers tritt weiter unten auf, als sonst, wie Girard und Bordas (16) beobachteten. Bei solchen Flüssen wirken zeitweilige Hochwässer förderlich auf die Selbstreinigung (Kabrhel [27]).

Die Ablagerung von Schwimmkörpern an den Ufern eines Flusses als selbstreinigender Vorgang wurde nur einmal ron Gärtner und Rubner (41) nebenher erwähnt, sonst jedoch nicht beachtet. Die Verdünnung der Abwässer in einem wasserreichen FluB ist, wie vielfach beobachtet, ein Faktor der Selbstreinigung. Hierdurch können Schmutzwässer derart rerdünnt werden, daB die Verunreinigung des Flußwassers chemisch und für das Auge nicht mehr nachweisbar ist. Diese Art Selbstreinigung ist zunächst eine ästhetische (Kruse [34]). Doch wird durch ausgiebige Verdünnung auch das Eintreten ron Fäulnis im Wasser verhindert. Eine absolute (nicht auf Verdünnung beruhende) Abnahme der Schwimm- und Schwebestoffe in einem Flusse läBt sich leicht mit freiem Auge sehen und wurde daher auch von den Autoren meist übereinstimmend beschrieben, doch kommen auch differierende Beobachtungen For (Prausnitz [42] gegenüber Haubenschmidt [37]). Quantitatire Bestimmungen hierüber sind nicht gemacht. Schwieriger ist es eine $\mathrm{Ab}$ nahme der gelösten Stoffe zu konstatieren. Blasius und Beckurts (25) glauben eine solche an der Ocker innerhalb etwa $50 \mathrm{~km}$ nach deren Verunreinigung nachgewiesen zu haben. Die meisten anderen Autoren, wie Prausnitz (4) und Heider (17) geben die Unmöglichkeit zu, diese Frage zu entscheiden, da die bei der chemischen Analyse des Wassers gefundenen Zahlen zu sehr schwanken und die Differenzen zwischen Rein- und Schmutzwasser innerhalb der Fehlergrenzen fallen.

Interessantere Ergebnisse hat die Untersuchung der Keimzahlen der verunreinigten Flüsse ergeben. Die Befunde sind jedoch ungemein verschieden. Während Blasius und Beckurts (25) beobachteten, dab die Keimzahlen der Ocker, knapp unterhalb der Verunreinigung sehr hoch, nach einem Laufe von $50 \mathrm{~km}$ auf einen kleinen Teil der ursprünglichcn Menge gesunken waren, erheben Frank (3) sowie Dirksen und Spitta (32) einen ähnlichen Befund erst dort, wo das Wasser durch eine seeartige Erweiterung des FluBbettes fast stagniert. Dort wo eine gründliche Untersuchung des Wassers in der ganzen Breite der Profile stattfand, und wo dafür gesorgt war, daß beim Schöpfen in verschiedenen Profilen stets die 
gleichen Wasserschichten zur Untersuchung gelangen, dort zeigte sicb keine nennenswerte Verminderung der Keimmengen im flieBenden Wasser (Heider und Kruse).

Die bisherigen bakteriologischen Befunde lehren daher, daB ein rasches zugrundegehen der Keime in Flüssen nicht stattzufinden pflegt. Sie zeigen uns aber noch etwas anderes. Es ist wichtig, die einem Flusse zugeführte Unratmenge und ihre täglichen Schwankungen zu kennen (bloße Kenntnis der täglichen Abwassermenge genügt nicht). Außerdem sind Daten über die Sekundenwassermenge des untersuchten Wasserlaufes bei den verschiedenen Pegelständen und Kenntnis der Wassergeschwindigkeit erforderlich, nach dieser sind die Entnahmezeiten einzurichten, endlich ist es nötig, an verschiedenen Stellen der Profile Wasser zu schöpfen. Nur dann lassen sich einwandfreie Befunde gewinnen. Die gefundenen Keimzahlen zeigen besonders deutlich, wie wichtig die Beobachtung dieser Vorschriften ist, aber auch für die chemische Wasseruntersuchung gelten sie.

Die Bestimmung der Keimzahlen im Flußwasser ist demnach, richtig vorgenommen, ein vorzügliches Mittel um zu erfahren, ob ein Fluß weiter oben Verunreinigungen ausgesetzt ist. Nach $\mathrm{Mez}$ (29). bleiben sogar die Keimzahlen noch eine Zeitlang hoch, nachdem die Verunreinigung eines Flusses verschwunden ist, da nach vollendeter Oxydation organischer Substanzen die ihrer Nahrung beraubten Keime nicht sofort absterben. Nur Prausnitz $(4,28)$ bestritt den Bakterien eine Rolle bei der Selbstreinigung, Emich (84) dagegen und in neuerer Zeit Mez (29), Spitta (36) und Büsing (40) weisen ihnen auf Grund ron Beobachtungen und Experimenten eine Hauptrolle beim Vorgang der Selbstreinigung zu. In den tierischen Bewohnern der Flüsse haben wir nach Büsing (40) einen wichtigen Faktor der Selbstreinigung zu sehen. Ein gleiches gilt nach Schenk (19) und Schorler (31) von Beggiatoa alba.

Die Rolle der Algen ist noch nicht entschieden. Pettenkofers Schule setzt sich mit viel Eifer für die Annahme ihrer selbstreinigenden Tirkung ein, ebenso Mutschler (26). Der experimentelle Beweis, dab Algen organische Substauzen assimilieren können, ist allerdings $\mathrm{L}_{0} w$ (6) und Bokorny (20) geglückt, doch genügt dies nicht um zu behaupten, daß die Algen bei der Selbstreinigung der Flüsse wirklich eine Rolle spielen. Auch Mutschlers Beweisführung ist nicht überzeugend. Dagegen machen es Schenk, Schorler und Spitta im Wege der Beobachtung, letzterer Autor auch durch einen Versuch überaus wahrscheinlich, daß den Algen bei der Selbstreinigung der Flüsse in der Regel keine Rolle zufällt. Übrigens soll zugegeben werden, daß die Verhältnisse nicht in allen Wasserläufen gleich sind. Mag nun der oder jener Gruppe 
ron Organismen der Hauptanteil an der Oxydation der organischen Substanzen eines verunreinigten Flusses zukommen, sicher ist gegenwärtig, daB die Tätigkeit von Organismen hierzu nötig ist. Emich (64) hat auch wahrscheinlich gemacht, daB dieser Vorgang längere Zeit in Anspruch nimmt. Oxydation ohne Fäulnis (durch Aërobier) kann sich nach Rubner (44) nur auf den kleineren Teil der orgauischen Stoffe eines Flusses beziehen.

Als wünschenswertes Ziel der Selbstreinigung muß angesehen werden: Verschwinden aller unästhetisch wirkenden Schwimm- und Schwebestoffe, Verminderung der fäulnisfähigen Substanzen in dem Grade, daB es nicht zur Fäulnis kommen kann, endlich Verminderung der Infektionserreger auf ein praktisch bedeutungsloses Minimum.

Licht, Iuftzutritt und Wärme sind zwar nach Blasius und Beckurts (25) wichtige Faktoren der Selbstreinigung, können aber als solche allgemein nicht anerkannt werden. Der von Buchner $(10,15)$ erkannte, von einigen anderen Autoren auch in Flüssen beobachtete schädliche Einfluß des Lichtes auf Bakterien kann nach den gegenwärtigen Anschauungen über die Bedeutung der Bakterien im FluBwasser kaum als wesentliches Moment der Selbstreinigung betrachtet werden.

Es ist klar, daB nicht in jedem verschmutzten Wasserlauf exalte Untersuchungen über Selbstreinigung angestellt werden können. Nicht für jeden FluB existieren entsprechend genaue hydrologische Daten, deren Kenntnis, wie schon gesagt, so wichtig ist.

Die Verunreinigung, deren Schicksal im Flusse rerfolgt wird, soll möglichst ausgiebig sein, sie soll ferner an einem oder doch an wenigen Punkten erfolgen, denn nur dann ist der verunreinigende $Z u f l u B$ vor seiner Mündung der qualitativen und quantitativen Untersuchung zugänglich.

Die Verhältnisse werden vereinfacht, wenn der FluB unterhalb der Hauptverunreinigung durch eine lange Strecke keine nennenswerten reinen oder unreinen Zufüsse erhält. Endlich muB es möglich sein aus der Strommitte und von beiden Ufern in beliebiger Tiefe Wasserproben zu entnehmen.

Diese Bedingungen sind an der Donau bei Wien in recht befriedigender Weise vereinigt (nur die Größe der Verunreinigung ist im Vergleiche zu den riesigen Wassermengen nicht bedeutend).

Schon vor einer Reihe von Jahren hat der seither leider verstorbene Assistent des hygienischen Institutes der Wiener Universität, Privatdozent Dr. Adolf Heider, eingehende auf fast 3 Jahre ausgedehnte Untersuchungen über die Selbstreinigung der Donau angestellt, welche im „Österreichischen Sanitätswesen" 1893 niedergelegt, und oben bereits gewürdigt sind. 
Seit dieser Zeit nun ist eine wesentliche Änderung in der Art und Weise der Donauverunreinigung eingetreten. Durch den inzwischen erfolgten Bau der beiden Hauptsammler wird die gesamte Abwassermenge Wiens an zwei Stellen dem Donaukanale zugeführt, während zu Heiders Zeiten eine Menge verschieden großer Kanäle den Lauf des Donaukanales sukzessive verunreinigten. Die Erfüllung des einen für exakte Untersuchungen oben gestellten Postulates, Kenntnis der Verunreinigungsgröße, war Heider demnach unmöglich. Er mußte sich für die Zusammmensetzung der Abwässer mit Stichproben, für ihre Menge mit vagen Schätzungen begnügen, die Sekundenunratmenge daraus zu berechnen war kaum annähernd möglich.

Auch für die andere Forderung sind seit Heider Fortschritte zu verzeichnen. Im Jahre 1897 wurden durch die k. k. hydrographische Zentralkommission ungemein zahlreiche und exakte hydrologische Untersuchungen angestellt. Eine Frucht derselben waren einwandfreie Daten über die Wassergeschwindigkeit und Sekundenwassermenge der Donau bei verschiedenen Pegelständen, aus welchen sich ergibt, daß die Heider zur Verfügung gestandenen hydrologischen Daten großenteils unrichtig waren.

Heider hatte den Schwerpunkt seiner Untersuchungen mit Rücksicht auf die damalige Art und Weise der Einmündung der Abwässer mit Recht auf den Donaukanal verlegt und im Strome weniger Untersuchungen gemacht. Erst die geänderten Verbältnisse gestatteten es, die Untersuchung der Verunreinigung und Selbstreinigung des Stromes selbst erfolgreich durchzuführen.

Endlich waren seit Heiders Publikationen mehrere Arbeiten aus dem Berliner hygienischen Institute erschienen, welche die Anwendung neuer Untersuchungsmethoden für verunreinigtes FluBwasser in Aussicht stellten.

Einige weitere Veränderungen, die Verschmutzung der Donau und deren Wasserlauf betreffend, seit Heid ers Zeiten waren: 1 . Die Herstellung eines Sammelkanals für die auf 45000 Einwohner angewachsene am linken Donauufer dem XX. und II. Bezirke Wiens gegenüber gelegene Gemeinde Floridsdorf und der Neubau von Regulierungsvorrichtungen an der Ausmündung des Donaukanales bei NuBdorf an Stelle des alten Sperrschiffes, welche es nunmehr erlauben den Wasserstand dieses Armes jederzeit nach Belieben zu regulieren.

Auf Grund aller dieser Umstände erschien es wohl als gerechtfertigt, die Verunreinigung und Selbstreinigung der Donau in einer gröBeren Reihe von Fahrten neuerlich einer gründlichen Untersuchung zu unterziehen.

Es folgt zunächst der Vollständigkeit halber eine Darlegung der wichtigsten hydrologischen Verhältnisse der Donau, obwohl sich die folgenden 
Ausführungen zum Teil mit denen Heiders decken werden. (Vgl. Taf. V und Tabelle XVII.)

Die Donau hat bei Wien (Reichsbrücke) einen Lauf von $894 \mathrm{~km}$ zurückgelegt. Von da bis PreBburg beträgt ibre Länge ca, $60 \mathrm{~km}$. Die Reichsbrücke wird mit $\mathrm{km} 0$ bezeichnet, und es beginnen hier stromauf- und -abwärts die Kilometerzahlen, letztere bis zur Landesgrenze gegen Ungarn bei der Marchmündung $(49 \mathrm{~km})$ fortgesetzt.

Im folgenden sollen alle auf die Donau oberhalb der Reichsbrücke bezüglichen Kilometerzahlen mit $\mathrm{Km}$. ob. Rb., die abwärts von dieser Brücke mit $\mathrm{Km}$. schlechtweg bezeichnet werden.

Etwas unterhalb Kilometer $5 \mathrm{ob}$. Rb. gibt der Strom rechts einen Arm, den Donaukanal ab, um ihn $13.8^{\mathrm{km}}$ weiter unten nächst Kilometer 10 wieder aufzunehmen. Dieser Arm macht, durch die Stadt fließend zahlreiche Windungen und es beträgt seine Länge $16.84 \mathrm{~km}$. Andere Nebenarme mit Strömung gibt es jetzt infolge der langjährigen Regulierungsarbeiten in dem ganzen untersuchten Gebiete nicht, dafür aber zahlreiche tote Arme von verschiedener Mächtigleit sowie Buchten, meist mit enger Mündung, fast parallel dem Strom verlaufend. Eine Mischung ihres Wassers mit dem des Stromes findet bei den gewöhnlichen Wasserständen kaum statt. Ihr Wasser ist daher oft ganz verschieden von dem des Stromes gefärbt.

Wichtig sind in dem Strome die zahlreichen Sandbänke und bleinen Inseln „Haufen" genannt. Während im Wiener Durchstich diese Sandbänke durch die daselbst schon weit rorgeschrittenen Regulierungsarbeiten nur geringe Ausdehnung und Mächtigkeit besitzen, werden dieselben unterhalb der Donaukanalmündung immer zahlreicher. Anfangs dort nur uferständig, abwechselnd rechts und links, von geringer Mächtigkeit und Höhe, nur bei Niederwasser sichtbar, geben sie dem Stromstrich einen schwach geschlängelten Verlauf. Bald unterhalb Fischamend gewinnen die Haufen bedeutend an Zahl, Höhe und Ansdehnung und treten auch in der Strommitte auf. Sie zwingen so das Wasser auch bei höheren Pegelständen bald vorwiegend die rechte, bald die linke Seite des Strombettes einzunehmen, bald sich in zwei Arme zu teilen. Von Hainburg an verlieren die Haufen wieder an Zahl und Bedeutung. Im Laufe der Jahre wechseln sie ihren Platz, indem das Wasser stellenweise Material abträgt und es an anderen stromabwärts gelegenen Stellen wieder ansetzt. Die Haufen bestehen aus grobem bis mittelfeinem Schotter. Die Ufer sind in dem in Frage kommenden Gebiete meist flach, eine Ausnabme machen oberhalb Wiens die Durchtrittstelle des Stromes zwischen Leopolds- und Bisamberg, unterhalb der Stadt rechts eine Strecke bei Croatisch-Haslau, wo der Steilrand des Wiener Beckens wiederholt an das Ufer herantritt, dann die Umgebung 


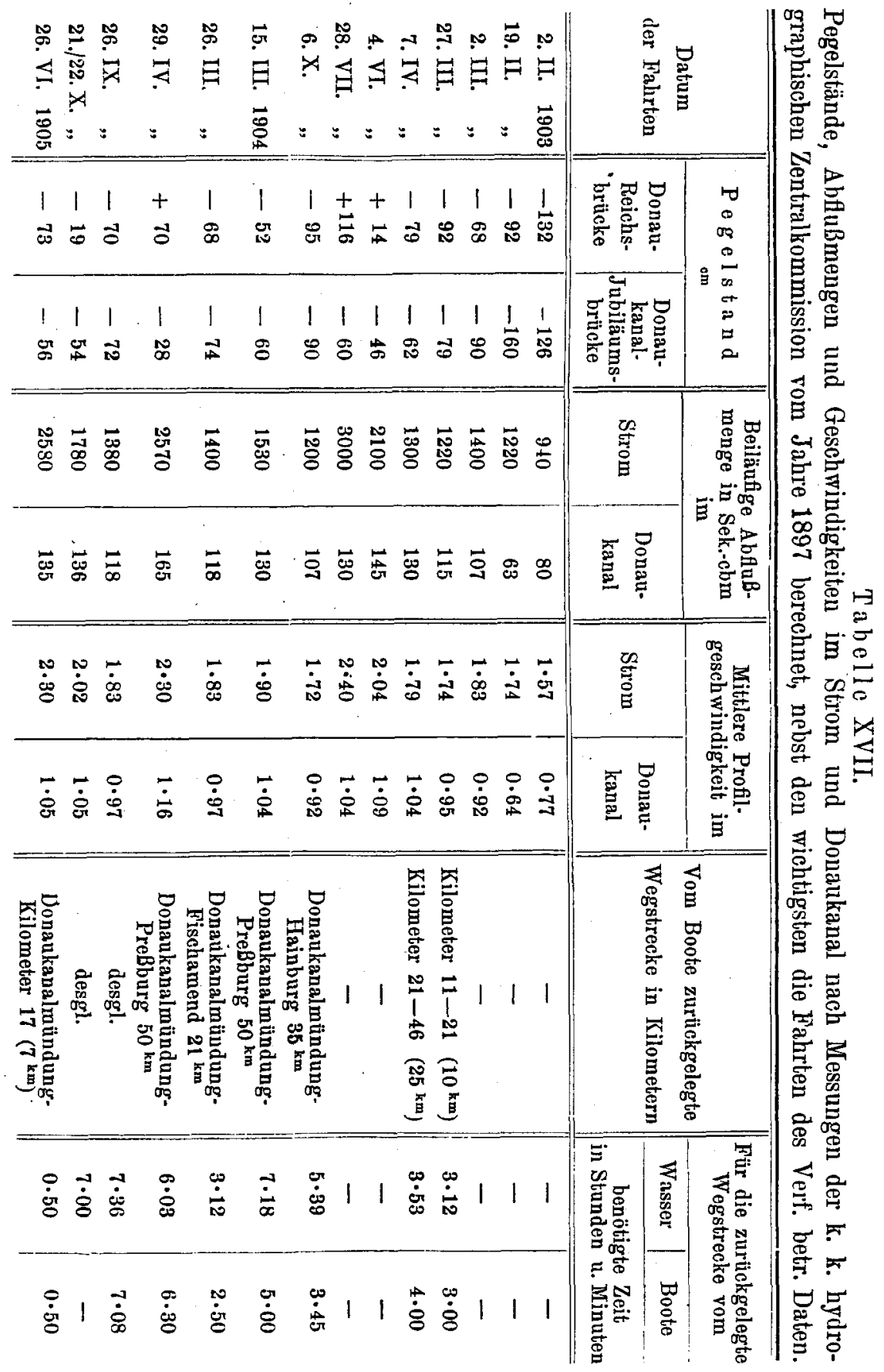


von Hainburg, links stromabwärts von der Marchmündung die bei Theben beginnenden kleinen Karpathen. Ausgedehnte Auen, stellenweise durch Wiesen unterbrochen, begleiten die Ufer des Stromes. Die Gegenden sind wildreich, groß ist namentlich die Zahl der Vögel, die die Ufer bevölkern. Auch der Fischreichtum des Stromes ist nicht unbeträchtlich.

Der Lauf des Stromes wird bis zur ungarischen Grenze beiderseits ron Steindämmen begleitet. Der Steinwarf reicht verschieden weit (bis $25^{\mathrm{m}}$ ) in das Strombett.

Im Gebiete des Wiener Durchstiches, das ist von Kilometer $5 \mathrm{ob}$. Rb. bis Kilometer 9.5 unterhalb, ungefähr der Strecke von NuBdorf bis zur Wiedereinmündung des Donaukanales entsprechend sind am linken Ufer sogenannte Niederwasserbauten in den Strom eingelegt. Diese haben den Zweck, die Hauptmasse des Wassers vom linken Ufer ab gegen die Strommitte und an das rechte Ufer zu drängen und eine allmähliche Verlandung der linken Seite des Flußbettes herbeizuführen.

Über die Wassermenge, welche die Donau pro Sekunde an Wien vorbeiführt, gibt Tabelle XVII Aufschluß. Aus dieser Tabelle ist zu ersehen, daB der Strom schon hier, im ersten Drittel seines Mittellaufes, die übrigen Ströme Mitteleuropas, den Rhein ausgenommen, an Sekundenwassermenge übertrifft, auch seine Geschwindigkeit ist hier sehr beträchtlich und München dürfte die einzige größere Stadt Mitteleuropas sein, die an einem schnelleren Wasserlaufe liegt. Selbst der rasch flieBende Rhein bleibt an Geschwindigkeit hinter der Donau zurück. Die Schwankungen des Wasserstandes lassen in der Donau einen echten Alpenfluib erkennen. Ähnlich wie beim Rhein fallen die höchsten Wasserstände in das späte Frühjahr und in den Beginn des Sommers, d. i. in die Zeit der Schneeschmelze im Hochgebirge und der reichlichen Niederschläge daselbst. Dann folgt ein sukzessives Sinken des Wasserstandes bis in die Mitte des Winters, hierauf wieder ein Ansteigen. Die Ströme, deren Quellgebiet in Mittelgebirge und Hügelland liegt, zeigen bekanntlich ein entgegengesetztes Verhalten (Elbe, Spree). [Hier muB bemerkt werden, daB mancher Autor den letzteren Typus irrtümlich als für jeden Strom gültig hingestellt und daran die Behauptung geknüpft hat, daß die Flüsse wegen ihres in der warmen Jahreszeit geringen Wasserstandes für die Aufnahme von Abfallstoffen überhaupt ungeeignet seien.]

Der Donaukanal nimmt nach Heider bei NuBdorf etwa den 8. Teil der gesamten Wassermenge auf, wenn der Pegelstand in beiden Gerinnen gleich ist. Dies ist aber heute kaum je der Fall. Die Nußdorfer Regulierungsvorrichtungen, wie schon erwähnt umgeändert und bedeutend rervollkommt, halten den Spiegel des Donaukanales nicht nur bei Hochwasser und bei Eisrinnen sondern auch sonst meist bedeutend niedriger. 
Das Verhältnis der Wassermengen: Sammelkanäle: Donaukanal: Donaustrom wechselt daher stetig und es war bei den vorliegenden Untersuchungen stets nötig den Pegelstand des Donankanales bei der Jubiläumsbrücke neben dem des Reichsbrückenpegels anzuführen. Aus Tabelle XVII ist zu ersehen, daB an den Untersuchungstagen der Donaukanal niemals $1 / 8$ der Wassermenge, sondern nur $1 / 10$ bis $1 / 25$ derselben führte.

Das Aussehen des Donauwassers schwankt im gleichen Sinne wie der Wasserstand. Schneeschmelze und reichliche Niederschläge bringen trübes Wasser, sonst ist es klar und grün, besonders klar natürlich ist das Winterwasser.

Außer den oben beschriebenen Schwankungen des Wasserstandes kommen noch alljährlich kleinere atypische durch lokale Witterungsrerhältnisse bedingte Veränderungen desselben in Betracht. Man kann wohl sagen, daB selten mehrere Monate rergehen, ohne daB ein oder das andere Mal böhere Wasserstände, bis zu 1 bis $2^{\mathrm{m}}$ über Null vorkommen, auch wirkliche Hochwässer sind nicht selten. Die hohe Bedeutung dieser Tatsache für die Selbstreinigung wird später gewürdigt werden. Wasserstände unter $-1^{\mathrm{m}}$ werden gewöhnlich als Niederwasserstand, solche über $+1^{\mathrm{m}}$ als höherer Wasserstand bezeichnet. Die Fahrten erfolgten meist bei mittlerem, eine bei niederem, eine bei höherem Wasserstande.

In die Donau münden zwischen Wien und Preßburg nur wenige und unbedeutende Nebenflüsse. 1. Die Wien, die in den Donaukanal mündet und außerhalb Wiens nirgends größere Schmutzwassermengen aufnimmt. Sie kommt nur als Aufnahmsgerinne für die Čberläufe der ihr Bett begleitenden Sammelkanāle der Stadt in Betracht. 2. Die Schwechat, bei Kilometer 15 mündend, mit relativ großer mineralischer Verunreinigung (siehe Tabelle XXX). 3. Die Fischa, die bei Kilometer 26 einmündet. 4. Links bei Kilometer 49 mündet die March. Diese ist zwar etwas wasserreicher, doch kann auch sie für die vorliegenden Untersuchungen unberücksichtigt bleiben, da eine Mischung ihres Wassers mit dem der Donau bis PreBburg bei Probeentnahme in der Strommitte ausgeschlossen werden kann.

Den stärkeren GrundwasserzufluB erhält die Donau auf der Strecke bis Hainburg von links, da rechts der Steilrand des Wiener Beckens das Gebiet begrenzt, von dem aus unterirdisch Wasser dem Strom zufließen kann.

Die auf der Donau wohnende Bevölkerung ist gering an Zahl, da der Dampferverkehr nicht allzu intensiv ist, auch die Fischerei ist nicht bedeutend.

Die Ufer der hier in Betracht kommenden Strecke sind schwach besiedelt, und zwar aus folgendem Grunde: Die exzessiven Hochwasserstände der Donau machen ein ausgedehntes sogenanntes Inundationsgebiet 
erforderlich, welches eigentlich zum Flußgebiete gehört, bei allen Kleinund Mittelwasserständen aber trocken liegt, und von den schon beschriebenen Auen und Wiesen bedeckt ist.

Am linken Ufer ist dieses Inundationsgebiet von Lang-Enzersdorf abwärts bis zur Marchmündung von dem erst in letzter Zeit ausgebauten Marchfeldschutzdamm begrenzt, der das reich bevölkerte Marchfeld vor Überschwemmungen durch die Donau schützt. Wo die Ufer flach sind, sind nirgends Ansiedlungen sichtbar. Rechts liegen die nächsten Dörfer etwa 2 bis $3^{\mathrm{km}}$ rom Ufer entfernt, oben am Steilrand des Wiener Beckens. Wo dieser an den. Strom herantritt, ist dies auch bei den Ortschaften der Fall, doch sind diese dann so hoch über dem Strom gelegen, daß ihnen direkte Beziehungen zu diesem fehlen. Dort, wo die Ufer wieder gebirgiger zu werden beginnen, wo sich daher Hochwässer nicht so stark ausbreiten können, treten Ortschaften direkt an den Strom heran: eine Häusergruppe von Deutsch-Altenburg und bald darauf der Markt Hainburg am rechten und stromabwärts von der Marchmündung Theben und PreBburg am linken Ufer. Wie Heider angibt, soll in Hainburg Donauwasser im Haushalte Verwendung finden, obwohl dort eine Wasserleitung besteht.

Maßgebend für die Beschaffenheit des Wassers der Donau oberhalb Wiens ist zunächst die Zusammensetzung des Quell- und Grundwassers ihres Niederschlagsgebietes. Modifiziert wird dasselbe zweifellos durch die in und auf dem Strome lebenden pflanzlichen und tierischen Organismen. Endlich müssen wohl auch die Abfallstoffe der Ortschaften im oberhalb Wiens gelegenen Teile des gesamten FluBgebietes einen gewissen EinfluB auf die Qualität des Wassers ausüben. Dieses Gebiet umfaßt den größeren Teil Süddeutschlands, einen Teil der Schweiz, Nordtirol, Salzburg, Oberōsterreich und die Westhälfte Niederösterreichs. Es hat eine Bevölkerung von mehreren Millionen Menschen und ist nicht abzuschätzen, wie viele von diesen ganz oder teilweise ihre Abfallstoffe der Donau und ihren Nebenflüssen übergeben. Das Gebiet ist jedoch zum gröBten Teil industriearm und wird von einer vorwiegend Ackerbau und besonders Viehzucht treibenden Bevōlkerung bewohnt. Aus diesem Grunde ist die anderwärts oft sehr bedeutende Einleitung von Industrieabwässern relativ gering. Der Landwirtschaft treibende Teil der Bevölkerung aber kommt für die Verunreinigung von Flüssen stets nur wenig in Betracht, da dieser seine Fäkalien und die seiner Haustiere der Verwertbarkeit als Dünger wegen den Flüssen nicht regelmäBig zu überantworten plegt, sonst aber relativ wenig Abgänge produziert. Eine wesentlichere Quelle der Verunreinigung sind daher in obigem Gebiete nur die Kanäle einiger Städte, unter denen München allein eine namhafte 
Einwohnerzahl hat. Von Linz abwärts liegt überhaupt keine Stadt von einiger Bedeutung an dem Strome und seinen Nebenflüssen, überdies ist das westliche Niederösterreich als nahezu industrielos $\mathrm{zu}$ bezeichnen. Die Verunreinigung der Donau oberhalb Wiens kann demnach im Vergleiche zu der des oberen Rheins, der oberen Elbe und der Spree als gering bezeichnet werden, und da Verunreinigungsquellen eine lange Strecke oberhalb der Stadt so gut wie vollkommen fehlen, finden wir hier einen Strom mit geringer normaler Verunreinigung im Sinne Kabrhels. Die Schwankungen in der Beschaffenheit des Wassers sind teils, wie bei höherem Wasserstande, auf zunehmende temporäre Verunreinigung im Sinne desselben Autors, sonst aber auf unbekannte Ursachen zurückzuführen.

Bei der vorliegenden Arbeit war es nötig, sich ein möglichst vielseitiges Bild von der Beschaffenheit des Wassers an den einzelnen Untersuchungsstellen zu machen.

Die chemischen Untersuchungsmethoden und die der bakteriologischen Keimzählung standen natürlich als die exaktesten im Vordergrund und wurden nahezu in allen Fällen angewendet. Zur Entnahme des Wassers für die chemische Untersuchung bediente ich mich des schon von Heider verwendeten schweren, gußeisernen Apparates, der mit einer entsprechend großen Flasche an einem Seile ins Wasser versenkt wurde. Eine einfache Vorrichtung ermöglichte es dabei, die Flasche in der Tiefe zu öffnen und zu schließen. Die Entnahmen für bakteriologische Zwecke geschahen nach der im hiesigen Institute seit langem gebräuchlichen Methode. Zylindrische, in ein rechtwinklig gebogenes Röhrchen auslaufende Gefäße wurden durch Verdampfen von Wasser luftleer gemacht und an der Spitze zugeschmolzen, dann wurden sie an einem Metallstabe bis zur gewünschten Tiefe ins Wasser versenkt, und dort das Ende des Röhrchens durch Anziehen an einer Schnur abgebrochen. Sobald die Gefäße voll Wasser waren, wurden sie emporgezogen, und die Offnung mit Siegellack geschlossen. Von dem so gewonnenen Wasser wurden nach gutem Durchschütteln im Laboratorium und Offnen des Kölbchens kleine Mengen zur Aussaat auf je 2 Gelatineplatten verwendet. Die Gelatineplatten wurden bei 20 bis $22^{\circ} \mathrm{C}$. gehalten und in der Regel nach 48 Stunden gezählt, nur in seltenen Fällen machte die fortschreitende Verflüssigung der Gelatine die Zählung schon nach 36 Stunden nötig. Die Zählung geschah mit der Lupe.

Bei den Fabrten verwendete ich eine der $\mathrm{k}$. $\mathrm{k}$. Donauregulierungskommission gehörige, mit 3 Bootsleuten bemannte Weidzille. Bei den Wasserentnahmen in der Nähe des Ufers (in der Regel $10^{m}$ von demselben) wurde diese durch eine Leine am Ufer festgehalten; in der Mitte des Stromes trachtete ich das gewünschte Profil so gut wie möglich festzuhalten, indem ich energisch der Strömung entgegenrudern ließ. Dieses 
Verfahren hatte den Nachteil, daß die Wasserentnahmeapparate an Stellen mit starker Strömung von dieser stromabwärts gerissen wurden, das genaue Einhalten einer bestimmten Tiefe war dann schwer, größere Tiefen konnten überhaupt nicht erreicht werden. Im Laufe meiner Untersuchungen gewann ich die Überzeugung, daß die Beschaffenheit des Wassers sich innerhalb weniger $100 \mathrm{~m}$ stromauf und ab nicht merkbar ändere, wo es dem. nach darauf ankam, aus größerer Tiefe Wasser zu schöpfen, verzichtete ich auf das Festhalten der Zille in einem bestimmten Profile. Das Fahrzeug wurde dann während einer Wasserentnahme 2 bis $300 \mathrm{~m}$ stromabwärts getrieben. Die Genauigkeit der Resultate exlitt dadurch keine Einbuße. Bei den auf den ersten Fahrten gewonnenen Wasserproben wurde zur Orientierung auf eine gröBere Zahl von Stoffen geprüft als bei den späteren. Es wurde bestimmt: Sulfatrückstand, Trockenrückstand bei $170^{\circ}$, Glührückstand, Eisenoxyd, Kalk, Magnesia, Ammoniak, Chlor, salpetrige und Salpetersäure, Schwefelsäure, Kaliumpermanganatverbrauch, Ges. Härte (deutsche Grade). Hierzu kamen von der zweiten Fahrt an die Bestimmung der freien und halbgebundenen Kohlensäure und des absorbierten Sauerstoffs. Angegeben wurde stets die Zahl der Milligramme im Liter. Alle Untersuchungen wurden im filtrierten Wasser ausgeführt. Bei den späteren Fahrten wurden die Untersuchungen auf Trockenrückstaud bei $170^{\circ}$, Ammoniak, Chlor, salpetrige und Salpetersäure, Kaliumpermanganatverbrauch, gelösten Sauerstoff, freie und halbgebundene Kohlensäure (diese Bestimmung fiel bei den letzten Fahrten gleichfalls weg) beschränkt, die übrigen Analysen, als wenig wertroll für den vorliegenden Zweck; nicht mehr vorgenommen.

In einzelnen Fällen erfolgte auch die Untersuchung des gesamten Stickstoffes, des Albuminoidammoniaks und bei den letzten Fahrten des Trockenrückstandes bei $170^{\circ} \mathrm{im}$ nicht filtrierten Wasser. Die chemische Untersuchung der Wasserproben fand in der k. k. Untersuchungsanstalt für Lebensmittel und Gebrauchsgegenstände in Wìen statt und zwar nach folgenden Methoden:

1. Kalk und Magnesia gewichtsanalytisch, ersterer als $\mathrm{CaO}$, letztere als $\mathrm{Mg}_{2} \mathrm{P}_{2} \mathrm{O}_{7}, 2$. Ammoniak kolorimetrisch nach Frankland und Armstrong, in den Kanalwässern durch Destillation nach Miller; Albuminoidammoniak durch Destillation nach Wanklyn, Chapman und Smith, 3. Stickstoff nach Kjeldahl, 4. Chlor nach Volhard, 5. salpetrige Säure nach Trommsdorff kolorimetrisch, 6. Salpetersäure durch Destillation nach Schulze-Tiemann (modifiziert), 7. Schwefelsäure gewichtsanalytisch als $\mathrm{BaSO}_{4}$, 8. Phosphorsäure gewichtsanalytisch als $\mathrm{Ng}_{2} \mathrm{P}_{2} \mathrm{O}_{7}, 9$. freie und halbgebundene Kohlensäure nach Pettenkofer, 10. absorbierter Sauerstoff nach L. W. Winkler, 11. organische Substanz nach Kubel. 
AuBer der bakteriologischen und chemischen Untersuchung des Wassers wurde auch in sehr zahlreichen Fällen das ausgeschiedene Sediment mikroskopisch untersucht, ferner fanden mitunter quantitative Bestimmungen der suspendierten Bestandteile bis zu einer bestimmten minimalen Größe statt, dann bei einzelnen Fahrten Untersuchung des FluBbodens und Untersuchung des Wassers auf Bacterium coli und in der Wärme wachsende Bakterien überhaupt, sowie auf Sauerstoffzehrung. Die angewendeten Verfahren werden an anderen Stellen beschrieben.

Bei den ersten Fahrten, im Nachwinter 1903 unternommen, trachtete ich ein Bild von der.Beschaffenheit des Donauwassers vor und knapp nach der Einmündung des Schmutzwassers, d. i. des Donaukanals, sowie von der Beschaffenheit dieses letzteren Gerinnes ober- und unterhalb der Sammlermūndung und endlich des Sammlerwassers selbst zu bekommen.

Die obere Grenze des untersuchten Gebietes bildete Kilometer $9 \mathrm{ob}$. Rb. Von hier bis zur Einmündung des Donaukanales empfängt die Donau rechts nur die Abwässer eines kleinen Teiles der Stadt Klosterneuburg (etwa 1000 bis 2000 Einwohner entsprechend) und außerdem die Kanäle des am rechten Donauufer neu entstehenden Wiener Stadtteiles, die derzeit noch ganz unbedeutend sind. $\mathrm{Um}$ die Reichsbrücke befindet sich der Landungsplatz der Schiffe. Auch diese sind eine nur unbedeutende Quelle ron Verunreinigung. Links, knapp unterhalb der Reichsbrücke, münden einige kleine Kanäle, deren Inhalt durch Färbereiabwässer intensiv tingiert ist. Diese stammen aus dem zu Wien gehörigen Stadtteile Kaisermühlen. Wichtiger sind die Abwässer der Stadt Floridsdorf, die 45000 Einwohner zählt und zur Zeit der Untersuchungen nächst Wien die größte Stadt in Niederösterreich war (Tabelle XVIII), gegenwärtig der Gemeinde Wien einverleibt ist. Damals mündeten diese Wässer in 2 Sammelkanälen, der obere bei Kilometer $\mathbf{3}$ oberhalb der Reichsbrücke, der untere bei Kilometer 6. Seither wurde die obere Mündung aufgelassen und die gesamten Abwässer dieses Gebietes münden nunmehr bei Kilometer 6 . (Mündliche Mitteilung des Hrn. k. k. Bezirksarztes in FloridsdorfUmgebung, Dr. Ferd. Domažlicky.

Die Floridsdorfer Abwässer bewirken zwar eine beträchtliche Erhöhung der Keimzahl im Donauwasser nächst dem linken Ufer, sind aber doch quantitativ zu unbedeutend, um die chemische Zusammensetzung desselben nachweisbar zu ändern. Das linksufrige Wasser kann daher bis $\mathrm{km} 11 \mathrm{im}$ chemischen Sinne als Reinwasser bezeichnet werden.

Die nachstehende Tabelle XIX „Reinwasser" umfaßt sämtliche in der Donau oberhalb der Donankanalmündung erhobene Befunde. Hierzu kommen 2 Befunde im Donaukanale oberhalb der Sperrvorrichtung, ferner unterhalb dessen Mündung Befunde im Strome an denjenigen Stellen 
entnommen, wo eine Mischung mit dem verschmutzten Wasser des Donaukanales noch nicht stattgefunden hat, also Kilometer 11, Mitte und linkes Ufer. Bakteriologisch gehören nicht hierher sämtliche Befunde vom linken Ufer, ab Kilometer 3.

\section{Tabelle XVIII.}

Befunde im Floridsdorfer Abwasser, erhoben am 2. März 190311 Uhr vormittags, unmittelbar an der alten, derzeit aufgelassenen Mündung.

Milligramme pro Liter.

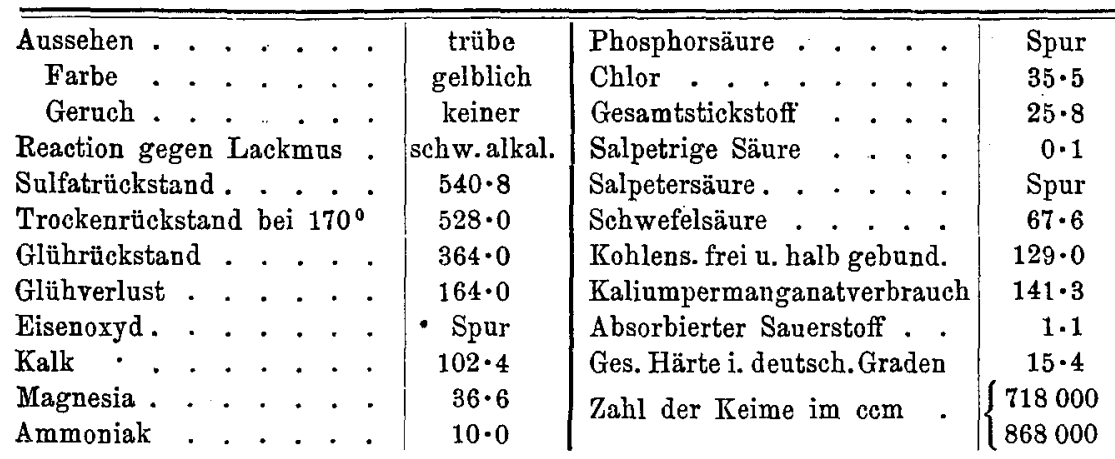

Es liegen somit 42 Befunde, erhoben an 12 verschiedenen Tagen an 8 verschiedenen Profilen bei total verschiedenen Wasserständen vor. In einzelnen Fällen wurden die Proben auch in verschiedenen Tiefen geschöpft, ergaben jedoch dann niemals über den Rahmen der zufälligen Schwankungen hinausgehende Unterschiede.

Chemische Befunde im Reinwasser (Tabelle XIX). Sämtliche Zahlen beziehen sich, wenn das Gegenteil nicht ausdrücklich erwähnt, hier wie im folgenden auf das filtrierte Wasser und bedeuten Milligramme im Liter.

1. Die Trockenrückstände schwanken zwischen $144 \cdot 0$ und $230 \cdot 0$; auch an einem und demselben Tage kommen ziemlich beträchtliche Schwankungen vor, doch läßt sich deutlich erkennen, daß bei niederen Wasserständen meist gröBere Zahlen vorwalten als bei höheren, eine schon oft auch bei anderen Flüssen beobachtete leicht verständliche Tatsache. Unverkennbar ist ferner ein höherer Trockengehalt des linksufrigen und Mittewassers gegenüber dem rechtsufrigen. Es mag dies damit zusammenhängen, daß die Donau ihr Grundwasser, die vornehmste Quelle für gelöste Mineralstoffe, hauptsächlich vom linken Ufer empfängt.

2. Trockenrückstände im nicht filtrierten Wasser. Hier liegen nur 3 Zahlen vor. Der Anteil des Trockenrückstandes, der von den im Wasser suspendierten Eörpern herrührt, ist demnach ebenfalls verschieden. 


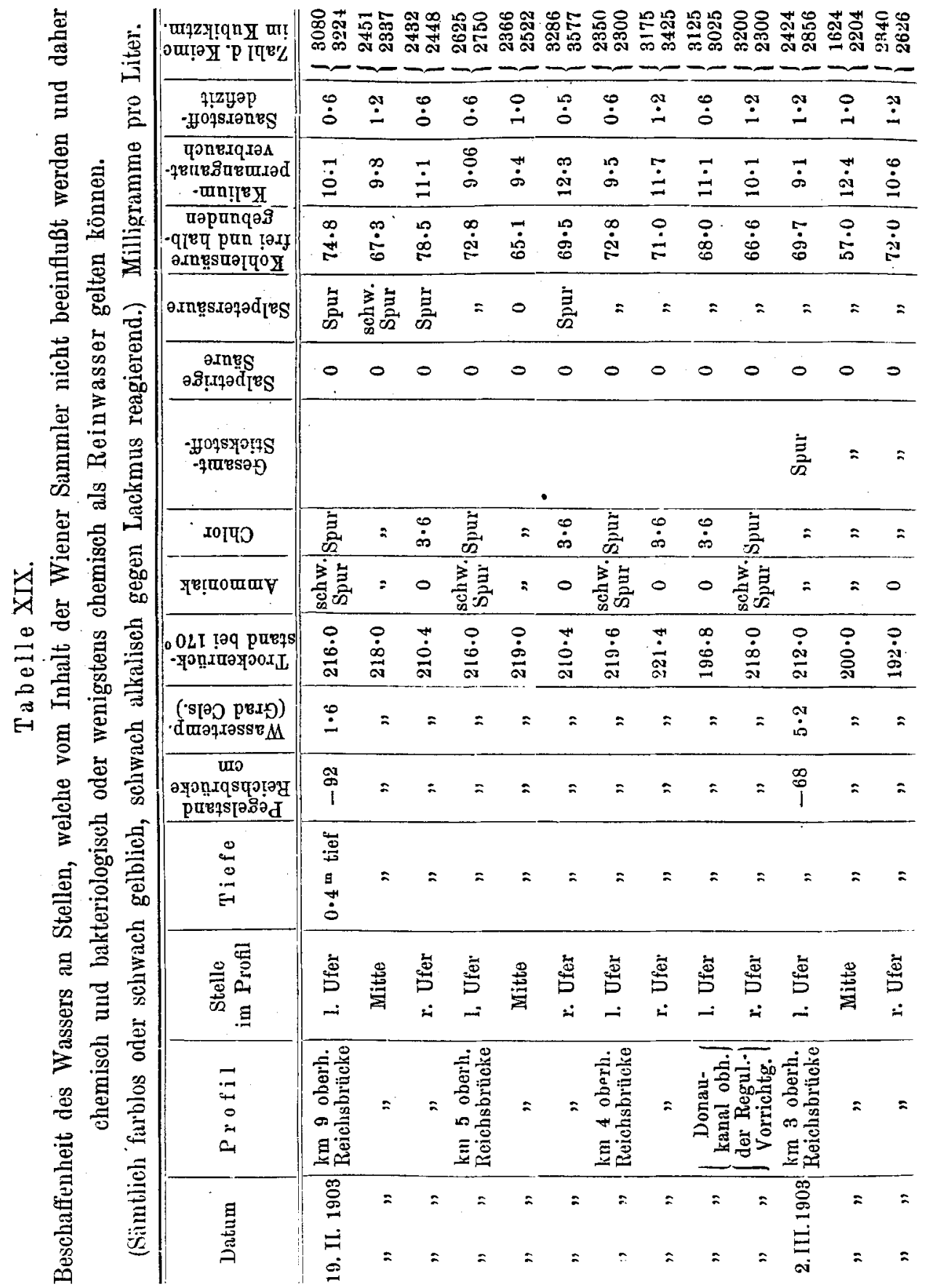




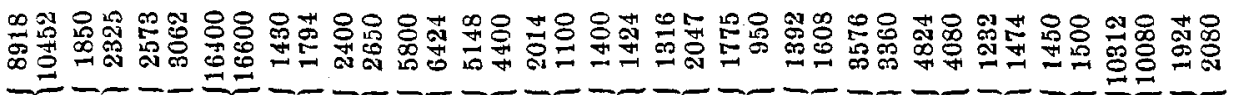

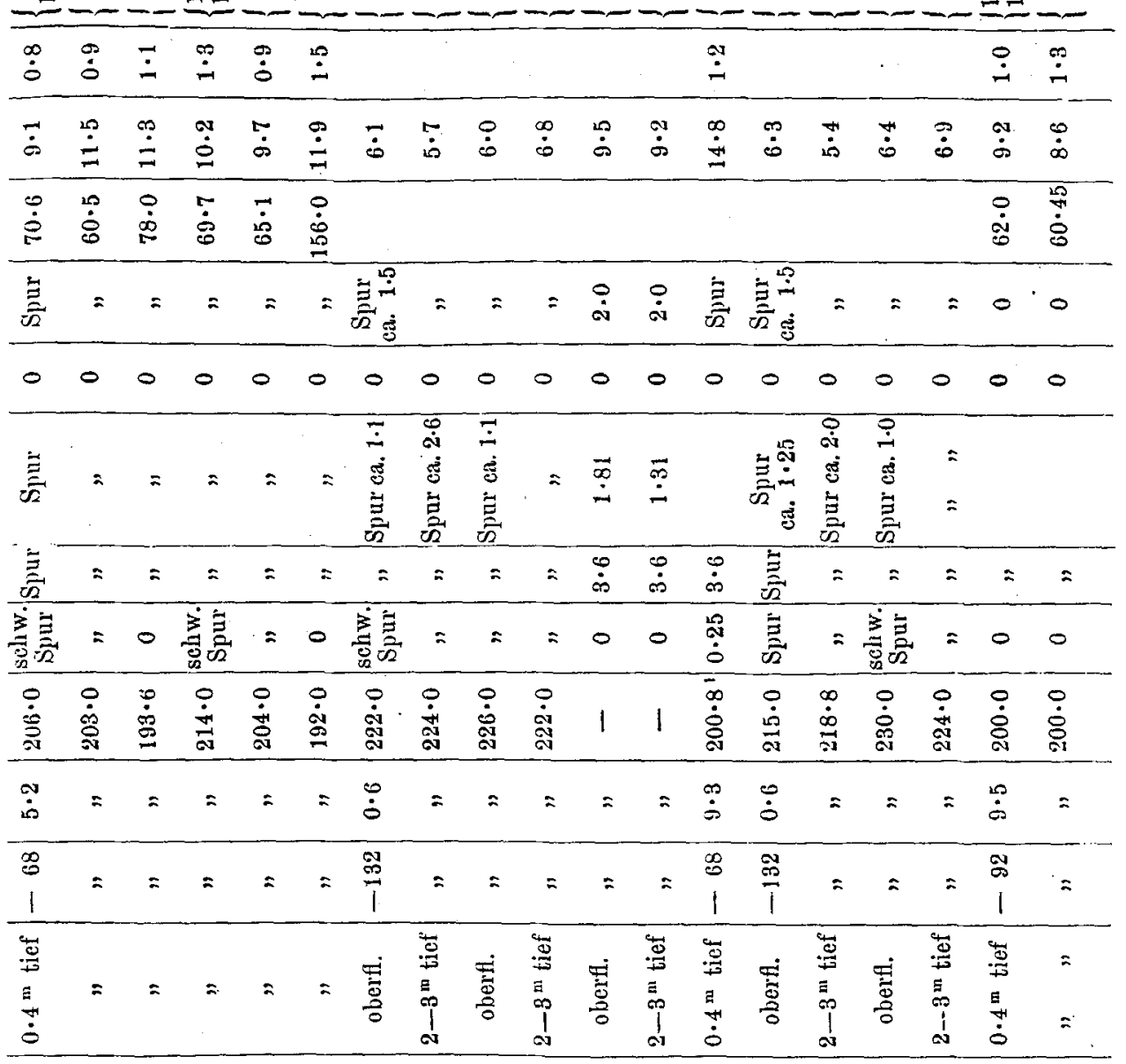

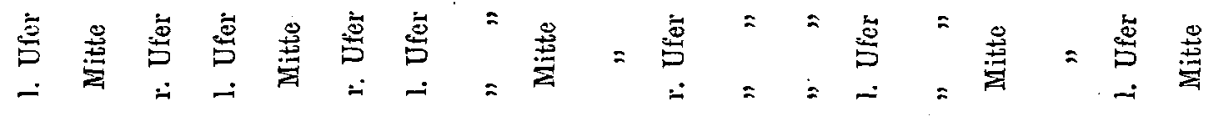

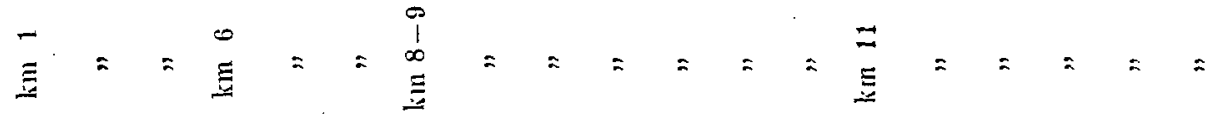

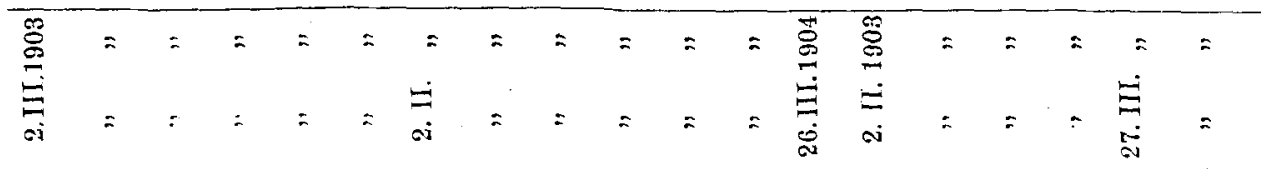




\begin{tabular}{|c|c|c|c|c|c|c|c|c|c|c|c|}
\hline 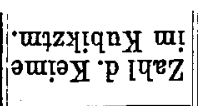 & 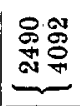 & 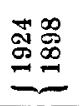 & 赵离 & 옹윰 & 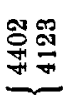 & 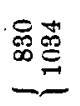 & & 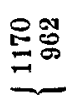 & 웡휴 용 & 路是 & \multirow{6}{*}{ 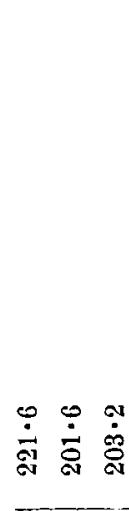 } \\
\hline $\begin{array}{c}\text { 7tzgəp } \\
\text {-yo7sxənes }\end{array}$ & $\dot{0}$ & $\dot{i}$ & $\check{0}$ & & 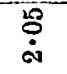 & $\stackrel{\circ}{\dot{0}}$ & $\stackrel{\sim}{\dot{\sigma}}$ & & $\stackrel{\infty}{\dot{0}}$ & $\stackrel{\infty}{\dot{0}}$ & \\
\hline 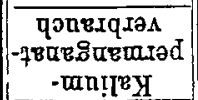 & 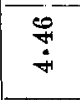 & $\dot{0}$ & $\stackrel{\leftrightarrow}{\dot{T}}$ & $\dot{10}$ & $\stackrel{g}{\dot{\Phi}}$ & $\stackrel{\oplus}{\dot{\Phi}}$ & $\overrightarrow{\dot{g}}$ & & & $\overrightarrow{\dot{\theta}}$ & \\
\hline 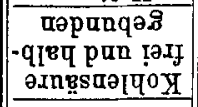 & $\stackrel{\mathscr{2}}{\dot{\varphi}}$ & $\stackrel{2}{\dot{q}}$ & $\stackrel{\ddot{0}}{\dot{0}}$ & :ै & 0 & $\ddot{\dot{\theta}}$ & & & & & \\
\hline ว.xnys & 0 & 0 & 0 & 0 & 0 & 0 & 芯 & & & 0 & \\
\hline 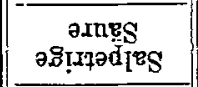 & 0 & 产言 & $\circ$ & 0 & 0 & 产竞 & 0 & & & 0 & \\
\hline 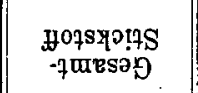 & & & & & & & & & & $\stackrel{\infty}{\dot{\sim}}$ & $\stackrel{8}{a}$ \\
\hline хо[प] & $\stackrel{\Xi}{\tilde{B}}$ & $=$ & $=$ & $=$ & $=$ & 5 & $\stackrel{\varphi}{\dot{\varphi}}$ & & & $\overline{\tilde{\Xi}}$ & \\
\hline 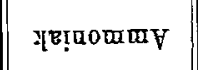 & 0 & $\circ$ & 0 & 0 & 0 & 0 & $\stackrel{20}{0}$ & & & ○ & $\overline{\bar{\Xi}}$ \\
\hline 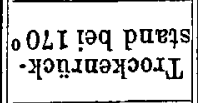 & 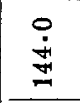 & \begin{tabular}{l}
0 \\
$\dot{0}$ \\
\multirow{2}{*}{} \\
\end{tabular} & 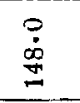 & 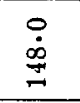 & $\ddot{\dot{0}}$ & $\begin{array}{l}\dot{\theta} \\
\dot{g}\end{array}$ & 告 & 1 & 1 & $\stackrel{\infty}{\dot{\Phi}}$ & $\stackrel{\square}{\stackrel{5}{0}}=$ \\
\hline 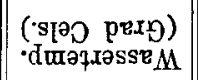 & $\stackrel{\bullet}{\dot{\theta}}$ & $\approx$ & $=$ & $=$ & $\stackrel{\mathscr{L}}{\dot{+}}$ & $\check{\check{2}}$ & $\stackrel{5}{+}$ & $\ddot{\theta}$ & $\ddot{s}$ & 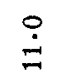 & \\
\hline 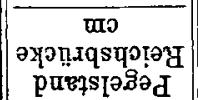 & $\begin{array}{l} \pm \\
+\end{array}$ & $=$ & $=$ & $=$ & $\stackrel{\oplus}{=}$ & $\stackrel{2}{0}$ & 放 & $\begin{array}{l}\infty \\
\infty\end{array}$ & $\begin{array}{l}9 \\
+\end{array}$ & $\frac{9}{1}$ & 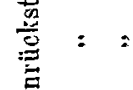 \\
\hline$\stackrel{0}{\stackrel{5}{E}}$ & 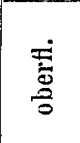 & 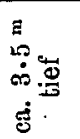 & 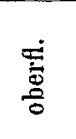 & $\begin{array}{l}a \\
\infty \\
1 \\
1 \\
\dot{0} \\
\dot{\sim}\end{array}$ & 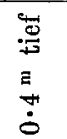 & $=$ & $=$ & $=$ & $=$ & $=$ & 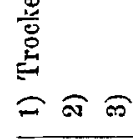 \\
\hline 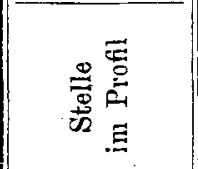 & 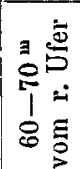 & $\begin{array}{l}= \\
\therefore\end{array}$ & 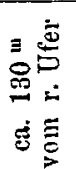 & $\begin{array}{l}= \\
=\end{array}$ & 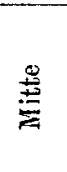 & $=$ & $=$ & $=$ & $=$ & $=$ & 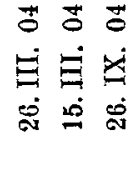 \\
\hline $\begin{array}{l}= \\
0 \\
0 \\
0\end{array}$ & $\begin{array}{l}\bar{E} \\
\Xi\end{array}$ & $=$ & $=$ & $=$ & $=$ & $=$ & $=$ & $=$ & $=$ & $=$ & \\
\hline$\underset{\Xi}{E}$ & $\begin{array}{l}9 \\
\dot{8} \\
\dot{+}\end{array}$ & $=$ & $=$ & $\begin{array}{l}\therefore \\
\therefore\end{array}$ & $\underset{\substack{\dot{\Sigma} \\
\infty}}{\dot{\infty}}$ & $\begin{array}{l}: \\
\dot{4} \\
\dot{0}\end{array}$ & 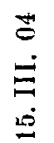 & $\dot{:}$ & $\dot{z}$ & $\begin{array}{l}\dot{\dot{\Delta}} \\
\dot{\leftrightarrow} \\
\dot{\omega}\end{array}$ & \\
\hline
\end{tabular}


3. Ammoniak fehlt oft vollkommen, häufiger ist es in verschwindenden Mengen vorhanden. In zwei Fällen war es eben quantitativ bestimmbar. Diejenige Probe, welche den gröBten von mir im Reinwasser gefundenen Ammoniakgehalt hatte, war zugleich am reichsten an organischer Substanz, parallel ging ein relativ hohes Sanerstoffdefizit. Beziehungen des Ammoniakgehaltes des Wassers zu Pegelstand, Temperatur oder anderen äußeren Umständen waren nicht nachweisbar.

4. Gesamtstickstoff wurde nur in einem Teil der Fälle bestimmt. Stickstoff fehlte im Reinwasser nie, doch war er stets nur in geringer Menge zu finden. Größere Mengen Stickstoff deuten daher auf äußere Verunreinigung des Donauwassers.

5. Chlor fehlte gleichfalls niemals, war aber in nicht bestimmbarer Menge oder in Quantitäten von weniger als $4 \mathrm{mg}$ vorhanden. Nur in einem Falle (6. Oktober 1903, Kilometer 11) enthielt das Reinwasser mehr Chlor. Bei der sonst in der Donau beobachteten, auch im Rhein nachweisbaren raschen Diffundierbarkeit der Chloride und dem Reichtum des Schmutzwassers an Chloriden an diesem Tage kann es sich damals ganz wohl um Diffusion vom rechten Ufer gegen die Mitte zu gehandelt haben, so daß diese vereinzelte Zahl keinen sicheren Reinwasserbefund darstellt.

6. Von salpetriger Säure war das Reinwasser meistens frei, in wenigen Fällen war diese in geringen Spuren nachweisbar.

7. Salpetersãure wurde meist in Spuren, selten in eben quantitativ bestimmbaren Mengen gefunden, mitunter fehlte sie vollkommen. Beziehungen zum Wasserstande waren nicht nachzuweisen. Niemals waren salpetrige und Salpetersäure nebeneinander vorhanden.

8. Freie und halbgebundene Kohlensäure. Die gefundenen Zahlen schwankten in der Regel zwischen 57 und 78. Nur einmal wurde an einer Stelle der hohe Wert von $156 \mathrm{mg}$ bei schwach mittlerem Wasserstande beobachtet. An einem Tage bei höherem Wasserstande betrugen (4. Juni 1903) die Werte bei Kilometer 11 46.5, am 28. Juli 1903 bei dem höchsten in Betracht lsommenden Pegelstande $(+116)$ fehlte die freie und halbgebundene Kohlensäure völlig und war an diesem Tage auch im verschmutzten Wasser nicht nachweisbar. Dieser merkwürdige Befund konnte nicht gedeutet werden. Auffällig ist, daB das rechte Ufer im allgemeinen höhere Zahlen aufweist, als die Mitte und das linke Ufer. Auch diese Tatsache ist nicht zu erklären. Die freie und halbgebundene Kohlensäure eignet sich danach nicht als Reagens auf Verschmutzung des Wassers.

9. Organische Substanz = Kaliumpermanganatverbrauch. Die Zahlen wiesen ungemein starke Schwankungen auf. Die Extreme der 40 Befunde betragen 4.6 und $19.1 \mathrm{mg}$ pro Liter, doch nur in 5 Fällen wurde die 
Zahl 12 juberschritten, nur 12 Zahlen sind kleiner als 8.0. Beziehungen zum Pegelstande und zur Temperatur des Wassers fehlen, ebenso solche zur Keimzahl. Dagegen sind Unterschiede innerhalb der einzelnen Profile deutlich. Das rechte Ufer hat fast immer merklich höhere Zahlen als Mitte und linkes Ufer, eine einstweilen nicht rerständliche Erscheinung. Sonst aber waren die an einem und demselben Tage gefundenen Mengen organischer Substanz ziemlich konstant. Für die Diagnose der Wasserverschmutzung sind daher die Mengen der organischen Substanz nur mit Vorsicht zu verwerten, namentlich im Hinblick auf die ohnehin höheren Werte am rechten Ufer.

10. Menge des im Wasser gelösten Sauerstoffes. Da der Absorptionskoeffizient des Wassers für Sauerstoff mit der Wassertemperatur sich stark ändert, erschien es rationeller, nicht die Sauerstoffmengen, sondern die Differenzen zwischen der tatsächlich gefundenen Menge und der maximalen für die jeweilige. Wassertemperatur miteinander zu vergleichen. Die bezüglichen Zahlen sollen nach Spittas Vorgang kurz als Sauerstoffdefizit bezeichnet werden. Dasselbe war (es liegen 31 Befunde vor) im Reinwasser in der Regel unbedeutend, es schwankte zwischen 0.2 und $1.5 \mathrm{mg}$. Innerhalb dieser Zahlen ließen sich lseinerlei Beziehungen zu Temperatur, Pegelhöhe, Keimzahl, sonstiger Verschmutzung des Wassers oder zur Stelle im Profil nachweisen. In folgenden Fällen aber wurde ein höheres Sauerstoffdefizit gefunden: Einmal (4. Juni 1904, Tabelle XXXIII) $2.0 \mathrm{mg}$ und zwar in gröBerer als in der sonst immer untersuchten Wassertiefe. Die Erklärung für diesen Befund liegt so nahe, daB eine Darlegung überflūssig ist; dann einmal 2.5 bei fallendem relativ keimreichen Hochwasser (28. Juli 1903, Tabelle XXXIV). Die Keimzahl des Wassers war zwar an diesem Tage verhältnismäBig hoch, doch wird hierdurch der Befund nicht erklärt, denn das Sauerstoffdefizit der keimreicheren linksufrigen Wasserproben unterhalb der Floridsdorfer Sammler war kleiner. Endlich einmal betrug das Defizit $\mathbf{2 . 2}$ in einer Wasserprobe, deren Keimzahl nicht bestimmt werden konnte, die aber durch gleichzeitigen relativ hohen Gehalt an Ammoniak und organischen Substanzen (beides Maxima für Reinwasser) sich stärler verschmutzt erwies als alle übrigen untersuchten Reinwasserproben (15. März 1904, Tabelle XXXVI).

Keimzahlen im Reinwasser erhoben bei 35 Wasserentnahmen an 12 rerschiedenen Tagen an 8 verschiedenen Profilen:

Das Minimum betrug 550 bis 775 Keime im Kubikzentimeter bei ziemlich niederem, klarem Wasser, das Maximum 4402 bis 4123 bei rapid fallendem, jedoch noch ziemlich hohem Wasserstande. In beiden Fällen war die Wassertemperatur mäBig hoch, doch wenig verschieden. 
Gewöhnlich bewregten sich die Keimzahlen zwischen 1000 und 2500 pro Kubikzentimeter. Im ganzen fanden sich bei niederem, daher klarem Wasser kleinere Zahlen als bei höherem trübem Wasser, ein Befund, der auch von anderen Autoren, besonders von Kabrhel erhoben wurde. Strenger Parallelismus bestand aber nicht. Beziehungen zwischen Keimzahlen und Wasser- oder Lufttemperatur waren nicht nachweisbar. Die gefundenen Keimzahlen unterscheiden sich weniger roneinander als die in anderen Flüssen erhobenen. Allerdings fehlen mir eigentliche Hochwasserzahlen, inbesondere Befunde bei beginnenden Hochwässern, da die Fahrten in solchen Fällen auf dem an sich schon ziemlich reißenden Strom aus äußeren Gründen unterbleiben müBten.

An den Ufern pflegten die Keimzahlen des Reinwassers ein wenig höher zu sein als in der Strommitte. Dort ist ja auch jeder Strom gewissen lokalen, sonst kaum nachweisbaren Verunreinigungen ausgesetzt, welche wegen der schwächeren Strömung nicht so leicht abgeführt werden. Die Zahlen schwankten, an jedem einzelnen Tage für sich betrachtet, nur wenig. Wesentliche Verschiedenheiten bezüglich der Tiefe, ans der das Wasser entnommen warde, waren gleichfalls nicht nachweisbar.

In später zu beschreibenden Versuchen wurde erhoben, daß das Reinwasser jedenfalls eine gröBere Zahl ron Keimen enthält, welche nur bei Bruttemperatur gedeihen. In $1 / 1000$, ja in $1 / 10000$ cm zur Aussaat verwendeten Wassers fanden sich solche Keime in genügender Anzahl, um wenigstens nach 48 Stunden in den beschickten Bouillonröhrchen eine schwache Trübung hervorzurufen. Fäulnisbakterien und Gärungserreger kommen stets vor, und speziell Bacterium coli commune ist ein regelmäBiger Bewohner des Reinwassers.

Die suspendierten Körper des Reinwassers.

Grobe, mit freiem Auge mehrere Meter weit sichtbare Körper sind relativ selten. Duhin gehüren Blätter und Zweige, vom Winde aus der Umgebung in den.Strom hineingeweht, sowie Holz- und Kohlenstückchen, die dem Dampferverkehr ihre Gegenwart in der Donau rerdanken.

Feine, doch mit freiem Auge noch sichtbare suspendierte Körper wurden zur quantitativen Bestimmung auf feinen Sieben aufgefangen (die Methode ist später beschrieben). Es liegen im ganzen 3 Befunde vom Reinwasser, erhoben an zwei verschiedenen Tagen, in beiden Fällen bei klarem Wasser vor. Dieselben stimmen ziemlich gut miteinander überein (siehe Tabellen XLI, XLII). Zur mikroskopischen Untersuchung der Suspensa wurde der Bodensatz verwendet, der sich in den geschöpften Wasserproben nach 2 bis 3 Tagen ruhigen Stehens abgesetzt hatte. Derselbe war stets ron bröckliger Konsistenz und bräunlich, ein Beweis für 
die geringe Beteiligung grūner Algen an seiner Zusammensetzung, indem, wie Spitta hervorhebt, das algenreiche Plankton der Havel und der Seen des Spree-Havelgebietes schon makroskopisch hellgrün gefärbt ist. Unter dem Mikroskope fanden sich wohl stets Individuen der Algenfamilien Diatomum, Navicula, Fragillaria, Surirella, Asterionella, seltener einiger anderer Familien. Nur die verhältnismäBig selten gefundenen Asterionellaexemplare sind aber Bewohner der Donau selbst, alle übrigen stammen aus den Seen des FluBgebietes der oberen Donau, wo sie reichlich vorkommen. Von dort werden stets Exemplare ron der Strömung mitgerissen und herabgeschwemmt. Sie gehen daun in der Donau früher oder später zugrunde.: (Mündliche Mitteilung von Prof. v. Wettstein.) Um reichlicher Material zu erhalten, machte ich im Herbst 1903 einige Fahrten mit dem Planktonnetze und ließ hierbei das Wasser, von ca. $4^{\mathrm{m}}$ Tiefe an aufwärts durch das Netz rinnen. Auch nach dieser Methode erhielt ich im Reinwasser nur ein schwach grünlich gefärbtes Residuum. Dasselbe enthielt die gleichen Algenarten wie das in den Flaschen abgesetzte Sediment, sowie alle übrigen Bestandteile des letzteren. Diese waren vorwiegend folgende: Gefäße und Gefäßbündel, Par- und Prosenchymzellen böherer Pflanzen, meist in kleinen, seltener in größeren Verbänden. Von Zelleinschlüssen hauptsächlich Kristalle. Dann mituuter ein- und mehrzellige Haare. Selten waren Protozoen. Relativ reichlich war ein wenig charakteristischer Detritus, der zum Teil durch grünlichen Schimmer Beimengungen pflanzlicher Elemente verriet, zum Teil aus feinsten Sandkörnchen bestand. Solchen Detritusklümpchen hingen mitunter Fäden von Beggiatoa alba an, niemals in größerer Menge.

Bei trübem Wasser war das Sediment reichlicher, besondere Zunahme einzelner Bestandteile desselben konnte nicht beobachtet werden.

An den Ufern des nicht verunreinigten Stromes lagern hier und da Zweige, ja sogar ganze Büsche. Der Steinwurf ermangelt eines Überzuges von grünen Algen, wie er bei manchen anderen Flüssen, z. B. bei der Isar von Pfeiffer und Eisenlohr (12) beschrieben ist.

Die im Reinwasser erhobenen Befunde, welche den FluBboden betreffen, werden später im Zusammenhang mit den übrigen Untersuchungen des Flußbodens abgehandelt werden.

Auch Heider hat das Wasser der Donau oberhalb ihrer Verunreinigung durch die Wiener Abwässer wiederholt untersucht. Tabelle III bringt die Zusammenstellung seiner Untersuchungen des bei Nußdorf geschöpften Wassers. Ein Vergleich mit meinen Befunden lehrt, daB sich in der Zwischenzeit die Beschaffenheit des Wassers nicht geändert hat. Wolfbauers Untersuchungen des Donauwassers aus dem Jahre 1878 (von Heider zitiert) sollen zum. Vergleiche nicht herangezogen werden. 
Die Kanalisation ron Wien.

Die Entfernung der Abfallstoffe in Wien, erfolgt durch Schwemmkanalisation. Ein Teil der Häuser, meistens ältere, besitzt allerdings noch schliefbare Hauskanäle, die zeitweise geräumt werden müssen, meistens erfolgt der Anschluß der Häuser an die Straßenkanäle derzeit durch Tonrohre; die Straßenkanäle sind durchweg schliefbar. Es bestehen in der Stadt noch etwa 5000 Senkgruben (meist in den peripheren Bezirken), doch wird deren flüssiger Inhalt nach dem Auspumpen zum gröBten Teile auch in die nächstgelegenen Kanäle entleert, so daB man zur Annahme berechtigt ist, daB der weitaus überwiegende Teil der rund 1700000 Einwohner zählenden Stadt in die Kanäle entwässert. Sichere zahlenmäBige Daten șind da nicht möglich (Kohl). Einige Häuserblocks am Donauquai und die Häuser von Kaisermühlen am linken Ufer der Donau entwässern direkt in den Strom.

Einbezogen sind in die Kanäle die aus dem Wienerwalde kommenden, durch die Stadt dem Donaukanale zuflieBenden Bäche: Schreiber-, Nessel-, Krotten-, Währinger-, Als- und Ottakringerbach.

Die eigentlichen Abfallstoffe, welche den Kanalinhalt bilden, setzen sich nach ihrer Herkunft folgendermaßen zusammen:

1. Fäkalien und Harn der Einwohner Wiens und eines Teils der Haustiere durch die Hauskanäle, 2. Haus- und Küchenabwässer auf demselben Wege, 3. das Regenwasser durch die Hauskanäle und Straßenwasserabläufe, 4. die Abwässer der StraBenreinigung, 5. der flüssige Inhalt der Senkgruben.

Dagegen gelangen nicht in die Kanäle folgende Abfallstoffe:

1. Die festen Abgänge der Straßenreinigung, 2. der Hauskebricht, 3. der feste Senkgrubeninhalt, 4. der gröBte Teil der Exkremente der Haustiere. Diese finden als Dünger Verwendung.

Die bei der manuellen Räumung der Sammelkanäle erhaltenen, fast rein mineralischen Stoffe werden auf Wagen, bezw. Schiffen abgeführt und bei Kilometer 10 in die Donau entleert. Haus- und StraBenkehricht werden entweder vergraben, oder teils zur Abfüllung alter Flußgerinne, teils zur Aufhöhung tiefliegenden Terrains verwendet oder -sonst aufgestapelt, teils zu landwirtschaftlichen Zwecken als Düngemittel verbraucht.

Der Verlauf der Kanäle am rechten Ufer des Donaukanales entspricht im allgemeinen dem Verlaufe der Täler zwischen dem Bergrücken, die der Wiener Wald dureh die Stadt hindurch der Donau zusendet. Sämtliche Sammler münden in die beiden an den Ufern des Donaukanales hinziehenden Hauptsammler. Bis zum Sommer 1904, also fast bis zur Zeit 
des Abschlusses der vorliegenden Untersuchungen, ergossen beide Hauptsammler ihre Abwasser in spitzem Winkel knapp oberhalb der Staatsbahnbrücke in den Donaukanal. Die Stelle liegt $5.9 \mathrm{~km}$ oberhalb der Donaukanalmündung. Der rechte Hauptsammler führt die weitaus überwiegende Schmutzwassermenge.

Dieser Zustand jedoch ist nur provisorisch. Abgesehen von den jährlichen Erweiterungen des Kanalnetzes findet eine sukzessive Verlängerung des rechten Hauptsammlers längs des Donaukanales nach abwärts zu statt. Im Sommer 1904 wurde die Mündung desselben um etwa $1^{\mathrm{km}}$ in der genannten Richtung verlegt. In den folgenden Jahren soll die Verlängerung fortgesetzt und überdies der linke Hauptsammler unter dem Bette des Donaukanales hinweg auf das rechte Ufer geleitet werden. Hier sollen dann beide Hauptsammler, gemeinsam eingewölbt, doch jeder in einem gesonderten Gerinne, bis $500 \mathrm{~m}$ unterhalb der Donaukanalmündung weitergeführt werden und sich daselbst gemeinsam in den Strom ergießen.

Das Gefälle der Haupt- und Zweigkanäle beträgt im Durchschnitt 10 bis 15 Promille, doch kommen, namentlich am linken Ufer des Donaukanales, Gefälle bis zu 1 Promille herab vor. Die beiden Hauptsammler besitzen auf sehr lange Strecken nur ein Gefälle von 0.4 pro mille. Schlammbildung findet im Kanalsysteme nicht statt. Es sedimentieren mineralische Stoffe (Sand und Schlacke) und Kohle, in den Hauptsammlern auch diese fast gar nicht. Notauslässe besitzen beide Hauptsammler nach dem Donaukanale, die Wienflußsammler nach dem Wienfluß. Diese treten bei 5 facher Verdünnung der Abwässer, jene bei 5 bis 20 facher Verdünnung in Tätigkeit (Mitteilung des Hrn. Baurat Kobl). Der Fall kommt selten vor. Der rechte Hauptsammler führt die Abwässer des I. und III. bis XIX. Bezirkes mit insgesamt rund 1468000 angeschlossenen Finwohnern der Donau zu. Der Sammler für den XI. Gemeindebezirk (Simmering) vereinigt sich mit dem Hauptsammler nur knapp oberhalb dessen damaliger provisorischer Mündung in den Donaukanal, daher muBten die Untersuchungen oberhalb dieser Stelle, also an einem Orte vorgenommen werden, wo nur die Abwässer von $17 \mathrm{der} 20$ Wiener Gemeindebezirke mit 1428000 Einwohnern vereinigt sind; der II. und XX. Bezirk, mit ca. 212000 Einwohnern, die durch den linken Sammler entwässern, sowie der oben erwähnte XI. Bezirk mit 40000 Einwohnern, also znsammen 252000 Einwohner oder ca. 15 Prozent der gesamten Wiener Bevölkerungszahl, blieben von den systematischen Untersuchungen ausgeschlossen und es wurden nur Stichproben über die Zusammensetzung der Abwässer gemacht, am linken Sammler überdies einmal die stündliche Wassermenge durch 24 Stunden gemessen. Anläßlich der vorliegenden Untersuchungen wurden an 3 Terminen Proben aus den Wiener Hauptsammlern geschöpft. 
1. Am 11. Februar einige Stichproben (Tabelle XX).

Tabelle XX.

Untersuchung des Inhaltes der beiden Hauptsammler an ihrer Mündung. 11. II. 1903. $1 / 211$ bis $1 / 2^{1} 2^{\mathrm{h}}$ vormittags. Milligramme pro Liter.

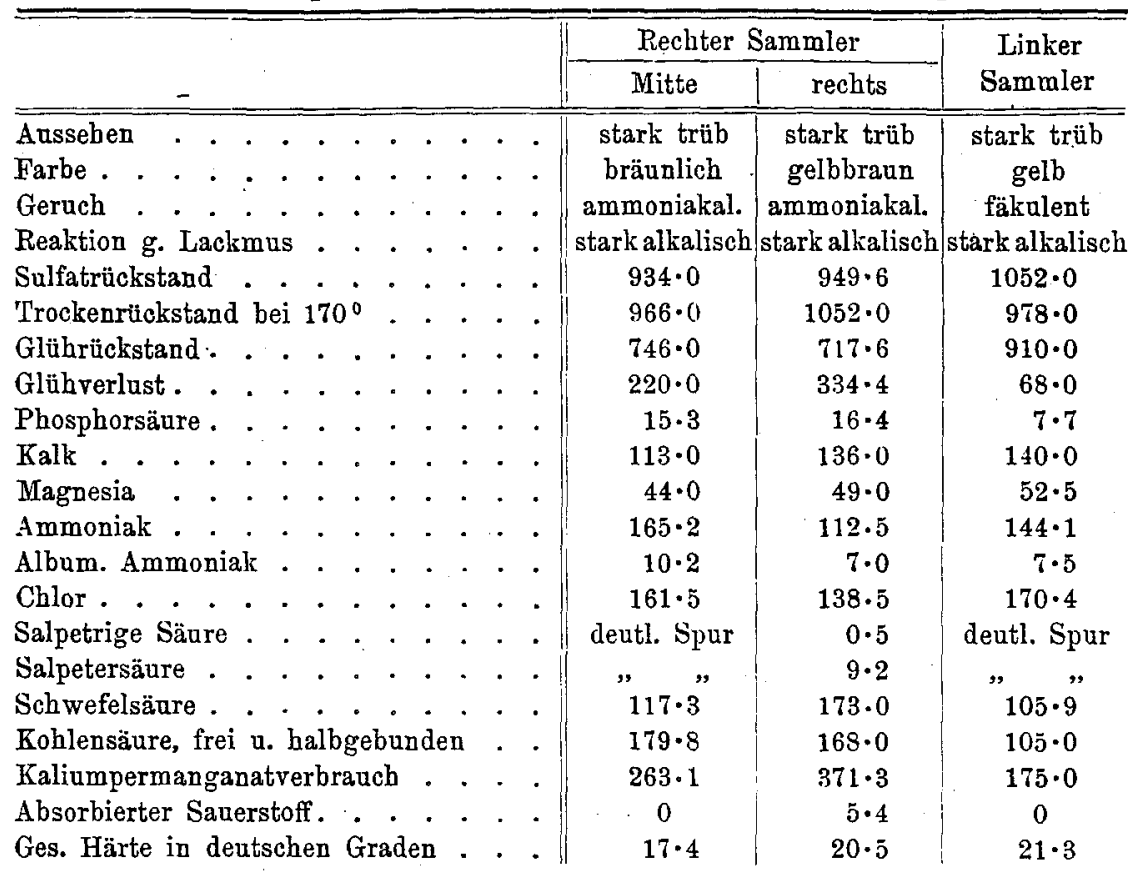

2. Am 22. und 23. Nai 1903 (Tabelle XXI).

3. Am 18. und 19. Januar 1904 (Tabelle XXII und XXIII).

An diesen beiden Terminen wurden von früh 9 bezw. $10 \mathrm{Uhr}$ an durch 24 Stunden stündlich Entnahmen aus dem rechten Hauptsammler vor der Aufnahme des Simmeringer Sammlers vorgenommen und zwar in folgender Weise: Ein Kanalräumer stellte sich in die Mitte des Kanales, versenkte eine Flasche mit der Mündung nach unten bis auf den Boden, drehte sie dort um und hob sie dann langsam empor, so daß sie, am Wasserspiegel angelangt, eben voll war. So wurde Wasser aus allen Höhenschichten in gleicher Menge geschöpft. Außerdem wurde durch Beamte des Wiener Stadtbauamtes die Höhe des Wasserstandes stündlich gemessen, die Strömungsgeschwindigkeit bestimmt und daraus die stündliche Abflußmenge berechnet. Die gleichen Messungen fanden beim linken Sammler statt. Dortselbst wurde aber nur je eine bis zwei Stichproben zur chemischen Untersuchung entnommen. Am 22. Mai 1903 wurden überdies aus dem Simmeringer Sammler (Tabelle XXI) zwei Proben geschöpft. 


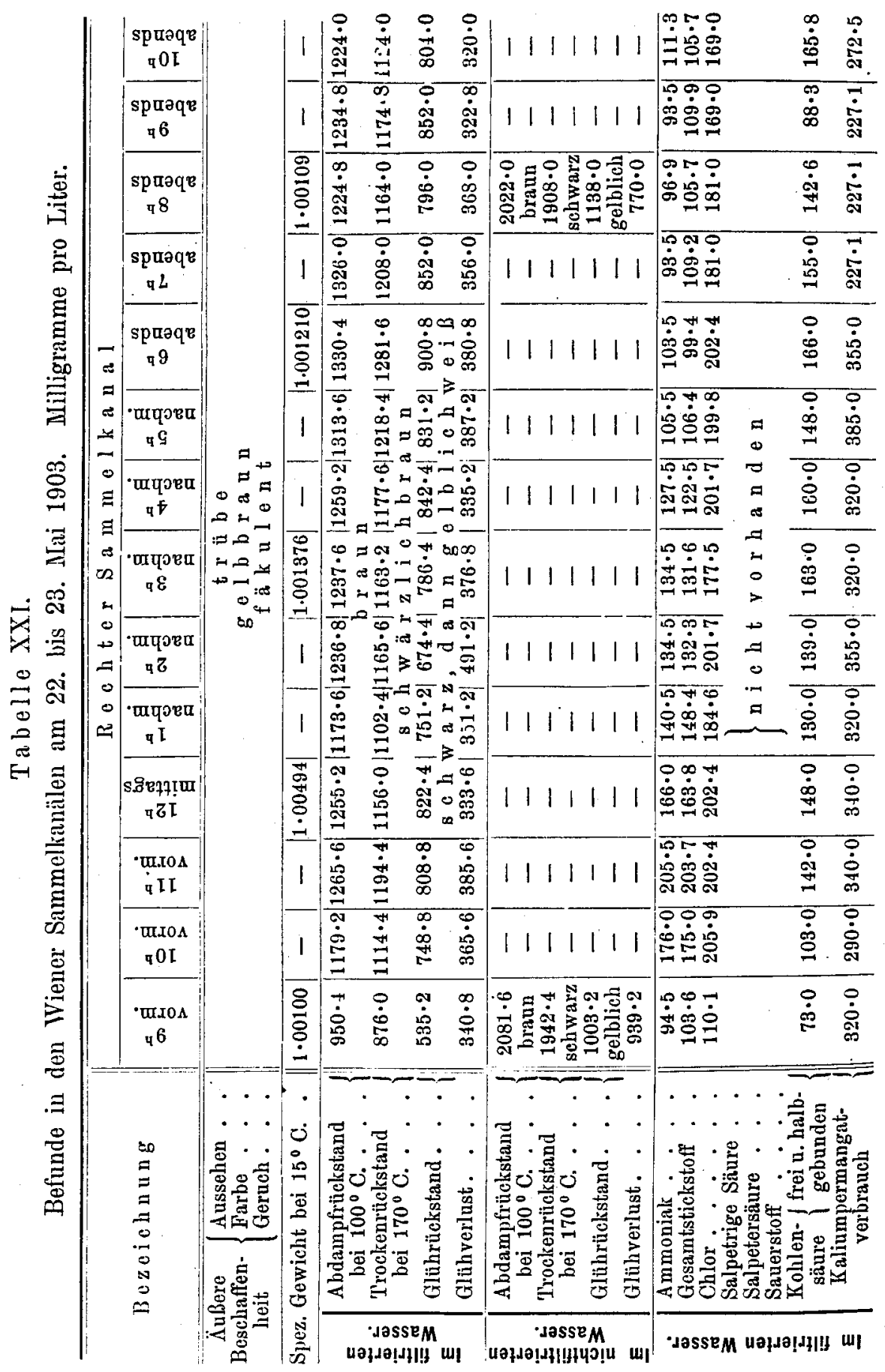


Dif Seldastreinigung der Donad.

433

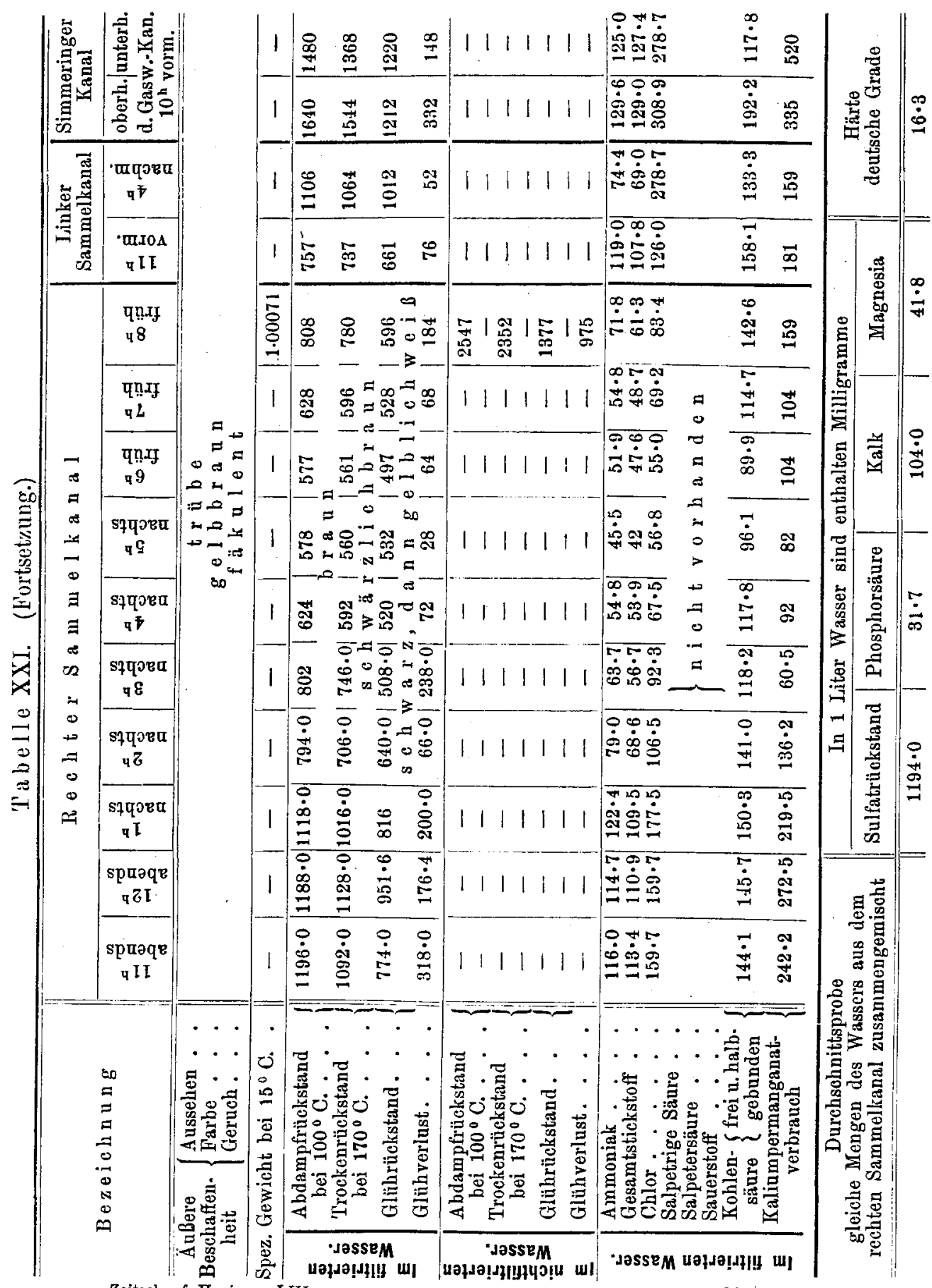




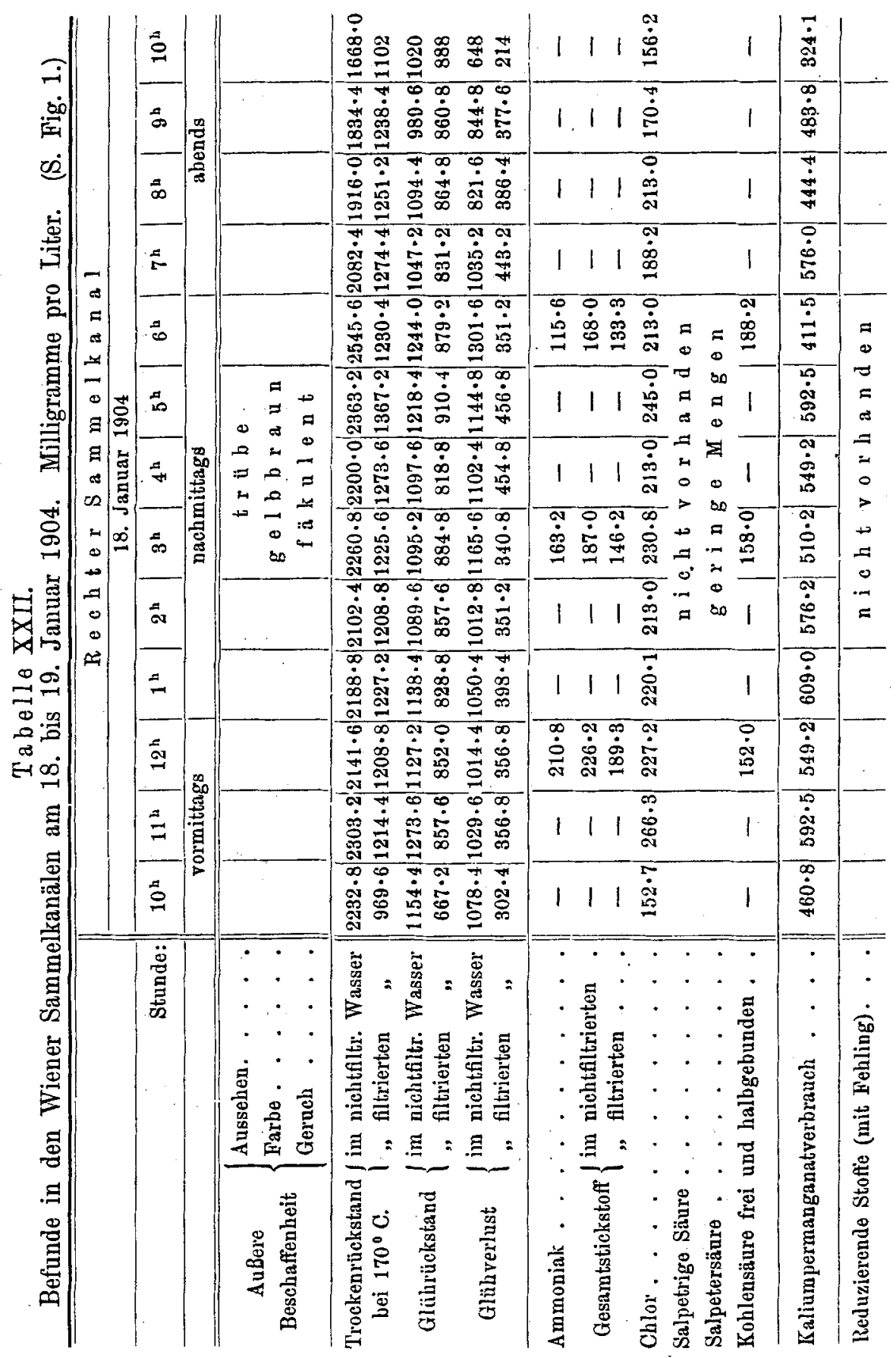


Dife Selbstreinigung Der Donat.

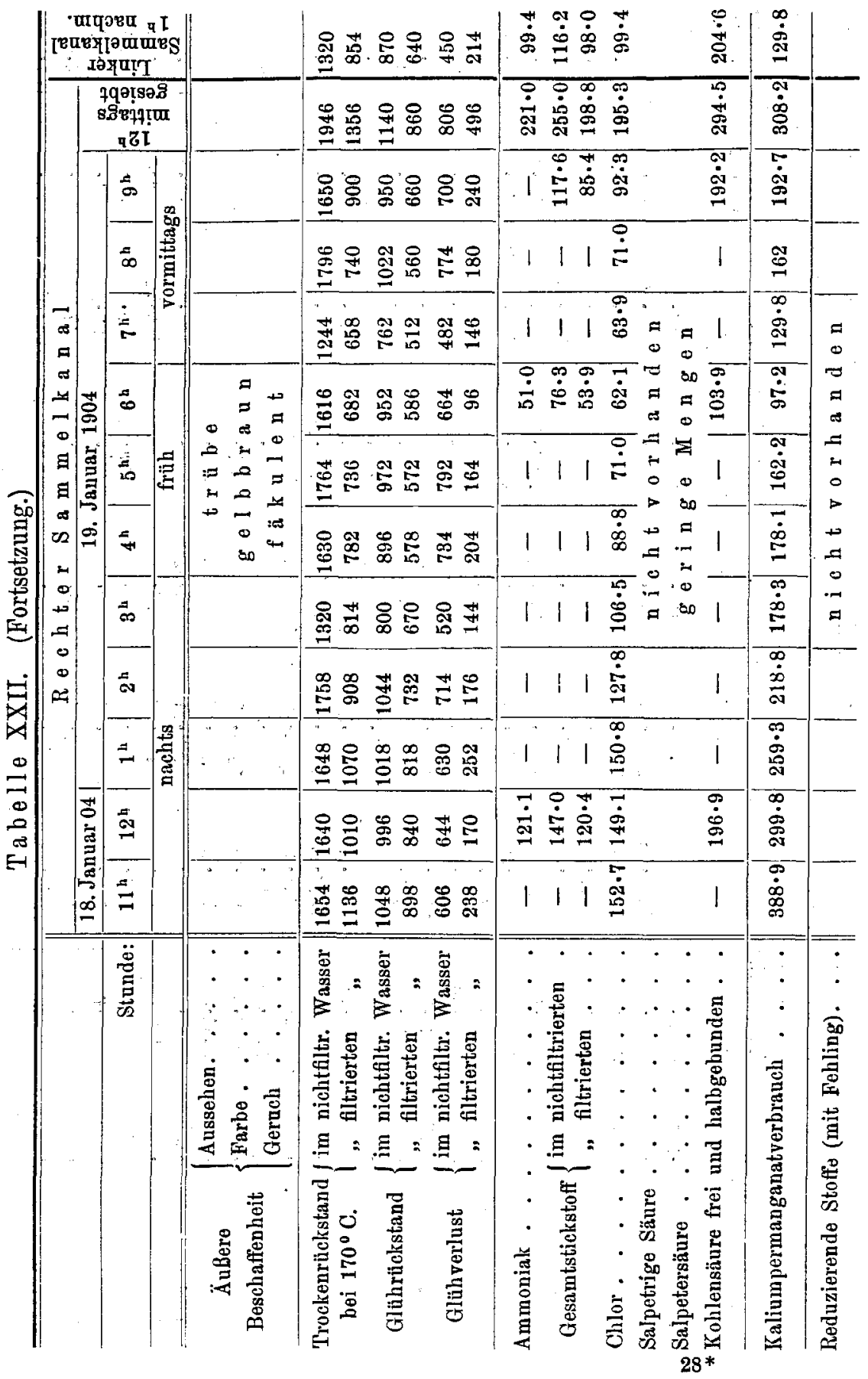




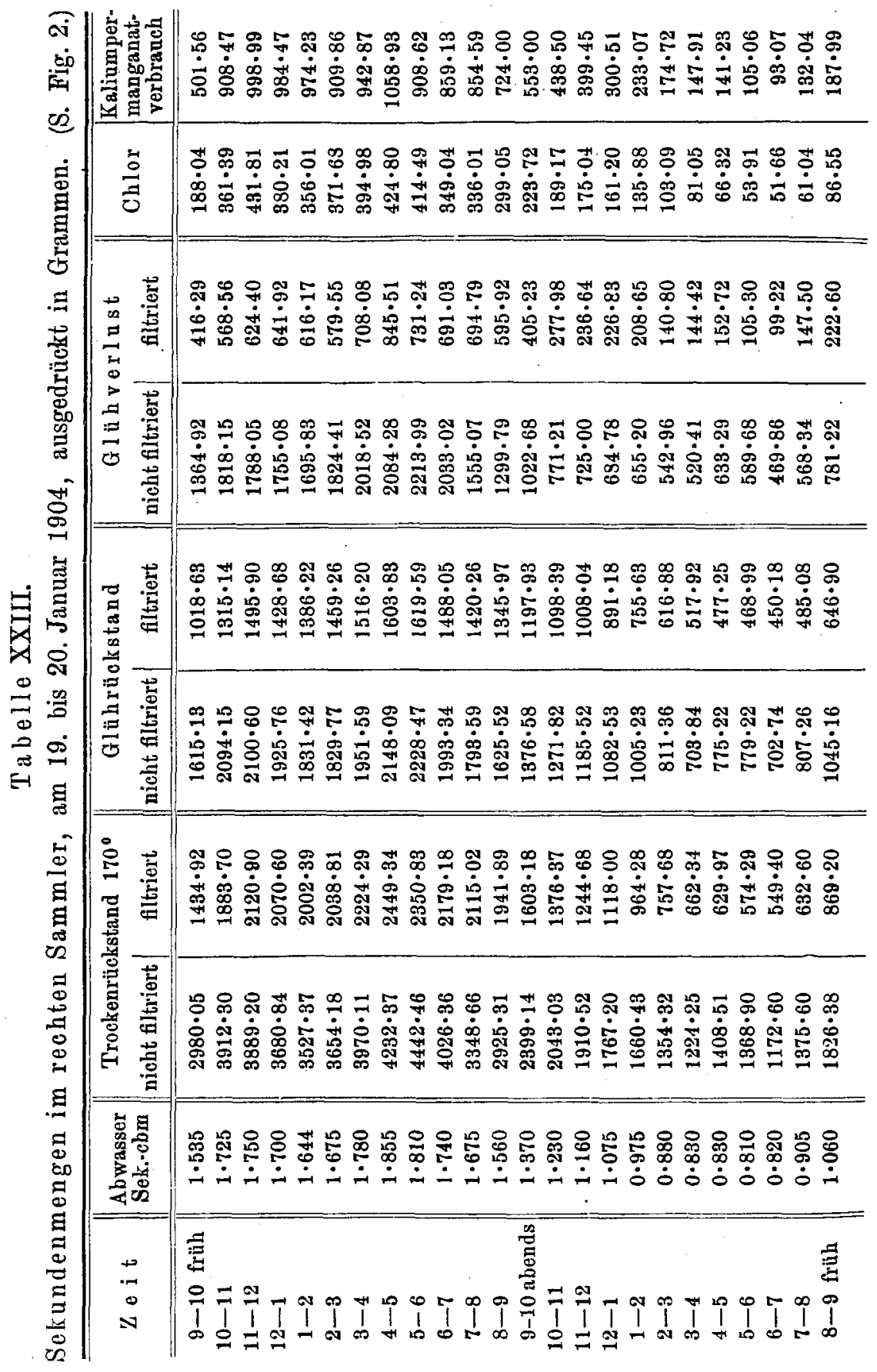


Tabelle XXIII. (Fortsetzung.)

\begin{tabular}{|c|c|c|c|c|}
\hline \multirow{2}{*}{$Z$ e it } & \multirow{2}{*}{ Ammoniak } & \multicolumn{2}{|c|}{ Gesamtstickstoff } & \multirow{2}{*}{$\begin{array}{c}\text { Kohlensäure } \\
\text { frei und halbgebunden }\end{array}$} \\
\hline & & filtriert & nicht filtriert & \\
\hline $12^{\mathrm{h}}$ mittags & $363 \cdot 63$ & $326 \cdot 54$ & $390 \cdot 2$ & $262 \cdot 2$ \\
\hline $3^{\text {b }}$ nachm. & $281 \cdot 83$ & $252 \cdot 56$ & $323 \cdot 4$ & $272 \cdot 95$ \\
\hline $6^{\mathrm{b}}$, & $205 \cdot 19$ & $236 \cdot 61$ & $298 \cdot 2$ & - \\
\hline $12^{\mathrm{h}}$ nachts & $135 \cdot 33$ & $134 \cdot 55$ & $164 \cdot 27$ & $220 \cdot 04$ \\
\hline $6^{\text {h }}$ früh & $41 \cdot 57$ & $43 \cdot 93$ & $62 \cdot 19$ & $34 \cdot 68$ \\
\hline $9^{\mathbf{h}}$, & - & $110 \cdot 81$ & $152 \cdot 59$ & $249 \cdot 38$ \\
\hline
\end{tabular}

Leider war am 22. bis 23. Mai 1903 der Pegelstand im Donaukanal so hoch, daß ein Rückstau des Wassers in die Sammler erfolgte. Die GröBe desselben wechselte während der Untersuchungszeit, und seine Wirkung auf die Abflußmenge der Sammler konnte nicht eruiert werden. Das Resultat der 24stündigen Untersuchungen war daher lediglich die Feststellung, wie viel ron den einzelnen Abfallstoffen im Liter Kanalwasser jeweils vorhanden war, mit anderen Worten die Konzentration der Abwässer, doch auch für diese sind die gewonnenen Zahlen von geringerem Werte als die am 18. und 19. Januar 1904 erhaltenen Befunde. Die wichtigere Frage, wie viel Abfallstoffe der rechte Sammler der Donau zuführt, wurde in der oben beschriebenen Weise bei der zweiten Untersuchung eruiert. Diese kann als einwandfrei gelten. Auch war damals infolge des kalten Wetters die Wassermenge der den Sammlern zufließenden Bäche relativ gering.

Die vorstehende Tabelle XXIII enthält die Resultate der Berechnung der Sekundenmenge für die einzelnen speziell untersuchten Abfallstoffe und die Sekundenwassermenge im rechten Sammler.

Da nur die Abgänge von etwa 85 Prozent der Einwohner Wiens den Untersuchungsort passieren, repräsentieren die Zahlen dieser Tabelle auch nur etwa den entsprechenden Teil der durch Kanāle abgehenden Abfallstoffe der Stadt. Die Zahlen der beiden obigen Tabellen XXII und XXII sind auf Figg. 1 u. 2 graphisch dargestellt.

Befunde am 18. und 19. Januar 1904.

Die Wassermenge des Sammlers ist morgens 5 bis $6 \mathrm{Jhr}$ am kleinsten, steigt dann konstant bis gegen Mittag, sinkt durch 2 Stunden etwas ab, steigt hierauf wieder, bis sie zwisehen 4 und $5 \mathrm{Chr}$ nachmittags ihr Maximum erreicht, und sinkt von da ab ziemlich gleichmäBig bis auf das Minimum am frühesten Morgen, wo durch ca. 3 Stunden keine wesentliche Ånderung der Wassermenge eintritt. Die gröBte Sekundenwassermenge ist mehr als doppelt so groß als die kleinste. Die Linie für den Trockenrückstand im nicht filtrierten Wasser zeigt einen im ganzen ähn- 


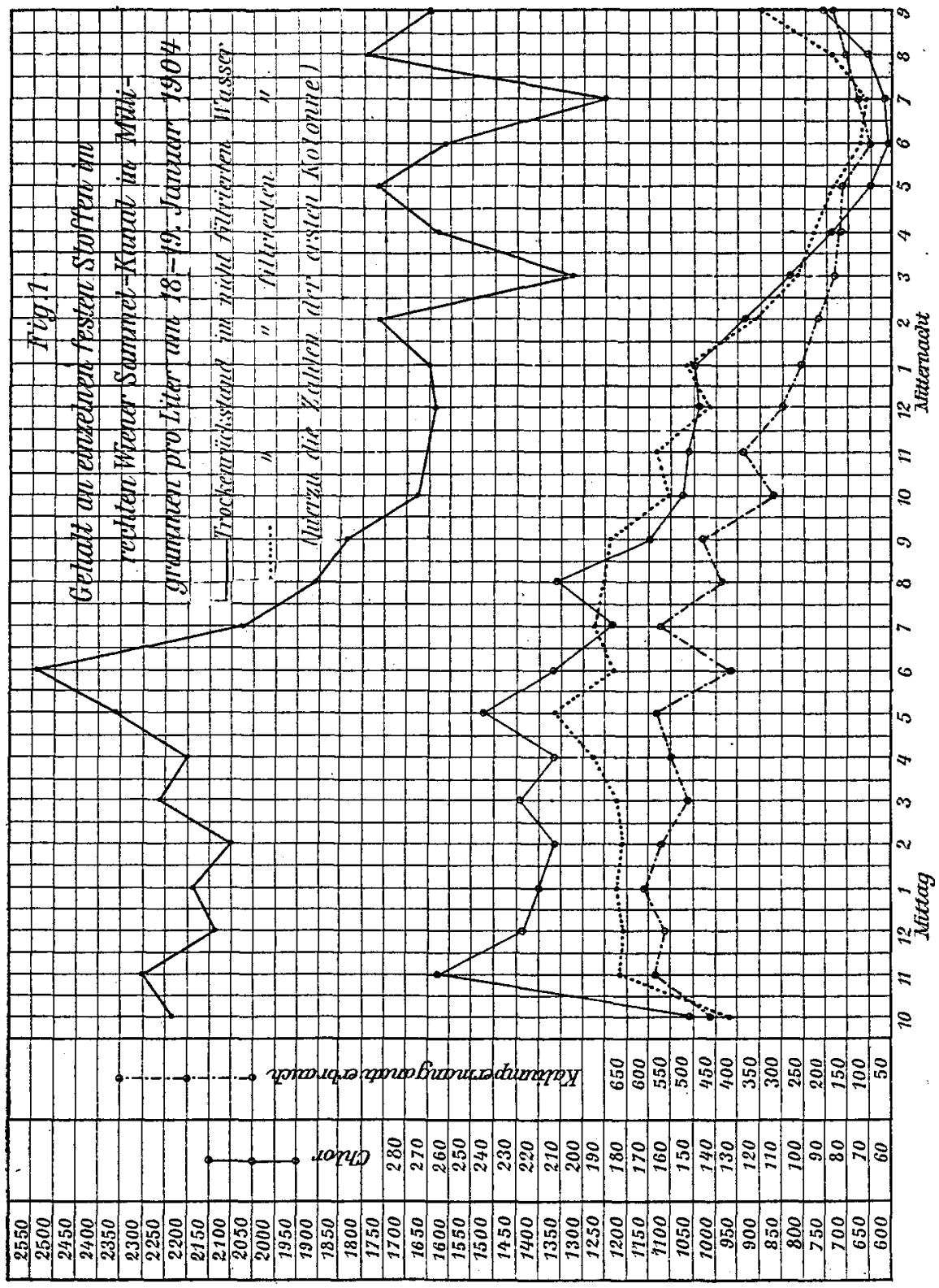

lichen Verlauf, jedoch mit einzelnen zwischenliegenden Sehwankungen, auch werden Maximum und Minimum etwas später erreicht. Die gröBte Konzentration beträgt etwa das Doppelte der kleinsten. Der linie für den Trockenrückstand im filtrierten Wasser fehlt der Vormittagsgipfel, sonst 


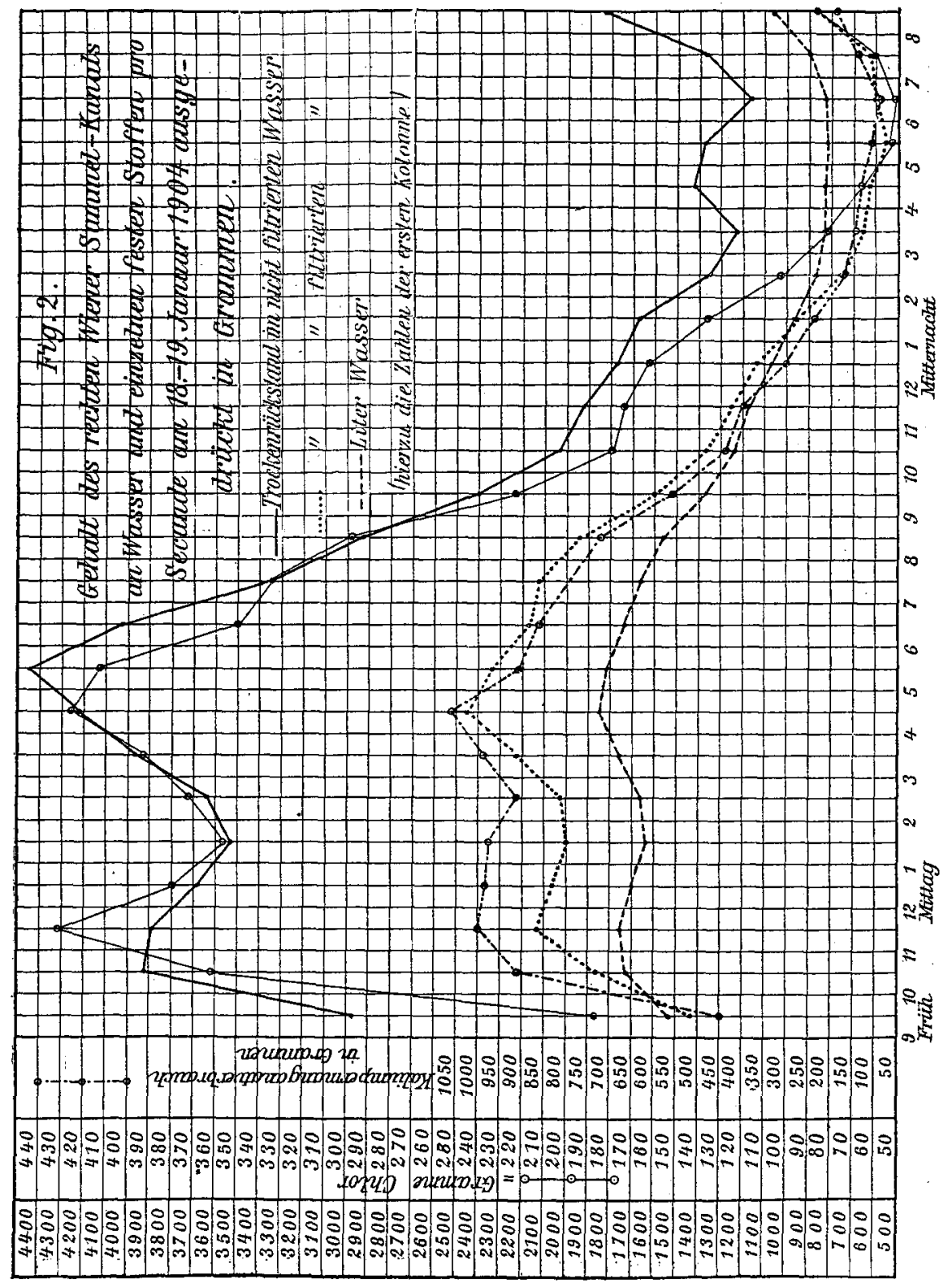

verläuft sie, von kleinen Schwankungen abgesehen, ganz ähnlich mit dem der vorigen. Maximum : Minimum = 2: 1. Beim Chlor stellt der Vormittagsgipfel das Maximum dar, sonst ist ihr Verhalten ähnlich den rorigen. Maximum : Minimum $=4: 1$. Der Gehalt an organischer Sub- 
stanz weist 3 Maxima von gleicher Höhe um 11, um 1 und um $5 \mathrm{Uhr}$ auf. Von $5 \mathrm{Jhr}$ nachmittags ab sinkt die Kurve, unterbrochen durch mehrere kleinere Erhebungen, bis 6 Uhr morgens. Das Maximum stellt das 6 fache des Minimums dar.

Die Ergebnisse der analogen Untersuchungen vom 22. bis 23. Mai 1903 waren den obigen im ganzen ähnlich. Damals wurde auch die Ammoniakmenge im Liter stündlich bestimmt. Diese ist maximal um $11 \mathrm{Uhr}$ vormittags, sinkt dann konstant bis $7 \mathrm{Uhr}$ abends, die Linie bildet dann einen Nebengipfel um $1 \mathrm{Uhr}$ nachts, worauf weiteres Sinken bis zum Morgen stattfindet. Maximum: Minimum wie 5:1.

Die Sekundenmengen der Abfallstoffe sind Funktionen der Menge und der Konzentration-des Abwassers. Da nun die Linien für Wassermenge und die für den prozentuellen Gehalt an den einzelnen Abfallstoffen am 18. und 19. Januar 1904 den gleichen Typus zeigten, kehrt dieser bei denjenigen Linien wieder, welche die Sekundenmengen der einzelnen Abfallstoffe darstellen, wobei die Hauptanschläge jener Linien verstärht hervortreten, während die kleineren Schwankungen verschwinden. Sämtliche 4 Linien zeigen einen Vor- und einen höheren Nachmittagsgipfel, welche von allen fast gleichzeitig erreicht wurden. Nur für Chlor stellt der erstere das Maximum dar. Der tiefste Stand fällt für alle Linien auf den Morgen. Sonst ist ihr Verlauf fast frei ron Schwankungen.

Das Maximum verhält sich zum Minimum

für den Trockenrückstand im nicht filtrierten Wasser wie $4: 1$

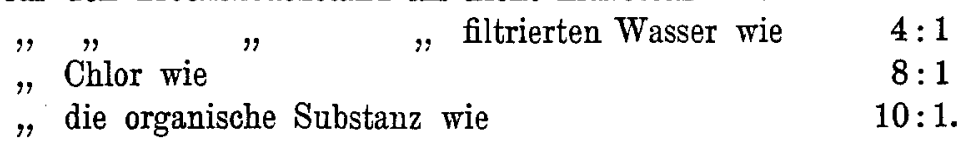

Nach Tabelle XXIII überwiegen die anorganischen gelösten Substanzen (Glührückstand) unter den Inhaltstoffen des Sammlers über die organischen (Glühveriust), das umgekehrte gilt für die ungelösten Körper.

Die absolute GröBe der täglichen Schwankungen ist also recht beträchtlich. Die Verschmutzung des Donaukanales und in zweiter Linie jene des Stromes schwanken demnach tagsüber entsprechend. Beurteilt man daher die Verschmutzung eines Flusses einfach nach der täglichen gesamten Unratmenge, so ist damit ein vollständiges Bild von dem $\mathrm{Zu}-$ stande desselben noch nicht gegeben, indem die tatsächliche Verschmutzung während einiger Tagesstunden größer, während der übrigen kleiner sein wird als die berechnete.

Das Wasser der Sammelkanäle führt außer den schon besprochenen Substanzen noch eine MIenge gröBerer und kleinerer Schwebestoffe, die 
zum Teil den Hals der zur Probenentnahme verwendeten Flasche wegen ihrer Größe überhaupt nicht passieren können (größere Kotballen, Früchte, Holzstücke), oder aus anderen Gründen tatsächlich nicht in die Flasche zu gelangen pflegen (Strohhalme, Zündhölzchen, Fetzen Papier). Die Verteilung dieser Körper im Sammlerwasser ist unregelmäßig.

Nun hat Monti mit anscheinend viel Erfolg die Berliner Abwässer auf ihren Gehalt an suspendierten Stoffen analysiert. Er brachte Proben des Wassers auf ein Sieb von $7 \mathrm{~mm}$ Maschendurchmesser und lieB das abfließende Wasser dann noch 4 weitere immer feinere Siebe, zuletzt ein Filter passieren. Die Siebrückstände und die auf dem Filter gebliebenen Suspensa sowie das Filtrat wurden dann untersucht. Monti hatte es jedoch mit Wasser zu tun, dessen gröbste Schwimm- und Schwebestoffe schon durch einen Rechen abgefangen waren, und auf diese kam es eben hier in Wien an, während die Körper, welche bei Montis Versuchen auf den Sieben bezw. auf dem Filter blieben, im vorliegenden Falle wohl auch größtenteils in die Flasche gelangen konnten. Eine Nachahmung der Versuche Montis war daher nicht am Platze, dieselben hätten auch eine ungemein grobe Zahl von Sieben erfordert. Die Kenntnis der Menge der groben Schwimm- und Schwebestoffe war indes doch wünschenswert. Bei ihrer ungleichmäßigen Verteilung in den Sammlern mußte eine möglichst große Abwassermenge auf ibren Gehalt an diesen Körpern untersucht werden. Dies geschah folgendermaßen: Um die Mittagszeit wurde ein 12 Liter fassendes verschließbares metallenes SchöpfgefäB $20 \mathrm{mal}$ in den Sammler versenkt, abwechselnd auf den Grund und in die oberen Wasserschichten, und daselbst gefüllt. Der Inhalt wurde jedesmal auf ein Roßhaarsieb von etwa $1 / 4$ qmm Maschenweite aufgegossen. Mit Rücksicht auf die unvermeidlichen Verluste betrug die Menge des aufgeschütteten Wassers etwa 200 Liter. Das Trockengewicht der auf dem Siebe verbliebenen suspendierten Stoffe betrug $81.5 \mathrm{grm}$, pro Liter Wasser also etwa $410 \mathrm{mg}$. Das durch das Sieb laufende Wasser wurde aufgefangen und analysiert. Der „Trockenrückstand im nicht filtrierten Wasser" der gesiebten Probe war pro Liter etwa $200^{\mathrm{mg}}$ geringer als jener des gleichzeitig geschöpften, ohne vorangegangene Siebung analysierten Wassers. Da die Zahlen für "Glührerlust im nicht filtrierten Wasser" in den beiden Proben ebenfalls $200^{\mathrm{mg}}$ differierten, waren diese $200^{\mathrm{mg}}$ so gut wie vollständig organischer Natur. Sie waren in dem einen Falle auf dem Siebe geblieben und dadurch der Wasserprobe entzogen worden. Der Siebrückstand pro Liter Wasser betrug aber etwa das doppelte, ca. $210^{\mathrm{mg}}$ Trockensubstanz mehr. Diese $210^{\mathrm{mg}}$ waren bei der ungesiebten Wasserprobe nicht in die Flasche gelangt, sie blieben als grobe Schwimm- und Schwebestoffe bei der gewöhnlichen Schöpfmethode von der Analyse ausgeschlossen. Ihre Menge 
betrug im rorliegenden Falle etwa 10 Prozent des gesamten Trockenrückstandes, auch sie waren nach den folgenden Ausführungen fast durchweg organische Stoffe. Auf dem Siebe fanden sich nämlich zunächst einige durch ihre Größe auffallende Körper: Mehrere große Kotballen, zwei halbe Zitronen, einige grūne Blätter, anscheinend Spinatblätter, gröBere Papierfetzen, Hobelspähne, Holzstïcke, Orangenschalen, Zündhölzchen. Diese Körper waren alle einer weichen, aus feinen, miteinander dicht verfilzten Massen bestehenden (s. Monti) grauen Masse aufgelagert, deren Struktur nur mikroskopisch zu erkennen war. Unter dem Mikroskope ließen sich dieselben Körper erkennen, welche wir später im Donaukanale und in den verschmutzten Gebieten des Donaustromes wiederfinden werden, nur waren gallig gefärbte Muskelfasern, Stärkekörner (zum Teil auch mit exhaltener Struktur und positiver Jodreaktion) viel häufiger als dort. Das ganze Sediment war auBerdem gröber, gröBere Zellverbände waren häufiger als im Strom.

Das Wasser des linken Sammlers wurde; so oft es untersucht wurde, viel ärmer an Abfallstoffen gefunden als die un die gleiche Tageszeit geschöpften Proben aus dem rechten Sammler, was durch die temporäre Einleitung der Kondenswässer eines großen Elektrizitätswerkes in diesen Kanal bedingt wurde. Dagegen war auch die Wassermenge relativ sehr groß. Umgekehrt enthielt der Simmeringer Sammler, am 22. Mai vor und nach der Einmündung der Abwässer der städtischen Gaswerke untersucht, im Verhältnis zu seiner Wassermenge zwar weniger Ammoniak und Gesamtstickstoff als der rechte Sammelkanal, sonst aber bedeutend mebr Abfallstoffe, insbesondere sehr viel organische Substanz. Demselben ist nicht, wie den übrigen rechtsuferigen Kanälen eine gröBere Menge Bachwasser beigemischt. Einige Keimzählungen wurden am 22. und 23. Mai 1903 vorgenommen; die Keimzahlen im rechten Sammler um 8 und $9 \mathrm{Uhr}$ früh, $3 \mathrm{Uhr}$ nachmittags und $8 \mathrm{Uhr}$ abends lagen durchweg zwischen 2.2 und 2.9 Millionen (die Zählungen muBten stets schon nach 36 Stunden erfolgen) pro Kubikzentimeter. Eine um Mitternacht geschöpfte Probe enthielt 3.4 Millionen: Keime. Die Keimzahlen am 11. Februar 190311 und 12 Uhr mittags im ungemischten (nicht gestauten) Wasser der Sammler betrugen 1 bis 1.4 Millionen. Diese Zahlen sind mit den Resultaten der chemischen Analyse keineswegs in Übereinstimmung. Vergleicht man sie mit den Keimzahlen, die an der Donaukanalmündung gewonnen werden, so findet man diese bedeutend höher, als sie mit Rücksicht auf die Verdünnung der Abwässer in letzterem Gerinne sein sollten. Die nächstliegende Erklärung für dieses eigentümliche Verhalten ist folgende: Das Abwasser enthält außer den frei suspendierten Keimen noch eine Menge Bakterien in den groben Schwimm- und Schwebestoffen aufgespeichert. Durch den allmählichen Zerfall dieser Körper werden fortwährend Keime 
frei (s. u.). Ihre Verteilung im Sammler ist aber, wie die jener Schwimmstoffe unregelmäBig. Die Zählung der Keime in den Sammlern gibt mit Rücksicht auf diese Verhältnisse keinen zuverlässigen Aufschlub über die jeweilige Qualität des Wassers, und wurde daher auch am 18. bis 19. Januar 1904 unterlassen.

Der Geruch der einzelnen Kanalwasserproben war ebenso wie der der Sammelkanäle selbst stets fäkulent. Sämtliche am-22. und 23. Mai geschöpften Wasserproben waren frei von absorbiertem Sauerstoff.

Die Tagesmenge der Abfallstoffe, welche den rechten Sammler an der untersuchten Stelle passieren, beträgt nach Tabelle XXIII $230760 \mathrm{~kg}$, für die ganze Stadt um 15 Prozent mebr, also $265374 \mathrm{~kg}$. Die Menge der Abfallstoffe pro Kopf und Tag berechnet sich daraus unter Berücksichtigung der nicht in die Flaschen gelangenden gröbsten Suspensa (Siebrückstand s. 0.) mit $177 \mathrm{grm}$, während Baumeister (9) etwas mehr, nämlich $190 \mathrm{grm}$ angibt. Freilich gelangen (s. S.429) in Wien nicht alle produzierten Abfallstoffe in die Sammler.

\section{Der Donaukanal}

durchfliebt die Stadt zwischen dem XX. und II. Bezirke (inkl. Prater) einerseits und dem XIX., IX., I., III. und XI. Bezirke andererseits in einigen Windungen. Sein Lauf ist daher, wie schon bemerkt, etwas länger $\left(16.84^{\mathrm{km}}\right)$ als der der entsprechenden Strecke des Stromes $\left(13.8^{\mathrm{km}}\right)$, die Wassergeschwindigkeit dementsprechend langsamer. Infolge der Nußdorfer Sperranlagen kann sein Niveau, daher auch seine Geschwindigkeit und seine Sekundenwassermenge künstlich herabgedrückt werden. Die hydrologischen Daten für den Kanal sind neben denen für den Strom auf Tabelle XVII zusammengestellt.

Die beiden oberen Drittel seiner Ufer zeichnen sich durch dichte Verbauung und lebhaften Verkehr aus. Auch bauliche Arbeiten wurden zur Zeit der Untersuchungen an denselben zeitweise ausgeführt. Der Lösch- und Ladeverkehr ist mitunter recht lebhaft, wiewohl er an Intensität keineswegs an den etwa auf der Spree herrschenden Verkehr heranreicht. Seitdem die zahlreichen Kanalmündungen durch Anlage der beiden Hauptsammler verschwunden sind, mündet außer diesen nur der jetzt gleichfalls regulierte WienfluB in den Donaukanal und zwar einige Kilometer oberhalb der Sammler. Durch diese Veränderung hat der Donaukanal seine zu Heiders Zeit so unangenehmen, hygienisch und ästhetisch bedenklichen Eigenschaften verloren. Sein Wasser ist jetzt, die seltenen Fälle der Tätigkeit der Notauslässe abgerechnet, für das Auge ähnlich dem Donaureinwasser. Immerhin bringen es die oben angeführten Momente mit sich, dab die chemische und balteriologische Beschaffenheit des 


\begin{tabular}{|c|c|c|c|c|c|c|c|c|c|c|}
\hline \multirow{2}{*}{ 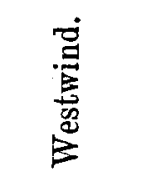 } & \multirow{5}{*}{ 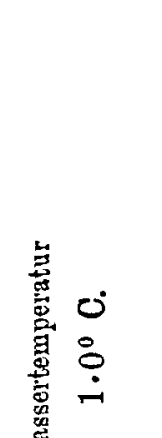 } & 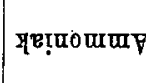 & 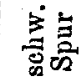 & $:$ & & $\stackrel{P}{\infty}$ & $\begin{array}{l}\infty \\
\dot{\infty}\end{array}$ & $\stackrel{\dot{\leftrightarrow}}{\mathbf{I}}$ & | & I \\
\hline & & 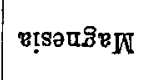 & 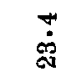 & $\dot{\dot{\sigma}}$ & $\stackrel{\infty}{\circ}$ & $\dot{\dot{8}}$ & $\dot{9}$ & $\dot{\text { ஸे }}$ & 1 & 1 \\
\hline \multirow{3}{*}{ 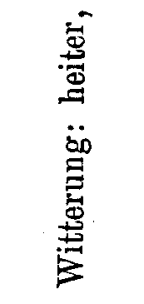 } & & 望 & $\stackrel{0}{\dot{p}}$ & $\stackrel{\mathscr{R}}{\dot{*}}$ & 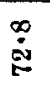 & 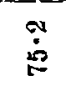 & $\stackrel{2}{\dot{\sigma}}$ & $\begin{array}{l}\dot{0} \\
\dot{0}\end{array}$ & 1 & 1 \\
\hline & & 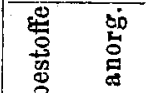 & $\stackrel{\infty}{\dot{\varphi}}$ & 1 & 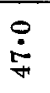 & 1 & 1 & $\stackrel{\mathscr{\dot { C }}}{6}$ & 1 & 1 \\
\hline & & 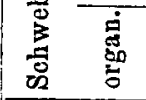 & $\dot{0}$ & 1 & $\stackrel{10}{\pi}$ & 1 & 1 & $\overrightarrow{\dot{s}}$ & 1 & 1 \\
\hline 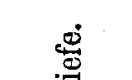 & & 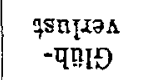 & $\dot{\dot{\sigma}}$ & $\stackrel{0}{\dot{\Phi}}$ & $\begin{array}{l}\varphi \\
\dot{⿵ 乃}\end{array}$ & $\stackrel{8}{\dot{0}}$ & $\begin{array}{l}\dot{0} \\
\dot{0}\end{array}$ & 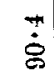 & 1 & 1 \\
\hline$\Xi$ & & 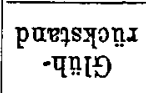 & 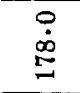 & $\stackrel{\dot{\Phi}}{\dot{g}}$ & : & $\stackrel{\infty}{\grave{D}}$ & 号 & 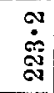 & 1 & 1 \\
\hline $\begin{array}{l}0 \\
. \Xi\end{array}$ & & 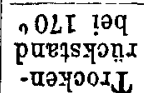 & $\begin{array}{l}\dot{p} \\
\dot{0} \\
\dot{0} \\
\dot{a}\end{array}$ & 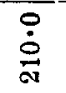 & : & జूँ & $\dot{0}$ & $\begin{array}{l}\dot{0} \\
\dot{m} \\
\dot{m}\end{array}$ & 1 & 1 \\
\hline 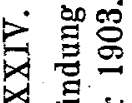 & 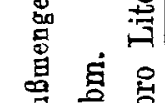 & $\begin{array}{l}\text { purassyวn } \\
\text {-78Jins }\end{array}$ & $\begin{array}{l}\hat{N} \\
\dot{\hat{\beta}} \\
\dot{a}\end{array}$ & 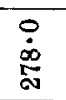 & $\begin{array}{l}0 \\
\dot{\infty} \\
\text { In } \\
\text { In }\end{array}$ & $\stackrel{0}{\stackrel{0}{0}}$ & 这 & $\begin{array}{l}\dot{0} \\
\dot{p} \\
\dot{\phi}\end{array}$ & $i$ & 1 \\
\hline D & 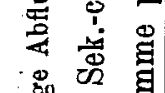 & 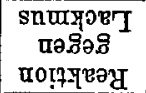 & 焉 & $=$ & $=$ & 2 & $=$ & $=$ & 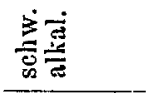 & $=$ \\
\hline$\underset{\mathscr{Z}}{\ddot{Z}}$ & $\underset{0}{5}$ & पon.eり & $\stackrel{\nexists}{ت}$ & $=$ & $=$ & $=$ & $=$ & $=$ & $\underset{\mathcal{E}}{\tilde{E}}$ & $=$ \\
\hline 参 & & Pqxes & $\dot{\overrightarrow{\vec{B}}}: 3$ & 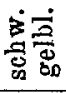 & & $\dot{\bar{\Xi}}$ & $=$ & $=$ & 竞: & $=$ \\
\hline 总 & & ueqəssn & 常总 & $=$ & 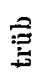 & $=$ & $=$ & $=$ & 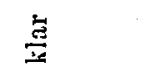 & $=$ \\
\hline 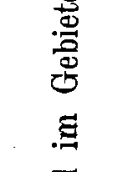 & 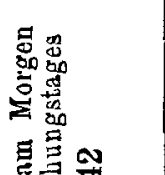 & 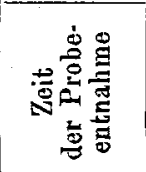 & 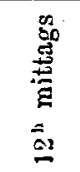 & $\begin{array}{l}= \\
=\end{array}$ & $\stackrel{+}{ \pm}$ & 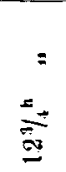 & $=$ & $\Rightarrow$ & $\begin{array}{l}\dot{\Xi} \\
\stackrel{\Xi}{\Xi} \\
= \\
=\end{array}$ & $=$ \\
\hline 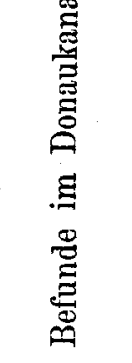 & 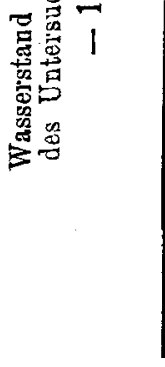 & 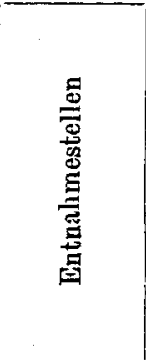 & 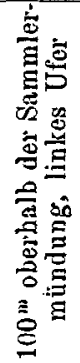 & 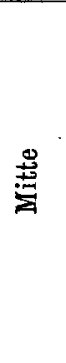 & 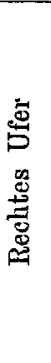 & 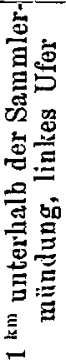 & 莣 & 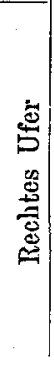 & 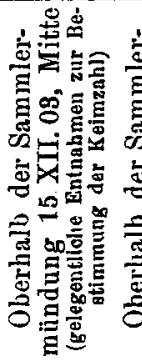 & 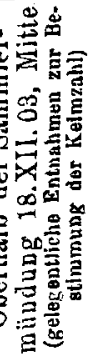 \\
\hline
\end{tabular}


Dif Selbstrennigung Der Donad.

\begin{tabular}{|c|c|c|c|c|c|c|c|c|}
\hline 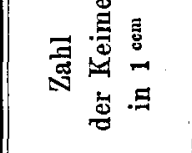 & $\begin{array}{l}\text { 号星 } \\
\text { 尔 } \\
-1\end{array}$ & 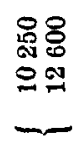 & 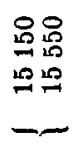 & $\begin{array}{l}88 \\
88 \\
142 \\
512 \\
-2\end{array}$ & 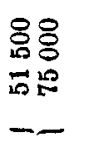 & 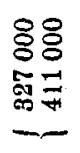 & 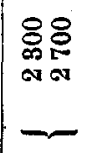 & 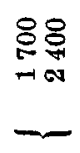 \\
\hline 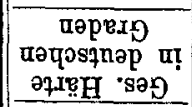 & $\check{\dot{g}}$ & $\dot{\infty}$ & $\stackrel{\check{0}}{\dot{0}}$ & $\begin{array}{l}5.5 \\
\dot{0} \\
\dot{0}\end{array}$ & $\dot{\grave{g}}$ & 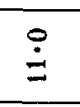 & I & 1 \\
\hline $\begin{array}{c}\text { 7!zyəp } \\
- \text {-707sxəueS }\end{array}$ & $\stackrel{5}{s}$ & $\stackrel{\varphi}{\dot{\alpha}}$ & $\stackrel{\infty}{i}$ & $\stackrel{\infty}{0}$ & $\stackrel{+}{+}$ & $\stackrel{\varphi}{=}$ & 1 & 1 \\
\hline 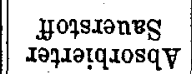 & $\stackrel{\leftrightarrow}{\leftrightarrows}$ & $\stackrel{\varrho}{\doteq}$ & $\stackrel{P}{\dot{\Xi}}$ & $\stackrel{9}{\check{2}}$ & $\stackrel{\leftrightarrow}{\dot{0}}$ & $\dot{\dot{v}}$ & 1 & 1 \\
\hline 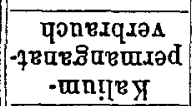 & $\vec{\phi}$ & $\dot{\sigma}$ & $\stackrel{9}{\dot{I}}$ & $\stackrel{5}{\Xi}$ & $\stackrel{9}{\dot{0}}$ & $\dot{\dot{\psi}}$ & 1 & 1 \\
\hline 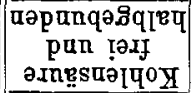 & $\dot{8}$ & $\dot{0}$ & $\stackrel{\leftrightarrow}{\dot{\$}}$ & $\stackrel{\infty}{\dot{E}}$ & $\begin{array}{l}\infty \\
\dot{\infty} \\
\dot{\infty}\end{array}$ & $\begin{array}{l}\stackrel{0}{\dot{3}} \\
\stackrel{0}{0}\end{array}$ & 1 & 1 \\
\hline 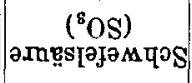 & $\dot{9}$ & $\stackrel{?}{\dot{a}}$ & $\dot{\dot{\lambda}}$ & $\stackrel{\text { i }}{\dot{\alpha}}$ & 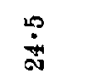 & 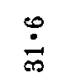 & 1 & 1 \\
\hline 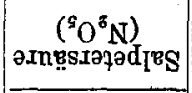 & 䓂它 & 0 & 'י & 言兑 & 竞 & $\stackrel{\leftrightarrow}{\dot{r}}$ & 1 & 1 \\
\hline 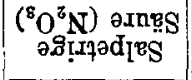 & 害当 & 0 & $\dot{0}$ & $\stackrel{\vec{a}}{a}$ & $=$ & $\ddot{\theta}$ & 1 & 1 \\
\hline 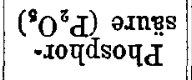 & 0 & 0 & $\begin{array}{l}\stackrel{0}{\infty} \\
\dot{\sim} \\
\dot{\omega}\end{array}$ & 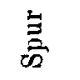 & $\therefore$ & $\check{\square}$ & 1 & 1 \\
\hline IOโ૫ & 营 & $\therefore$ & $\dot{m}$ & $\overrightarrow{\bar{z}}$ & a & $\stackrel{\infty}{\dot{a}}$ & 1 & 1 \\
\hline 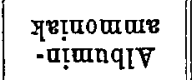 & 宗官 & 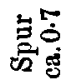 & 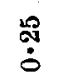 & 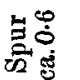 & $\begin{array}{l}\infty \\
\dot{\phi}\end{array}$ & 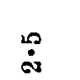 & 1 & 1 \\
\hline 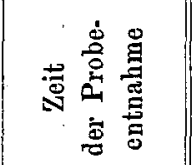 & 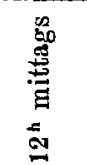 & $=$ & 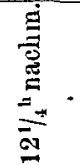 & $\begin{array}{l}= \\
= \\
=\end{array}$ & $=$ & $=$ & $\begin{array}{l}: \\
*\end{array}$ & : \\
\hline 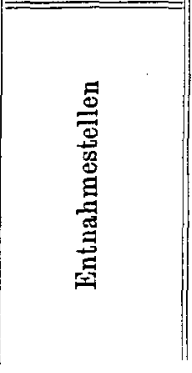 & 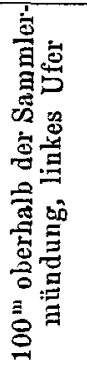 & 总 & 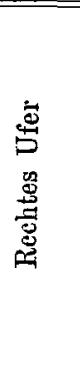 & 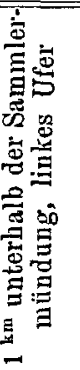 & 密 & 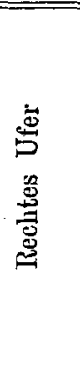 & 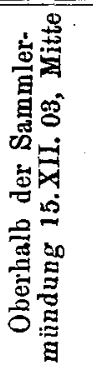 & 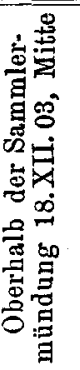 \\
\hline
\end{tabular}


Donaukanalwassers zeitweise doch etwas ungünstiger ist als die des reinen Stromwassers. Eine eingehende Untersuchung des Donaukanales lag nicht in dem Plane der vorliegenden Arbeit. Es wurden daher nur wenige gelegentliche Untersuchungen des Wassers ausgeführt. Dieselben sind auf Tabelle XXIV zusammengestellt.

Nach den Keimzahlen stellt sich die Beschaffenheit des Wassers am 11. Februar 1902 als relatir ungünstig dar. Die Keimzahlen, die in zwei anderen Fällen oberhalb der Sammlermündung genommen wurden, entsprechen ungefähr den im Reinwasser erhobenen Befunden. Die Einmündung der beiden Sammler in den Donaukanal erfolgte zur Zeit der Untersuchungen, wie schon erwähnt, $5.9 \mathrm{~km}$ oberhalb dessen Mündung in den Strom. Nur bei ausgesprochenem Niederwasser sinkt der Wasserspiegel des Donaukanales unter die Soole der Sammler. Das Abwasser stürzt dann mit Gewalt in den Donaukanal hinein, ähnlich wie Prausnitz es für die Einmündung des Eisbaches in die Isar beschreibt, und es kommt baldigst $z u$ einer für das beobachtende Auge vollständigen Durchmischung, indem der bis dahin grünes oder graues Wasser führende Donaukanal eine dunkelbraune Farbe annimmt. Gewöhnlich liegen die Verhältnisse jedoch so, daß die Sammlermündungen in oder unter dem Wasserspiegel zu liegen kommen. Die Abwässer fließen dann eine Strecke weit an den Ufern des Donaukanals dahin, links von der Flußmitte ein Band reinen Wassers lassend. Erst allmählich findet die Mischung statt. Am 11. Februar lagen die zuerst beschriebenen Verhältnisse vor. Aus Tabelle XXIV ist zu ersehen, wie sehr die Schmutzwassermenge im rechten Sammler überwiegt, denn die in der Mitte geschöpften Wasserproben zeigen in mancher Hinsicht höhere Verschmutzungswerte, als die vom linken Ufer. Das Wasser am rechten $U$ fer ist weitaus am meisten verschmutzt.

Einige Kilometer weiter unten an der Donaukanalmündung ist die Durchmischung des Wasser bereits ziemlich grûndlich erfolgt, doch auch hier ist die Verschmutzung an dem rechten Ufer noch etwas größer (Tabelle XXV).

Die Beschaffenheit des Wassers an der Donaukanalmündung unterliegt starken Schwankungen. Sie hängt hauptsächlich von folgenden Bedingungen $a b$ :

1. Von der jeweiligen Beschaffenheit des Reinwassers (Schwankungen nach Jahreszeit, Pegelstand im Strome und aus anderen unbekannten Ursachen). Diese Schwankungen betreffen besonders Trockenrückstand und organische Substanz.

2. . Die bezüglichen Schwankungen kehren in 24 stündigen Perioden wieder und sind sehr groß. Ob die Menge der Abfallstoffe von Tag zu Tag sich 
Die Selbstrentigung der Donad.

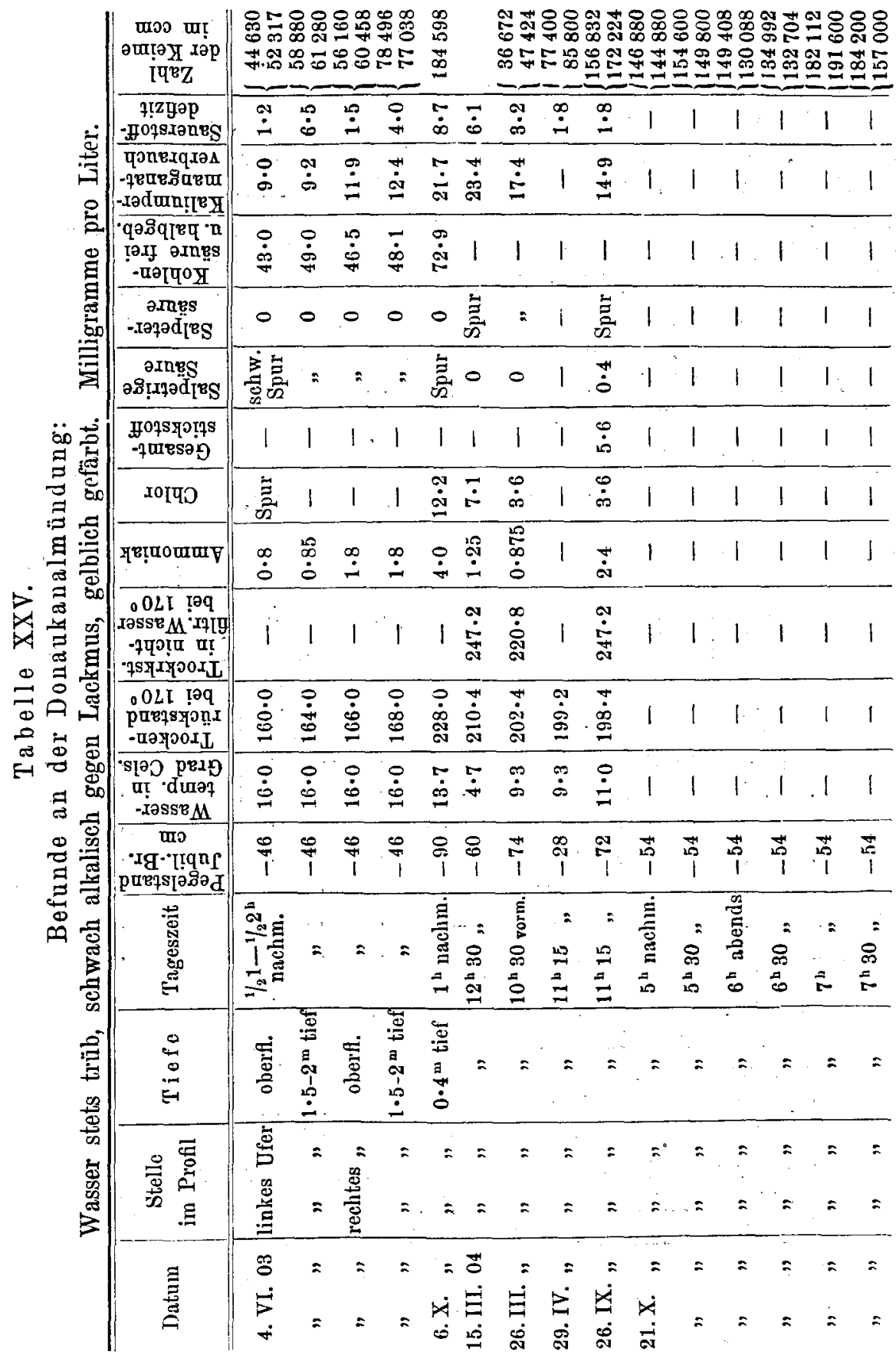


nennenswert ändert, konnte nicht eruiert werden. Keinesfalls dürften diese Schwankungen an Größe die täglichen erreichen.

3. Von der durch die NuBdorfer Regulierungsvorrichtung künstlich geschaffenen Sekundenwassermenge des Donaukanales: Je geringer dieselbe ist, desto mehr wird die gleiche Abwassermenge das Wasser des Donaukanales relativ verschlechtern. Auf Tabelle XXV sind sämtliche chemische und bakteriologische Befunde von der Donaukanalmündung zusammengestellt. Subtrahiert man von den bezüglichen Zahlen die des Reinwassers an dem gleichen Tage, so geben die erhaltenen Differenzen an, um wie viel das Wasser des Donaukanales durch die Abfallstoffe Wiens verunreinigt wurde. Diese Differenzen für Trockenrückstand, Ammoniak, Chlor und Oxydierbarkeit sind auf Tabelle XXVI zusammengestellt.

Tabelle XXVI.

Differenzen zwischen den Befunden im Reinwasser und an der Donaukanalmündung an den gleichen Tagen.

Milligramme pro Liter.

\begin{tabular}{|c|c|c|c|c|c|c|c|c|c|c|c|}
\hline Datum & 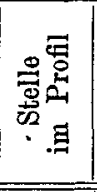 & Tiefe & zeit & 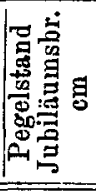 & 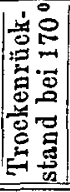 & 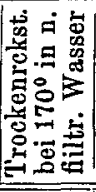 & 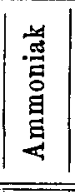 & $\frac{a}{0}$ & 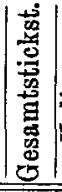 & 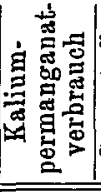 & 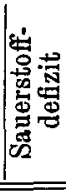 \\
\hline 4. VI. 03 & 1. Ufer & oberfi. & & -46 & $|12 \cdot 0|$ & - & 0.8 & 0 & - & $3 \cdot 8$ & 0.4 \\
\hline " & , & $1 \cdot 5-2^{m}$ tief & $1 / 21-1 / 22$ & -46 & $16 \cdot 0$ & - & 0.85 & 0 & - & $4 \cdot 0$ & $4 \cdot 0$ \\
\hline "' & r. Ufer & oberfl. & m. & -46 & $18 \cdot 0$ & - & $1 \cdot 8$ & 0 & - & $6 \cdot 7$ & $0 \cdot 7$ \\
\hline$"$ & $"$ & $1 \cdot 5-2^{m}$ tief & & -46 & $20 \cdot 0$ & - & $1 \cdot 8$ & 0 & - & 7.2 & $1 \cdot 5$ \\
\hline 6.X. " & ", & $0.4^{\mathrm{m}}$ tief & nm. & -95 & $32 \cdot 0$ & - & 4.0 & $6 \cdot 5$ & - & $11 \cdot 5$ & $8 \cdot 1$ \\
\hline 15. III. 04 & ", & " & $12^{\mathrm{h}} 30$ & -52 & $20 \cdot 0$ & $45 \cdot 6$ & $0 \cdot 75 \mid$ & $3 \cdot 5$ & - & $4 \cdot 3$ & $3 \cdot 9$ \\
\hline 26. III. ", & " & & $10^{\text {t }} 30 \mathrm{vm}$. & -68 & $-5 \cdot 6$ & -0.8 & 0.63 & 0 & - & $2 \cdot 6$ & $2 \cdot 0$ \\
\hline 2. IX. , & , & , & $11^{\mathrm{b}} 15$ & -70 & $8 \cdot 0$ & $44 \cdot 2$ & $2 \cdot 4$ & 0 & $2 \cdot 8$ & $4 \cdot 8$ & $1 \cdot 0$ \\
\hline
\end{tabular}

Dividiert man die Sekundenmenge der um eine bestimmte Tageszeit dem Donaukanal zugeführten Abfallstoffe durch die Zahl der Sekundenliter des Donaukanales, so bedeutet das Resultat annähernd den Zuwachs, den der Donaukanal pro Liter an den einzelnen Abfallstoffen um die betreffende Zeit erhält. Diese Rechnung wurde für jene Tage, für die Befunde von der Donaukanalmündung vorliegen, und zwar für die gleichen Stoffe wie Tabelle XXVI, durchgeführt. Als Grundlage dienten dabei die Zahlen der Tabelle XXIII vermehrt um 15 Prozent, die Pegelstände an diesen Tagen und die Entnahmezeit, wobei natürlich die Zeit berūcksichtigt wurde, die das Wasser von der Sammlermündung bis zum Ende des Donaukanales braucht. Eine Zusammenstellung dieser Befunde gibt Tabelle XXVII. 
Tabelle XXVII.

Verschmutzungszuwachs im Donaukanal berechnet nach der Menge der Wiener Abfallstoffe vom 19. I. 1904, der Tageszeit und dem Pegelstand an der.Jubiläumsbrücke. Milligramme pro Liter.

\begin{tabular}{|c|c|c|c|c|c|}
\hline D a t a $\mathrm{m}:$ & 4. VI. 03 & 6.X. 03 & 15. III. 04 & 26. ㅍ. 04 & 26. IX. 04 \\
\hline Pegelstand . . : . . & -46 & -95 & -60 & -74 & -72 \\
\hline Tageszeit. . . . . . & $\begin{array}{l}1 / 21-1 / 2^{\mathrm{h}} \\
\text { nachm. }\end{array}$ & $1^{\text {b }}$ nachm. & $\begin{array}{l}12^{\mathrm{h}} 30 \\
\text { nachm. }\end{array}$ & $10^{\mathrm{h}} 30 \mathrm{vm}$ & $11^{\mathrm{h}} 15 \mathrm{vm}$. \\
\hline Trockenrückstand bei $170^{\circ}$ & $16 \cdot 8$ & $22 \cdot 8$ & $18 \cdot 6$ & $14 \cdot 0$ & $14 \cdot 0$ \\
\hline $\begin{array}{l}\text { Trockenrückstand bei } 170^{\circ} \\
\text { im nichtfiltrierten Wasser }\end{array}$ & $30 \cdot 8$ & $41 \cdot 8$ & $34 \cdot 4$ & $29 \cdot 0$ & $29 \cdot 0$ \\
\hline Ammoniak . . . . & $1 \cdot 67$ & $2 \cdot 27$ & $1 \cdot 86$ & $2 \cdot 05$ & $2 \cdot 05$ \\
\hline Chlor . . . . . . , & $3 \cdot 4$ & $4 \cdot 6$ & $3 \cdot 8$ & $1 \cdot 8$ & $1 \cdot 8$ \\
\hline Kaliumpermanganatverbr. . & 7.9 & 10.7 & $8 \cdot 8$ & $4 \cdot 9$ & $4 \cdot 9$ \\
\hline
\end{tabular}

Es ist wohl nicht überraschend, wenn die tatsächlichen Befunde zum Teil eine stärkere', zum Teil eine geringere Verschmutzung des Donaukanales anzeigen, als sie nach dieser Rechnung sein sollte. Die tägliche Menge der Abfallstoffe Wiens und ihre Verteilung auf die einzelnen Tagesstunden ist wohl kaum stets gleich. Es ist daher auch nicht erlaubt, für die Stoffe, bei denen die Analyse meist kleinere Zahlen ergab, als die Berechnung, einen Verlust durch Selbstreinigung auf der kurzen Strecke von $5.9 \mathrm{~km}$ anzunehmen. Eine ähnliche Berechnung, wiedergegeben auf Tabelle V, hat Heider für die Pegelstände $0,-100$ und -200 aus geführt. Als Grundlage dienten ihm dabei seine Untersuchungen bezw. Schätzungen der Abfallstoffe Wiens, sowie die Sekundenwassermengen des Donaukanales. Ebenso hat Heider die Differenzen zwischen seinen Befunden an der Donaukanalmündung und den Reinwasserbefunden der gleichen Tage berechnet. Diese sind auf Tabelle VI wiedergegeben. Diese Tabelle ist sehr lehrreich, denn sie zeigt deutlich, da $B$ die Verschmutzungszunahme im umgekehrten Sinne wie der Wasserstand schwankt und im Laufe des Tages, entsprechend der Menge der Abfallstoffe, sich ändert. Ein Vergleich meiner Zahlen mit denen Heiders ist nicht tunlich, denn die Einmündungsstellen der Abwässer waren damals bekanntlich anders verteilt, auch untersuchte er bei anderen (im ganzen wohl höheren) Wasserständen, ferner ist, wie schon erwähnt, nicht zu eruieren, welehen Wassermengen seine Pegelstände entsprachen, und es fehlt für seine Befunde meist die Angabe der Tageszeit.

1 Siehe den später besprochenen Zerfall der Kotballen. 
Das Wasser des Donaukanales enthielt an seiner Mündung stets mehr Trockenrückstand als das Reinwasser des gleichen Tages, stets bezw. meist quantitativ bestimmbare Mengen Ammoniak und Chlor, ferner in allen Fällen wesentlich mehr organische Substanz, und weniger, oft viel weniger gelösten Sauerstoff. Dagegen fehlen salpetrige Säure und Salpetersäure ganz oder fast ganz, ebenso wie im Reinwasser. Nach den Befunden in den Sammlern ist letzteres $\mathrm{zu}$ erwarten. Die Keimzahlen stellen stets ein Vielfaches gegenüber dem Reinwasser vor. Die Keimzahlen nach Heider, im großen ganzen anscheinend etwas kleiner als meine, sind auf Tabelle VII dargestellt.

Sehr charakteristisch ist das Aussehen der Wasseroberfläche am unteren Donaukanale. Die Farbe des Wassers ist in dicken Schichten braun, in dünner Schicht in der Flasche betrachtet gelb, es ist stark trüb. Die Wasserfläche ist von stets zahlreichen, doch an Menge nach der Tageszeit stark schwankenden groben Schwimmkörpern bedeckt, auch in der Tiefe enthält es viele suspendierte Körper. Diese sind schon oben bei der Beschreibung des Sammlerinhaltes erwähnt. Am meisten fallen in die Augen: Kotballen, Papier, Heu- und Strohhalme, Zitronen, Korkstoppeln, Vogelfedern, Holzstückchen, Fetzen von Kleiderstoffen, ferner je nach der Jahreszeit wechselnde Abfälle von Gemüsen und Früchten; worunter besonders Orangenschalen durch Menge und lebhafte Färbung vom Februar bis Mai hervorstechen. Der ganze Anblick ist recht unerfreulich. Er wird in ganz ähnlicher Weise von Heider geschildert. Zur Bestimmung der suspendierten Stoffe wurde jenes Sieb ron ca. 1/4 qmm Naschenweite verwendet, welches auch bei den Sammleruntersuchungen in Gebrauch war. Die Trockensubstanz der Stoffe, welche auf dem Siebe zurückgehalten wurden, betrug für ca. 60 Liter Wasser (Tabellen XLI, XLII) bei zwei Untersuchungen 322.6 und $924.8^{\mathrm{mg}}$; beide Zahlen sind Vielfache der entsprechenden Reinwasserzahlen, obwohl dort feinere Siebe zur Anweudung kamen. In den an der Donaumündung gefüllten Flaschen setzte sich ein schwärzlichbrauner Niederschlag ab. Dieser war von ausgesprochen schleimiger Konsistenz, dabei reichlicher und von dunklerer Farbe als im Reinwasser. Der Niederschlag wurde mikroskopisch untersucht, er enthielt såmtliche Körper, die sich im Reinwasser gefunden hatten. Dazu kamen die durch Einmündung der Sammler beigemischten Suspensa: Größere Zellverbände pflanzlichen Ursprunges, Reste pflanzlicher Gefäßbündel (Treppen-, Netz-, Spiral- und getüpfelte Gefāße) strukturlose Schollen vom Aussehen gequollener Stärke, selten wohlerhaltene, die Jodreaktion gebende Stärkekörner; ungeformte und zellenartige Körper mit galliger Färbung, dann verschieden gut erhaltene Stücke quergestreifter Muskulatur. Ferner fanden sich Leinen-, Baumwoll- und Wollfasern, 
mitunter auch lebhaft gefärbte. Reste von Kleiderstoffen. In der Regel enthielt das Sediment auch zahlreiche Protozoen. Beggiatoa alba kam reichlich in Büscheln, an Detritusklümpchen haftend, doch nie in so groBer Menge vor, daB sie makroskopisch wahrnehmbar gewesen wäre. Mitunter gewann ich auch mit dem Planktonnetze die suspendierten Stoffe an der in Rede stehenden Stelle. Die Ausbeute war dann wegen der großen, durch das Netz rinnenden Wassermenge sehr reichlich, mitunter so reichlich, dab die schleimigen Massen den Ablaufkanal des Netzes verstopften. Der am meisten in die Augen fallende Unterschied zwischen dem Rein- und dem Schmutzwassersedimente war wohl die schleimige Konsistenz des letzteren.

An der Donaukanalmündung machte sich stets ein mehr oder weniger intensiver übler Geruch bemerkbar. Die einzelnen Wasserproben für sich waren jedoch geruchlos. LieB man sie im Laboratorium bei Zimmertemperatur oder bei $37^{\circ}$ geschlossen oder offen mehrere Tage stehen, so stellte sich gleichfalls kein übler Geruch ein. Jede Spur von Fäulnis blieb aus. Feuchtes Bleipapier, in den Hals der Gefäße gesteckt, schwärzte sich nicht. Entwicklung von Schwefelwasserstoff fand also nicht statt. Am Ufer des unteren Donaukanales waren bei niederem, besonders bei langsam fallendem Wasser zahlreiche, vorwiegend spezifisch leichte Schwimmkörper abgelagert, die von den Wellen ans Land geworfen wurden. Darunter waren Korkstoppel am reichlichsten vertreten. Die Ufersteine in geringer Höhe über dem Wasserspiegel waren dunkel und schmutzig, doch fehlte der bei anderen Flüssen öfters beschriebene Überzug von grünen Algen vollkommen. [Auch die das Reinwasser begleitenden Ufersteine ermangelten solcher Algenrasen].

Die Beschaffenheit des Flußbettes soll später besprochen werden.

Der Donaukanal ergieBt sich unter einem weit spitzeren Winkel in den Strom als die Sammler in ersteren. Die Hauptbedingung für rasche Mischung der beiden Wässer ist daher nicht gegeben. Nachdem wir im vorhergehenden das reine Wasser des Donaustromes, die Verschmutzungsquelle, nämlich die Sammler sowie das verschmutzte Wasser des Donaukanales, kennen gelernt haben, ist es nunmehr Hauptaufgabe, die nach Vereinigung der beiden Wässer in einem Bett sich abspielenden Vorgänge zu besprechen. Die Untersuchung der Wiener Abwässer hatte gelehrt, daß die Kanäle der Stadt in den späteren Nachmittagsstunden der Donau die meisten Abfallstoffe zuführen. Die Versehmutzung des Stromes an der Mündung des Donaukanales muBte daher gegen Abend am größten sein, und demnach wäre es wünschenswert gewesen, die Fahrten donauabwärts um diese Zeit zu beginnen, doch waren nächtliche Fahrten aus 
begreiflichen Gründen nicht durchführbar. Unbedingt erforderlich war es dagegen, mit der Untersuchung des Stromes nicht am frühen Morgen zu beginnen. Die Fahrten mußten also so spät am Tage begonnen werden, als die Zeit des Sonnenuntergangs und die Verkehrsverhältnisse es erlaubten. Nur bei der ersten Fahrt stromabwärts am 27. Nārz 1903 wurde dieser Grundsatz aus Unkenntnis der Verhältnisse außer acht gelassen, daher wurden damals sehr geringe Verunreinigungen im Strome gefunden. Ein zweiter Grundsatz war, mit dem Boote der Strömung nicht roranzueilen, da sonst Wasser von anderer Mischung gesclöpft würde. Die gefundenen Unterschiede hätten dann eine falsche Deutung erfahren können. Da meine Fahrten stets bei ansteigender Verschmutzung oder um die Zeit des ersten Maximums derselben begannen, hatte das zu rasche Fahren am 6. Oktober 1903 (Tabelle XXXV) zur Folge, daß stromabwärts relativ reineres Wasser geschöpft wurde. Am 15. März 1904 (Tabelle XXXVI) waren, wie es scheint, große Schwankungen im Gehalt des Reinwassers an organischer Substanz aus anderen unbekannten Gründen.

Um untereinander vergleichbare Zahlen zu erhalten, erwies es sich praktisch, stets wieder an den gleichen Stromstellen Wasser zu schöpfen. Da nun bei Kilometer 10 der Donaukanal einmündet, wurde zunächst $1 \mathrm{~km}$ weiter stromabwärts, bei Kilometer 11, Wasser entnommen. Die übrigen häufiger benützten Entnahmestellen lagen unterhalb Fischamend bei Kilometer 21, dann bei Kilometer 31 (unterhalb Kroatisch-Haslau), ferner bei Kilometer 45 (Hainburg), endlich bei Kilometer 60 (PreBburg). Die Strecke bis Kilometer 21 wurde als Anfangsstrecke genauer durchforscht, war auch leichter zugänglich als die folgende und wurde wiederholt in mehrere Teilstrecken zerlegt. AuBerdem wurden nur an zwei Stellen auf je einer Fahrt Wasserentnahmen eingeschaltet und zwar bei $\mathrm{km} 25$ und 38.

Auf den folgenden Seiten sind sämtliche chemische und bakteriologische Befunde tabellarisch zusammengestellt, welche uuf den Fahrten im Donaustrome (auch oberhalb der Donaukanalmündung) gewonnen wurden. Gleichzeitige andere Beobachtungen sind den Tabellen beigegeben. (Tabellen XXVIII bis XL.)

Am linken Donauufer wurden bei den späteren Fahrten nur selten Proben entnommen, da das Wasser daselbst bakteriologisch unter dem unkontrollierbaren Einflusse der Floridsdorfer Abwässer stand. Im folgenden wird die Beschaffenheit des Donauwassers auf der Strecke Donaukanalmündung-PreBburg beschrieben werden. Dabei wird das Aussehen des Stromes und seiner Ufer, die chemische Beschaffenheit des Wassers, die Keimzahl, die Menge der mit freiem Auge noch sichtbaren Schwebestoffe, das mikroskopische Bild des sich absetzenden Niederschlages zur Darstellung kommen. 
Die Selbstreinigung Der Donau.

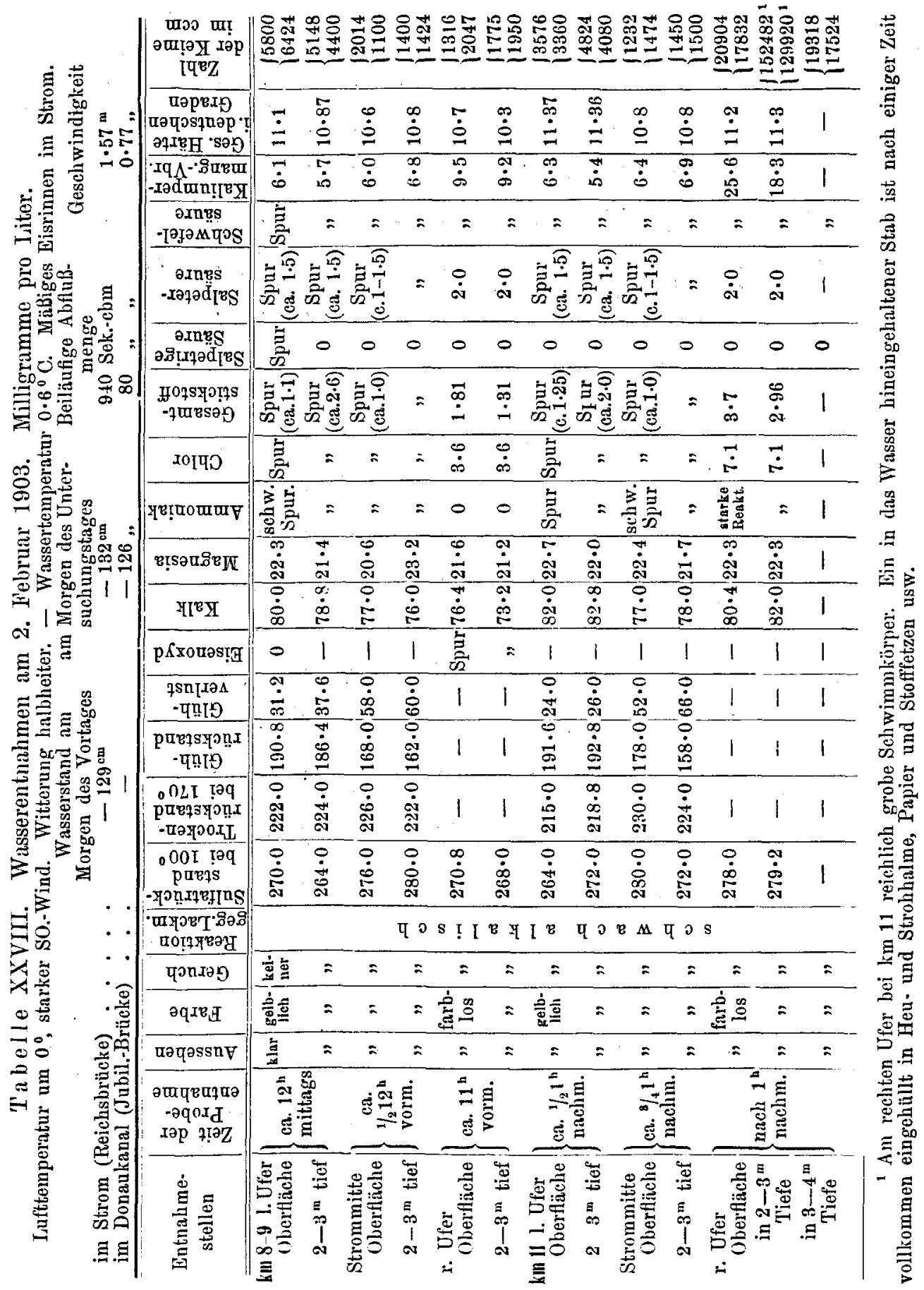




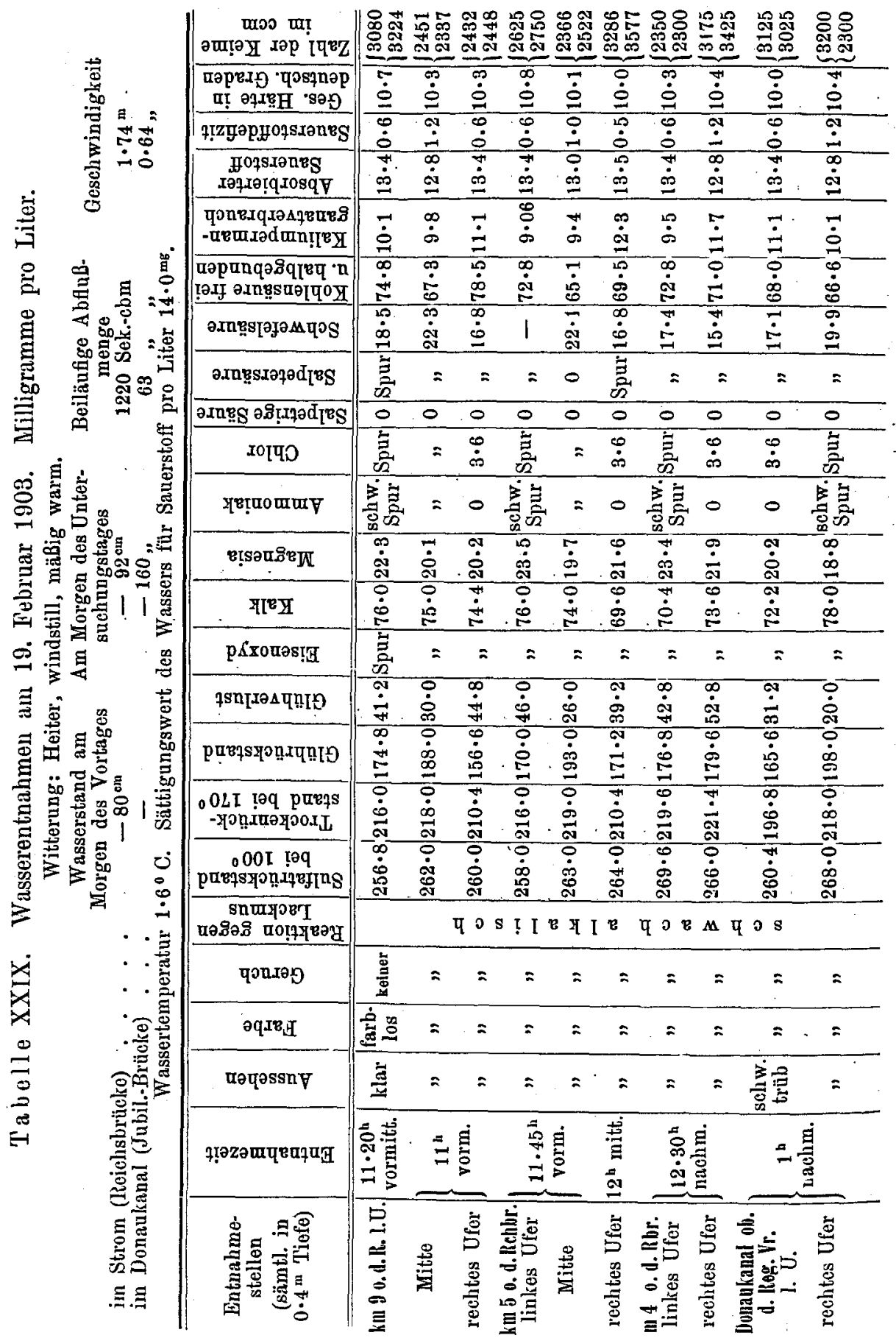


Die Selbstreinigung der Donad.

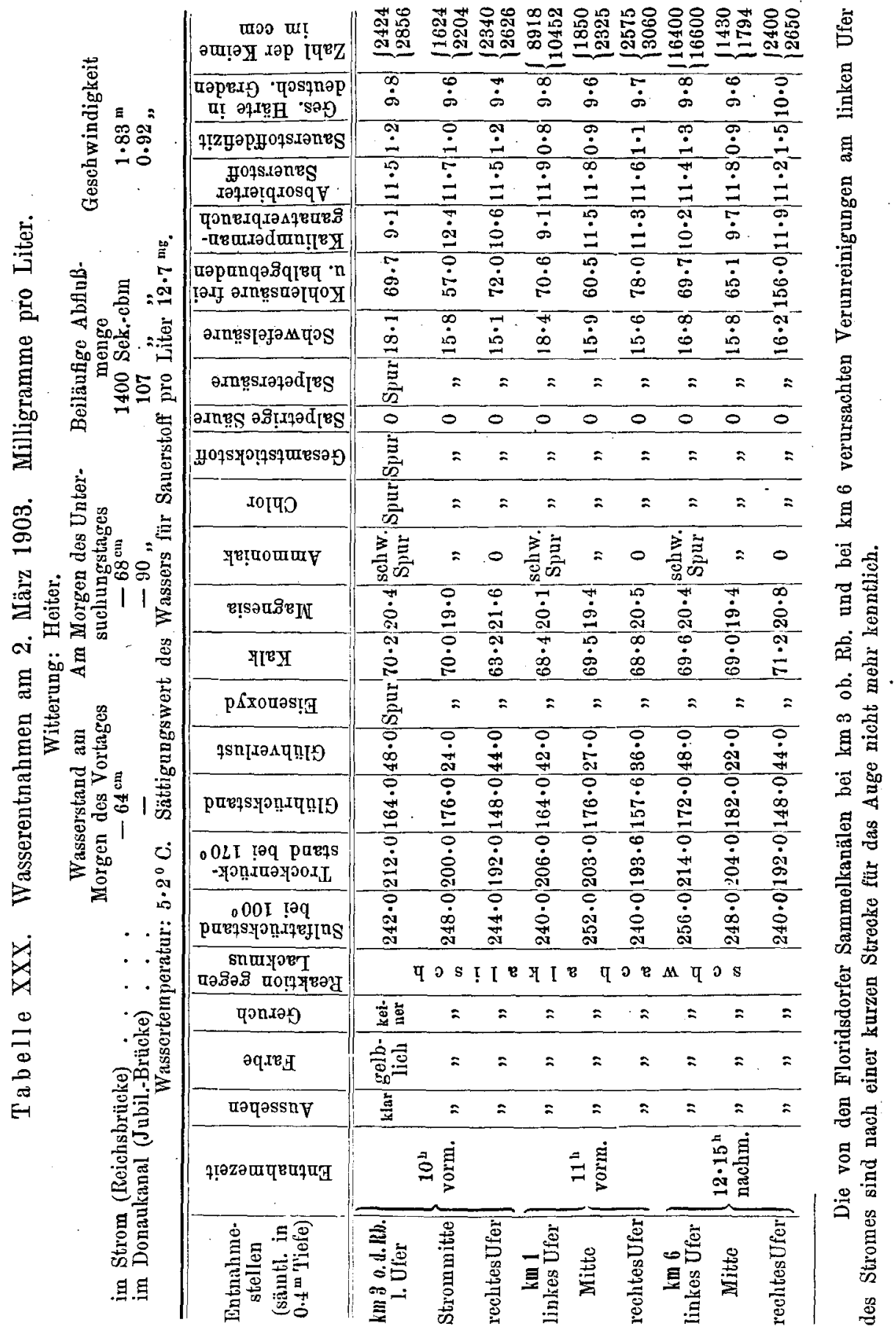




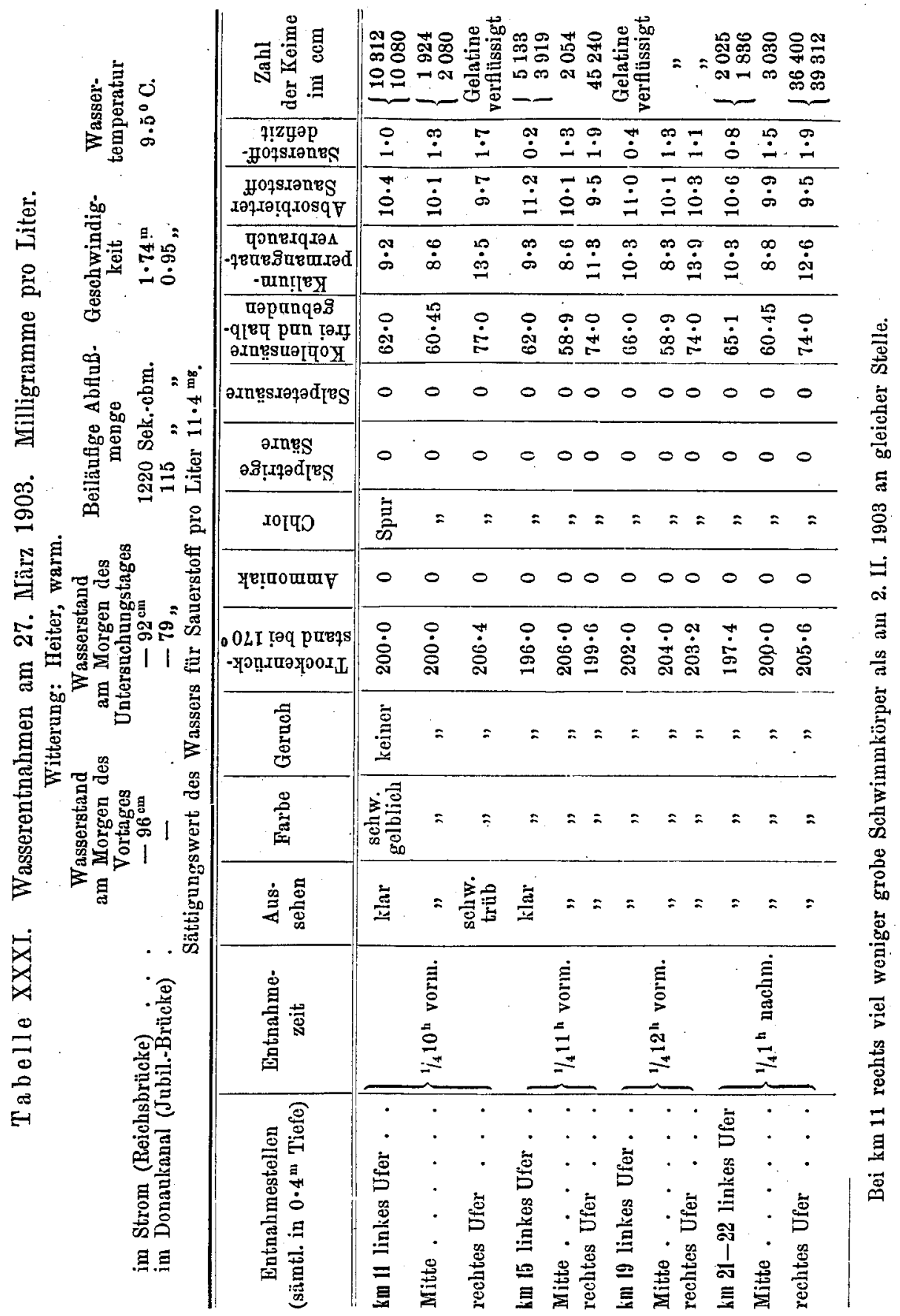




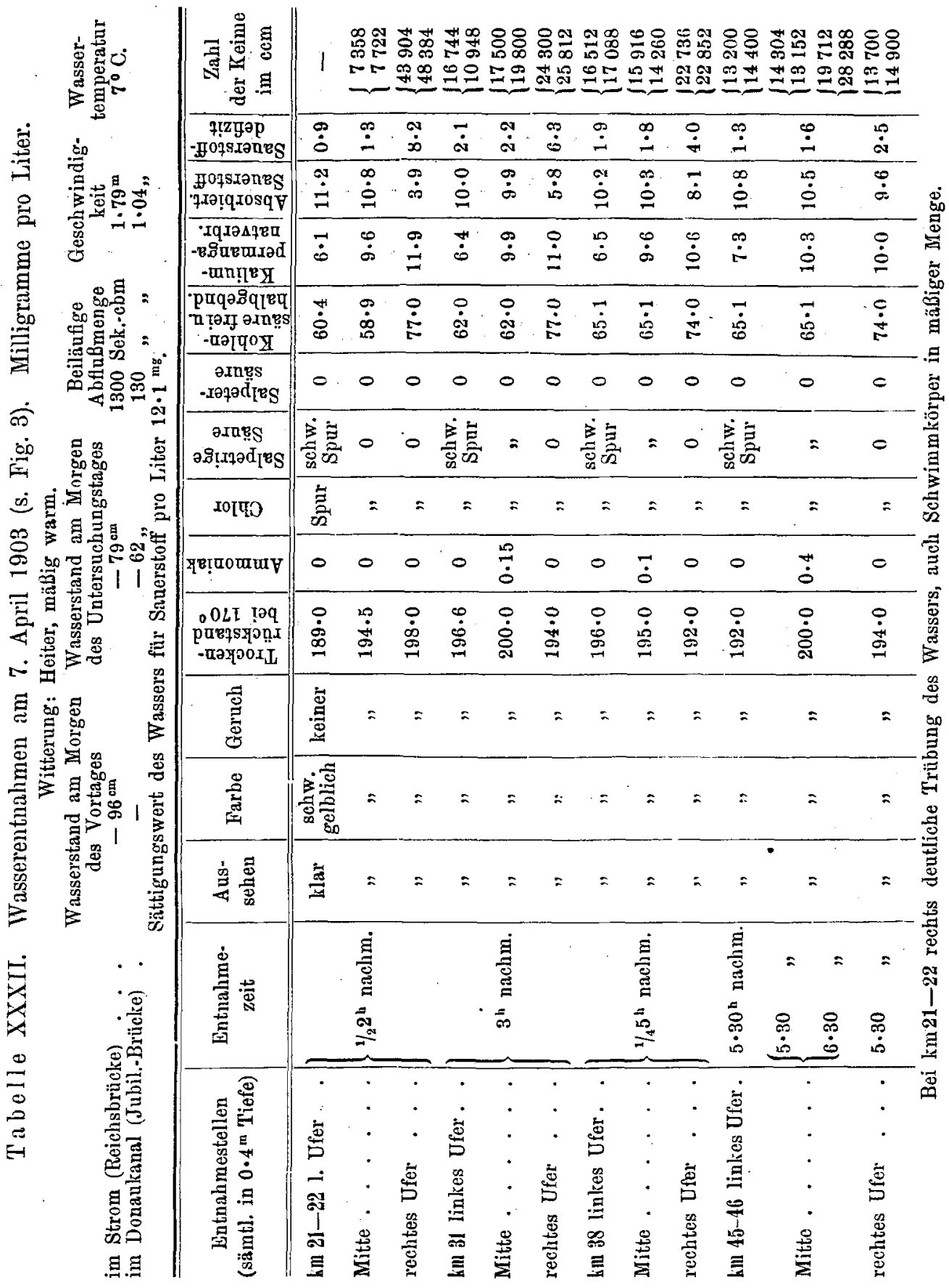




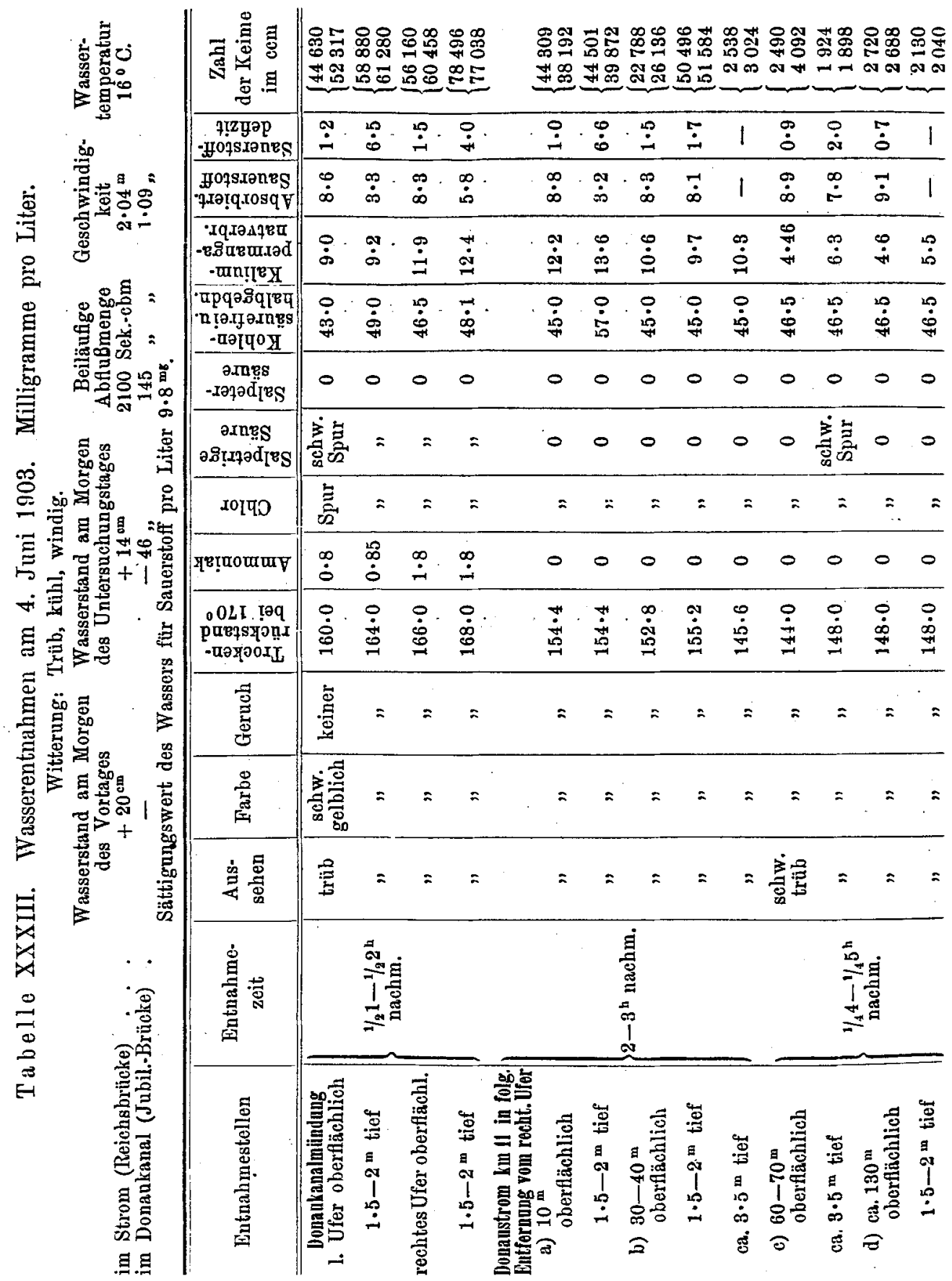




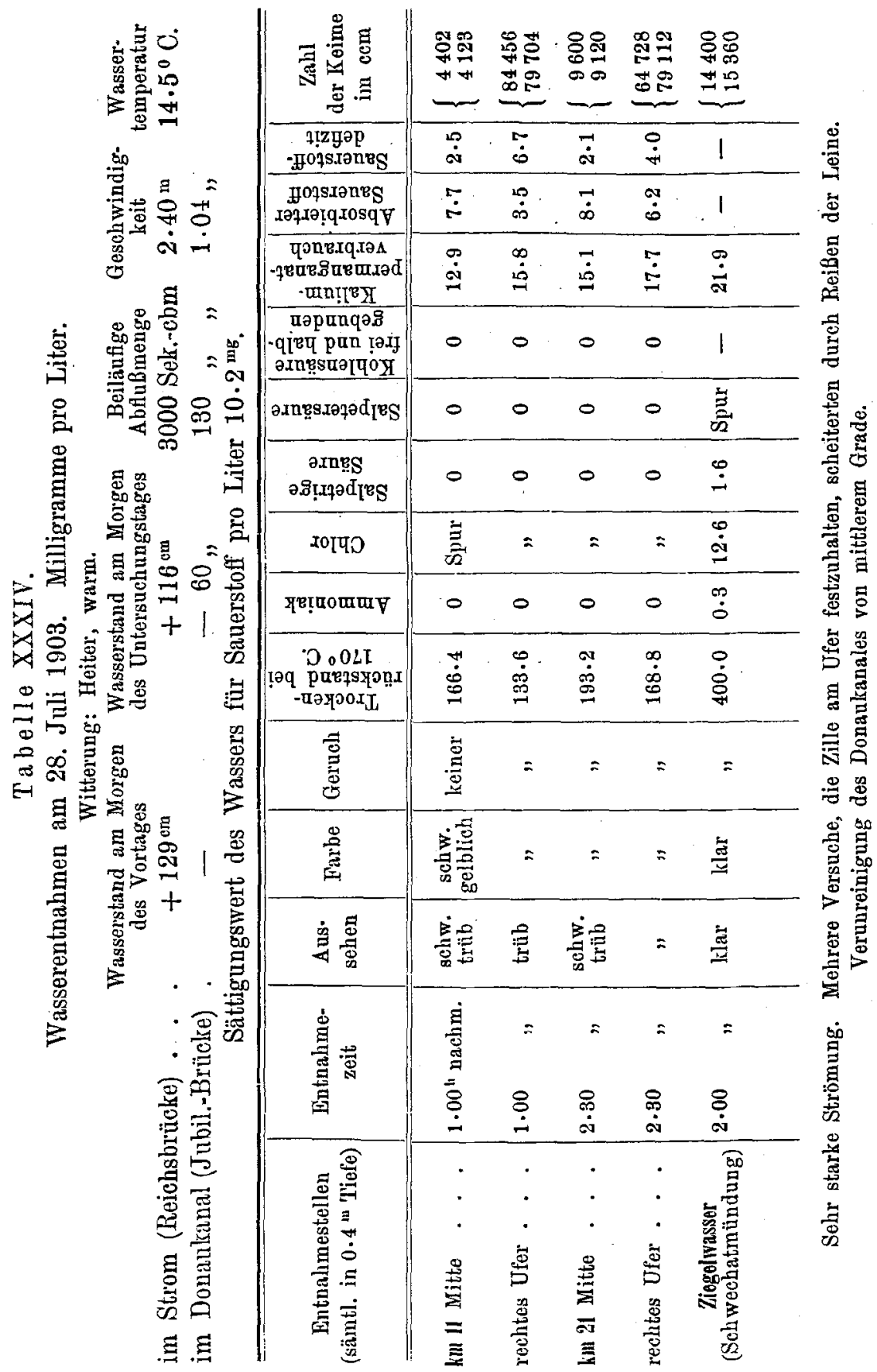




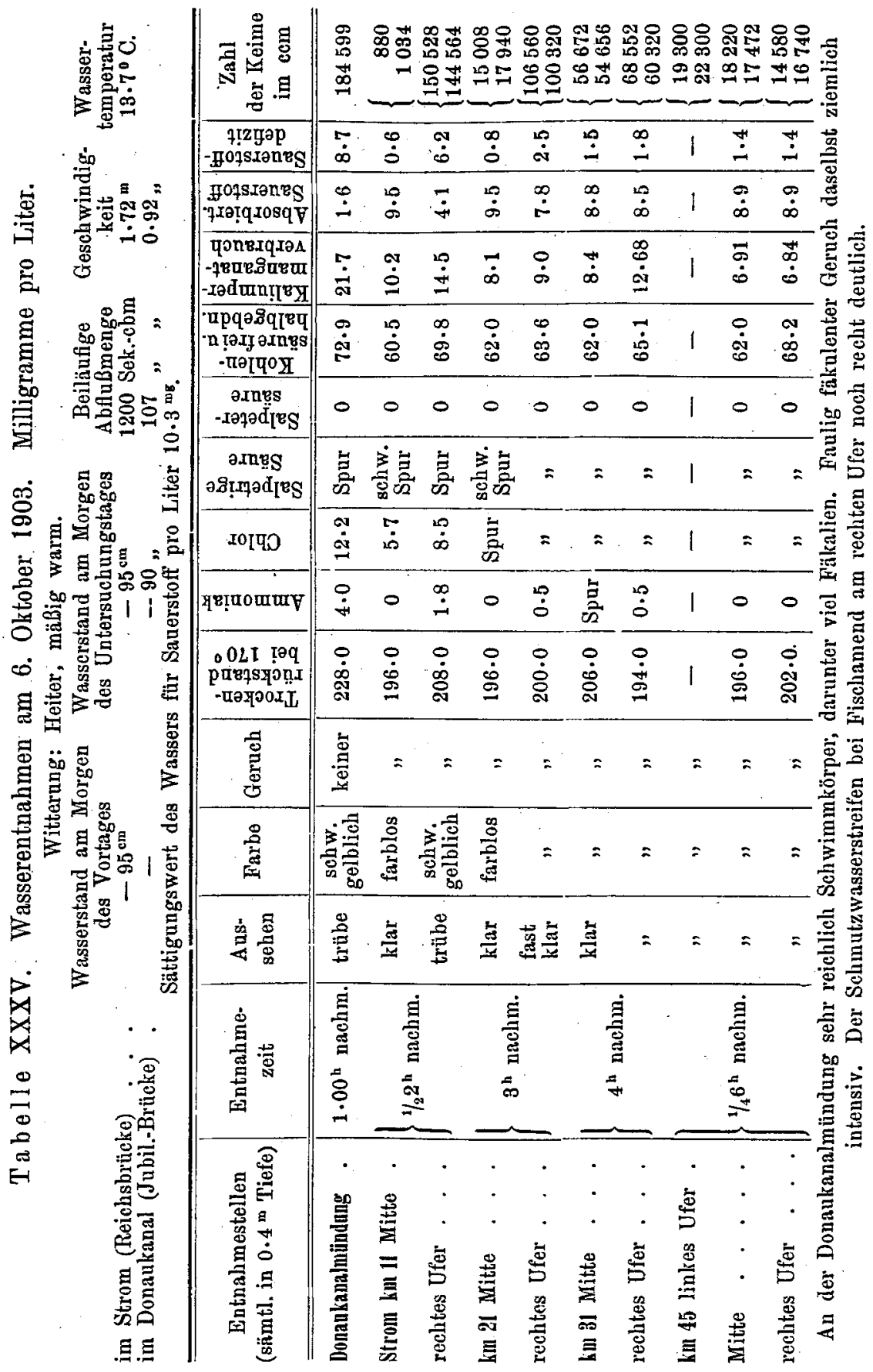




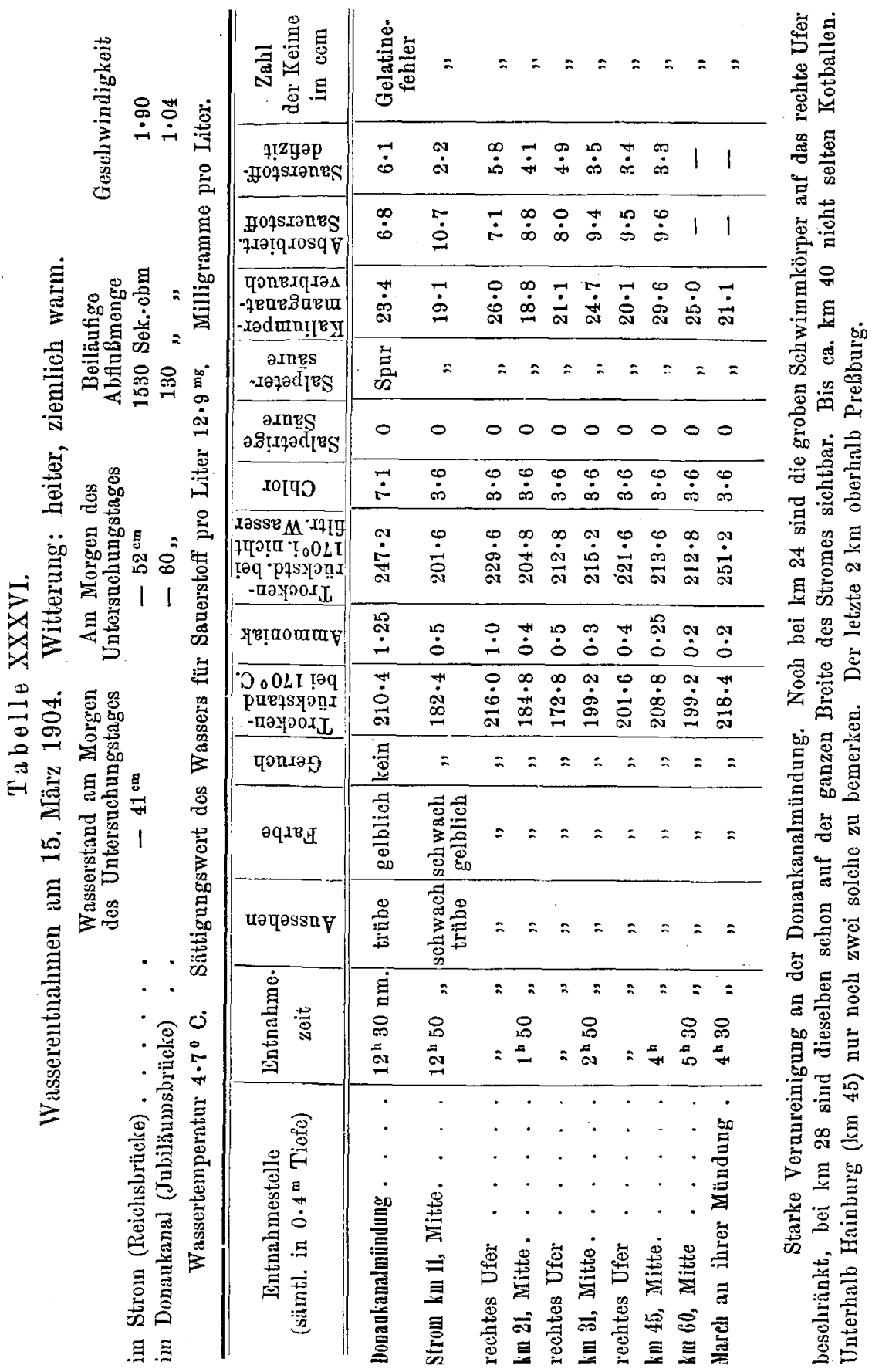




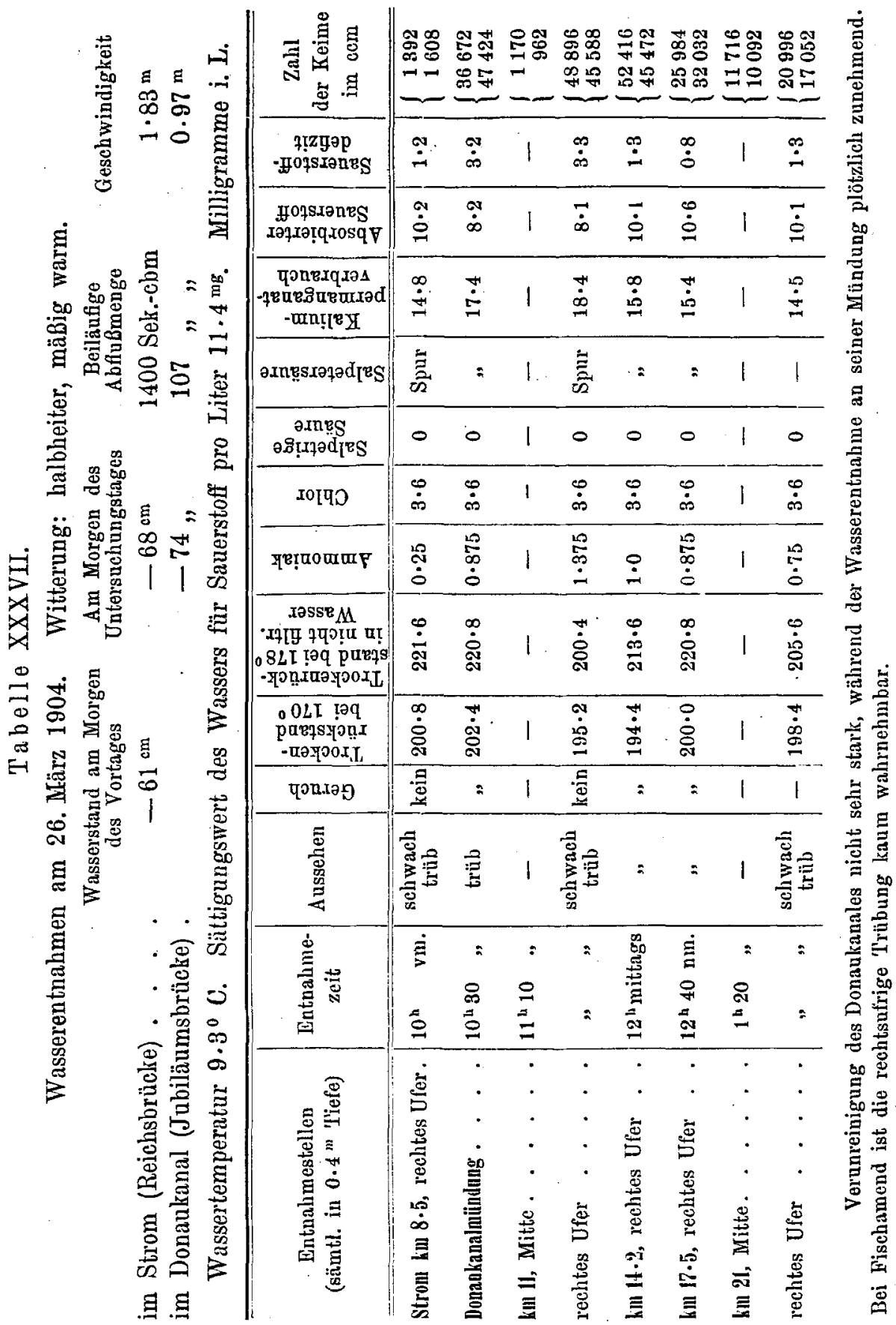




\section{Tabelle XXXVIII.}

Wasserentnahmen am 29. April 1904 (s. Fig. 4). Witterung: halbheiter. am Morgen

Wasserstand
am Morgen
des Vortages
Am Morgen
des Unter-
suchungstages

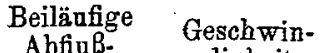
im Strom (Reichsbrücke) $+66^{\mathrm{cm}}$ $+70 \mathrm{~cm}$ 2570 Sek. $\cdot \mathrm{cbm}$ digkeit. im Donaukanal (Jubil.-Br.) 


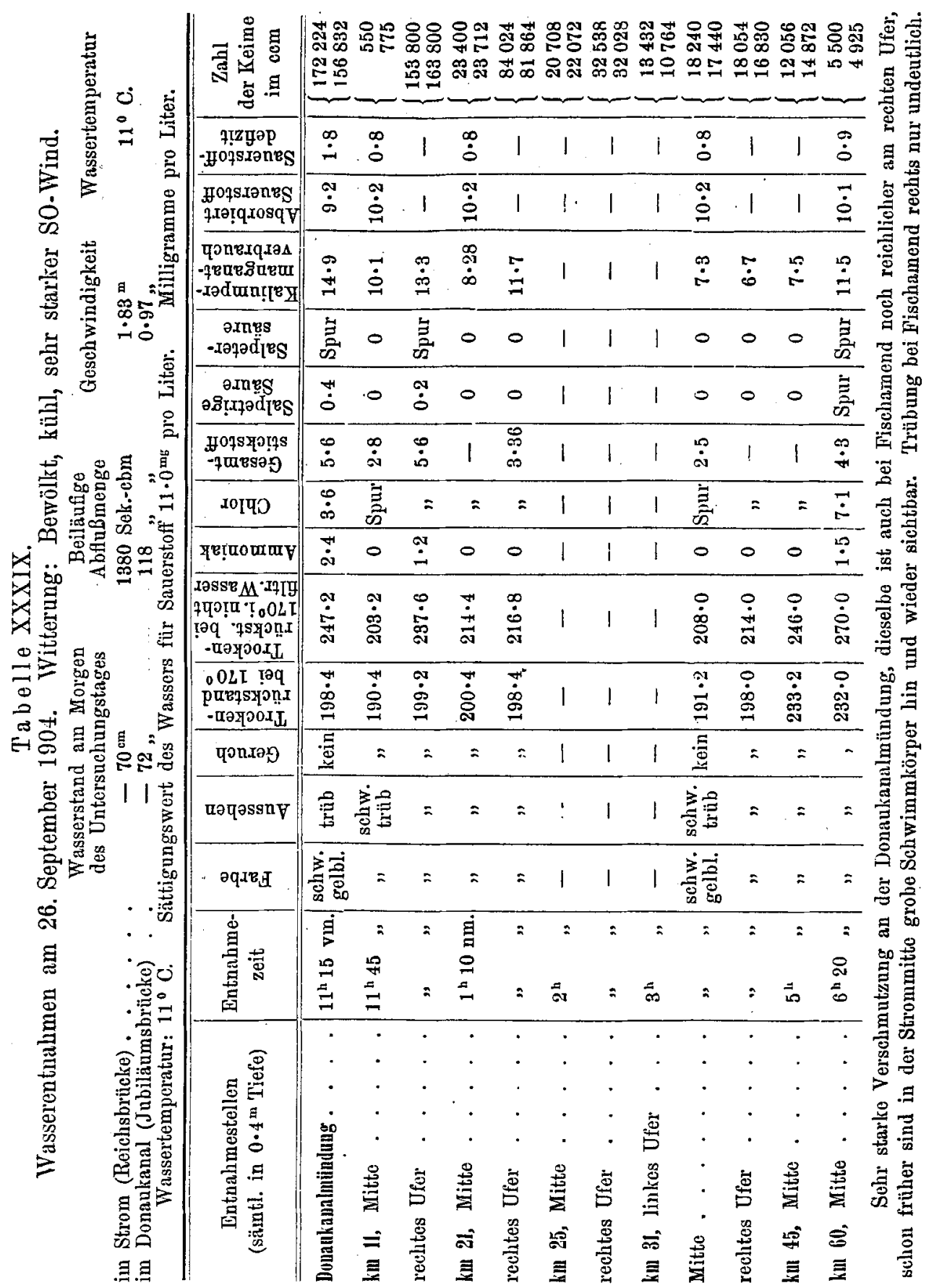


Tabelle XL.

Wasserentnahme am 21 bis 22.0 oktober 1904. Witterung: Klar, windstill. Wasserstand am Morgen des Untersuchungstages:

$$
\begin{aligned}
& \text { im Strom . . . . . }-19^{\mathrm{cm}} \\
& \text { im Donaukanal . . . . }-54 \text {, }
\end{aligned}
$$

Beiläufige Abflußmenge:

im Strom . . . . . . 1780 Sek.-cbm.

im Donaukanal . . . . 136 "

\begin{tabular}{|c|c|c|c|c|c|}
\hline $\begin{array}{l}\text { Entnahme- } \\
\text { stelle }\end{array}$ & $\mathbf{k m}$ & Profil & Tiefe & Entnahmezeit & $\begin{array}{c}\text { Zahl der Keime } \\
\text { im ccm }\end{array}$ \\
\hline \multirow[t]{6}{*}{$\begin{array}{l}\text { Donaukanal- } \\
\text { mündung }\end{array}$} & & \multirow[t]{6}{*}{$\begin{array}{l}\text { rechtes } \\
\text { Ufer }\end{array}$} & \multirow[t]{6}{*}{$0 \cdot 4^{\mathrm{m}}$} & $5^{\mathrm{b}}$ nachm. & $\begin{array}{l}146880 \\
144880\end{array}$ \\
\hline & & & & $5^{b} 30$ & $\begin{array}{l}154600 \\
149800\end{array}$ \\
\hline & & & & $6^{h}$ abends & $\begin{array}{l}149408 \\
130088\end{array}$ \\
\hline & & & & $6^{\mathrm{h}} 30$ & $\left\{\begin{array}{l}134992 \\
132704\end{array}\right.$ \\
\hline & & & & $7^{\mathrm{h}}$ & $\left\{\begin{array}{l}182112 \\
191600\end{array}\right.$ \\
\hline & & & & $7^{\mathrm{h}} 30$ & $\begin{array}{l}184200 \\
157000\end{array}$ \\
\hline \multirow[t]{5}{*}{ PreBburg } & \multirow[t]{5}{*}{60} & \multirow[t]{5}{*}{ Mitte } & \multirow[t]{5}{*}{$0 \cdot 4^{\mathrm{m}}$} & $1^{\text {h }} \overline{\jmath 0 \text { nachts }}$ & $\begin{array}{l}24900 \\
22200\end{array}$ \\
\hline & & & & $2^{\text {h }} 25$ & $\begin{array}{l}33720 \\
28800\end{array}$ \\
\hline & & & & $2^{\mathrm{h}} 50$ & $\begin{array}{l}25500 \\
27000\end{array}$ \\
\hline & & & & $3^{\mathrm{h}} 15$ & $\begin{array}{l}24000 \\
29640\end{array}$ \\
\hline & & & & $3^{\mathrm{h}} 40$ & $\begin{array}{l}30120 \\
27880\end{array}$ \\
\hline
\end{tabular}

Geschwindigkeit: $2.02^{\mathrm{m}}$ bzw. $1.05^{\mathrm{m}}$.

Verschmutzung des Donaukanales sehr stark, übler Geruch daselbst deutlich.

\section{A. Beobachtung mit freiem Auge.}

Gleich nach Einmündung des Donaukanales in den Strom fließen die beiden, durch ihre Farbe auch bei trübem Stromwasser voneinander unterschiedenen Wässer nebeneinander dahin, ihre Grenze ist zunächst scharf, nach kurzer Strecke beginnt sich zwar die scharfe Linie zu verwischen, doch sind die beiden Wasserarten bei Kilometer 11 noch unschwer durch ihre Farbe zu differenzieren. AuBerdem ist dort das Wasser am rechten Ufer noch fast ebenso reichlich mit groben Schwimmstoffen bedeckt, wie an 
der Donaukanalmündung. Der üble Geruch ist schwächer geworden, doch noch deutlich wahrnehmbar. Allmählich nehmen die Unterschiede ab, und unterhalb Fischamend bei Kilometer 21 ist die Verschiedenheit der

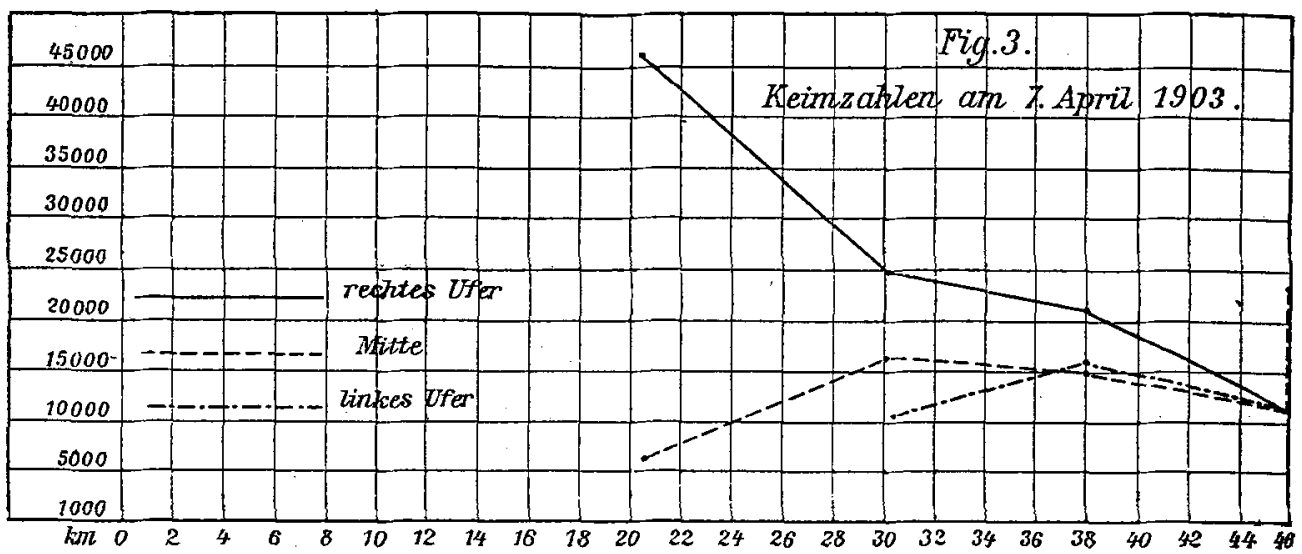

Wasserfärbung nur für das bereits geübte Auge erkennbar und nur dann, wenn das reine Stromwasser klar und das Donaukanalwasser ausgiebig verschmutat ist. Durch die Menge grober Schwimmstoffe dagegen ist das Wasser am rechten Ufer hier noch deutlich zu unterscheiden, außer etwa

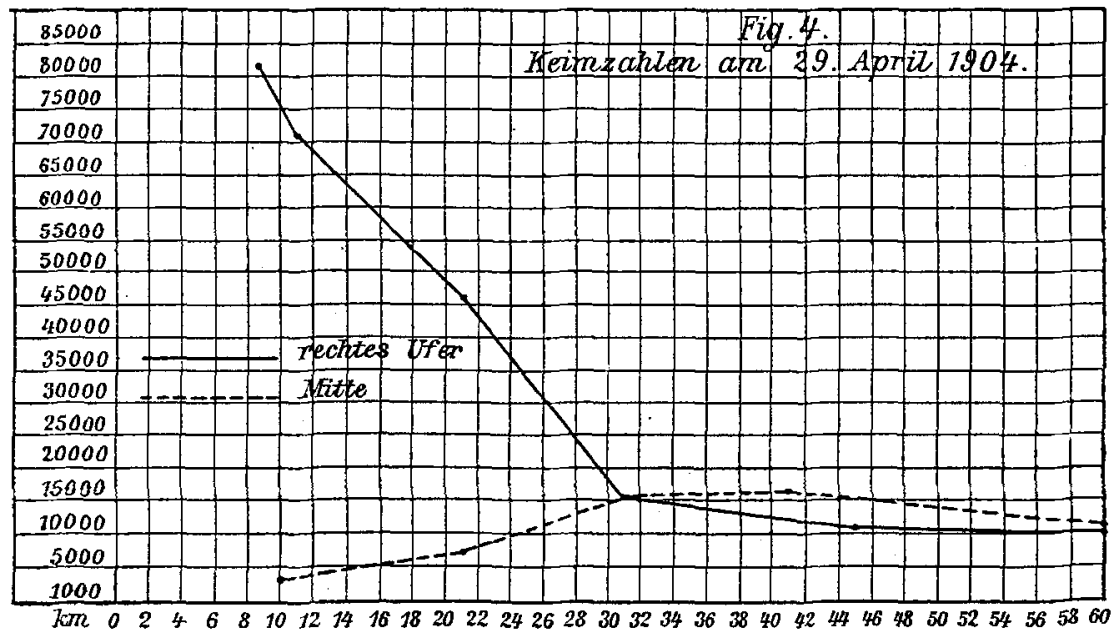

in den ersten Vormittagsstunden. Orangenschalen, Kotballen usw. wird man in der Strommitte hier meist noch vergeblich suchen. Unter den groben Schwimmkörpern haben die Kotballen die stärkste Abnahme erfahren. Bald unterbalb Kilometer 21 schreitet der Ausgleich der be- 
schriebenen Unterschiede zwischen dem Wasser des rechten Ufers und der Mitte des Stromes fort. Schon bei Kilometer 26 ist das Wasser seiner ganzen Breite nach gleichmäßig gefärbt, die den Sammlern entstammenden Schwimmkörper erscheinen auch in der Strommitte und bald darauf am linken Ufer, nehmen dabei an Zahl im gànzen ab, insbesondere werden die Kotballen immer seltener. Der üble Geruch, bei Kilometer 21 mitunter noch wahrnehmbar, verschwindet vollkommen. Bei Kilometer 31 fehlen alle grobsinnlich wahrnehmbaren Unterschiede innerhalb des Profiles, das Wasser [,Mischwasser"], ist von derselben Farbe und Klarheit wie das jeweilige Reinwasser. Von hier bis PreBburg erfolgt eine weitere Abnahme der groben Schwimmkörper, doch sind diese auch dort noch quantitativ und qualitativ von denen des Reinwassers vor der Einmündung des Donaukanales deutlich verschieden. Die Kotballen sind bei Hainburg schon recht selten, bei PreBburg gelang es mir auf 3 Fahrten im ganzen nur in einem Falle Kotballen zu beobachten. Schiffslente in PreBburg versicherten mir allerdings, daB sie solche oft genug zu sehen bekommen. Die absolute Verminderung der groben Schwimmstoffe wird durch einen Blick auf die Ufer und die Haufen đes Stromes erklärlich. Die leichten Korke finden sich massenhaft am rechten Ufer, viele Kilometer weit. Die schwereren Schwimmstoffe, wie Holz, Zweige, Früchte und deren Schalen, Salatblätter usw. lagern sich mit Vorliebe an günstig gelegenen Haufen, und zwar von Kilometer 26 angefangen auch am linken Ufer ab. Eine solche Hauptlagerstätte bemerkte ich am 7. April 1904 Hainburg gegenüber. Ein mehrere Meter breiter ziemlich langer Streifen Kies war mit derartigen, den Wiener Sammlern entstammenden Körpern geradezu besät. In solcher Mächtigkeit sind die Ablagerungen freilich nur nach länger dauerndem Niederwasser, also im Beginne des Frühjahres, zu sehen. Kotballen bemerkte ich nie an solchen Punkten. Ihr spezifisches Gewicht erschwert zweifellos das Auswerfen derselben, auch zerfallen sie bei Wellenschlag weit leichter als andere grobe Schwimmkörper. Sicher sind Kotballen als Ganzes durch ihren Gasgehalt in der Regel leichter als Wasser, ganze Kotballen sedimentieren daher gewöhnlich nicht, dies ist nur nach ibrem Zerfall bei einzelnen ihrer Bestandteile möglich. Der Zerfall der Kotballen findet im Strom mit seinem oft starken Wellenschlage im höheren MaBe statt als im Donaukanal und in den Sammlern.

B. Untersuchung der Flaschensedimente.

Das mikroskopische Bild des Bodensatzes ist bei Kilometer 11 rechts gleich dem an der Donaukanalmündung, doch ist das Sediment etwas minder reichlich und weniger viskös. Bei Kilometer 21 rechts haben die 
spezifischen Kanalkörper abgenommen, die Viskosität des Sedimentes ist weniger intensiv, aus den in der Strommitte geschöpften Wasserproben fällt ein ähnliches Sediment aus, wie aus den Reinwasserproben. Bei Kilometer 31 ist ein Unterschied zwischen Mitte und rechts nur mitunter noch angedeutet. Die Niederschläge sind in beiden Fällen etwas schleimig, am rechten Ufer vielleicht in etwas höherem Maße. Die spezifischen Körper aus den Kanälen sind selten, doch sind Gewebefasern, sowie auch Stückchen quergestreifter Muskulatur bei längerem Suchen oft noch zu finden. In einer mit dem Planktonnetze gewounenen Probe suspendierter Körper aus der Mitte bei Kilometer 31 waren sogar mehrere Muskelfasern zu entdecken. Bei Kilometer 45 und 60 sind die Niederschläge ähnlich den Sedimenten bei $\mathrm{km}$ 31, doch schon mehr bröcklig, an die aus dem Reinwasser erinnernd, aber immer noch andeutungsweise schleimig. Protozoen waren in allen Mischwasserproben reichlicher als im Reinwasser, desgleichen war Beggiatoa alba nachweisbar.

\section{Chemische Untersuchungen.}

Bei Kilometer 11 sind die Unterschiede zwischen dem rechten Ufer und der Strommitte (Reinwasser) noch fast ebenso deutlich wie die zwischen Donaukanalwasser und Reinwasser. Der Trockenrückstand ist rechts konstant um mehrere Milligramme größer, nur am 28. Juli 1903 war das Verhältnis umgekehrt. Die Ursache konnte nicht aufgeklärt werden. Ammoniak war rechts häufig in bestimmbarer Menge vorhanden, Chloride sehr häufig auch. Salpetrige und Salpetersäure fehlten am rechten Ufer des Stromes ganz oder fast ganz. [Nach der oben beschriebenen Beschaffenheit der Sammler war dieser Befund auch zu erwarten.] Die Gesamtstickstoffmenge dagegen war am rechten Ufer eine gröBere. Stets verbrauchte das rechtsufrige Wasser pro Liter um mehrere Milligramme mehr Kaliumpermanganat zur Oxydation der organischen Substanzen. Auch das Sauerstoffdefizit war rechts stets größer, der Unterschied war oft erheblich. Die Größe aller dieser Unterschiede war jedoch an den einzelnen Tagen verschieden, bald war für diesen, bald für jenen Stoff die Differenz zwischen Mitte und rechts gröBer. Die Unterschiede waren im ganzen beträchtlicher bei niederem Pegelstande und in den späteren Tagesstunden, wenn nämlich viel konzentriertes Sammlerwasser sich einer rerhältnismäBig geringeren Reinwassermenge zumischte, doch lieBen sich damit allein die Verschiedenheiten der Befunde nicht erklären, es müssen noch andere Ursachen, vor allem wohl die nicht periodischen Schwankungen in der Zusammensetzung des Sammelkanalwassers und andere Momente hierfür mabgebend sein. Verschieden groB waren insbesondere die Differenzen des Sauerstoffdefizits, indem dieses bei den Schmutzwasser- 
proben mitunter ein vielfaches der für das Reinwasser gefundenen ausmachte, mitunter nur wenig - doch stets deutlich - höher war als dieses.

Bei Fischamend war der Chlorgehalt des Wassers an allen Stellen des Profiles stets gleich. Die gefundenen Chlormengen waren entweder quantitativ nicht bestimmbar, oder sie betrugen nicht mehr als $3.6 \mathrm{mg}$ pro Liter. Auch Ammoniak zeigte nur mitunter geringe Unterschiede. Der Trockenrückstand pro Liter Wasser war in der Mehrzahl der Fälle rechts, mitunter aber in der Mitte größer. Dagegen verbrauchte das rechtsufrige Wasser immer noch mehr Kaliumpermanganat und hatte auch ein größeres Sauerstoffdefizit.

Es muß betont werden, daß alle die genannten Unterschiede, selbst die zwischen dem Wasser an der Donaukanalmündung und dem Reinwasser nur dann zu beobachten sind, wenn man die bei jeder einzelnen Fahrt für sich gewonnenen Befunde untereinander vergleicht. Die Reinwasserzahlen einzelner Tage sind jedoch höher als die rechtsufrigen, ja sogar höher als die Donaukanalzahlen an anderen Tagen. Besonders gilt dies für den Trockenrückstand des Wassers und seinen Gehalt an organischer Substanz.

Bei Kilometer 31 sind die Unterschiede zwischen Mitte und rechts schon verwischt, man findet im Einzelfalle bald da, bald dort um einige Milligramme mehr Trockenrückstand. Für die Chlormenge gilt das gleiche wie bei Fischamend. Ammoniak war hier schon selten quantitativ bestimmbar.

Der Verbrauch von Kaliumpermanganat und das Sauerstoffdefizit mögen hier im ganzen vielleicht noch ein geringes Überwiegen der Verunreinigung am rechten Ufer (großes Sauerstoffdefizit rechts am 7. April 1903) zeigen. Bei Kilometer 45 und 60 aber war von einer größeren Verschmutzung am rechten Ufer so wenig mehr die Rede, daB ich der Einfachheit halber mich bei den späteren Fahrten für chemische Untersuchungen auf eine Entnahme in der Strommitte beschränken konnte.

Aus dem eben Gesagten läßt sich schon voraussehen, was für Unterschiede das Wasser an homologen Stellen der Profile (bei jeder einzelnen Fahrt für sich) aufweist.

Am rechten Ufer war stets eine allmähliche Abnahme der Verschmutzung unverkennbar, trotz einzelner gegenteiliger Befunde; diese beziehen sich jedoch immer nur auf einen oder den anderen Stoff und sind bei der schwankenden Zusammensetzung des Rein- und Schmutzwassers leicht begreiflich. Umgekehrt zeigte sich in der Strommitte eine Zunahme der Verschmutzung, welche freilich relativ geringer ist als die Abnahme am rechten Ufer, da sich eine kleine Menge schmutzigen mit einer großen Menge reinen Wassers mischt. Deutlich ist diese zunehmende 
Verschmutzung in der Strommitte nur, wenn man in größeren Distanzen geschöpfte Wasserproben miteinander vergleicht. Innerhalb kurzer Strecken tritt der Vorgang nicht immer klar zutage, am deutlichsten wohl für den Trockenrückstand und das Sauerstoffdefizit. Chlor dagegen hat die Tendenz, sich schon anfangs rasch über die ganze Profilbreite gleichmäBig zu verteilen und zeigte daher diese Zunahme in der Strommitte weiter unten nickt. Auch beim Ammoniak ist dies nur mitunter der Fall.

Das Wasser der Strommitte war bei Preßburg am 29. September 1904 (Tabelle XXXIX) chemisch ungemein verschmutzt. Aus äuBeren Gründen (Dunkelheit, Eile wegen rechtzeitigen Erreichens des Zuges, gleichzeitige Entnahmen zu anderen Zwecken) wurde damals auf die Lage der Schöpfstelle im Profil für die chemische Untersuchung zu wenig Rücksicht genommen. Vermutlich fand die betreffende Entnahme an einem Punkte des Stromes statt, der bereits unter dem Einflusse eines PreBburger Sammelkanales stand, also zu weit links und stromabwärts. Die knapp vorher gemachte Entnahme für Keimzählung zeigte die Spuren einer derartigen Verschmutzang nicht,. die Verunreinigung muB also eine frisch dem Strom beigemengte, räumlich beschränkte gewesen sein. Der Befund ist daher nicht geeignet das durch die übrigen Analysen geschaffene Bild zu modifizieren.

Die Mengen der freien und halbgebundenen Kohlensäure waren an der Donaukanalmündung und am rechten Ufer bedeutend größer als in der Strommitte und links. Da die Sammler keine sehr große Menge freier und halbgebundener Kohlensãure führen (s. o.), müBte ihr Zuwachs im Donaukanal, mit Rücksicht auf die eintretende Verdünnung berechnet, nur wenige Milligramme betragen, im Mischwasser verschwindend gering sein. Die tatsächlich gefundene Zunahme am rechten Ufer des Stromes ist jedoch bedeutend gröBer. Sie ist auch in Hainburg, also im Mischwasser, noch ebenso ausgesprochen, wie bei Kilometer 11, aber auch hier auf das rechte Ufer beschränkt. Übrigens ist der Mehrgehalt an freier und halbgebundener Kohlensäure am rechten Ufer des Stromes schon oberhalb der Mündung des Donaukanales angedeutet. Die Sammelkanäle können daher nicht Ursache dieses Befundes sein. Lokale, dem rechten Donauufer entlang wirkende Verhältnisse müssen diese eigentümliche Tatsache bedingen. Dieselbe muB hier unerklärt bleiben, ist jedoch mehr für den Geologen und Hydrographen von Interesse. DaB auch nicht etwa nachträglich auftretende Entwicklung freier Kohlensäure aus den dem Strome beigemischten Schmutzstoffen durch Zersetzung organischer Substanz Ursache des Befundes sein kann, ist nach dem eben Gesagten verständlich. 


\section{Keimzahlen.}

Während, wie oben erwähnt, der Bakteriengehalt der Sammler für die Beurteilung des Zustandes der Abwässer wenig geeignet ist, gibt es keine Methode, welche Unterschiede in der Beschaffenheit des Stromwassers so klar und mit solcher Feinheit und Konstanz zum Ausdruck brächte, wie die Keimzählung. Schon Heider hat auf die Überlegenheit dieser Methode gegenüber der chemischen Untersuchung aufmerksam gemacht. Die Keimzallen an der Donaukanalmündung und am rechten Ufer des Stromes sind stets vielfache der Reinwasser-Keimzahlen. Auch bei Kilometer 21 sind sie am rechten Ufer noch um vieles höher als in der Strommitte. Die geringste Differenz daselbst war am 26. März 1904 (Tabelle XXXVII, Keimzahlen am rechten Ufer knapp doppelt so groß als in der Strommitte).

Einer vollkommenen Änderung der VerhäItnisse begegnen wir an der Entnahmestelle bei Kilometer 31. Hier sind die Keimzahlen rechts gar nicht oder nur wenig höher als in der Mitte. Die Verteilung der Keime im Wasser bei Hainburg war vollkommen gleichmäßig, die Differenzen der zur gleichen Tageszeit gefundenen Zahlen lagen innerhalb der Fehlergrenze der Methode. Die rechtsufrigen Keimzahlen von der Donaukanalmündung an für sich betrachtet, werden siromabwärts zu immer kleiner, die Differenzen von einer Entnahmestelle zur anderen sind verschieden groB. In der Strommitte steigt umgekehrt die Keimzahl an und erreichte bei drei Fahrten ihren höchsten Wert bei Kilometer 31, in einem Falle aber schon unterhalb Fischamend bei Kilometer 21. Hierauf folgt ein konstantes Fallen der Keimzahlen stromabwärts zu. Die wenigen für das linke Ufer vorliegenden Befunde ergaben zunächst eine durch allmähliche Verteilung der Floridsdorfer Abwässer bedingte Abnahme 'der Keimzahlen, doch sind diese bei Kilometer 11 links noch höher als in der Strommitte. Es folgt eine mäßige Zunahme der Bakterienmenge zwischen Kilometer 21 und 31, herrorgerufen durch gleichmäBige Verteilung des Schmutzwassers vom rechten Ufer aus über die ganze Breite des Profils. Von hier ab verhalten sich die Keimzahlen am linken Ufer ebenso wie an den übrigen Stellen des Profils. Im allgemeinen waren sämtliche bakteriologische Befunde einander ähnlich, in bezug auf Einzelheiten zeigten sich jedoch manche Verschiedenheiten, diese bedürfen der Erklärung: Bei den großen Schwankungen in der Verschmutzung des Stromes innerhalb je 24 Stunden muBten Unterschiede zwischen den Geschwindigkeiten des Bootes und des Wassers an den Keimzahlen deutlich zum Ausdrucke kommen.

Am 6. Oktober 1903 ( $\mathrm{Tab} \cdot \mathrm{XXXV}$ ) war die Geschwindigkeit des Bootes eine $z \mathfrak{u}$ groBe gewesen. Bis unterhalb Kroat.-Haslau hatte sich. das Boot 
in ziemlich verschmutzten Wasserschichten bewegt. Fin Blick auf die graphischen Darstellungen der Sammlerbefunde vom 18. bis 19. Januar 1904 macht dies sofort verständlich. Von da ab war aber die Zille dem Strome weiter voraneilend in Wasser geraten, welches nur durch Morgenabwässer, also relativ wenig verunreinigt war. Daher die große Zunahme der Keimzahlen in der Strommitte von Kilometer 21 bis 31, gefolgt von einem ebenso starken Abfall bei Kilometer 45; analog war auch die Abnahme der Oxydierbarkeit zwischen den beiden letztgenannten Entnahmestellen. Ein merkwürdiges Verhalten zeigen die Keimzahlen rom 26. September 1904 (Tabelle XXXIX). Schon von Fischamend abwärts war eine allgemeine $A b-$ nahme der Keime zu sehen. Die Keimzahlen bei Hainburg und Preßburg, am 29. April 1904 (Tabelle XXXVIII) einander gleich, zeigen einen großen Unterschied zuungunsten der Preßburger Zahlen. Wassermischung kaun dies natürlich nicht verursacht haben, ferner war das Boot an diesem Tage der mittleren Geschwindigkeit des Stromes für den damaligen Wasserstand nicht vorausgeeilt, sondern eher etwas zurückgeblieben (Tabelle XVII). An diesem Tage herrschte jedoch ein ungemein heftiger, stromanfwärts und dabei etwas vom rechten Ufer gegen die Mitte gerichteter Wind. Nur durch kräftiges Rudern konnte das Boot vorwärts gebracht werden. Offenbar hatte also der Wind die oberen Wasserschichten mindestens bis zu der gewöhnlichen Entnahmetiefe von $0.4^{\mathrm{m}}$ derart aufgehalten, daB ich auf der Fahrt sukzessive in weniger verschmutzte Wasserschichten gelangte. Auf den gleichen Grund ist es wohl zurückzuführen, daB an diesem Tage schon etwas oberhalb Fischamend grobe Schwimmkörper in der Strommitte zur Beobachtung gelangten, was sonst nie der Fall war. Uber den EinfluB des Windes auf die Verteilung des Wassers s. Holst usw. (38).

Die im Mischwasser gefundenen Keimzahlen waren stets vielfache der Reinwasserzahlen vom gleichen Tage.

E. Die feinen bis mikroskopischen suspendierten Bestandteile.

Unter A. war von den groben Schwimmkörpern die Rede, deren Natur von weitem ohne eigene Untersuchung erkennbar ist. Die quantitative Bestimmung solcher Körper in einem Strome ist nicht möglich. Bei ihrer ungleichen Verteilung auf der Wasseroberfläche wären hierzu Rechen zum Auffangen derselben während längerer Zeit nötig, eine in einem öffentlichen Wasserlaufe nicht anwendbare Methode. Die wiederholte genaue Beobachtung der Wasseroberflāche genügte aber, um von der Menge und Verteilung der groben Schwimmstoffe ein Bild zu erhalten. AuBerdem enthält jedoch das Wasser jederzeit suspendierte Stoffe 
ron größerem oder geringerem Volumen, welche den Klarheitsgrad des Wassers mit bedingen. Nach zahlreichen vergeblichen Versuchen ein Verfahren zu finden, nach dem diese Körper quantitativ bestimmt werden könnten, führte dieselbe Methode zu einem leidlichen Resultate, welche bereits bei der Beschreibung der Sammleruntersuchungen angegeben ist. Das RoBhaarsieb von $1 / 4{ }^{\mathrm{qmm}}$ MaschengröBe, welches dort zur Benutzung gelangte, wurde auch beim Donaukanal gebraucht, für den Strom dagegen kamen Seidensiebe von ${ }^{1 / 33} \mathrm{gmm}^{\mathrm{mm}}$ Maschengröße in Verwendung. Durch diese letzten Siebe sollten alle eben noch mit freien Auge sichtbaren Schwebestoffe zurückgehalten werden. Im Donaukanal war ihre Benützung wegen allzu schleimiger Beschaffenheit der Suspensa ausgeschlossen. Tabellen XLI und XLII zeigen die Resultate der Untersuchungen.

Tabelle XLI.

Trockengewicht der Siebrückstände aus ea. 60 Liter Wasser. 15. März 1904. (Schwebestoffe.)

Donau Kilometer 9 bis 10 (Reinwasser) . $0.0404 \mathrm{grm}$ Donaukanalmündung linkes Ufer . . . . 0.3668 Donan Kilometer 11 reahtes Jfer. Donan Kilometer 11 rechtes Ufer. . . . $0.3226, " 1 / 33$ ", Donau Kilometer $21 \quad " \quad$ " . . . . $0.0622, " 1 / 33$ " Donau Kilometer $31 \quad " \quad$ " . . . . $0.0453, " 1 / 33$, Donau Kilometer $45 \quad " \quad, . .9 .0 .0538, " 1 / 33 "$

Tabelle XLII.

Trockengewicht der Siebrückstände aus ca. 60 Liter Wasser. 26. März 1904.

(Schwebestoffe.)

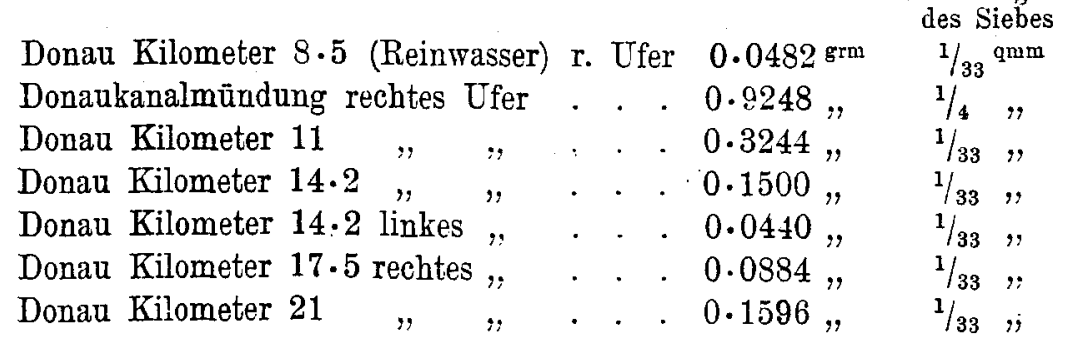

Um Durchschnittszahlen zu erhalten, wurde der früher beschriebene Apparat an jeder Entnahmestelle $6 \mathrm{mal}$ mit Wasser gefüllt und der Inhalt aufgegossen, in jedem Falle also etwa 60 Liter durch das Sieb geschickt. Eine verhältnismäßig lange Zeit war für diesen Vorgang nötig. Auch mußten dabei mehrere Personen zugreifen. Daher konnten die Entnahmen 
nur am Ufer $\left(10^{\mathrm{m}}\right.$ weit) gemacht werden, während die Zille am Seile festgehalten wurde. Der Gehalt des Reinwassers an solchen Suspensis muBte deshalb. statt in der Strommitte am rechten Donauufer oberhalb der Donaukanalmündung bestimmt werden. In der Strommitte wäre die Menge der Suspensa vielleicht noch etwas geringer gewesen. Von einer häufgen Wiederholnng der Versuche wurde abgesehen, denn die auf den zwei Fahrten gewonnenen Befunde stimmten gut miteinander überein, besonders wichtige Aufschlüsse über die Beschaffenheit des Donauwassers waren weiter nach dieser Methode nicht zu erwarten, und der zur Durchführung der Versuche nötige Apparat war kompliziert und unbequem transportierbar. Die Siebe mit den nassen Rückständen wurden unter sorgfältigem Vermeiden jedes Verlustes heimbefördert, die Rückstände dann getrocknet und gewogen. Der Gehalt des Reinwassers an Siebrückständen war in beiden Versuchen fast gleich, bei Kilometer 11, rechts war deren Menge in beiden Fällen viel bedeutender, noch größer aber war er an der Donaukanalmündung, obwohl dort jenes gröbere Sieb zur Anwendung kam. Die Unterschiede zwischen Rein- und Schmutzwasser sind bei dieser Methode viel mehr in die Augen fallend als nach den chemischen Befunden. Diese bedeutenden Mengen an Siebrückstand am rechten Ufer nehmen aber stromabwärts zu bald stark ab. Nach kurzer Strecke ist gegenüber dem Reinwasser ein wesentlicher Unterschied nicht mehr vorhanden, obwohl hier sogar die chemische Untersuchung, öfters auch die Klarheit des Wassers noch deutliche Differenzen zeigten. Die Ursachen, welche die allmähliche Reinigung des rechtsufrigen Wassers bewirken, genügen also nicht, um diesen auffälligen Befund zu erklären. Die rasche Abnahme der Siebrückstände muB einen anderen Grund haben. Sedimentierung kann aus später zu erörternden Gründen nicht dafür verantwortlich gemacht werden. Es ist nun wahrscheinlich, daß nicht allein die Größe der suspendierten Partikeln für deren Verbleiben auf dem Siebe maBgebend ist, sondern auch deren Konsistenz. Auch kleine, jedoch von einer Schleimschicht umgebene Fetzchen aus verschmutzten Wasserproben werden auf dem Siebe zurückgehalten, weiter stromabwärts, wo die Schwebestoffe ihre schleimige Beschaffenheit z. T. verloren haben, werden gleichgroße Suspensa durchgeschwemmt. Die Unterschiede sind daher wohl teilweise auf mechanische Verhältnisse zurückzuführen. Für diese Auffassung spricht auch die bereits erwähnte Beobachtung über die verschieden stark schleimige Beschaffenheit der Bodensätze in den Flaschen. Ferner wurden auch Versuche, das Plankton aus dem Donaukanal mit dem Planktonnetze zu gewinnen, öfters durch Verstopfung des ziemlich weiten Netzabflubkanales aus dem gleichen Grunde erschwert, was schon früher erwähnt wurde. 
Die Beschaffenheit des Schmutzwassers und Mischwassers in verschiedenen Tiefen wurde an 3 Tagen untersucht und zwar am 2. Febr. 1903 (Tabelle XXVIII) und am 4. Juni 1903 (Tabelle XXXIII) chemisch und bakteriologisch, am 29. April 1904 (Tabelle XXXVIII) nur bakteriologisch.

Die Keimzahlen waren knapp unter dem Wasserspiegel im Schmutzwasser kleiner als in der Tiefe. Ungewöhnlich ausgesprochen war die Differenz am 2. Februar 1903 bei Kilometer 11 rechts. Zwischen den Keimzahlen der gewöhnlichen Entnahmetiefe von $0.4^{\mathrm{m}}$ und denen in größerer Entfernung vom Wasserspiegel besteht kein Unterschied mehr.

Die relative Bakterienarmut des Schmutzwassers dicht unter dem Wasserspiegel kann daher nicht auf ein Niedersinken der Bakterien mit ihren Nahrungszentren, den Schwebestoffen, zurückgeführt werden. Vielleicht ist daher der zerstörende EinfluB des Lichtes auf die Keime an der Wasseroberfläche im Sinne Buchners Ursache dieses Befundes. Kruse (34), v. Rigler (30) und Prausnitz (4, 28), haben ähnliche Beobachtungen gemacht.

Umgekehrt kann die hohe Keimzahl bei Preßburg in $0.4^{\mathrm{m}}$ Tiefe am 22. Oktober 1904 nachts auf den Wegfall jeder Lichtwirkung auf der Strecke Wien-PreBburg in den Abend- und Nichtstunden bezogen werden (Tabelle XL).

Am 2. Februar 1903 wurde bei Kilometer 11 rechts etwa $\mathbf{3 . 5}$ m unter der Wasseroberfläche wieder keimärmeres Wasser gefunden. Es scheint sich daher der verschmutzte Inhalt des Donaukanales nach seiner Einmündung in den Strom zunächst dem Reinwasser aufzulagern. Die Mischung der Wässer geht auch in vertikaler Richtung nur langsam vor sich. Am letztgenannten Untersuchungstage herrschten nun sehr niedrige Wasserstände. Es wurde daher offenbar mit dem Entnahmeapparat die rom Schmutzwasser gebildete Schicht durchdrungen und aus dem weiter unten fließenden relativ reinen Wasser geschöpft. Das Sauerstoffdefizit im Schmutzwasser knapp unter der Oberfläche ist kaum größer als im Reinwasser. Der Befund ist nicht überraschend, da der verbrauchte Sauerstoff hier jederzeit aus der atmosphärischen Luft sofort ersetzt werden kann. Mit Rücksicht auf die kleineren Keimzahlen könnte auch der Sauerstoffverbrauch selbst hier geringer sein. Differenzen in der chemischen Beschaffenheit des Wassers in verschiedenen Tiefen wurden nicht beobachtet.

Die zahlreichen Wasserentnahmen am 4. Juni 1903 bei Kilometer 11 wurden vorgenommen, um die Beziehungen zwischen Rein- und Schmutzwasser an dieser Stelle genau kennen zu lernen. Leider war der Wasserstand an diesem Tage nicht besonders niedrig, und daher die Strömung 
ziemlich stark. Die Distanzen der einzelnen Entnahmestellen vom rechten Ufer - ohnehin nur nach Schätzungen bestimmt, - konnten danach nur ganz beiläufig eingehalten werden, ferner war es nicht möglich aus dem Wasser nahe dem FluBboden Entnahmen zu machen. Dennoch wurde durch diese Untersuchung die schon durch den Augenschein gewonnene Uberzeugung in exakter Weise begründet, daB der Inhalt des Donaukanales hier, $1^{\mathrm{km}}$ unterhalb seiner Ausmündung, noch eine vom Reinwasser ziemlich scharf gesonderte Wassermasse bildet, und daB eine seitliche Ausbreitung des Schmutzwassers hier noch nicht stattgefunden hat, höchstens nach der Tiefe zu. Die Verdünnung des Schmutzwassers ist bei Kilometer 11 daher nur gering.

\section{Untersuchung nach anderen Methoden.}

Zur Ergänzung der vorliegenden Resultate kam bei den auf den späteren Fahrten entnommenen Wasserproben noch eine Reihe anderer Untersuchungsmethoden zur Anwendung, und zwar:

1. wurde das Vorkommen bei Bruttemperatur wachsender Keime im Wasser mittelst eines Anreicherungsverfahrens untersucht, zur Ergänzung der Resultate der Keimzählungen auf Gelatine,

2. wurde die im Wasser von verschiedenen Schöpfstellen eintretende Sauerstoffzehrung durch Stehenlassen der Proben im Laboratorium untersucht Spitta (36),

3. fanden Untersuchungen über die Beschaffenheit des Flußbodens unter dem Rein-, Schmutz- und Mischwasser statt. Hierdurch sollte bestimmt werden, ob und inwieweit die ungelösten Stoffe des Wassers sedimentieren, und welche Bedeutung die Sedimentierung für die Selbstreinigung der Donau besitzt.

Am 11. November 1903 wurden verschiedene Mengen Donauwasser ron zwei Entnahmestellen mit entsprechenden Mengen Bouillon rersetzt, die Röhrchen kamen auf 24 Stunden in den Brutschrank, worauf mit angefeuchtetem Bleipapier auf Entwicklung von Schwefelwasserstoff geprüft wurde Von jeder Probe wurden zwei Röhrchen angesetzt. Vom Inhalt einiger Röhrchen wurden kleine Mengen Meerschweinchen intraperitoneal injiziert.

Tabelle XLIII gibt die Versuchsresultate wieder.

+ bedeutet Trübung der Röhrchø̨n. (+) bedeutet schwache Trübung der Röhrchen. - bedentet Klarbleiben. 
Tabelle XLIII (11. November 1903).

\begin{tabular}{|c|c|c|c|c|c|c|}
\hline $\begin{array}{l}\text { Wasser. } \\
\text { menge }\end{array}$ & $100 \mathrm{~cm}$ & $10^{\mathrm{ccm}}$ & $1 \mathrm{ccm}$ & $0.1 \mathrm{~cm}$ & $0.01 \mathrm{ccm}$ & $0.001 \mathrm{ccm}$ \\
\hline $\begin{array}{c}\text { Bonillon- } \\
\text { menge }\end{array}$ & $100 "$ & $10 "$ & 2, & $2 \cdot 9$ & $3 \cdot 0 \quad$, & $3 \cdot 0$ \\
\hline $\begin{array}{l}\text { Rein- } \\
\text { wasser }\end{array}$ & $\begin{array}{c}++ \\
\text { Blei- } \\
\text { papier } \\
\text { stark ge- } \\
\text { schwärzt }\end{array}$ & $\begin{array}{c}++ \\
\text { Blei- } \\
\text { papier } \\
\text { ziemlich } \\
\text { stark ge- } \\
\text { schwärzt }\end{array}$ & $\begin{array}{c}++ \\
\text { Bleipapier } \\
\text { mäBig stark } \\
\text { geschwärzt } \\
2 \text { Meerschw. } \\
\text { injiziert; bde. } \\
\text { nach 12-16 St. } \\
\text { gestorben. }\end{array}$ & \begin{tabular}{|c|}
++ \\
Bleipapier \\
schwarz \\
gefärbt \\
2 Meerschw. \\
injiziert; beide \\
nach $12-16$ St. \\
gestorben.
\end{tabular} & 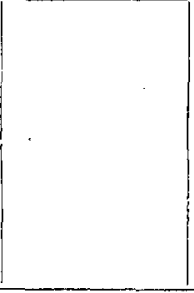 & \\
\hline $\begin{array}{c}\text { Schmutz- } \\
\text { wasser } \\
\text { von } \\
\mathrm{km} 11 \\
\text { rechts }\end{array}$ & & & $\begin{array}{c}++ \\
\text { Mäßige } \\
\text { Schwärzung } \\
\text { des } \\
\text { Bleipapieres }\end{array}$ & $\begin{array}{c}++ \\
\text { Mäßige } \\
\text { Schwärzung } \\
\text { d.Bleipapieres } \\
2 \text { Meerschw. } \\
\text { injiziert; beide } \\
\text { naeh 12-16 St. } \\
\text { gestorben. }\end{array}$ & $\begin{array}{c}++ \\
\text { MäBige } \\
\text { Schwärzung } \\
\text { d.Bleipapieres } \\
\text { 2 Meerschw. } \\
\text { injiziert; beide } \\
\text { nach 12-16 St. } \\
\text { eingegangen. }\end{array}$ & $\begin{array}{c}++ \\
\text { Starke } \\
\text { Schwärzung } \\
\text { d. Bleipapieres } \\
\text { 2 Meerschw. } \\
\text { injiziert; beide } \\
\text { nach 12-16 St. } \\
\text { eingegangen. }\end{array}$ \\
\hline
\end{tabular}

Der Obduktionsbefund war bei allen Tieren ähnlich: MäBig reichlich seröses oder serös-eitriges Exsudat des Peritonealraumes, enthaltend Gramnegative Stäbchen in groBer Menge. Bald stärkere, bald schwächere Injektion der Gefäße des Peritoneums. Aus Peritonealfiüssigkeit und Herzblut konnten Bakterien gezüchtet werden, die sich durch ihre (meist nicht sehr lebhafte) Beweglichkeit, weinblattartiges Aussehen der Kolonien, Fehlen des Peptonisierungsvermögens, Erzeugen von Milchgerinnung, Vergären von Dextrose als Angehörige der Coli-Gruppe erwiesen. Auch aus den Bouillonröhrehen konnte dieses Bakterium isoliert werden, wenn es auch nicht in Reinkultur vorhanden war.

Am 15. März wurde ein ähnlicher Versuch gemacht. Die Röhrchen enthielten absteigende Mengen Wassers und soviel Bouillon, daB der Gesamtinhalt jedes Röhrchen $3 \mathrm{~cm}$ ausmachte. Es wurden je zwei Röhrchen mit der gleichen Wassermenge beschickt, dieselben blieben durch 48 Stunden im Brutschrank.

Der Versuch ist auf Tabelle XLIV zusammengestellt.

In einem Parallelversuche wurde statt Peptonbouillon 1 prozentiges Peptonwasser verwendet. Die Resultate waren ganz ähnlich.

(Irrtümlich wurden in diesem Falle keine Reinwasserproben angesetzt, daher unterblieben auch Tierversuche vollständig.) 
Tabelle XLIV (15. März 1904).

\begin{tabular}{|c|c|c|c|c|c|}
\hline Wassermenge: & $0.1 \mathrm{cms}$ & $0.01 \mathrm{ccm}$ & $0.001 \mathrm{~cm}$ & $0 \cdot 0001 \mathrm{cem}$ & $0.00001 \mathrm{~cm}$ \\
\hline $\mathrm{km} 11$ rechts & $\underset{\substack{+ \\
\text { Bleipapier } \\
\text { geschwärzt }}}{+}$ & $\begin{array}{c}+\quad+ \\
\text { Bleipapier } \\
\text { geschwärzt }\end{array}$ & $\begin{array}{c}(+)(+) \\
\text { Bleipapier } \\
\text { nicht } \\
\text { geschwärzt }\end{array}$ & $\begin{array}{c}(+)(+) \\
\text { Bleipapier } \\
\text { nicht } \\
\text { geschwärzt }\end{array}$ & +- \\
\hline $\mathrm{km} 21$ rechts & $\begin{array}{c}+\underset{+}{+} \\
\text { Bleipapier } \\
\text { geschwärzt }\end{array}$ & $\begin{array}{c}+\quad+ \\
\text { Bleipapier } \\
\text { geschwärzt }\end{array}$ & $\begin{array}{c}+\quad+ \\
\text { Bleipapier } \\
\text { nicht } \\
\text { geschwärzt }\end{array}$ & $+\quad+$ & \\
\hline km 45 Mitte & $\begin{array}{c}+\quad+ \\
\text { Bleipapier } \\
\text { geschwärzt }\end{array}$ & $\begin{array}{l}(+)(+) \\
\text { Bleipapier } \\
\text { geschwärzt }\end{array}$ & $\begin{array}{c}+- \\
\text { keine } \\
\text { Schwärzung } \\
\text { d. Bleipapieres }\end{array}$ & $-\quad-$ & -- \\
\hline
\end{tabular}

(Bezeichnung die gleiche wie bei Tabelle XIIII.)

Am 29. April und 26. September 1904 wurden analoge, jedoch ausgedehntere Versuche gemacht. Die Resultate sind auf Tabelle XLV und XLVI zusammengestellt.

Tabelle XLV (29. April 1904).

Befunde in dem mit Donauwasser beschickten Bouillonröhrchen nach 24 Stunden (oberhalb des Striches) nach 48 Stunden (unter dem Strich) nebst Angabe der Schwärzung des in die Röhrchen eingehängten Bleipapieres. (Je 2 Röhrchen à $10^{\mathrm{ccm}}$.)

\begin{tabular}{|c|c|c|c|c|c|c|}
\hline \multirow{2}{*}{$\begin{array}{l}\text { Entnahme- } \\
\text { stellen }\end{array}$} & à & $\mathrm{b}$ & $\mathrm{c}$ & d & $\mathrm{e}$ & $f$ \\
\hline & $0 \cdot 1$ & 0.01 & 0.001 & 0.0001 & 0.00001 & $0.000001 \mathrm{ccm}$ \\
\hline \multirow[b]{2}{*}{ km 10 Mitte } & $+t$ & ++ & -- & $-\quad-$ & -- & \\
\hline & $\begin{array}{c}\text { māBige } \\
\text { Schwärzg. }\end{array}$ & $\begin{array}{l}\text { Schwärzg. } \\
\text { wie bei a }\end{array}$ & $\begin{array}{l}+ \\
\text { Schwärzg. } \\
\text { wie bei a }\end{array}$ & & & \\
\hline \multirow[b]{2}{*}{$\mathrm{km} 11$ rechts } & \pm+ & \pm+ & $+t$ & $+\quad+$ & +- & $+\quad-$ \\
\hline & $\begin{array}{l}\text { Schwärzg. } \\
\text { stark }\end{array}$ & sehr stark & mäBig & mäBig & $\begin{array}{l}(+) \\
\text { gering }\end{array}$ & gering \\
\hline \multirow[b]{2}{*}{$\mathrm{km} 21$ rechts } & ++ & ++ & $+\quad+$ & $+\quad+$ & $+\quad+$ & $+\quad+$ \\
\hline & $\begin{array}{c}\text { Seh wärzg. } \\
\text { stark }\end{array}$ & sehr stark & mäBig & stark & mäBig & mäBig \\
\hline \multirow[b]{2}{*}{$\mathrm{km} 31$ rechts } & ++ & $+\quad+$ & ++ & +- & -- & - \\
\hline & $\begin{array}{l}\text { Schwärzg. } \\
\text { stark }\end{array}$ & stark & mäBig & $\begin{array}{r}(+) \\
\text { gering }\end{array}$ & negativ & negativ \\
\hline
\end{tabular}


Tabelle XLV. (Fortsetzung.)

\begin{tabular}{|c|c|c|c|c|c|c|}
\hline \multirow{2}{*}{$\begin{array}{l}\text { Entnahme- } \\
\text { stellen }\end{array}$} & $\mathbf{a}$ & $b$ & c & $d$ & $\mathrm{e}$ & $\mathrm{f}$ \\
\hline & $0 \cdot 1$ & $0 \cdot 01$ & 0.001 & 0.0001 & $0 \cdot 00001$ & 0.000001 \\
\hline \multirow[b]{2}{*}{$\mathrm{km} 45$ Mitte } & \pm+ & \pm+ & ++ & $1--$ & -+ & -- \\
\hline & $\begin{array}{l}\text { Schwärzg. } \\
\text { sehr stark }\end{array}$ & mäBig & gering & $\mid \begin{array}{c}\text { im trüben } \\
\text { Röhrchen } \\
\text { gering }\end{array}$ & $\begin{array}{c}\text { im klaren } \\
\text { Röhrchen } \\
\text { negativ }\end{array}$ & \\
\hline \multirow[b]{2}{*}{$\mathrm{km} 60$ Mitte } & \pm+ & ++ & +- & $=+$ & -- & \\
\hline & $\begin{array}{l}\text { Schwärzg. } \\
\text { sehr stark }\end{array}$ & mäBig & $\begin{array}{r}+ \\
\text { gering }\end{array}$ & $\begin{array}{c}\text { im trüben } \\
\text { Röhrchen } \\
\text { negativ }\end{array}$ & $\begin{array}{l}\text { im klaren }^{+} \\
\text {Röhrchen } \\
\text { negativ }\end{array}$ & \\
\hline
\end{tabular}

Tabelle XIVI (26. September 1904).

Gleiche Versuchsreihe wie am 29. April 1904.

\begin{tabular}{|c|c|c|c|c|c|c|c|}
\hline \multirow{2}{*}{$\begin{array}{l}\text { Entnahme- } \\
\text { stellen }\end{array}$} & a & $\mathrm{b}$ & c & d & $\mathrm{e}$ & $\mathrm{f}$ & $\mathrm{g}$ \\
\hline & $0.1^{\mathrm{cem}}$ & 0.01 & 0.001 & $0 \cdot 0001$ & $0 \cdot 00001$ & 0.000001 & 0.0000001 \\
\hline \multirow[b]{2}{*}{ km 1 Mitte } & $+\quad+$ & $(+)+1$ & -- & -- & -- & & \\
\hline & $\begin{array}{c}\text { Seh wärzg. } \\
\text { des Blei- } \\
\text { papieres } \\
\text { stark }\end{array}$ & mäBig & $\begin{array}{l}+ \\
\text { negativ }\end{array}$ & $\begin{array}{l}+ \\
\text { negativ }\end{array}$ & negativ & & \\
\hline \multirow{2}{*}{$\begin{array}{c}\text { Donau- } \\
\text { kanal- } \\
\text { mündung }\end{array}$} & $+\quad+$ & \pm+ & ++ & $+\quad+$ & ++ & $=-$ & -- \\
\hline & stark & stark & stark & sehr stark & negativ & $\begin{array}{c}+\quad+ \\
\text { negativ }\end{array}$ & $\begin{array}{l}+ \\
\text { negativ }\end{array}$ \\
\hline \multirow{2}{*}{$\begin{array}{l}\mathrm{km} 11 \\
\text { rechts }\end{array}$} & $+\quad+$ & ++ & $+t$ & ++ & -- & \multicolumn{2}{|c|}{ verunreinigt } \\
\hline & stark & mäBig & $\begin{array}{l}\text { sehr } \\
\text { stark }\end{array}$ & negativ & $\begin{array}{c}+\quad+ \\
\text { negativ }\end{array}$ & & \\
\hline \multirow[b]{2}{*}{$\begin{array}{l}\mathrm{km} 21 \\
\text { rechts }\end{array}$} & $+\quad+$ & $+t$ & ++ & -1 & -- & -- & -- \\
\hline & stark & mäßig & mäßig & $\begin{array}{c}+\quad+ \\
\text { negativ }\end{array}$ & $\begin{array}{c}+\quad+ \\
\text { negativ }\end{array}$ & $\begin{array}{c}+\quad+ \\
\text { negativ }\end{array}$ & $\begin{array}{l}++ \\
\text { negativ }\end{array}$ \\
\hline \multirow[b]{2}{*}{$\underset{\text { Mitte }}{\mathrm{km} 31}$} & $+\quad+$ & ++ & +- & +- & $+\quad+$ & $-\quad-$ & -- \\
\hline & sehr stark & $\begin{array}{l}\text { sehr } \\
\text { stark }\end{array}$ & $\begin{array}{c}+ \\
\text { mäBig }\end{array}$ & $\begin{array}{c}+ \\
\text { im 2. Röhr- } \\
\text { chen neg. }\end{array}$ & stark & $\begin{array}{c}+\quad+ \\
\text { negativ }\end{array}$ & $\begin{array}{l}(+)(+) \\
\text { negativ }\end{array}$ \\
\hline \multirow[b]{2}{*}{$\begin{array}{c}\mathrm{km} 4 \overline{5} \\
\text { Mitte }\end{array}$} & \pm+ & ++ & --1 & -- & $-\quad-$ & -- & -- \\
\hline & mäßig & gering & $\begin{array}{c}++ \\
\text { gering }\end{array}$ & $\begin{array}{c}+\quad+ \\
\text { negativ }\end{array}$ & $\begin{array}{c}+\quad+ \\
\text { negativ }\end{array}$ & $\begin{array}{c}-+ \\
\text { negativ } \\
\text { im klaren }\end{array}$ & $\begin{array}{c}-\quad+ \\
\text { negativ } \\
\text { Röhrchen } \\
\end{array}$ \\
\hline \multirow[b]{2}{*}{$\underset{\text { Mitte }}{\mathrm{km} 60}$} & $+\quad+$ & ++ & -- & -+ & -+ & -- & -- \\
\hline & stark & $\begin{array}{l}\text { sehr } \\
\text { stark }\end{array}$ & $\begin{array}{l}++ \\
\text { stark }\end{array}$ & $\begin{array}{l}(+) \\
\text { mäBig }\end{array}$ & $\begin{array}{c}\text { im trüben } \\
\text { Röhrchen } \\
\text { negativ }\end{array}$ & & \\
\hline
\end{tabular}

+ bedeutet Trübung. (+) Trübung sehr schwach. - keine Trübung. 
Nach diesen Versuchen kommen im Reinwasser Bakterien, deren Wachstumsoptimum bei Bruttemperatur liegt, ungemein reichlich vor, Trübung der Bouillon beim Stehen im Brutschrank tritt schon ein, wenn ihr sehr kleine Mengen des Wassers zugesetzt sind. Noch wesentlich reichlicher kommen solche Bakterien im Schmutzwasser vor. Bezeichnet man die kleinste, noch Trübung der Bouillon rerursachende Wassermenge für jede Entnahmestelle als deren "Wärmebakterientiter", das betreffende Rōhrchen als "Grenzröhrchen", so lieB sich folgendes konstatieren: der Wärmebakterientiter im Schmutzwasser (Kilometer. 11 und 21 rechts) war ungemein niedrig, ein vielfaches niedriger als im Reinwasser; der Titer des Mischwassers lag zwischen jenen beiden, jedoch näher dem Titer des Schmutzwassers. Ein paralleles Verhalten des Wärmebakterientiters und der übrigen Anzeichen der Wasserverunreinigung war nicht zu beobachten. Die Zahl der klarbleibenden Röhrchen war allerdings bei den am meisten stromabwärts gelegenen Schöpfstellen gröBer als beim Schmutzwasser. Die Entwicklung von Schwefelwasserstoff in den einzelnen Röhrchen erfolgte nicht proportional der zur Aussaat verwendeten Wassermenge.

Anschließend an den Versuch vom 29. April 1904 wurden folgende Tierrersuche gemacht: Je ein Meerschweinchen erhielt (intraperitoneal) $\mathbf{3}^{\mathrm{ccm}}$ des einen mit $0.1^{\mathrm{cm}}$ Wasser beschickten Bouillonröhrchens von jeder Entnahmestelle. Sämtliche Tiere waren nach weniger als 20 Stunden eingegangen, das Tier, welches $3^{\mathrm{ccm}}$ vom Inhalt des Reinwasserröhrchens erhalten hatte, ging etwas später ein als die übrigen. AuBerdem wurden je 1 bis 2 Tiere mit 3 cem vom Inhalte der "Grenzröhrchen" (f. 24 und 48 Stunden) von jeder Entnahmestelle behandelt. Von diesen Tieren wurde nur eines (Fntnahmestelle bei Kilometer 60) krank, erholte sich aber wieder. Alle übrigen blieben gesund.

Die beiden Versuchsreihen rom 29. April und 26. September 1904 zeigen einige Verschiedenheiten. Der Wärmebakterientiter war bei dem 2weiten Versuche durchschnittlich niedriger. Im ersten Falle änderte sich der Befund vom ersten auf den zweiten Tag fast gar nicht, im zweiten Fall trat in einer Reihe von Röhrchen erst nach Ablauf von 24 Stunden Trübung ein. In beiden Versuchen kamen verschiedene Arten von Bakterien zur Entwicklung, darunter jedesmal Bacterium coli. Dieses wurde bei dem Versuche vom 29. April in den meisten Röhrchen gefunden, mitunter in überwiegender Menge, in dem zweiten Versuche trat es gegenüber anderen Bakterienarten (Kokken, Stäbchen) mehr zurück.

Der Obduktionsbefund der eingegangenen Meerschweinchen war dem bei den früheren Versuchen ähnlich. In der Peritonealflüssigkeit fand sich stets reichlich Bacterium coli, meist in Reinkultur. Aus dem Herz- 
blut bonnten die gleichen Bakterienspezies gezüchtet werden, mitunter waren einzelne Exemplare derselben im Ausstrichpräparate vom Herzblute nachweisbar. Das Resultat der Tierversuche war demnach wenig wertvoll, eine Wiederholung derselben fand nicht statt.

Die Untersuchung des Wassers auf das Vorkommen bei Bruttemperatur wachsender Bakterien mittelst des geschilderten Anreicherungsverfahrens zeigte, wie die Versuche ergeben, eklatante Unterschiede zwischen "Schmutzund Reinwasser. Feinere Differenzen treten nach dieser Methode nicht hervor. Dieses Verfahren ist demnach nicht geeignet, die alte Methode der Keimzählung zu verđrängen, wohl aber sie zu ergänzen.

In einem Falle (15. März 1904) untersuchte ich das Reinwasser auf das Vorkommen streng anaërober sporenbildender Keime. Solche fanden sich regelmäbig schon bei Aussaat von $0.2 \mathrm{~cm}$. Ihr Nachweis erfolgte durch Beschicken von koaguliertem, mit Bouillon überschichtetem Eiweiß mit der genannten Menge zuvor auf $80^{\circ}$ erhitzten Wassers. Buchnerrohr. - Brutschrank. Isoliert wurde in einem Falle ein streng anaërobes Bakterium, welches im hiesigen Laboratorium von Hrn. Dr. Fritz Passini genauer studiert, als typischer Gasphlegmonebazillus erkannt und zu weiteren Versuchen verwendet wurde.

Untersuchungen der Sauerstoffzehrung. (Tabelle XLVII.)

Am 29. April und am 26. September 1904 wurden an einzelnen, wichtigen Entnahmestellen mehrere Proben für diesen Zweck entnommen. Im ersten Falle erfolgte die Entnahme wie sonst zur Sauerstoffbestimmung in Halbliter-Flaschen, deren Stöpsel mit Pergamentpapier umwickelt waren. Je eine Flasche von jeder Entnahmestelle erhielt stets einen Zusatz von Chloroform. In dieser Flasche wurde der Sauerstoffgehalt des Wassers sofort, in den übrigen ein-, zwei- und dreimal 24 Stunden nach der Entnahme untersucht.

Am 26. September 1904 wurde folgendes Verfahren angewendet. Je 7 Flaschen kamen nach Entfernen der eingeschliffenen "Stöpsel in einen eigens hierzu konstruierten Apparat, so daB ihre Mündungen in gleicher Höhe standen. Sie wurden durch eine an der Unterseite mit Filz belegte Metallplatte verschlossen, der Apparat hierauf in die gewünschte Tiefe $(0.4 \mathrm{~m})$ gebracht, dort geöffnet und nach erfolgter. Füllung der Flaschen wieder verschlossen und emporgehoben, die Flaschen dann sofort verstöpselt. Diejenigen unter ihnen, in welchen keine weitere Sauerstoffzehrung stattfinden sollte, waren schon vorher nach Winklers Methode mit Kalilauge versetzt worden. Die sonstige Durchführung des Versuches erfolgte in gleicher Weise wie am 29. April 1904. Der Wert der Bestimmung der Sauerstoffzehrung gegenüber der einmaligen Sauerstoff- 


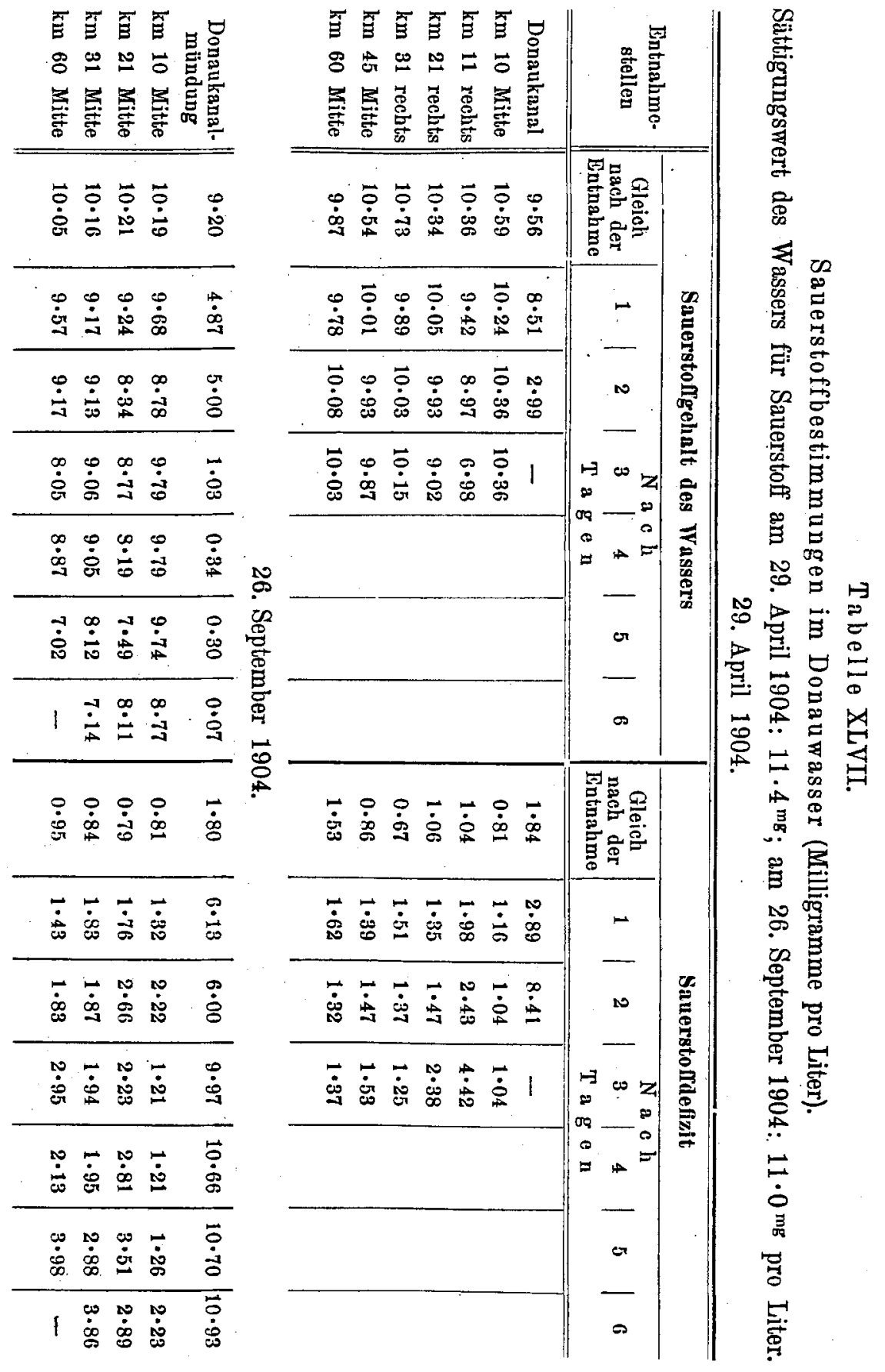


bestimmung liegt hauptsächlich darin, daß erstere noch Difterenzen in der Beschaffenheit verschiedener Wasserproben aufdeckte, deren anfänglicher Sauerstoffgehalt gleich oder nur wenig verschieden war. Das Wasser von verschiedenen Schöpfstellen von scheinbar gleicher chemischer Beschaffenheit und gleicher Menge gelösten Sauerstoffs im Augenblick der Entnahme zeigte verschieden intensive Sauerstoffzehrung. Diese war in der Regel umso intensiver, je größer die Zahl der Keime im Kubikzentimeter war, jedoch ohne dieser etwa proportional zu sein. Die Sauerstoffzehrung war noch am Ende der untersuchten Strecke etwas stärker als im Reinwasser. Die Mlethode, man könnte sie die biologische nennen, war demnach nächst der Keimzählung die beste und feinste der von mir angewendeten. Ein Nachteil war ihre Umständlichkeit.

Untersuchung des FluBbodens. Der Boden des Donaubettes besteht aus gröberem und feinerem Geschiebe, das der sehr rasch fließende Strom hauptsächlich aus den Alpen mitführt. Nach längeren erfolglosen Versuchen wurde ein Apparat von Trichterform mit geschlossenem Boden und einem seitlichen Schlitz konstruiert, der an eine Sondierstange geschraubt wurde und zur Hebung von Bodenproben verwendbar war. Die das Flußbett bildenden Geschiebesteine sind an vielen Stellen so grob, daß sie wegen ihrer Größe nicht gehoben werden konnten, auch im Donaukanal ist dies der Fall. Oft gelang es jedoch mit obigem Apparate, die den FluBboden bedeckenden Steinchen von NuB- bis Erbsengröße emporzubringen. An zwei Tagen (26. März und 29. April 1904) wurden derartige Untersuchungen gemacht und an beiden Tagen oftmals, mindestens je $100 \mathrm{mal}$ Sondierungen in dem Gebiete von Kilometer 8 abwärts vorgenommen. Am 26. März 1904 wurde das FluBbett bis Kilometer 21, am 29. April 1904 bis an die ungarische Grenze in dieser Weise untersucht, und dabei wurden beide Ufer und die Strommitte berücksichtigt. Die letzten $200^{\mathrm{m}}$ des Donaukanals wurden an beiden Tagen gleichfalls in dieser Weise untersucht.

Resultate: An Stellen mit tiefem Wasser und dementsprechend starker Strömung waren die emporgebrachten Steine in beiden Versuchen stets glatt und rein, auch dort, wo das darüberstreichende Wasser die stärksten Verschmutzungsgrade aufwies. Wesentlich anders war der Befund am 26. März 1904 an Stellen mit seichtem Wasser, namentlich neben den Haufen und am stromabwärts gerichteten Ende derselben. Hier waren die Steine schleimig anzufühlen, die kleinsten klebten den größeren mitunter an, oft waren spärlich schwärzliche Massen eingelagert. Alles dies gleichmäBig an beiden Ufern, auch dort, wo nach den Wasseranalysen und der Richtung des Stromes eine Verschmutzung mit Sammlerwasser 
auszuschließen war. Die aus dem Donaukanal entnommenen Bodenproben hatten ein ähnliches Aussehen. Reichlicheres Vorkommen jener schmierigen Massen zwischen den Steinchen war hier nicht nachweisbar. Mit freiem Auge waren demnach die Sedimente des FluBbodens unter dem Rein- und unter dem Schmutzwasser voneinander nicht zu unterscheiden, eher aber unter dem Mikroskope. Hier boten die Sedimente im ganzen ein ähnliches Bild wie die Bodensătze aus den Flaschen. Hier wie dort herrschte ein formloser, zum Teil grünlich tingierter Detritus vor, der wohl eine Mischung feinster mineralischer mit zerriebenen pflanzlichen Elementen darstellt. Auch geformte Reste höherer Pflanzen kamen im Bodensediment vor, namentlich die ziemlich resistenten Teile von Gefäßen, größere Zellverbände aber fehlten ganz. Rechts waren mitunter lebhaft gefärbte, faserige Substanzen, anscheinend von Kleiderstoffen herrührend, zu finden, niemals quergestreifte Muskulatur. Am 26. März 1904 waren Algen im Bodensediment links etwas reichlicher als sonst unter den suspendierten Stoffen des Wassers, doch fanden sich nur einzelne Esemplare, keine Rasen, rechts dafür mehr Fadenpilze und besonders viel mehr Protozoen, letztere sogar sehr reichlich. Auch Würmer wurden im Sediment öfters, einmal links bei Kilometer 14 ein ganzer Haufen, ca. 20 Exemplare, gefunden.

Am 29. April 1904 wurden an zahlreichen Stellen die Geschiebesteine frei von jenem schleimigen, die Suspensa enthaltenden Überzug gefunden, der anlä:Blich der Untersuchungen vom 26. März desselben Jahres nachgewiesen worden war. Die zwischenliegenden, zeitweilig hohen, doch nicht abnorm hohen Wasserstände hatten demnach genügt, um die Gewalt der Strōmung an jenen Stellen derart zu steigern, daß die Sedimente weggespült murden (vergl. Kabrhel [27]). Am 29. April 1904 fehlten die Protozoen auck an jenen Stellen fast ganz, wo die schleimigen Massen nicht weggespült worden waren.

Diese Untersuchungen des Flußbodens bewiesen folgendes:

1. Sedimentierung im Wasser suspendierter nicht mineralischer Stoffe findet tatsächlich statt, und zwar im Rein- und Schmutzwasser ziemlich gleich stark.

2. An derselben nehmen auch die dem Strome aus den Wiener Sammlern zugeführten Stoffe teil, wie das Vorkommen künstlich gefärbter Fasern beweist.

3. Das Geschiebe des Flußbodens wirkt heftig zermalmend auf die Sedimente; denn während aus physikalischen Gründen anzunehmen ist, daB hauptsächlich die voluminösesten Suspensa, wie gröBere Zellverbände, zu Boden sinken, finden sich auf dem FluBboden im ganzen kleinere Körper als im Sediment der zur. Wasseruntersuchung gefüllten Flaschen. 
4. Die Quantität der sedimentierten Stoffe ist relativ gering. Das ergibt sich aus folgender Überlegung. In jeder an beliebiger Stelle des Stromes entnommenen Wasserprobe setzt sich nach 1-2 tägigem Stehen ein deutlich mit freiem Auge sichtbares Sediment ab. Im Laufe ron Wochen und Monaten durchfließt nun eine ungeheure Menge solchen Wassers das Donaubett. Dagegen ist nur ein kleiner Teil des FluBbettareals, das sind die oben erwähnten seichten Stellen, zur Sedimentierung geeignet. Die Gesamtmenge der Sedimente, auf ein verhältnismäBig kleines Ablagerungsgebiet eingeengt, ist demnach viel zu gering, um gegenüber den im Donauwasser suspendierten Stoffen von Belang zu sein. Mit anderen Worten: nur ein kleiner Teil der im Donauwasser suspendierten Körper kommt zum Absetzen auf dem Boden des Flußbettes.

Bei Besprechung der Wiener Kanalisation wurde erwähnt, daß die in den beiden Hauptsammlern abgelagerten Sinkstoffe trotz der massenhaften, von dem Wasser mitgeführten pflanzlichen und tierischen Stoffe fast rein aus mineralischen Körpern und Kohle bestehen. Die Strömungsgeschwindigkeit der Sammler ist nun nicht gröBer als die der Donau, selbst bei Niederwasser. Auch aus diesem Grunde ist es unwahrscheinlich, daB in der rascher fließenden Donau ein reichlicheres Niedersinken suspendierter organischer Stoffe stattfindet. Gegen diese Behauptung könnte eingewendet werden, daB am rechten Ofer des Stromes von der Donaukanalmündung an eine rasche Abnahme der Siebrückstände stattfindet. Diese Tatsache ist aber, wie schon erwähnt, einerseits durch Abnahme der Viskosität der Suspensa zu erklären, andererseits durch deren fortdauernde Zerkleinerung. Solche feine Suspensa wurden aber nach meinen Untersuchungen nicht auf den Sieben, sondern nur auf dem Filter zurückgehalten. Eine ausgiebige Sedimentierung feiner suspendierter Stoffe wäre daher nur dann anzunehmen, wenn die Differenzen der Trockenrückstände im filtrierten und im unfiltrierten Wasser von der Donaukanalmündung an bis PreBburg stärker abnehmen würde, als der Verdünnung des Schmutzwassers entspricht. Dies ist aus den drei hierfür vorliegenden Befunden nicht zu entnehmen. Allerdings muß zugegeben werden, daB für eine so subtile Unterscheidung eine sehr groBe Zahl von Versuchen nötig gewesen wäre.

Die Frage, ob am Grunde der Donau an jenen zur Sedimentierung geeigneten Stellen Schlammverzehrung stattfindet, ist durch die vorliegenden Untersuchungen nicht gelöst worden. Es ist wohl möglich, daß ein Teil der sedimentierenden Körper durch Bakterien (vielleicht Anaerobier) zerstört wird, jedoch durchaus nicht sicher. Noch wahrscheinlicher ist es, daß die Protozoen in jenen Stoffen ihre Nahrung finden. Insbesondere spricht das reichlichere Vorkommen dieser Organismen in den, dem Schmutzwasser entsprechenden Sedimentiergebieten dafür, daB 
dort die Körper an organischer.Substanz reicher sind als die Reinwassersedimente, und daher von den Protozoen bevorzugt werden. Wenn aber auch eine Schlammverzehrung stattfindet, so ist diese quantitativ sicher nicht sehr bedeutend, denn die Menge der FluBbodensedimente wird s. 0. - hauptsächlich von der Höhe der Wasserstände, d. i. von der Gewalt der Strömung, beeinflußt. Ausgiebige Schlammzehrung kann wohl nur bei sehr schwacher oder fehlender Strömung stattfinden, und so ist wahrscheinlich der an der Ëlbmündung (Büsing [48]) erhobene Befund zu erklären, daß bei fast fehlender Strömung in einem an sedimentierenden Stoffen sehr reichen Wasser eine Anhäufung ron Schlamm ausbleibt. Offenbar findet hier unter günstigen Verhältnissen eine sehr ausgiebige Schlammzehrung statt. Langsamkeit der Strömung allein scheint aber noch nicht zu genügen, damit eine solche stattfinde, denn sonst wäre z. B. in der Seine unterhalb Paris (1) jene außerordentlich bedeutende Schlammbankbildung nie möglich gewesen. Es müssen in dieser Richtung noch andere, unbekannte Momente von Wichtigkeit sein.

Die im vorigen geschilderten Betrachtungen genügen, um ein Bild von dem Schicksale der Fremdstoffe zu machen, die der Donaukaual dem Strome zuführt: Es handelt sich im wesentlichen um eine Ausbreitung der zunächst auf einen relativ schmalen Streifen am rechten Ufer konzentrierten Schmutzwassermasse über die ganze Breite des Stromes. Hiermit gleichzeitig findet eine parallel fortschreitende Verdünnung des Schmutzwassers statt. Das Überwandern von rechts nach links erfolgt nicht für alle im Wasser bestimmten Stoffe und Körper gleichmäBig schnell: Einzelne gelöste Stoffe, und zwar Chloride und vielleicht auch das Ammoniak scheinen der Mischung des Wassers vorauszueilen und im Wege der Diffusion sich verhältnismäßig rasch über die ganze Breite des Profils zu verteilen. Hierfür sprechen namentlich die Befunde auf Tabelle XXXV. Es ist möglich, daB auch manche durch Kaliumpermanganatverbrauch angezeigte Substanzen an diesem Diffusionsrorgange teilnehmen. Die Analysen ergaben zwar bei Kilometer 21-22 stets höhere Oxydierbarkeit am rechten Ufer als in der Strommitte, doch begegnen wir, wie bereits bei Besprechung des Reinwassers gesagt wurde, vor der Einmündung des Donaukanales Differenzen im gleichen Sinne zwischen Mitte und rechts.

Über die tatsächliche Mischung des Rein- und Schmutzwassers kann aber nur die Verteilung der Schwimm- und Schwebestoffe, ron letzteren speziell der Bakterien, AufschluB geben. Schwimmkörper nun, bei Fischamend noch auf das rechte Ufer beschränkt, sind $10 \mathrm{~km}$ 
weiter unten schon reichlich in der Strommitte und bald darauf sogar am linken Ufer sichtbar. Bei Hainburg fand ich eine groBe Lagerstätte solcher Körper am linken Ufer. Mit diesen ausnahmslos bei jeder Fahrt gemachten Beobachtungen stimmt auch die Aussage von Donaufischern sowie die eines Gastwirtes in Fischamend überein. Nach diesen Gewährsmännern halten sich die das Schmutzwasser vorziehenden Fischarten auf der Strecke Donaukanalmündung-Fischamend am rechten Ufer des Stromes auf, die übrigen meiden es. In Fischamend wird nach Regengüssen bei Wien, die ein rasches Steigen des Wassers vierursachen, mitunter eine bedeutende Zunahme der groben Schwimmkörper beobachtet. Diese lagern sich beim Fallen des Wassers am Ufer ab, und zwar bei Fischamend ausschlieBlich am rechten Ufer. Ferner ist die Donau an Tagen mit klarem Reinwasser bei Kilometer 11 rechts stark trüb, bei Kilometer 21 ist ein Unterschied in der Färbung des Wassers noch gut wahrzunehmen, schon oberhalb Kilometer 31 fehlt dieser vollkommen. Genaueren AufschluB gibt der Vergleich der Keimzahlen. Bei Kilometer 11 ist das Wasser in der Strommitte keimarm, am rechten Ufer fast so keimreich wie der Donaukanal. Bei Kilometer 21 hat der Ausgleich der Keimzahlen eben erst begonnen, bei Kilometer $3 \mathbf{i}$ dagegen sind wesentliche Unterschiede von Bakterienmengen $z$ wischen verschiedenen Stellen des Profiles nicht mehr zu beobachten. Das Sediment in den Flaschen ist bei Kilometer 21 Mitte noch rein bröcklig und frei von Produkten des menschlichen Stoffwechsels. Solche Körper waren bei Kilometer 31 schon über das ganze Profil verteilt, auch die Konsistenz der Sedimente war hier meist gleich.

Am 26. September 1904 herrschte heftiger Südostwind. An diesem Tage waren grobe Schwimmkörper, durch den Wind getrieben, ausnahmsweise schon oberhalb Fischamend (etwa bei Kilometer 17) in der Strommitte sichtbar.

Auf Grund aller dieser Beobachtungen wäre nochmals folgende Tatsache hervorzuheben: Die Wässer des Donaustromes und des Donaukanales flieben nach ihrer Vereinigung eine kurze Strecke nebeneinander dahin, ohne sich zu mischen, dann beginnt langsam die Mischung. Bei Kilometer 21 ist dieselbe meist eben erst im Beginne, bei Kilometer 31 dagegen so gut'wie vollendet. Sie vollzieht sich demnach hauptsächlich zwischen dem 10. und 20. Kilometer nach Vereinigung der beiden Gerinne. Als Grund dieses höchst auffallenden Befundes kann wohl nur die Konfiguration des FluBbettes angesprochen werden. Wie einleitend gesagt, sind die Haufen bis Fischamend nur uferständig und unbedeutend und nehmen bald unterhalb dieses 
Ortes an Zahl und Mächtigkeit zu. Sie sind es, welche das Wasser 2wingen, seine Richtung fortwährend zu ändern, und so eine gründliche Mischung veranlassen. Die Schiffsleute der k. k. Donauregulierungs-Kommission, welche sehr gut wissen, daß das Schmutzwasser nur bis Fischamend als gesonderter Streifen sichtbar sei, gaben auf Befragen stets an, da $B$ die dort beginnenden Haufen und Inseln die gleichmäBige Verteilung des Wassers bewirken. Die im Laufe der Jahre wechselnde Lage der Haufen macht es auch wahrscheinlich, daB die Mischungsverbältnisse sich innerhalb gröBerer Zeiträume ändern. In der Tat fand auch ca. 12 Jahre früher Heider, daB bei Hainburg das rechtsseitige Uferwasser noch reicher an Keimen war, als das in der Mitte und links. Die Lage der Haufen scheint damals für das Zustandekommen der Mischung minder günștig gewesen zu sein.

Es ergaben sich nun weiter folgende Fragen:

1. Wie unterscheidet sich das Wasser der Donau nach vollendeter Mischung, also bei Kilometer 31 vom Reinwassser?

2. In welchen Punkten bestehen noch Unterschiede in der Beschaffenheit des Wassers am Ende der untersuchten Strecke (Kilometer 60), auch schon Kilometer 45, und des Reinwassers?

3. Was für Vorgänge spielen sich in der Donau, von Kilometer 31 angefangen, also im Mischwasser, ab?

Die Antwort auf diese Fragen ergibt șich aus den besprochenen Tatsachen in einfacher Weise.

ad 1. Das Donauwasser ist bei Kilometer 31 reicher an groben Schwimmstoffen als das Reinwasser, und zwar an solchen, welche den Wiener Sammelkanälen entstammen. Der aus dem Wasser sich absetzende Niederschlag ist nicht, wie im Reinwasser, bröcklig, sondern etwas schleimig. Mikroskopisch betrachtet enthält er regelmäßig Körper, welche Verunreinignng mit Kanalinhalt anzeigen. Der Trockenrückstand des unfiltrierten Wassers ist bei Kilometer 31 etwas grö̉er als im Reinwasser (leider liegen hierüber nur wenig Befunde vor). Die Keimzahlen sind dort stets um das Vielfache größer, der Wärmebakterientiter viel kleiner. Das Sauerstoffdefizit ist größer, die beim Stehen eintretende Sauerstoffzehrung gleichfalls. Die Protozoen sind im Mischwasser hänfiger als im Reinwasser. Endlich war die Ammoniakmenge hier etwas häufiger quantitatir bestimmbar als im Reinwasser. Die Zahlen für Trockenrūckstand im filtrierten Wasser und Kaliumpermanganatverbrauch dürften bei Kilometer 31 im allgemeinen ein wenig höher liegen als im Reinwasser, doch sind die Mengen dieser Stoffe ron Fall zu Fall so schwankend, daB die höheren Zahlen auch auf Zufälligkeiten beruhen können. Chlorgehalt und Klarheit der beiden Wasserarten zeigen keinen Unterschied. Auf 
Tabelle XIVIII.

Zunahme einzelner Bestandteile im Donaustrome, Milligramme pro Liter Wasser, berechnet nach den jeweiligen Differenzen zwischen den Befunden an der Donaukanalmündung bezw. bei Kilometer 11 rechts einerseits und im Reinwasser anderseits unter Berüclisichtigung des Wasserstandes.

\begin{tabular}{|c|c|c|c|c|c|c|c|c|c|}
\hline \multirow{2}{*}{ 1)atum } & \multirow{2}{*}{ 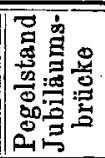 } & \multirow{2}{*}{ 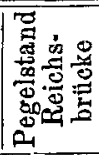 } & \multicolumn{2}{|c|}{$\begin{array}{c}\text { Seknnden- } \\
\text { Wassermenge }\end{array}$} & \multirow{2}{*}{ 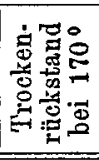 } & \multirow{2}{*}{ 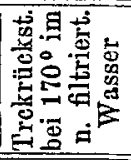 } & \multirow{2}{*}{ 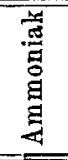 } & \multirow{2}{*}{$\stackrel{\dot{s}}{\stackrel{3}{0}}$} & \multirow{2}{*}{ 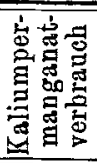 } \\
\hline & & & $\begin{array}{l}\text { Donau- } \\
\text { kanal }\end{array}$ & Strom & & & & & \\
\hline 2. II. & -126 & -132 & 80 & 940 & - & - & - & $0 \cdot 34$ & 1 \\
\hline 4. VI. 03 & -46 & +14 & 1. & 2100 & $1 \cdot 14$ & - & 0.06 & - & $0 \cdot 4$ \\
\hline 6. X. 03 & -90 & -95 & 10 & 1200 & 2 . & - & $0 \cdot 36$ & 0.6 & 1.0 \\
\hline 15. III. 04 & -60 & -52 & 130 & 1530 & 1 & $3 \cdot 9$ & 0.06 & 0.3 & $0 \cdot 4$ \\
\hline 26. IX. 04 & -72 & -70 & 118 & 1380 & 0.7 & 3.8 & 0.2 & - & 0.4 \\
\hline
\end{tabular}

Tabelle IL.

Durch Einmündung des keimreichen Donaukanales in den Donaustrom verursachte Zunahme der Keime pro Kubikzentimeter im Mischwasser.

A. Keimzahlen auf Grund der Befunde im Donaukanal oder bei Kilometer 11 rechts mit Rücksicht auf die Wassermengen im Donaukanal und im Strom berechnet.

B. An der unteren Donau gefundene Keimzunahmen (= beobachtete Keimzahlen, vermindert um die Keimzahlen des Reinwassers am gleichen Tage).

\begin{tabular}{|c|c|c|c|c|c|c|c|c|}
\hline \multirow{2}{*}{ Datam } & \multirow{2}{*}{ 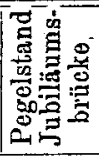 } & \multirow{2}{*}{ 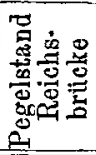 } & \multicolumn{2}{|c|}{$\begin{array}{c}\text { Sekunden- } \\
\text { Wassermenge }\end{array}$} & \multirow{2}{*}{$\begin{array}{c}\text { A. } \\
\text { Berechnete } \\
\text { Zunahme } \\
\text { der Keime } \\
\text { pro ccm }\end{array}$} & \multicolumn{3}{|c|}{$\begin{array}{c}\text { B. Beobachtete Zunahme } \\
\text { der Keime bei }\end{array}$} \\
\hline & & & $\begin{array}{c}\text { Donau- } \\
\text { kanal }\end{array}$ & Strom & & $\mathrm{km} 31$ & 45 & \\
\hline 2. & -126 & --132 & & & 4550 & & & - \\
\hline 7. IV. , & -62 & - 79 & 130 & & - & $13850^{1}$ & $11943^{1}$ & - \\
\hline 4. VI. , & -46 & +14 & 145 & 2100 & 3785 & - & - & - \\
\hline 28. VII. ", & -60 & +116 & 130 & & $3228^{2}$ & - & - & - \\
\hline 6. X. & -90 & -95 & 107 & & 15052 & $45073^{s}$ & $17137^{4}$ & - \\
\hline 26. III. 04 & -74 & -68 & 118 & & $3580^{2}$ & - & - & - \\
\hline 29. IV. , & -28 & +70 & 165 & 25 & 4734 & 12160 & 928 & 7712 \\
\hline 26. IX. , & -72 & -70 & 118 & 13 & 12903 & $15131^{5}$ & $12802^{\mathrm{s}}$ & $4550^{5}$ \\
\hline 21.-22. X & -54 & -90 & 136 & 1780 & $11470^{16}$ & - & - & $25020^{7}$ \\
\hline
\end{tabular}

1 Für das Reinwasser wurde die Keimzahl 2000 angenommen.

- Berechnet nach dem Befunde bei Kilometer 11 rechts.

${ }^{3}$ Für das linke Ufer wurde, sicher zo niedrig, die Keimzahl 12000 angenommen.

4 Gilt für eine ca. 2 Stdn. frühere Tageszeit als die berechnete Keimzahl, wäre sonst noch höher.

s Sehr heftiger Gegenwind und Wellensehlag s. o. im 'Text.

${ }^{6}$ Berechnet nach den Befunden von $1 / 27,7,1 / 28^{\text {b }}$ abends.

\footnotetext{
$7 \quad$ " $\quad 1 \cdot 50,2,2 \cdot 25,2 \cdot 50$ nachts.
} 
Tabelle L.

Keimzunahme im Donaustrom pro Kubikzentimeter Wasser bei verschiedenen Wasserständen berechnet nach dem Keimgehalt der Sammler zu verschiedenen Tagesstunden, angenommen mit 1, 2, 3 und 4 Millionen Keimen im Kubikzentimeter.

\begin{tabular}{|c|c|c|c|c|c|}
\hline & \multirow{2}{*}{ Tagesstunden } & \multicolumn{4}{|c|}{ Sek.-cbm } \\
\hline & & 1000 & 1500 & 2000 & 3000 \\
\hline \multirow{3}{*}{$\begin{array}{l}1 \text { Million Keime } \\
\text { im ccm }\end{array}$} & $9-10$ & 1770 & 1180 & 885 & 590 \\
\hline & $11-12$ & 2000 & 1330 & 1000 & 665 \\
\hline & $4-5$ & 2150 & 1435 & 1075 & 715 \\
\hline \multirow{3}{*}{$\begin{array}{l}\text { 2. Millionen Keime } \\
\text { im cem }\end{array}$} & $9-10$ & 3540 & 2360 & 1770 & 1180 \\
\hline & $11-12$ & 4000 & $\mathbf{2 6 6 0}$ & 2000 & 1330 \\
\hline & $4-5$ & 4300 & 2870 & 2150 & 1430 \\
\hline \multirow{3}{*}{$\begin{array}{l}3 \text { Millionen Keime } \\
\text { in ccm }\end{array}$} & $9-10$ & 5310 & 3540 & 2655 & 1770 \\
\hline & $11-12$ & 6000 & 3990 & 3000 & 1995 \\
\hline & $4-5$ & 6450 & 4305 & 3225 & 2145 \\
\hline \multirow{3}{*}{$\begin{array}{l}\text { 4. Millionen Keime } \\
\text { im ccm }\end{array}$} & $9-10$ & 7080 & 4720 & 3540 & 2360 \\
\hline & $11-12$ & 8000 & 5320 & 4000 & 2660 \\
\hline & $4-5$ & 8600 & 5740 & 4300 & 2860 \\
\hline
\end{tabular}

Tabelle XLVIII ist berechnet, welche Veränderungen das Wasser des Donaustromes durch Beimischung des Schmutzwassers mit Rücksicht auf die eintretende Verdünnung in chemischer Hinsicht erleiden sollte. Die berechnete Zunahme der Verschmutzung ist, ausgenommen den Trockenrückstand im nicht filtrierten Wasser, wie die Tabelle zeigt, verschwindend klein. Die tatsächlichen Befunde stimmen demnach mit den berechneten überein.

Die Donau bei Kilometer 31 zeigt also wohl in mehrfacher Hinsicht Spuren der stattgehabten Verunreinigung, doch von verschmutztem Wasser im gewöhnlichen Sinne kann dort sicher nicht gesprochen werden, auch nicht unter ungünstigen Verhältnissen. Es hat also in gewissem Sinne bis hierher eine Selbstreinigung des Stromes stattgefunden, und zwar durch Verdünnung des Schmutzwassers (Mischung), sowie in zweiter Linie auch durch Ausschwemmen von Schwimmstoften ans Ufer und durch Zerfall ron Kotballen.

Die bei Kilometer 31 im Donaustrome gefundene Bakterienmenge war (s. Tab. IL) in der Regel größer als die auf Grund der Verdūnnung des Schmutzwassers berechnete, meist auch noch bei Kilometer 45 und 60 . Es muB also auf irgend einem Wege eine Zunahme der Keime auf der Strecke von Kilometer 10 bis Kilometer 31 stattfinden. Eine analoge Beobachtung findet sich nirgends in der Literatur. Von den zwei sorgfältigsten Beobachtern der Keimzahlen, Heider und Fruse, findet ersterer 
bei Hainburg weniger Keime, als seine Berechnung ergibt (Tabelle VIII), letzterer entweder langsame Abnahme oder Gleichbleiben der Zahl der zu Beginn der untersuchten Strecke im Strome befindlichen Bakterięn (Tabelle XI, XII). Die Erklärung für den Unterschied zwischen meinen Befunden und denen Heiders ist bereits durch das früher Gesagte gegeben (zu rasche Fahrt Heiders auf der Donau mit seinem Boote, unrichtige hydrologische Daten bei diesem Autor). Am 20. Mai 1893 hatte Heider dafür gesorgt, daß zu verschiedenen Tageszeiten ungefähr die gleichen Wasserschichten an der Donaukanalmündung und in Hainburg zur Untersuchung gelangten. Tatsächlich nähern sich auch die Befunde Heiders von diesem Tage den meinigen.

Die Verschiedenheit der Befunde Kruses von meinen Zahlen muB auf einen anderen Grund zurückgeführt werden, denn Kruse hat die Wasserentnahmezeiten in verschiedenen Profilen der Geschwindigkeit des Rheins angepaßt. Die Abwasserkanäle der rheinischen Städte führen aber, wie in neuester Zeit $0 \mathrm{hlmüller} \mathrm{sagt,} \mathrm{nur} \mathrm{zum} \mathrm{geringsten} \mathrm{Teil} \mathrm{die} \mathrm{Fäkalien}$ ab. AuBerdem werden die Kotballen dort, wo Schwemmkanalisation inklusive Fäkalien besteht, durch Sandfänge und Rechen am Hineingelangen gehindert (private Mitteilung Hrn. Prof. Kruses). Diese Stoffe beherbergen aber (Spitta) groBe Mengen von Keimen. Der Zerfall der Kotballen.im Donaustrome wurde bereits oben bemerkt. Durch diesen Vorgang wurden dem Wasser Keime in erheblicher Menge allmählich zugemischt, namentlich anfangs, solange jene noch zahlreich sind. Ob auBerdem im Strome eine wirkliche Vermehrung der Bakterien erfolgt, ist nicht zu entscheiden, jedoch unwahrscheinlich.

ad 2. Die meisten Unterschiede, die nach obigen Ausführungen zwischen dem Wasser bei Kilometer 31 und dem Reinwasser bestehen, gelten auch, wenn man die Beschaffenheit des Wassers am Ende der untersuchten Strecke mit der des Reinwassers vergleicht, aber die Differenzen sind viel kleiner geworden. Schon bei Hainburg, noch mehr bei PreBburg sind die für die Kanalverunreinigung charakteristisehen Körper nur noch selten zu finden, die Konsistenz des Flaschensedimentes ist nur andeutungsweise schleimig. Unterschiede in Bezug auf chemische Beschaffenheit des Wassers, auch im Sauerstoffgehalte, fehlen ganz; nur Sauerstoffzehrung, Keimzahl und Wärmebakterientiter zeigen die stattgehabten Verunreinigungen noch deutlich an. Auch Protozoën sind dort noch reichlicher vertreten als im Reinwasser.

ad 3. Auf der Strecke von Kilometer 31 bis Kilometer 60 nimmt die Menge der groben Schwimmstoffe, besonders der wenigen noch vorhandenen Kotballen $a b$, unter den feinen, ungelösten Stoffen vermindern sich anscheinend die für Verunreinigung charakteristischen, der schleimige Cha- 
rakter des Sedimentes verliert sich fast ganz. Die Bakterien nehmen etwas an Zahl ab, die Substanzen, welche auf biologischem Wege oxydierbar sind, werden etwas vermindert (Versuch vom 29. April 1904, Tab. XLVII).

Die. Vorgänge, welche sich von Kilometer 31 angefangen im FluBbette abspielen, werden nicht, wie bis dorthin, von zunehmender Verdünnung des Schmutzwassers begleitet, können also als Selbstreinigung im engeren Sinne bezeichnet werden.

Die Selbstreinigung in der Donau beruht auf zweierlei Vorgängen, mechanischen und chemisch-biologischen. $\mathrm{Zu}$ den ersteren gehört die Ausschwemmung grober Schwimmstoffe an die Uंfer, die Zerkleinerung ekelhaft aussehender Körper wie Kotballen, vor allem die Verdünnung der Schmutzwässer und endlich im geringen Grade die Sedimentierung. Eine definitive Beseitigung ron Schmutzstoffen bewirken alle diese Vorgänge nicht. Die Zerkleinerung der Kotballen hat zwar eine ästhetische Verbesserung des Wasserlaufes zur Folge, bedingt aber unter Umständen eine zeitweilige hygienische Verschlechterung, denn dabei können Krankheitserreger dem Wasser mitgeteilt werden, welche vorher im Inneren der Kotballen verborgen, also unschädlich waren. Durch Ausschwemmung (und Sedimentierung) geht zwar eine Abnahme der verunreinigenden Körper vor sich, aber nur so lange, als der Wasserstand nicht steigt. Beim Steigen nimmt der Strom diese Körper wieder auf. Der Schaden ist allerdings nicht groB, denn der Zunahme dieser Schwimmund Schwebestoffe geht dann stets eine Vermehrung der Wassermenge parallel. Die Ufer der Donau sind für den Vorgang der Ausschwemmung im großen Ganzen geeignet. Die günstige Wirkung der Verdünnung ist einerseits eine ästhetische, indem durch sie das trübe Schmutzwasser in dem klaren Reinwasser verschwindet; andererseits wird hierdurch verhindert, daB der Sauerstoffgehalt des Schmutzwassers eine weitere Abnahme erfahre, die Gefahr der Wasserfäulnis wird also verhütet.

Hiermit steht die zweite Art der selbstreinigenden Vorgänge in Beziehung, die chemisch-biologische Reinigung. Diese ist weit weniger klargestellt als die mechanische, das wünschenswerte Ziel ist dabei die möglichste Verminderung der fäulnisfähigen organischen Stoffe, ohne daB es hierdurch zur Färlnis selbst kommt. Wir können, wie gesagt, auf die Menge der fäulnisfähigen gelösten organischen Stoffe nur indirekt nach Spitta durch Tntersuchung von Sauerstoffgehalt und Sauerstoffzehrung schließen. Die Sauerstoffzehrung in dem am 29. April 1904 geschöpften Wasser zeigt nun eine Abnahme der orga- 
nischen Substanz von Kilometer 31 bis Kilometer 60 an; die Befunde vom 26. September 1904 sind leider nicht so klar. Die Ursache ist bereits oben angegeben.

Die Sauerstoffbefunde in der Donau zeigen, daB auf der Strecke Kilometer 31 bis 60 eine Verminderung der organischen Substanz vor sich geht. Abnahme der organischen Substanz kann nach den Untersuchungen anderer Autoren nur durch Organismen bedingt sein, und zwar durch Bakterien [Emich (64), Spitta (36)]. Den Algen fällt in der Donau sicher keine Rolle bei der Selbstreinigung zu, denn ihr Vorkommen ist, wie früher beschrieben, äuBerst spärlich und im Schmutzund Mischwasser durchaus nicht reichlicher als im Reinwasser. Den Protozoën kann vielleicht eher eine Rolle bei der Selbstreinigung zugeschrieben werden, ibr reichliches Vorkommen am Flußboden unterhalk des Schmutzwassergebietes spricht dafür, daß sie an der Zerstörung sedimentierter Schmutzstoffe beteiligt sind. Diese Frage ist durch die vorliegenden Untersuchungen nicht genügend aufgeklärt. $\mathrm{Ob}$ der Pilz Beggiatoa alba imstande ist, organische Substanz zu zerstören, konnte durch vorliegende Untersuchungen gleichfalls nicht geklärt werden. Nach den Befunden im Donaustrome haben wir also allen Grund, reichliche Bakterien vegetation in einem verunreinigten Flusse nicht zu verhindern, wie schon Mez und Spitta hervorgehoben haben, und das Ziel der Selbstreinigung ist nicht in einer möglichst raschen Keimabnahme zu erblicken.

Die im Wasser beim Stehen eintretende Sauerstoffzehrung ist bei PreBburg etwas größer als im Reinwasser, daher ist hier, am Ende der untersuchten Strecke, der Reinheitszustand des Wassers oberhalb Wiens noch nicht wieder erreicht. Oberhalb Budapest nun ist nach v. Rigler die Keimzahl im Strome nicht größer als dort. Da nun, wie auch $\mathrm{Mez}$ sagt, die Bakterien bei eintretendem Nahrungsmangel im Flusse nicht sofort absterben, sondern noch eine Zeitlang lebend fortgeschwemmt werden, muB die Donau bereits eine Strecke oberhalb Budapest ebenso arm an Bakteriennährstoffen geworden sein, wie bei Wien vor Einmündung des Donaukanales. Dieser Zustand wird erreicht, obwohl dem Strome auf dieser Strecke auBer reinen Zuflüssen auch verschmutzte, wie die Abwässer der Stadt Preßburg, beigemischt werden. Es ist daher zu vermuten, daB der Strom seinen ursprünglichen Reinheitszustand schlieBlich im Wege der biologischen Selbstreinigung erlangt. Nach den Untersuchungen über Sauerstoffzehrung in den zwischen Kroatisch-Haslau und PreBburg entnommenen Wasserproben war dies anzunehmen. Nun aber ist die Donaustrecke von Kilometer 31 bis 60 zur Entscheidung der Frage, ob eine biologische Selbstreinigung besteht, insofern geeignet, als hier 
eine Verminderung der fäulnisfähigen Substanzen durch Verdünnung gar nicht stattfindet. Durch die selbstreinigenden Vorgänge oberhalb dieser Strecke ist aber die Menge dieser Substanz bei Kilometer 31 recht gering, die Sauerstoffzehrung beim Stehenlassen der Wasserproben im Laboratorium nicht sehr erheblich. Gegen die obige Deutung der Befunde vom 29. April (und 26. September) 1904 im Sinne einer fortschreitenden biologischen Selbstreinigung stromabwärts zu könnte daher der Einwand erhoben werden, daß die gefundenen Unterschiede zu gering sind und auf Zufall beruhen konnten.

Anders liegen die Verhältnisse im Gebiete von der Donaukanalmündung an einige Kilometer stromabwärts am rechten Ufer. Eine Verdünnung des Donaukanalwassers findet hier wohl statt, sie ist aber gering, und ihre GröBe ist durch Vergleichen der Keimzahlen bestimmbar. (Die auf dieser Strecke durch Zerfall der Kotballen eintretende Keimvermehrung ist nicht so groB, um praktisch von Einfluß zu sein, meine Befunde und Spittas Versuche machen dies wahrscheinlich.) Die Menge der fäulnisfähigen Substanzen ist daher auf dieser Strecke relativ bedeutend. Gelang es nun nachzuweisen, daB beim Stehen der Proben von einer Entnahmestelle zur anderen eine wesentlich stärkere Abnahme der Sauerstoffzehrung eintritt, als der durch die Keimzahlen nachgewiesenen Verdünnung entspricht, so war es damit ungemein wahrscheinlich gemacht, daB auch im Strome selbst auf der Strecke $z$ wischen zwei solchen Stellen eine Zerstörung organischer Substanzen auf biologischem Wege vor sich geht, welche es mit sich bringt, daB an der unteren Entnahmestelle die Sauerstoffzehrung wegen relativen. Mangels an organischen Substanzen langsamer ist.

Ich unternahm daher nach AbschluB vorliegender Ontersuchungen noch folgenden ergänzenden Versuch (Tabelle LI).

Am 26. Juni 1905, am späten Nachmittage, zur Zeit der maximalen Verschmutzung des Donaukanales, wurden aus dem Reinwasser und ferner aus dem Donaukanal (Mündung), dann aus dem Strome, rechtes Ufer, bei Kilometer 11, 14 und 17, Proben zu bakteriologischen Zwecken und zugleich zur Bestimmung der Sauerstoffzehrung (in gleicher Weise wie am 26. September 1904) entnommen. Dabei wurde sehr darauf geachtet, daB Boots- und Stromgeschwindigkeit übereinstimmten. Die Proben, in denen der Sauerstoffgehalt nach verschieden langem Stehen bestimmt werden sollte; blieben im Laboratorium, also bei einer Temperatur von 20 bis $24^{\circ} \mathrm{C}$. stehen. $\mathrm{Um}$ zu erfahren, ob und welche Beziehungen zwischen der Sauerstoffzehrung und der jeweiligen Keimzahl bestehen, wurden vor jeder Sauerstoffbestimmung aus der bezüglichen Flasche zwei Aussaaten 
Tabelle LI.

Untersuchung des Keim- und Sauerstoffgehaltes der Donau vor dem Eintritt der gründlichen Mischung des Rein- und Schmutzwassers. Bestimmung des Verhaltens der Keimzahlen in den geschöpften Wasserproben beim Stehen im Laboratorium, sowie der in diesen Proben eintretenden Sauerstoffzehrung.

Pegelstand am Morgen

$\begin{array}{ccc} & \text { des } & \text { Beiläufige } \\ \text { Vor- } & \text { Unter- } & \text { Wasser- } \\ \text { führung } \\ \text { tages } & \text { suchungs- } & \text { Sek.cbm } \\ & \text { tages } & \text { Sek.cbo }\end{array}$

Geschwin- Wasserdigkeit temperatur

im Strom $\therefore . \quad+74$ $+73 \quad 2580$ $-56 \quad 135$

$2 \cdot 30^{\mathrm{m}} \quad 16 \cdot 2^{\circ} \mathrm{C}$

"Donaukanal. . $-56 \quad-56$

$1351 \cdot 05^{\mathrm{m}}$

Sauerstoffkapazität des Wassers bei der herrschenden Temperatur in Milligrammen pro Liter:9.9.

\begin{tabular}{|c|c|c|c|c|c|c|c|c|}
\hline & \multirow{3}{*}{ 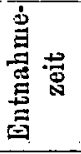 } & \multirow{3}{*}{ 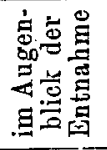 } & \multicolumn{6}{|c|}{$\mathrm{N} a \mathrm{ch}$} \\
\hline & & & 1 & 2 & 3 & 4 & 5 & 6 \\
\hline & & & \multicolumn{6}{|c|}{$\mathrm{T}$ a $g$ e $\mathrm{n}$} \\
\hline & \multicolumn{8}{|c|}{ Zahl der Keime proKubikzentimeter } \\
\hline $\begin{array}{l}\text { a) Reinwasser } \\
\mathrm{km} 10 \text { Mitte }\end{array}$ & $5 \cdot 50$ & $\begin{array}{l}2000 \\
1800\end{array}$ & $\begin{array}{l}2400 \\
2400\end{array}$ & $\begin{array}{l}4800 \\
3200\end{array}$ & $\begin{array}{r}1100 \\
900\end{array}$ & $\begin{array}{l}2500 \\
2100\end{array}$ & $\begin{array}{l}900 \\
800\end{array}$ & $\begin{array}{r}1300 \\
900\end{array}$ \\
\hline $\begin{array}{l}\text { b) Donaukan.- } \\
\text { Mündung }\end{array}$ & $6 \cdot 05$ & $\begin{array}{l}112000 \\
108000\end{array}$ & $\begin{array}{l}329000 \\
396000\end{array}$ & 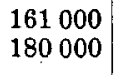 & $\begin{array}{l}220000 \\
323000\end{array}$ & $\begin{array}{l}301000 \\
126000\end{array}$ & $\begin{array}{l}158000 \\
175000\end{array}$ & $\begin{array}{l}144000 \\
131000\end{array}$ \\
\hline c) $\mathrm{km}_{\text {rechts }} 11$ & $6 \cdot 15$ & $\begin{array}{l}86000 \\
84000\end{array}$ & $\begin{array}{l}238000 \\
231000\end{array}$ & $\begin{array}{l}50000 \\
56000\end{array}$ & $\begin{array}{l}14000 \\
16000\end{array}$ & $\begin{array}{l}14000 \\
16000\end{array}$ & $\begin{array}{l}9700 \\
7900\end{array}$ & $\begin{array}{r}9300 \\
10300\end{array}$ \\
\hline $\begin{array}{l}\text { d) } \mathrm{km} 14 \\
\text { rechts }\end{array}$ & $6 \cdot 30$ & $\begin{array}{l}64000 \\
60000\end{array}$ & $\begin{array}{r}122000 \\
99000\end{array}$ & $\begin{array}{lll}47 & 000 \\
46 & 000\end{array}$ & $\begin{array}{l}21000 \\
20000\end{array}$ & $\begin{array}{l}10000 \\
14000\end{array}$ & $\begin{array}{l}7300 \\
8700\end{array}$ & $\begin{array}{l}8200 \\
8500\end{array}$ \\
\hline - e) $\mathrm{km} 17$ & $6 \cdot 50$ & $\begin{array}{l}41000 \\
39000\end{array}$ & $\begin{array}{r}104000 \\
99000\end{array}$ & $\begin{array}{ll}41 & 000 \\
36 & 000\end{array}$ & $\begin{array}{l}20000 \\
24000\end{array}$ & $\begin{array}{r}9500 \\
8400\end{array}$ & $\begin{array}{l}7800 \\
7600\end{array}$ & $\begin{array}{l}6900 \\
6500 .\end{array}$ \\
\hline
\end{tabular}

Sauerstoffmengen (Milligramme pro Liter).
a) Reinwasser . .

$\left|\begin{array}{c}9 \cdot 2 \\ 8 \cdot 1 \\ 8 \cdot 9 \\ 9 \cdot 2 \\ 9 \cdot 4\end{array}\right|$

\begin{tabular}{l|}
$9 \cdot 9$ \\
1.7 \\
$6 \cdot 8$ \\
$7 \cdot 8$ \\
$7 \cdot 8$
\end{tabular}

\begin{tabular}{l|}
$8 \cdot 9$ \\
0.3 \\
4.5 \\
$6 \cdot 6$ \\
$7 \cdot 0$
\end{tabular}

\begin{tabular}{l|}
$8 \cdot 6$ \\
$0 \cdot 14$ \\
$3 \cdot 7$ \\
$5 \cdot 9$ \\
$6 \cdot 5$
\end{tabular}

\begin{tabular}{|l|c|}
8.2 & 8.1 \\
0.07 & Spuren \\
3.0 & 1.6 \\
5.4 & $\mathbf{5 . 2}$ \\
5.9 & 5.7 \\
\hline
\end{tabular}
\begin{tabular}{ll|l} 
d) $\operatorname{km} 14$ rechts &. & $9 \cdot 2$ \\
e) $\mathrm{km} 17$ rechts . . & $9 \cdot 4$
\end{tabular}

Saberstoffdefizit (Milligramme pro Liter).
a) Reinwasser ... 0.7

\begin{tabular}{l|}
0.0 \\
8.2 \\
3.1 \\
$2 \cdot 1$ \\
2.1
\end{tabular}

\begin{tabular}{l|}
$1 \cdot 0$ \\
$9 \cdot 6$ \\
$5 \cdot 4$ \\
$3 \cdot 3$ \\
$2 \cdot 9$
\end{tabular}

\begin{tabular}{|l|l|}
\hline 1.3 & 1.7 \\
9.76 & 9.83 \\
6.2 & 6.9 \\
4.0 & 4.5 \\
3.4 & 4.0 \\
\hline
\end{tabular}
\begin{tabular}{l|l}
1.8 & 2.5 \\
9.9 & 9.9 \\
8.3 & 8.4 \\
4.7 & 5.1 \\
4.2 & 4.4
\end{tabular} 
gemacht, ein bisher von niemand, auch von Spitta nicht geübter Vorgang. Die Zählungen erfolgten stets nach 36 Stunden. Die Resultate waren folgende:

Das Schmutzwasser des Donaukanales ist, nach den Keimzahlen beurteilt, bei Kilometer 11 auf 78 Prozent, bei Kilometer 14 auf 56 Prozent, bei Kilometer 17 auf 36 Prozent seiner ursprünglichen Konzentration verdünnt, die Verdünnung ist also namentlich bei Kilometer 11 noch recht geringfügig. In sämtlichen Proben war nach 24 Stunden eine Zunahme der Keime eingetreten. Dieselbe war sowohl absolut als prozentuell um so stärker, je keimreicher das Wasser ursprünglich gewesen war. Bei Serie b) (Donaukanal) blieben die Keimzahlen auch fernerhin böher als im Augenblick der Entnahme, wiewohl die nach 24 Stunden beobachteten Zahlen vicht wieder erreicht wurden. Bei Serie c), d), e) (Stromschmutzwasser) folgte nach Ablauf von 24 Stunden ein rascher Abfali der Zahlen, späterhin Gleichbleiben derselben, bei Serie a) waren die Zahlen verschieden, bald höher, bald niedriger als zur Zeit der Entnahme. Das Maximum trat hier erst nach 48 Stunden auf.

Das Sauerstoffdefizit im Moment der Entnahme war gröBer in den keimreicheren Proben, doch nur bei Serie b) wesentlich. Wenn das der Reinwasserprobe (a) etwas gröber war, als das von Kilometer 17 rechts (e), so ist auf diesen ein wenig atypischen Befund kein Wert zu legen, denn nach 24 Stunden war das Sauerstoffdefizit in Serie a) kleiner als das in Serie e), es ist also wohl anzunehmen, daB das Defizit in Serie a), Moment der Entnahme, einen durch eine unbekannte Ursache herbeigeführten Ausnahmebefund darstellt.

Die beim Stehen der Proben eintretende Sauerstoffzehrung war um so größer, je keimreicher das Wasser bei der Entnahme war, die Zehrung war aber durchaus nicht proportional der Keimzahl. Besonders deutlich ist dies, wenn man Serie b), und c) vergleicht. Das Donaukanalwasser zeigte, wiewohl nicht sehr viel keimreicher als das bei Kilometer 11, eine ungleich stärkere Sauerstoffzehrung, indem nach 24 Stunden dort schon der größte Teil des Sauerstoffs aufgezehrt war, hier aber kaum ein Viertel. Als Ursache kann schwächere Keimvermehrung in der zweiten Probe nicht angesehen werden, denn diese war auch hier sehr beträchtlich.

Da nun die Abnahme der organischen Substanz bei Kilometer 11 durch Verdünnung nur gering ist, bleibt nur die Erklärung übrig, daB. hier. die Menge der organischen Substanz durch die Tätigkeit der Bakterien im Strome selbst stark abgenommen hat, daB es mithin diesen Organismen in den bei Kilometer 11 rechts entnommenen.Proben schon an Material für eine rapide Sauerstoffzehrung fehlte. Der Vergleich der übrigen Proben führt, wenn auch in minder prägnanter Weise, zum 
gleichen Ergebnis. Die Voraussetzung, die zum Anstellen vorliegenden Versuches geführt hatte, war demnach richtig gewesen.

Der Vergleich der Sauerstoffzehrungen mit den entsprechenden Keimzahlen (gleicher Tag, gleiche Probe) lehrt folgendes:

Nur sehr ausgiebige Sauerstoffzehrung ist meist von Keimzunahme begleitet. Ganz erhebliche Zehrung aber kann auch noch stattfinden, während die Keimzahlen auf gleicher Höhe bleiben oder gar abnehmen. Letzterer Befund ist eine weitere Stütze für obige Erklärung. Würde eine ausgiebige Sauerstoffzehrung stets von Zunahme der Keime begleitet, so könnte gegen den Versuch der Einwand erhoben werden, daß er keinen Schluß auf die Verhältnisse im Strome gestatte, da ja in diesem eine nennenswerte Zunahme der Keime nicht anzunehmen ist. So aber zeigt der Versuch, daß auch bei gleichzeitiger Keimabnahme Sauerstoffzehrung und mithin Zerstörung der organischen Substanz stattfinden kann. Übrigens geben die Keimzahlen wohl kaum ein rollständiges Bild des in den Proben und auch im Strome sich abspielenden Bakterienlebens. Es ist viel wahrscheinlicher, daB in beiden Fällen stets ein Teil der Keime sich vermehrt - namentlich die zur Verzehrung der organischen Substanz geeignetsten Keime -, ein anderer Teil abstirbt. Die Zu- oder Abnahme der Keimzahlen ist dann nur der Ausdruck dafür, welcher dieser beiden Vorgänge augenblicklich den anderen überwiegt.

Aus der Betrachtung der Zahlen für Sauerstoff, namentlich Serie b) ergibt sich endlich noch eine wichtige Tatsache: Die Sauerstoffzehrung ist, eine entsprechende Menge oxydierbarer Stoffe vorausgesetzt, am raschesten bei Anwesenheit von genügend viel Sauerstoff. Die letzten Reste derselben verschwinden nur langsam aus dem Wasser. Dies spricht dafür, daß die Zerstörung der organischen Substanz im offenen Flußlaufe rascher erfolgt, als in den Flaschen, da hier immer neue Mengen Sauerstoff aus der Luft aufgenommen werden und das entstehende Defizit wieder größtenteils decken. Man könnte sagen, daß den Bakterien der Abbau der organischen Substanz durch fortwährenden Sauerstoffzutritt erleichtert wird. So ist es wohl zu erkiären, daß auf der kurzen Strecke von der Donaukanalmündung bis Kilometer 11 eine so ausgiebige Verminderung der organischen Substanz stattfindet. Die Beobachtung von Blasius und Beckurts (25) über das Ausbleiben der Selbstreinigung der Ocker nach Bildung einer Eisdecke spricht für diese Auffassung (Sauerstoffmangel). Aber auch die Menge der organischen Substanz dürfte von Einfluß auf das Tempo des beschriebenen biologischen Vorganges sein, denn sonst wäre nicht einzusehen, warum in den an organischer Substanz ärmeren Wasserproben nicht anfangs. eine gleichstarke Sauerstoffzehrung stattfindet, 
wie in den mehr verunreinigten, dort aber dann bald vollkommen aufhört, fortzuschreiten. Eine Reihe oben nicht wiedergegebener Befunde Spittas spricht auch für diese Ansicht. Von Kilometer 31 ab ist, wie schon gesagt, die Verdünnung der fäulnisfähigen Substanzen in der Donau schon so bedeutend, daB die biologischen Vorgänge nur sehr langsam sind, und es ist zu vermuten, daB es eine Vęrdünnungsgrenze für diese Substanzen gibt, bei der ihre Zersetzung praktisch ganz aufhört, so daB eine vollständige Zerstörung dieser Stoffe im Flusse wohl nie erreicht wird.

Während durch die früheren Versuche das Bestehen einer biologischen Selbstreinigung nur wahrscheinlich gemacht wurde, ist dies durch den vorliegenden wohl so gut wie bewiesen worden. Sie ist jedoch mehr von theoretischem Interesse, praktisch genügt die mechanische Selbstreinigung der Donau vollkommen.

Schon früher worde die Tatsache erwähnt (s. o. Tabelle IL), daß von Kilometer $\mathbf{3 1}$ angefangen eine langsame, aber regelmäBige Abnahme der Keimzahlen im Strome stattfindet, welche nicht durch Verdünnung des Wassers bedingt sein kann. Vermutlich hat hier durch die oberhalb sich abspielenden selbstreinigenden Vorgänge (Verdünnung, biologische Prozesse) eine derartige Abnahme der Bakteriennährstoffe stattgefunden, daB ein kleiner Teil der Keime bald darauf abstirbt.

Die Frage, ob die Einleitung der Abwässer Wiens in die Donau rom hygienischen Standpunkte unzulässig sei, kann man getrost mit. Nein beantworten.

Der Strom ist so wasserreich, $d a B$ er auch bei niederem Wasserstande den ihm zugeführten Unrat sehr stark verdünnt, um so mehr, als die Wasserstände im Sommer, wenn Fäulniserscheinungen auftreten könnten, in der Regel hoch sind. Auch bei bedeutender Zunahme der Einwohnerzahl Wiens ist eine übermäBige Verunreinigung des Stromes nicht zu befürchten. Nicht ganz so günstig kann die Art und Weise der Absassereinleitung in den Strom beurteilt werden, und zwar die gegenwärtige und die für die Zukunft projektierte. Der untere Donaukanal und das rechte Ufer des Stromes eine Strecke weit unterhalb dessen Mündung bieten durch die zahlreichen Schwimmstoffe einen recht unerfreulichen Anblick, auch übler Geruch fehlt nicht. Die hydrologischen Verhältnisse daselbst sind für das baldige Zustandekommen einer ausgiebigen Mischung, wie schon gesagt, nicht günstig; durch die immer weiter stromabwärts fortschreitende Regulierung des Stromes werden die Zustände in , dieser Richtung eher noch schlechter werden. Wenn einmal die Einmündung der gesamten Abwässer unterhalb der Donaukanalmündung am rechten Donauufer erfolgt, 
so wird der Schmutzwasserstreifen am rechten Ufer schmäler und dafür noch dunkler und reicher an Unratstoffen, die Wassermischung wird noch mehr verzögert sein. Ein Moment, welches den geübten Vorgang teilweise rechtfertigt, ist nun wohl, daß die Gegend am rechten Ufer der Donau fast unbewohnt ist. Die Verhältnisse könnten jedoch ohne besondere Kosten durch zwei in ähnlichen Fällen bereits wiederholt vorgeschlagene MaBnahmen wesentlich verbessert werden:

1. Zurückhalten der groben Schwimm- und Schwebestoffe durch passende Vorrichtungen.

2. Einleiten der so modifizierten Abwässer in den Strom in mehreren über das Profil entsprechend verteilten Mündungen. Die erste MaBregel hätte auch den nicht zu unterschätzenden Vorteil, daB hierdurch ein großer Teil der dem Strome gegenwärtig zugeführten pathogenen Keime von ihm ferngehalten würde. Die unter den Schiffern auf der Donau weit verbreitete Unsitte, von dem Wasser des Stromes zu trinken, dürfte wohl kaum auszurotten sein, diese lassen von ihrer Gewohnheit nicht ab, obwohl ihnen bekannt ist, daß ,manche vom Donauwasser den Typhus kriegen". Auch die gewiB empfehlenswerte Fürsorge für frisches Trinkwasser würde daran kaum viel ändern. Obige Maßnahme gehört daher sicher in den Bereich der praktischen Hygiene. Fernhaltung der Wiener Abwässer vom Donaustrome ist dagegen durchaus nicht als sanitäres Postulat $z u$ bezeichnen. Der schon öfter aufgetauchte Plan, die Abwässer zur Berieselung des Marchfeldes zu verwenden, kann nicht vom sanitären, sondern muß lediglich vom ökonomischen Standpunkte aus beurteilt werden. Hier ist nicht der Ort, auf die Frage einzugehen. 


\section{Literaturverzeichnis.}

\section{A. Arbeiten über Flußverunreinigung und Selbstreinigung} der Flüsse.

1. Reinigung und Entwässerung von Paris. Anhang III zur Reinigung und Entwässerung Berlins. Berlin 1876.

2. Rosenberg, Die Bakteriologie des Mainwassers. Archiv für Hygiene. 1886. V. S. 446 .

3. Frank, Die Veränderungen des Spreewassers in Berlin. Diese Zeitschrift. 1888. III. S. 355 .

4. Prausnitz, Der Einfluß deṛ Münchener Kanalisation auf die Isar. Hygien. Tagesfragen. München 1890.

5. Schlatter, Der Einfluß des Abwassers der Stadt Zürich auf den Bakteriengehalt der Limmat. Diese Zeitschrift. 1890. IX. S. 56.

6. Löw, Zur Selbstreinigung der Flüsse. Archiv für Hygiene. 1891. XII. S. 261.

7. Pettenk ofer, Zur Selbstreinigung der Flüsse. Ebenda. 1891. XII. S. 269.

8. Schmidt, Über den EinflaB der Bewegung anf das Wachstum und die Virulenz der Bakterien. Ebenda. 1891. XIII. S. 247.

9. Baumeister, Über FluBverunreinigung. Deutsche Vierteljahresschrift für öffentl. Gesundheitspflege. 1892. XXIV. S. 467.

10. Buchner, Der EinfluB des Lichtes auf Bakterien. Centralblatt für Bakterio. logie. 1892. XI. S. 781 .

11. Niedner, Bakteriologische und chemische Untersuchung des Elbwassers. Deutsche Vierteljahresschrift für öffentl. Gesundlieitspflege. 1892. XXIV. -S. 122.

12. Pfeiffer und Eisenlohr, Zur Selbstreinigung der Flüsse. Archiv für Hygiene. 1892. XII. S. 190.

13. Uffelmann, Die Selbstreinigung der Flüsse. Berliner klin. Wochenschrift. 1892. S. 423 .

14. Axfield, Die wahrscheinliche Zerstörung der Bakterien des unreinen Flußwassers durch Protozoen. Ref. Chem. Centralblatt. 1893.

15. Buchner, Über den Einfluß des Lichtes anf Bakterien und die Selbstreinigung der Flüsse. Archiv für Hygiene. 189⿳亠丷. XVII.

16. Girard et Bordas, La Seine de Corbeil à Rouen, Ann. d'hygiène publ. 1893. 
17. Heider, Untersuchungen über die Verunreinigung der Donau durch die Ábwässer der Stadt Wien. Das österreich. Sanitätswesen. 1893.

18. Köhn, Untersuchungen zur Feststellung der Selbstreinigung der Flüsse. Deutsche Vierteljahresschrift für offentl. Gesundheitspflege. 1893. XXV. S. 693.

19. Schenk, Die Bedeutung der Rheinvegetation für die Selbstreinigung dieses

Flusses. Centralblatt für allgem. Gesundheitspflege. 1893. XII. S. 365.

20. Bokorny, Die Beteilignng der chlorophyllführenden Pflanzen an der Selbstreinigung der Flüsse. Archiv für Hygiene. 1894. XX. S. 181.

21. Dräer, Das Pregelwasser bei Königsberg in bakteriolog. u. chem. Beziehung. Ebenda. 1894. XX. S. 323.

22. Klett, Über die Frage der FluBverunreinigung. Ref. Chem. Centralblatt. 1894. S. 160 .

23. Stutzer und $\mathrm{Knublauch}$. Untersuchungen über den Bakteriengehalt des Rheinwassers ober- und unterhalb Köln. Centralblatt für allgem. Gesundheitspflege. 1894. XIII. S. 123.

24. Amthor und Zink, Untersuchung des Illwassers. Bygien. Rundschau. 1895. V. S. 200.

25. Blasins und Beckurts, Vernnreinigung und Reinigung der Flüsse nach Untersuchungen des Wassers der Oker. Deutsche Vierteljahresschrift für öfentliche Gesundheitspflege. 1895. XXVII. S. 337.

26. Mutschler, Das Aarewasser bei Bern. Forschungsberichte über Lebensmittel. 1896. III. S. 399.

27. Kabrbel, Bakteriolog. u. krit. Studien über Verunreinigung und Selbstreinigung der Flüsse. Archiv für Hygiene. 1897. XXX. S. 32.

28. Goldschmidt. Luxemburger, F. H. L., Neumayer, Prausnitz, Das Absterben der Mikroorganismen u. die Selbstreinigung der Flüsse. Hygien. Rundschau. 1898. VIII. Nr. 4.

29. Mez, Mikroskopische Wasseranalyse. Berlin 1898.

30. v. Rigler, Die chemischen u. bakteriologischen Eigenschaften des Donauwassers. Mathem.-naturw. Berichte aus Ungarn. 1898. XIV. S. 22.

31. Schorler, Die Vegetation der Elbe u. ihre Bedeutung für die Selbstreinigung. Zeitschrift für Gewässerkunde. 1898. I. S. 25.

32. Dirks en u. Spitta, Die Veränderungen des Spreewassers auf seinem Laufe durch Berlin. Archiv für Hygiene. 1899. XXXV. S. 83.

33. Frank, Das Wasser der Spree bei Berlin. Diese Zeitschrift. 1899. XXXII. S. 487.

34. Kruse, Über Verunreinigung und Selbstreinigung der Flüsse. Centralblatt für allgem. Gesundheitspflege. 1899. XVIII. S. 16.

35. König, Beiträge zur Selbstreinigung der Flüsse. Zeitschrift $f$. Untersuclunng der Nahrungs- und Genußmittel. 1900. III. S. 377.

36. Spitta, Untersuchungen über Verunreinigung u. Selbstreinigung der Flüsse. Archiv für Hygiene. 1900. XXXVIII. S. 160, 215.

37. Haubenschmidt, Allgem. Fischereizeitung. 1902. Ref. Hygien. Rundschau. 1902. XII. S. 406.

38. Holst, Geirsvold, Schmidt-Nielsen, Über Verunreinigung des Hafens und des Flusses Aakerselven durch die Abwässer von Christiania. Archiv f. Hygiene. 1902. XLIII. S. 153.

39. Schümann, Die Vernnreinigung der öffentlichen Wasserläufe in Berlin. Vierteljahresschrift für öffentl. Gesundheitspflege. 1902. XXXIV. S. 226. 
40. Bü sing, Entwässerungs- u. Wasserversorgungsfrage in Hamburg. Gesundheits-Ingenieur. 1903. XXVI. S. 433.

41. Gärtner u. Rubner, Gutachten über die Einleitung der Abwässer Dresdens in die Elbe. Arbeiten aus dem Kaiserl. Gesundheitsamte. 1903. XIX. S. 458.

42. Prausnitz, Der Einfluß der Münchener Kanalisation auf die Isar. Bygien. Rundschau. 1903. XIII. S. 273.

43. Spitta, Weitere Untersuchungen über FluBverunreinigung. Archiv f. Hyg. 1903. XLVI. S. 166.

44. Rubner, Das Sielwasser und seine Beziehnngen zur FluBverunreinigung. Ebenda. 1903. XLVI. S. 1.

45. Ohlmüller, Gutachten über die Einleitung der Mainzer Kanalwässer einschlieBlich der Fäkalien in den Rhein. Arbeiten aus dem Kaisert. Gesunzdheitsamte. 1904. XX. S. 258.

46. Rapp, Über den EinfluB des Lichtes auf Bakterien mit Berücksichtigung der Selbstreinigung der Flüsse. Archiv für Hygiene. 1904. XLVIII. S. 179.

B. Anderweitige Arbeiten.

1. Über Kanalisation und Kanalwässer.

47. Bericht über die vom k. k. Ackerbauministerium einberufene Expertise, betr. die landwirtsehafti. Verwertung der Wiener Abfallwïsser. Wien 1895.

48. Monti, Schwimm- und Schwebestoffe im Berliner Sielwasser. Archiv für Hygiene. 1903. XLVI. S. 121.

49. Kohl, Die Entwässerungsanlagen der Stadt Wien. Wien 1905.

2. Über Vorkommen von Bacterium coli im. Wasser.

50. Blachstein, Contribution à l'étude microbienne de l'eau. Annales de l'Inst. Pasteur. 1893. S. 689.

51. Freudenreich, Über den Nachweis von Bacterium coli im Wasser und seine Bedeatung. Centralblatt für Bakteriologie. 1894. XVI. S. 102.

52. Schardinger, Beitrag zur hygien. Beurteilung des Trinkwassers. Ebenda. 1894. XVI. S. 853.

53. Ha mmerl, Über Vorkommen von Bacterium coli im Flußwasser. Hygien. Rundschau. 1897. VII. S. 59.

54. Levy und Bruns; Zur Hygiene des Wassers. Archiv für Hygiene. 1899. XXXVI. S. 178.

55. Weissenfeld, Befund von Bacterium coli im Wasser. Diese Zeitschrift. 1900. XXXV. S. 78.

56. Petruschky und Pusch, Bedeutung des Bacterium coli für die Fäkalverunreinigung der Gewässer. Ebenda. 1903. XLIII. S. 304.

57. Wolf, Die Einwirkung verunreinigter Flüsse auf das im Ufergebiete befindliche Grundwasser. Arbeiten aus dem hygien. Institut in Dresden. Dresden 1903.

3. Über Sedimentation und Lebensdauer der Bakterien im stehenden Wasser.

58. Kaiser, Über die Bedeutung des Bacterium coli im Brunnenwasser. Archiv für Hygiene. 1905. LII. S. 221.

59. Bolton, Über das Verhalten verschiedener Bakterienarten im Wasser. Diese Zeitschrift. 1886. I. S. 76 . 
60. Kraus, Über das Verhalten pathogener Bakterien im Trinkwasser. Archiv für Hygiene. 1887. VI. S. 235.

61. Wolffhügel und Riedel, Die Vermehrung der Bakterien im Wasser. Arbeiten aus dem Kaiserl. Gesundheitsamte. 1886. I. S. 455.

62. Krüger, Physikal. Einwirkung von Sinkstoffen auf die im Wasser befindlichen Mikroorganismen. Diess Zeitschrift. 1889. VII.

63. Rubner, Beitrag zur Lehre von den Wasserbakterien. Archiv f. Hygiene. 1890. XI. S. 365 .

\section{Sonstige Arbeiten.}

64. Emich, Sitzungsberichte der Akademie der Wissenschaften. Math.-naturw. Klasse. 1885. Abtlg. II. S. 67.

65. Uffelmann, Die Oxydation des Ammoniaks in Wasser und Boden. Areliv für H.ygiene. 1886. IV. S. 82.

66. Knauthe, Kreislauf der Gase in unseren Gewässern. Biolog. Centralblatt. 1898. XVIII. S. 785.

67. Penck, Die Donau. Wien 1891.

68. H. Chick, A study of unicellular green alga occurring in polluted water with especial reference to its nitrogenous metabolism.

69. Kolkwitz und Marsson, Grundsätze für die biologische Beurteilung des Wassers nach seiner Fauna und Flora. Mitteilungen der königl. Prüfungsstation für Wasserversorgung und Abwasserreinigung. Berlin 1903.

70. Marsson, Spitta n. Tham, Gutachten über die Zulässigkeit der Fäkalienabschwemmung der Stadt Hanan und Main. Ebenda. Berlin 1905.

Während der Drucklegung erschien:

71. Hofer, Über die Vorgänge der Selbstreinigung im Wasser. Münchener med. Wochenschrift. 1905. S. 2266. 


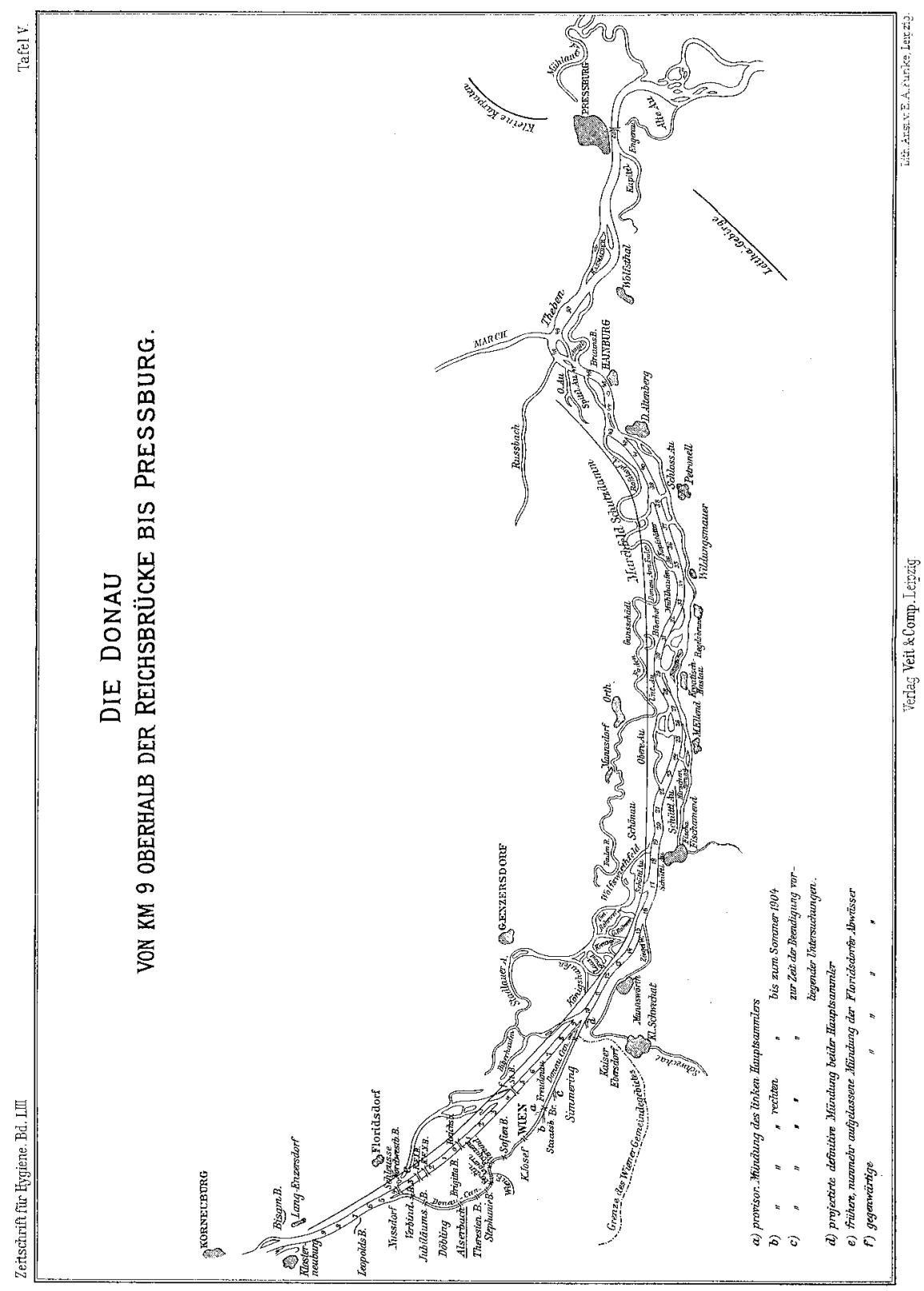

